\title{
Dynamic microsimulation for public policy analysis
}

Citation for published version (APA):

Li, J. (2011). Dynamic microsimulation for public policy analysis. [Doctoral Thesis, Maastricht University]. Boekenplan. https://doi.org/10.26481/dis.20111222jl

Document status and date:

Published: 01/01/2011

DOI:

10.26481/dis.20111222jl

Document Version:

Publisher's PDF, also known as Version of record

\section{Please check the document version of this publication:}

- A submitted manuscript is the version of the article upon submission and before peer-review. There can be important differences between the submitted version and the official published version of record.

People interested in the research are advised to contact the author for the final version of the publication, or visit the DOI to the publisher's website.

- The final author version and the galley proof are versions of the publication after peer review.

- The final published version features the final layout of the paper including the volume, issue and page numbers.

Link to publication

\footnotetext{
General rights rights.

- You may freely distribute the URL identifying the publication in the public portal. please follow below link for the End User Agreement:

www.umlib.nl/taverne-license

Take down policy

If you believe that this document breaches copyright please contact us at:

repository@maastrichtuniversity.nl

providing details and we will investigate your claim.
}

Copyright and moral rights for the publications made accessible in the public portal are retained by the authors and/or other copyright owners and it is a condition of accessing publications that users recognise and abide by the legal requirements associated with these

- Users may download and print one copy of any publication from the public portal for the purpose of private study or research.

- You may not further distribute the material or use it for any profit-making activity or commercial gain

If the publication is distributed under the terms of Article $25 \mathrm{fa}$ of the Dutch Copyright Act, indicated by the "Taverne" license above, 


\section{Dynamic Microsimulation for Public Policy Analysis}

Jinjing Li 
ISBN 9789086662265

Copyright $@ 2011$ Jinjing Li

Some rights reserved. This work is licensed under the Creative Commons AttributionNonCommercial-NoDerivs 3.0 Netherlands License. To view a copy of this license, visit http://creativecommons.org/licenses/by-nc-nd/3.0/nl/ or send a letter to Creative Commons, 444 Castro Street, Suite 900, Mountain View, California, 94041, USA.

Published by Boekenplan, Maastricht, the Netherlands 
Dynamic Microsimulation for Public Policy Analysis

\section{Dissertation}

to obtain the degree of Doctor at Maastricht University, on the authority of the Rector Magnificus, Prof. dr. G.P.M.F. Mols,

in accordance with the decision of the Board of Deans, to be defended in public on Thursday, $22^{\text {nd }}$ December 2011, at 14:00 hours

By

Jinjing Li 
Promoter:

Prof. Dr. Chris de Neubourg

Supervisor:

Dr. Cathal O’Donoghue (Teagasc, Ireland)

Assessment Committee (in alphabetical order):

Prof. Dr. Robin Cowan (Chair)

Dr. Gijs Dekkers (Federal Planning Bureau, Belgium)

Prof. Dr. Lennart Flood (University of Gothenburg, Sweden)

Prof. Dr. Jacques Mairesse

Dr. Raymond Wagener (L'Inspection Générale de la Sécurité Sociale, Luxembourg)

Fonds National de la This research is partially funded by the National Research Recherche Luxembourg Fund, Luxembourg(PHD-09-085). 


\section{Acknowledgements}

There are many people that I would sincerely thank for their contributions to this dissertation. In the first place, I would like to express my deepest gratitude to my supervisor Dr. Cathal O'Donoghue, whose guidance and support from the initial to the end enabled me to develop this piece of work. He shared his knowledge, insightful comments and hundreds of thousands lines of code from previous work which built the foundation of this research.

I am truly grateful to my promoter, Prof. Dr. Chris De Neubourg, who offered me a great working environment at the Maastricht Graduate School of Governance and made the school a home with many nice memories. I would like to express my profound gratitude to Dr. Mindel van de Laar, Dr. Franziska Gassmann and Dr. Annemarie Rima for their support and encouragements in every important step of my PhD.

I would also like to sincerely express thanks to the reading committee members for their valuable comments as well as the international microsimulation community for their extensive support. Special appreciations go to Dr. Raymond Wagner from the L'Inspection Générale de la Sécurité Sociale (IGSS), Luxembourg and Dr. Gijs Dekkers, from Belgium Federal Planning Bureau (FPB) and Prof. Dr. Lennart Flood from the University of Gothenburg, Sweden for their continuous encouragements and helpful comments. In addition, I would like to thank Dr. Denis de Crombrugghe, Dr. Michele Belloni, Dr. Elisa Baroni, Dr. Philippe Liegeois, Dr. Nizamul Islam, Dr. Rick Morrison, Howard Redway, Dr. Paul Williamson, Prof. Dr. Jacques Mairesse, Prof. Dr. Elsa Fornero, Alari Paulus, Prof. Dr. Adam Szirmai and many others for their fruitful discussions and valuable feedbacks. I am also grateful for comments from various conference and seminar participants, as well as anonymous journal referees. A special thank you goes to the professionals and great teachers from the ILO Geneva office, Dr. Michael Cichon, Hiroshi Yamabana, Wolfgang Scholz and others who inspired me to work in the field of economic and social simulation.

I am also deeply indebted to Mieke Drossaert, Susan Roggen, Céline Duijsens, Janneke Knaapen, Eveline in de Braek and many others who made my life as a foreigner a lot easier in this beautiful town. I would also like to thank Pamela Metz who helped me immensely 
during my research visit at the Kennedy School of Government, Harvard University; Olivia Vega-Vega who greatly helped me while I was in Ireland; Patrick Quill, who lend a hand to dig out the (almost) century old records from the basement of Central Statistics Office in Dublin; and Angelina Frank who supported me with the practical issues around my grant from the Luxembourg National Research Fund.

Furthermore, friends and colleagues in Maastricht and elsewhere have contributed immensely to both my academic and personal life. I am grateful to Denisa Maria Sologon, for all the work we have done together, her friendship and the great hospitality at her home in Romania. All my former and current office mates and friends with whom I share great memories have played an important part as well: Bianca Buligescu, Henry Espinoza, Seda Arican, Nyasha Tirivayi, Irina Burlacu, Andrea Franco-Correa and Manuel Mullers. I would also like to thank Metka Hercog, Maha Ahmed, Nevena Zhelyazkova, Kwan Suddhi-Dhamakit, Patrick Wells, Lala Gurbanova, Ruta Norvaisaite, Florian Henning, Judit Vall, Victor Cebotari, Robert Bauchmuller, Cheng Ong, Yu Hao, Melissa Siegel, Zina Nimeh, Sonila Tomini, Florian Tomini, Sepide Yousefzadeh, Christiane Arndt, Jessica Hagen-Zanker, Martin Rehm and many others for the drinks, food, squash, parties, trips and conversations over the past years. I would also like to take the opportunity to thank Erëblina Elezaj, Gintare Mažeikaite, and Iva Tasseva for the inspiring works we have done.

During my stay in Maastricht, I was glad to meet the small, yet growing Chinese community as well as many great friends: Wang Zhen, Bente Besemer, Wang Qi, Gu Pingshi, Zhang Xiaoyan, Du Caicai and many others. Their friendships, support, (and great food) mean a lot to me.

In particular, I would like to express my appreciation to my parents and extended family: my grandparents, aunts, uncles, cousins and relatives for supporting me in my decision to study abroad. They have always created an environment in which following this path seemed natural.

I would like to dedicate this last paragraph to express my deepest gratitude to Jasmin Kientzel, whom I met during my $\mathrm{PhD}$. Her love, patience and understanding supported me enormously during the most challenging part of this journey. She introduced me to many beautiful parts of Europe I never knew before. I am deeply grateful for the joys and happiness she brought into my life. 


\section{Table of Contents}

Acknowledgements........................................................................................i

[1] Introduction ................................................................................ 1

1.1 Policy Evaluation using Dynamic Microsimulation Models ........................................... 2

1.2 Methodological Challenges in Modelling Dynamic Microsimulation.......................... 3

1.2.1 Datasets in Microsimulation Models .......................................................................... 4

1.2.2 Alignment in Microsimulation Models .................................................................... 5

1.2.3 Behaviour Response in Microsimulation Models ....................................................... 5

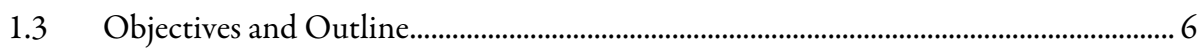

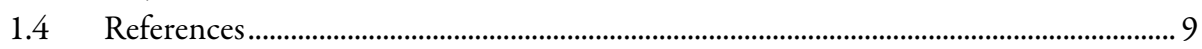

[2] A Methodological Review of Dynamic Microsimulation Models... 13

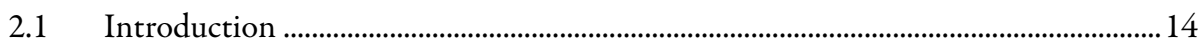

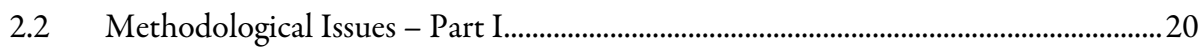

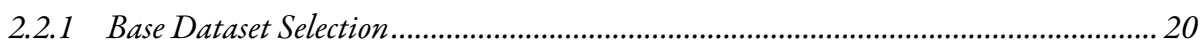

2.2.2 Development Environment of Dynamic Microsimulation Models............................. 25

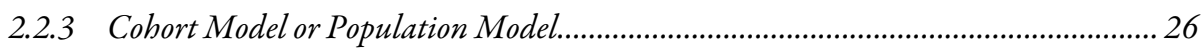

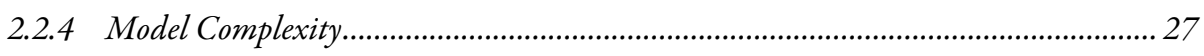

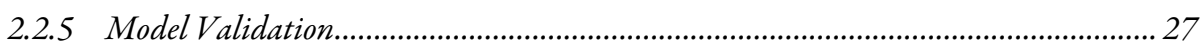

2.3 Methodological Issues - Part II .......................................................................................29

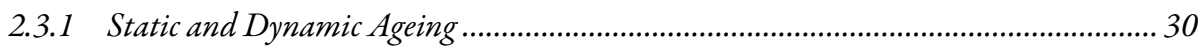

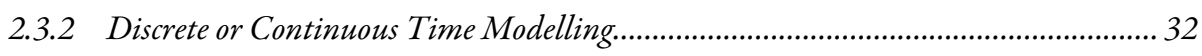

2.3.3 Behavioural Equations or Probabilistic Based Modelling ......................................... 33

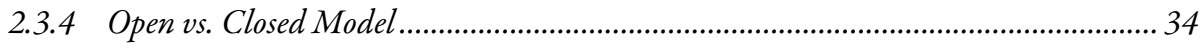

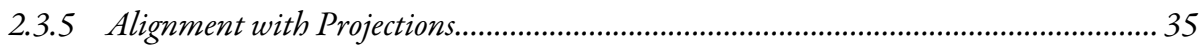

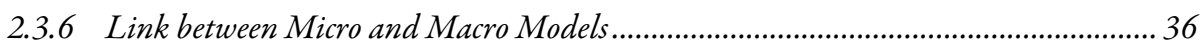

2.3.7 Links and Integrations with Agent Based Models ................................................... 37

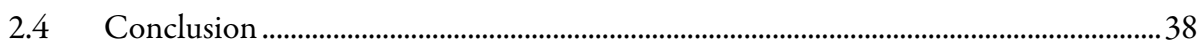


[3] Simulating Histories within Dynamic Microsimulation Models ... 49

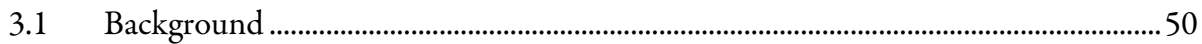

3.2 Base Dataset Issues in Dynamic Microsimulation ………………………………….....50

3.2.1 Base Dataset Selection ..................................................................................... 50

3.2.2 LIAM and its Base Dataset .......................................................................... 53

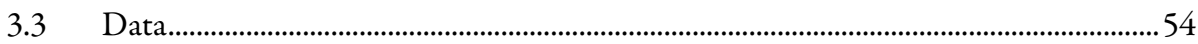

3.3.1 Demographic Base Data ............................................................................ 54

3.3.2 Exploiting the Retrospective Variable .................................................................. 56

3.4 Methodology I: Modelling the Histories ....................................................................58

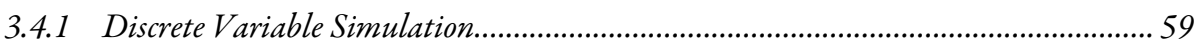

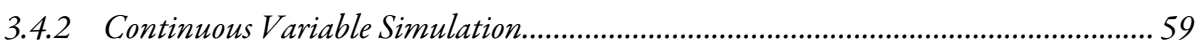

3.5 Methodology II: Alignment and Adjustment in the Simulation ………....................6

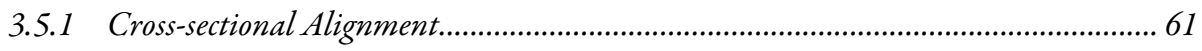

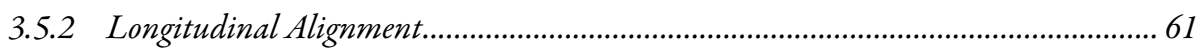

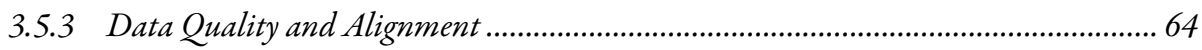

3.6 Results I: Back Simulating Employment Status.............................................................64

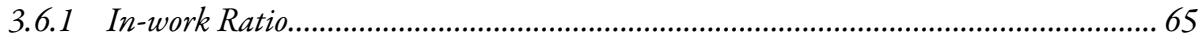

3.6.2 Employment Sectors and Self-employment …………………………………....... 68

3.7 Results II: Pension Memberships and Eligibilities …………………………………....72

3.7.1 State Pension Eligibilities ............................................................................... 72

3.7.2 Occupational Pension Membership.................................................................... 73

3.8 Results III: Income Variables .........................................................................................

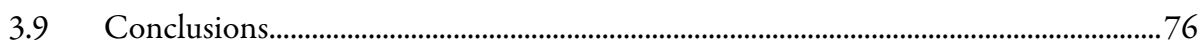

3.10 References ................................................................................................................79

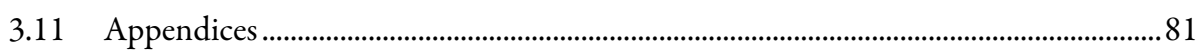

[4] An Evaluation of Binary Alignment Methods in Microsimulation

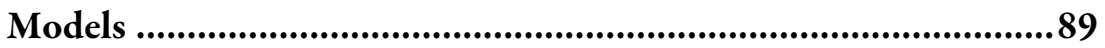

4.1 Introduction ……………………………………………………………………...99

4.2 Alignment in Microsimulation....................................................................................92

4.2.1 The Purpose of Alignment ………………………………………………..... 92

4.2.2 Alignment Methods .................................................................................. 94

4.3 Methods of Evaluating Alignment Algorithms ……………………………………...97

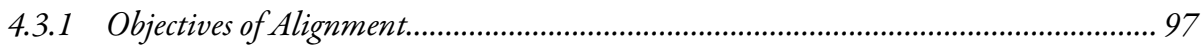

4.3.2 Indicators of Alignment Performance ...................................................................... 98 
4.3.3 Alignment Algorithms Evaluated ......................................................................... 101

4.4 Datasets and Scenarios in Alignment Algorithm Evaluation ......................................102

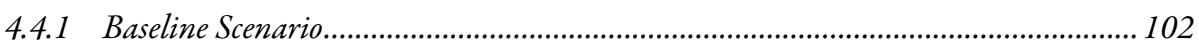

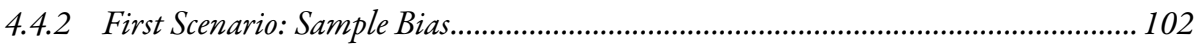

4.4.3 Second Scenario: Biased Alpha (Intercept) ............................................................... 103

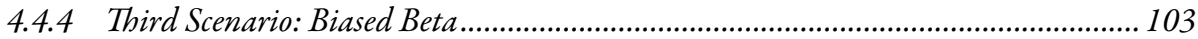

4.4.5 Forth Scenario: Biased Intercept and Beta.............................................................. 104

4.4.6 Evaluation Using a Real World Dataset.............................................................. 104

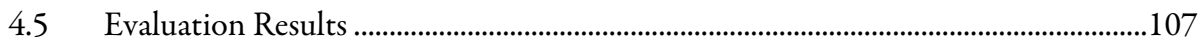

4.5.1 Evaluation Results using Synthetic Datasets ....................................................... 107

4.5.2 Evaluation Results using a Real-world Dataset .................................................... 110

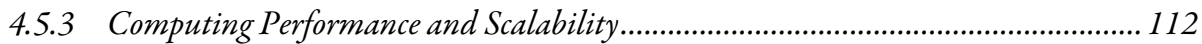

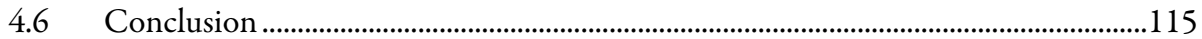

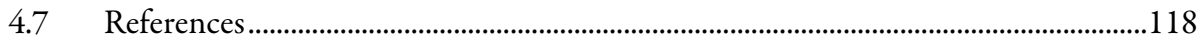

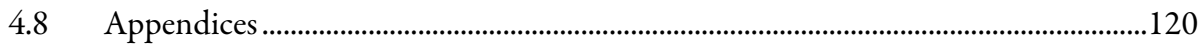

[5] A Continuous Labour Supply Model in Microsimulation............. 127

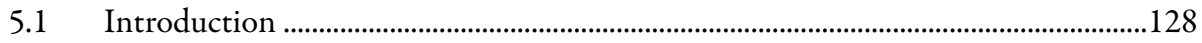

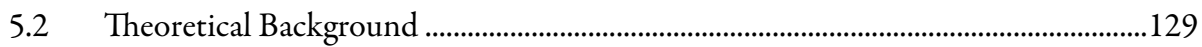

5.3 A Life-Cycle Model of Labour Supply...............................................................................131

5.3.1 A Life-Cycle Model of Labour Supply under Certainty........................................... 131

5.3.2 An expansion of the economic labour supply model under uncertainty ...................... 138

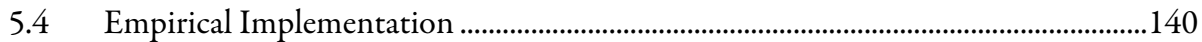

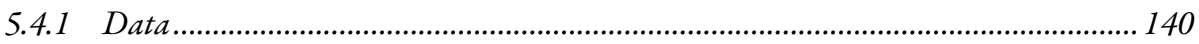

5.4.2 The Empirical Model of Lifetime Labour Supply under Certainty .......................... 141

5.4.3 The Empirical Model of Lifetime Labour Supply under Uncertainty ....................... 147

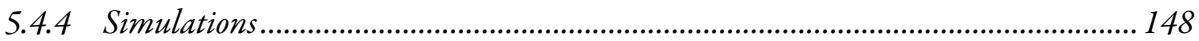

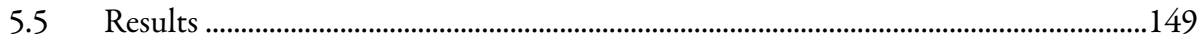

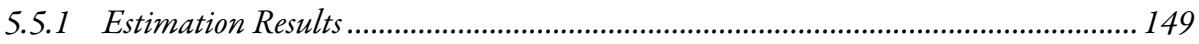

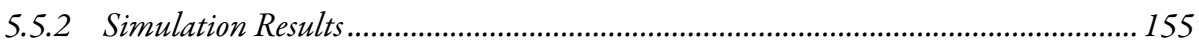

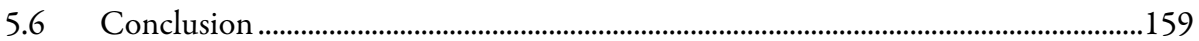

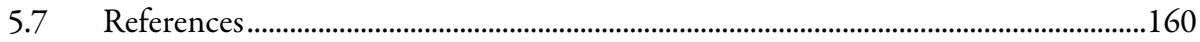

[6] Incentives of Retirement Transition for Elderly Workers............. 161

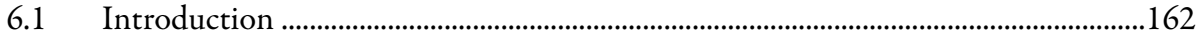

6.2 Description of the Irish Tax-Benefit Systems for Elderly ...........................................164

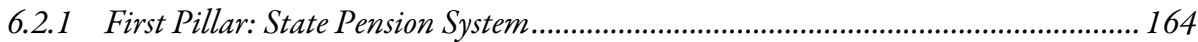


6.2.2 Second Pillar: Occupational and Private Pension Membership ............................... 165

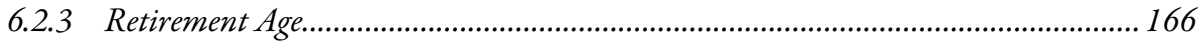

6.3 Methodology I: Replacement Rate Measures................................................................166

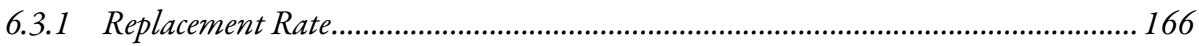

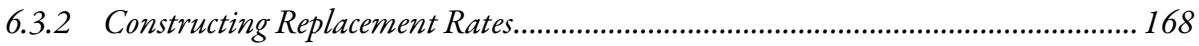

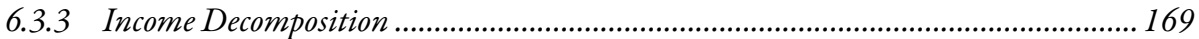

6.4 Methodology II: The Use of Tax-Benefit Microsimulation Model ............................170

6.5 Data and Sample Selection ............................................................................................... 171

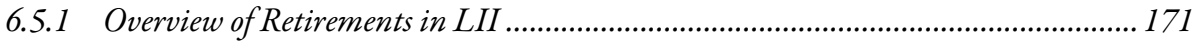

6.5.2 Income Level of Elderly Workers in Ireland ......................................................... 173

6.6 Results I - Synthetic Replacement Rate of Irish Tax-Benefit System ........................175

6.7 Results II - The Distribution of Replacement Rates...................................................179

6.7.1 Distribution of Net Replacement Rates for Retired .............................................. 179

6.7.2 Distributions of Simulated Replacement Rate ........................................................ 180

6.7.3 The Socio-Economic Characteristics of Retirees with Different Replacement Rates .. 181

6.7.4 Time dependency of the replacement rate and earning decomposition ....................... 183

6.8 The Retirement Pattern and Replacement Rates..............................................................186

6.8.1 Observed Retirement Pattern and the Observed Replacement Rates........................ 186

6.8.2 Social-Economic Characteristics of the Early and Late Retirement Groups ............. 189

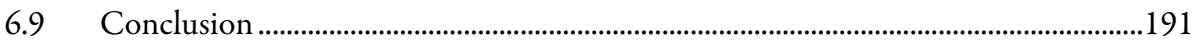

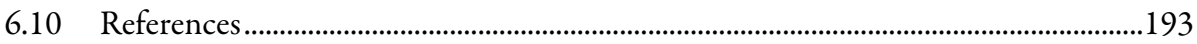

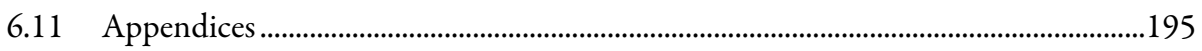

[7] Household Retirement Choice Simulation with Heterogeneous Pension Plans ...............................................................................201

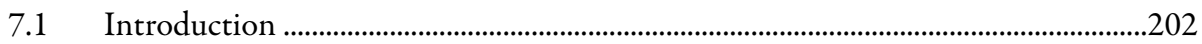

7.2 The Background of Irish Pension System...................................................................204

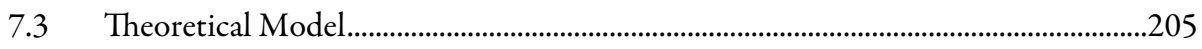

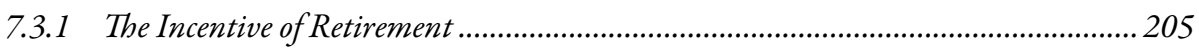

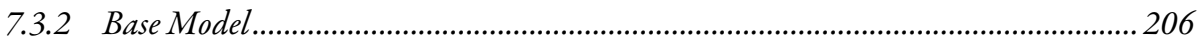

7.3.3 Retirement Model with Household Extension ........................................................207

7.4 Empirical Specification......................................................................................................208

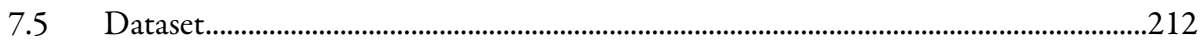

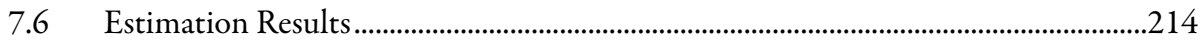

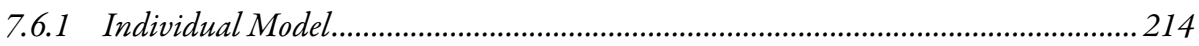

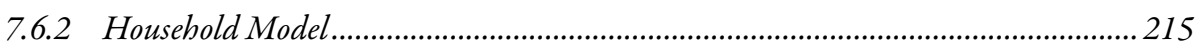

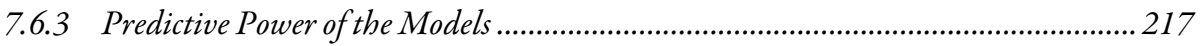




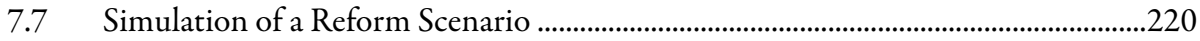

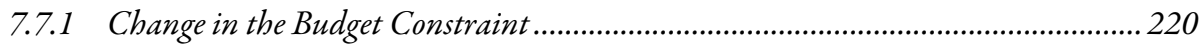

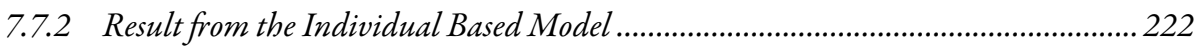

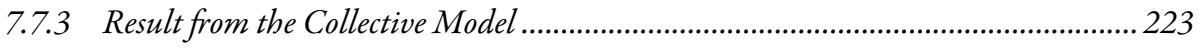

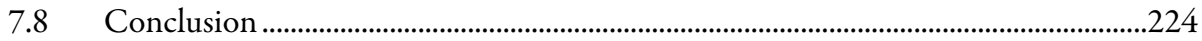

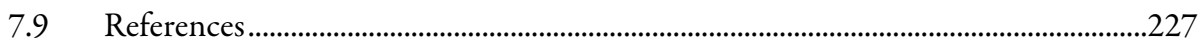

[8] Conclusions .............................................................231

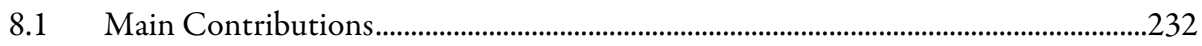

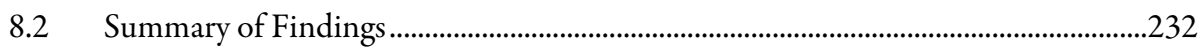

8.2.1 Part I: Data Issues and Alignment Techniques in Microsimulation........................ 232

8.2.2 Part II: Behaviour Modelling in Microsimulation ................................................2. 234

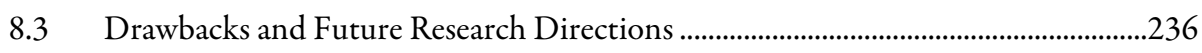

8.4 Concluding Remarks ....................................................................................................237

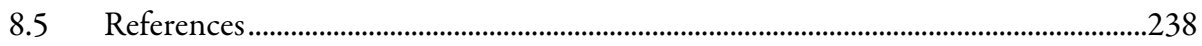

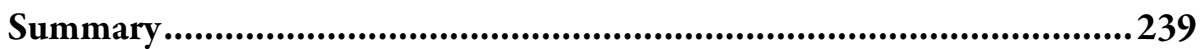

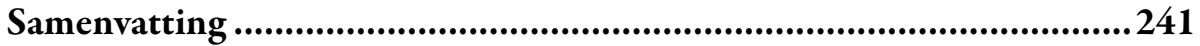

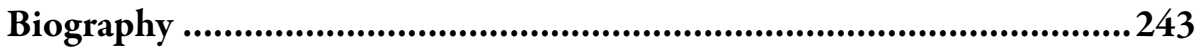



[1] Introduction 


\subsection{Policy Evaluation using Dynamic Microsimulation Models}

With rising life expectancy and declining fertility rates being observed around the world, the proportion of the global population aged $60+$ years will increase from $10.0 \%$ in 2000 to $21.8 \%$ in 2050 , and then to $32.2 \%$ in 2100 (Lutz et al., 2008). This rapid demographic change has far-reaching policy implications, as pension and health care costs are expected to rise while the relative size of the working population declines. Numerous research papers (Werding, 2008; Masson, 1990; Klevmarken and Lindgren, 2008) have discussed the policy implications of an ageing population.

While demographic ageing itself is a macro-level phenomenon, researchers use both macro models (Börsch-Supan, 2006) and micro models (Harding et al., 2009) to study the policy implications of ageing. Macro models can provide useful projections at the aggregate level, but their analyses are usually insufficient to reveal the individual impact on savings, health and retirement decisions. With the increasing availability of micro datasets and the improvement of econometric techniques, micro models are now widely being used to study the effect of policy implementation at the individual level, and compared with macro models, micro models can potentially reveal more information on individual behaviour. However, certain evaluations of the pension system, e.g. the redistributive impact over the course of life, require a micro dataset that does not exist, either because the analysis relates to the future, as in the case of pension forecasts, or because collected datasets do not cover sufficiently long time frames. Therefore, researchers are using microsimulation models to assist this type of analysis, an idea that was initially suggested by Orcutt (1957).

Microsimulation is a technique used to model complex real-life events by simulating the actions of, and/or the impact of, policy change on the individual micro unit (Harding, 2007a). Compared with macro based simulation models, microsimulation allows researchers to model the individual units in greater detail and to evaluate policies at the same level as policy objectives. With improved data availability, over recent decades a number of microsimulation models have been developed to study various policy issues.

Traditionally, microsimulation models are categorised into either "static" or "dynamic" forms. Static models are mainly arithmetic models that evaluate the immediate impact of policy changes, assuming there is no behavioural response to the policy shock, although a few newer static models also incorporate certain immediate behaviour changes, e.g. IZAYMOD (Peichl et al., 2010). Static microsimulation models are widely used for predicting the immediate effects of policy change, including the distributional impacts of a tax-benefit system, as in EUROMOD (Mantovani et al., 2007) or health policy, e.g. STINMOD (Raymond and Parsons, 2007).

Dynamic models, such as DESTINIE, PENSIM, SESIM (Bardaji et al., 2003; Curry, 1996; Flood, 2007), extend the static model by allowing the individuals to change their 
characteristics due to endogenous factors within the model (O’Donoghue, 2001) and the properties of the micro units are progressively updated as time moves forward. Following the introduction of the time dimension in dynamic microsimulation, these models can provide useful projections for the trend in socio-economic development under current policies, e.g. DYNASIM2/3, APPSIM (Wertheimer et al., 1986; Favreault and Smith, 2004; Harding, 2007b). These models can also be used to evaluate the future performance of various programmes such as pensions reform, e.g. DYNACAN, LIAM (Morrison, 2000; O'Donoghue, 2009), and study the inter-temporal processes and behaviours using longitudinal data, e.g. CORSIM (Keister, 2000).

Compared with static microsimulation models, dynamic models are more suitable for pension analysis due to the long-term nature of the policy. A pension reform usually takes decades to mature; for instance, a change in pension contribution and eligibilities would only reach its full effect when the youngest cohort in the labour market retires. In this case, a dynamic microsimulation model could offer more insight because of its capacity for longterm simulation.

\subsection{Methodological Challenges in Modelling Dynamic Microsimulation}

A number of dynamic microsimulation models have been compiled in recent years to study the issues linked with social security, retirement incomes, and pension reforms, e.g. MIDAS, SADNAP (Dekkers and Belloni, 2009; Van Sonsbeek, 2009). The rising popularity of microsimulation models has brought about methodological advancements as well as challenges to this field. Harding (2007a) lists the six challenges facing today's dynamic microsimulation models as:

- Budgets and project management

- Collaboration and co-operations

- Microdata quality

- Alignment

- User friendliness

- Behaviour response and macro feedback

Among the listed issues, three of them (microdata quality, alignment, behaviour response) are directly linked to the methodological development of the microsimulation model, while the other three mostly relate to the management and presentation of the model. This thesis mainly focuses on the three methodological challenges that have been raised, particularly within the context of dynamic microsimulation for pension analysis. 


\subsubsection{Datasets in Microsimulation Models}

Data is one of the most important components in microsimulation as the quantity and quality of the variables in the base dataset has a direct impact on the outcome of a policy analysis. However, choosing a dataset is not an easy task as dynamic microsimulation models have a high requirement on the variables, and this dilemma has been discussed in several papers (Cassells et al., 2006; Zaidi and Scott, 2001). For microsimulation models analysing the dynamics of elderly earnings or pensions, it is essential to include historical variables that affect the evolution of elderly social economic status. This implies that an ideal dynamic microsimulation base dataset for pension analysis should contain the following information for each individual from birth:

- Demographic information, including age, education, marriage, birth of children, and household (or tax unit) formation/dissolution

- Employment trajectory information, including labour force participation records, historical earnings, and type of jobs etc.

- Pension membership and entitlement information, including the records of various pension schemes participation (including state, occupational, and private pensions).

What these requirements imply is that a longitudinal panel dataset containing rich demographic, employment, and pension data is required. This is not an easy task, as hardly any micro datasets contain all of the above information. Neither administrative records nor a detailed household survey dataset could offer a comprehensive dataset as described above. Therefore, compromises are often made in order to make the simulation possible.

Some models, e.g. DYNASIM, use a matching approach where the missing information required is extracted from a comparable dataset over a similar time frame. For instance, DYNASIM3 (Favreault and Smith, 2004) matches two survey datasets, namely the Survey of Income and Program Participation (SIPP) and the Panel Study of Income Dynamics (PSID), in order to obtain a more complete history of the individuals being analysed. Another example is PENSIM2, which matches the Family Resource Survey (FRS) and British Household Panel Survey (BHPS) to the Lifelong Labour Market Database (LLMDB) to incorporate household contextual data (Emmerson, 2004).

Another approach is to generate a synthetic historical panel with the information from the base dataset itself. Because of the high requirement for consistency, there are many challenges in attempting to "back-cast" or "back simulate" historical earnings (and other characteristics) earlier in life (Harding, 2007a). The DYNANCAN model uses a limited back simulation technique by imputing the historical earning profiles with limited retrospective consistency (Morrison, 1997). The CORSIM model simulates part of the historical profile based on a historical cross-sectional dataset and matches the model output to historical aggregate information such as fertility and mortality rates (Caldwell, 
1997). Nevertheless, none of the models proposed so far have been able to provide a comprehensive longitudinal panel to be used in dynamic microsimulation.

\subsubsection{Alignment in Microsimulation Models}

In order to match the projection to some key macro statistics, dynamic microsimulation often adopts a technique called alignment. This is defined as "a process of constraining model output to conform more closely to externally derived macro-data" (Scott, 2001). Over the past decade, aligning the output of a microsimulation model to exogenous assumptions has become standard practices, despite some theoretical concerns, and alignment is seen as an effective pragmatic solution for highly complex models (O’Donoghue, 2010).

Depending on the type of variables, different methods are used for the alignment process. For a continuous variable e.g. earnings, alignment is usually an "uprating" process, whereby a fixed ratio is applied in order to ensure that the simulated value matches the assigned target. For discrete variables, there is no consensus on the right method to use and different models adapt different methods as they see fit. As a result, various methods, e.g. multiplicative scaling, sidewalk, sorting based algorithm etc., have been experimented with during the development of microsimulation models (see Morrison, 2006).

For microsimulation models using historical datasets, alignment is important in shaping a credible historical profile, as in the case of CORSIM (SOA, 1997). Models that work prospectively, e.g. APPSIM, also utilise the technique to align the resulting simulation with external projections (Kelly and Percival, 2009). Nonetheless, the understanding of the simulation properties of alignment in microsimulation models is very limited. Literature on this topic is scarce, except for publications by Anderson (1990), Caldwell et al. (1998), Neufeld (2000), Chénard (2000a, 2000b), Johnson (2001), Baekgaard (2002), Morrison (2006), Kelly and Percival (2009) and O’Donoghue (2010). Although some new alignment methods have been developed in an attempt to address the theoretical and empirical deficiencies of earlier methods, discussions on the empirical simulation properties of different alignment algorithms are almost non-existent.

\subsubsection{Behaviour Response in Microsimulation Models}

Earlier microsimulation models only consider limited behaviour factors. Many static models are only arithmetic models, while the dynamic models are often limited to the response of an individual's own characteristic update, e.g. a change in labour supply due to the birth of a child without considering the responses induced by the policy change. This then presents a challenge in pension policy analysis as many reform proposals are designed to cause behaviour changes such as the postponing of retirement. Klevmarken (1997) 
outlined three criteria for choosing what types of behavioural equations should be included in a microsimulation model:

- They should be relevant for the objectives of the model

- There should be major behavioural adjustments to the policy changes the model is built to analyse

- Behaviour that influences the fiscal balance should be included

Compared with earlier microsimulation models, more models today have incorporated behavioural responses into their design, although the response is often limited to labour market simulations. Models such as MICROHUS, PRISM, SESIM, NEDYMAS, SAGE and LIAM all incorporate labour supply behavioural responses in the tax-benefit system, whilst DYNAMITE, ANAC and SADNAP model retirement decisions depending on the social security system. However, there is still only limited implementation in life-cycle models and Pudney and Sutherland $(1994,1996)$ have found that predictions based on behavioural models have very wide confidence intervals. In addition, certain behaviour models, e.g. a labour supply model based on policy independent personal characteristics, contain the implicit assumption that the policy remains the same, which means that this type of model is not suitable for reform analysis, and are often restricted to simulating status quo only.

\subsection{Objectives and Outline}

The thesis is built around the methodological issues of microsimulation, specifically the ones discussed in the section above. The main objective of the thesis is to advance the current methodological practice in dynamic microsimulation modelling, including dataset selection, alignment method chosen for use and structured behaviour modelling. The first part of the thesis (Chapters 2 - 4) focuses on current practices, dataset selection and alignment issues, while the second part of the thesis (Chapters 5 - 7) concentrates mainly on behaviour modelling within dynamic microsimulation.

Chapter 2 extends the discussion on the methodological challenges of developing a dynamic microsimulation and surveys current practice worldwide, covering a wide range of methodological issues. These include general model development aspects such as base dataset selection, cohort or population-based model structure, the programming environment, and model validation, as well as some technical choices in model implementations such as open or closed models, behaviour responses implementation, alignment usage, etc. The chapter provides an overview of the methodological choices made in more than 50 known dynamic microsimulation models and discusses the advantages and disadvantages of different practices. 
Chapter 3 focuses on the base dataset dilemma discussed earlier. The chapter proposes a back simulation method that has the potential to generate a consistent synthetic historical panel, based on a typical household survey dataset with some complementary macro statistics. This method could open the possibility for further investigation into several fields of application such as life-cycle income analysis and pension reform evaluation, which typically require historical profiles of individuals.

Chapter 4 discusses and evaluates six common binary alignment algorithms used in dynamic microsimulation through a set of theoretical and statistical criteria proposed in the literature (Morrison, 2006; O’Donoghue, 2010). This chapter details and compares alignment processes, probability transformations, and the statistical properties of alignment outputs in transparent and controlled setups with both a synthetic and a real life dataset (Living in Ireland, LII).

A structural inter-temporal labour supply model that can simulate the dynamics of labour supply in a continuous setting is then presented in Chapter 5, which addresses the two main drawbacks of most of the existing models. The first limitation is the inability to incorporate individual heterogeneity, as every agent shares the same parameters of the utility function, and the second is the strong assumption that individuals make decisions in a world of perfect certainty.

Chapter 6 examines the monetary incentives behind the tax benefit system for elderly workers in Ireland, using an estimated replacement rate, and compares the monetary incentives with the pattern of retirement. The analysis in this chapter is based on a mixed method of synthetic household simulation and empirical estimations from the panel dataset LII. Simulations using the synthetic household data allow existing incentives embedded in the state pension regulation to be easily observed, while the empirical dataset helps to analyse the relationships between observed replacement rate and retirement ages. This chapter lays the theoretical groundwork for an elderly labour supply model.

Chapter 7 estimates a structured life-cycle model of family retirement decisions using a unique historical dataset back simulated from the LII survey produced in Chapter 4 . The model takes advantage of the dataset and models retirement decisions in terms of monetary and leisure incentives, which may reflect the complex welfare system in Ireland. The household extension version of the model adapts a collective modelling approach, whereby intra-household bargaining is considered. The model also incorporates the element of complimentary leisure to analyse the interactions of spouses' retirement timing. In addition, the model is used to assess individual budgetary implications and retirement behaviour shifts of a synthetic reform proposal. 
Chapter 8 draws together the overall conclusions of this thesis and highlights the main findings. In addition, the chapter also discusses some of the weaknesses of the research and raises potential future research questions. 


\subsection{References}

Anderson, J.M., 1990. Micro-Macro Linkages in Economic Models, in Lewis, G.H., Michel, R.C. (eds.) Microsimulation techniques for tax and transfer analysis. Washington DC: Urban Institute.

Baekgaard, H., 2002. Micro-macro linkage and the alignment of transition processes : some issues, techniques and examples, National Centre for Social and Economic Modelling Technical paper

Bardaji, J., B. Sédillot and E. Walraet. 2003. Un outil de prospective des retraites: le modèle de microsimulation Destinie, Économie et prévision pp. 193-214.

Börsch Supan, A., Ludwig, A., Winter, J., 2006. Ageing, Pension Reform and Capital Flows: A Multi Country Simulation Model. Economica 73, 625-658.

Caldwell S., Favreault M., Gantman A., Gokhale J., Johnson T. and Kotlikoff L.J. (1998) Social Security's Treatment of Postwar Americans, NBER Working Paper No. W6603

Caldwell, Stephen B. 1997. CORSIM 3.0 User and Technical Documentation. Ithaca, NY: Cornell University.

Cassells, R., et al., 2006. Problems and Prospects for Dynamic Microsimulation: A Review and lessons for APPSIM. NATSEM Discussion Papers no. 63.

Chénard, D., 2000a. Earnings in DYNACAN: distribution alignment methodology, Paper Presented to the 6th. Nordic Workshop on Microsimulation, Copenhagen, June.

Chénard, D., 2000b. Individual alignment and group processing: an application to migration processes in DYNACAN D. in Mitton, L., Sutherland, H. and Weeks, M. Microsimulation Modelling for Policy Analysis: Challenges and Innovations. Cambridge: Cambridge University Press.

Curry C. 1996. "PENSIM: A Dynamic Simulation Model of Pensioners' Incomes”. London: Department of Social Security.

Dekkers, G., \& Belloni, M., 2009. Microsimulation, Pension adequacy and the Dynamic Model MIDAS: an Introduction. Project AIM - Deliverable 4.10

Emmerson, C., H. Reed and A. Shephard, 2004, An assessment of PenSim2.

Favreault, M., Smith, K., 2004. A Primer on the Dynamic Simulation of Income Model (DYNASIM3) The Urban Institute Discussion Paper.

Flood, L. 2007. Can we Afford the Future? An evaluation of the new Swedish pension system, Modelling our future: population ageing, social security and taxation pp. 33 .

Harding, A., 2007a. Challenges and Opportunities of Dynamic Microsimulation Modelling

Harding, A., 2007b. APPSIM: The Australian Dynamic Population and Policy Microsimulation Model.

Harding, A., Kelly, S., Percival, R., Keegan, M., 2009. Population Ageing and Government Age Pension Outlays.

Johnson, T., 2001. Nonlinear Alignment by Sorting, CORSIM Working Paper

Keister, L. 2000. Wealth in America: Trends in Wealth Inequality. Cambridge: Cambridge University Press.

Kelly, S. and R. Percival, 2009. Longitudinal benchmarking and alignment of a dynamic microsimulation model, IMA Conference Paper.

Klevmarken N.A., 1997. "Modelling behavioural response in EUROMOD”, Paper presented to Conference of European Microsimulation, Brussels, April 18th. 
Klevmarken, A., Lindgren, B., 2008. Simulating an ageing population: a microsimulation approach applied to Sweden. Emerald Group Publishing.

Lutz, W., Sanderson, W., Scherbov, S., 2008. The coming acceleration of global population ageing. Nature 451, 716-719.

Mantovani, D., F. Papadopoulos, H. Sutherland and P. Tsakloglou., 2007. Pension incomes in the European Union: policy reform strategies in comparative perspective, Micro-simulation in action: policy analysis in Europe using EUROMOD pp. 27.

Masson, P.R., Tryon, R.W., 1990. Macroeconomic effects of projected population aging in industrial countries. Staff Papers-International Monetary Fund 37, 453-485.

Morrison, R., 1997., "DYNACAN, the Canadian pension plan policy model: demographic and earnings components", Proceedings of the Microsimulation Section at the International Conference on Information Theory, Combinatorics, and Statistics, Portland, Maine, July 1997.

Morrison R. 2000. “Assessing the Quality of DYNACAN's Synthetically-Generated Earnings Histories”, Paper Presented to the 6th Nordic Workshop on Microsimulation, Copenhagen, June.

Morrison, R., 2006. Make it so: Event alignment in dynamic microsimulation. DYNACAN paper.

Neufeld, C., 2000. Alignment and Variance Reduction in DYNACAN” in Anil Gupta and Vishnu Kapur (eds) Microsimulation in Government Policy and Forecasting. North-Holland.

O’Donoghue C. 2001. Dynamic Microsimulation: A Survey, Brazilian Electronic Journal of Economics

O’Donoghue, C., J. Lennon and S. Hynes, 2009, The Life-Cycle Income Analysis Model (LIAM): A Study of a Flexible Dynamic Microsimulation Modelling Computing Framework. CeRP Working Papers.

O’Donoghue, C., 2010. Alignment and calibration in LIAM, LIAM working paper

Orcutt, G., 1957. A new type of socio-economic system. The Review of Economics and Statistics 39, 116-123.

Peichl, A., Schneider H. and Siegloch S. 2010. Documentation IZAYMOD: The IZA Policy Simulation Model, IZA working paper 4865

Pudney S and Sutherland H., 1996. "Statistical reliability in microsimulation models with econometricallyestimated behavioural responses" in A Harding (ed.) Microsimulation and public policy, Elsevier, Amsterdam, 473-504.

Pudney, S. and Sutherland, H. 1994, "The statistical reliability of micro-simulation estimates: Results fora UK tax-benefit model”, Journal of Public Economics, 53, 327-365.

Raymond, C., Parsons, B., 2007. Modelling Medicare and Pharmaceutical Benefits Scheme (PBS) Utilisation and Costs. Modelling Our Future: Population Ageing, Health and Aged Care, 197.

Scott, A., 2001. computing strategy for SAGE: 1. Model options and constraints. Technical Note 2. London, ESRC-Sage Research Group.

SOA, 1997. Chapter 5 on CORSIM, Society of Actuaries, [http://www.soa.org/files/pdf/Chapter_5.pdf] accessed June 10th 2010.

Van Sonsbeek, J., 2009, Micro Simulations on the Effects of Ageing-Related Policy Measures: The Social Affairs Department of the Netherlands Ageing and Pensions Model.

Werding, M., 2008. Ageing and Productivity Growth: Are There Macro-level Cohort Effects of Human Capital? CESifo. 
Wertheimer, R., S.R. Zedlewski, J. Anderson and K. Moore, 1986, "DYNASIM in comparison with other microsimulation models" in G. Orcutt, J. Merz and H. Quinke (eds.) Microanalytic Simulation Models to Support Social and Financial Policy. Amsterdam: North-Holland

Zaidi, A. and A. Scott, 2001, Base dataset for the SAGE model, (Sage Technical Note). 



\section{[2] A Methodological Review of Dynamic Microsimulation Models ${ }^{1}$}

\footnotetext{
${ }^{1}$ An earlier version of this chapter is available as: Li, J. and O'Donoghue C., 2010. Methodological Aspects of Dynamic Microsimulation Models in: O’Donoghue, C. (Ed.), Life-Cycle Microsimulation Modelling: Constructing and Using Dynamic Microsimulation Models. LAP LAMBERT Academic Publishing
} 


\subsection{Introduction}

Micro level data, such as data obtained from a household survey, is often chosen as the basis for social economic research. In order to evaluate certain impacts of public policies, e.g. the redistributive impact over the course of a lifetime, it is necessary to utilise a long panel dataset. In general, such datasets are not available, either because the analysis relates to the future, as in the case of pension forecasts, or because collected datasets do not cover sufficiently long time periods; therefore, analysts use dynamic microsimulation models to assist in their analysis, a concept which was initially suggested by Orcutt in 1957. Essentially, microsimulation is a tool to generate synthetic micro-unit based data, which can then be used to answer many "what-if" questions that, otherwise, cannot be answered.

Microsimulation models, as in the field of policy modelling, are usually categorised as "static" or "dynamic." Static models, e.g. EUROMOD (Mantovani et al., 2007), are often arithmetic models that evaluate the immediate distributional impact upon individuals/households of possible policy changes. Dynamic models, e.g. DESTINIE, PENSIM, and SESIM (Bardaji et al., 2003; Curry, 1996; Flood, 2007), extend the static model by allowing individuals to change their characteristics due to endogenous factors within the model (O’Donoghue, 2001). Although some static models, e.g. IZAYMOD (Peichl et al., 2010), also incorporate certain behaviour responses, this is usually limited to certain overnight effects. Dynamic microsimulation models in theory, could offer further insights as they can integrate long-term projections and time dependent behaviour simulations.

Dynamic microsimulation models can have many uses and this section provides an overview of the principle uses. Table 2.1 summarises many of the existing dynamic microsimulation models in terms of their main purpose, which covers projection, evaluating/designing public policies, inter-temporal behaviour studies, etc.

Following the introduction of the time dimension into dynamic microsimulation, these models are able to provide useful projections for the trend of socio-economic development under current policies. DYNASIM2/3 (Wertheimer et al., 1986; Favreault and Smith, 2004), APPSIM (Harding 2007b), the SfB3 population model (Galler and Wagner, 1986), DYNAMITE (Ando et al., 2000), SADNAP (Van Sonsbeek, 2009) and DESTINIE1/2 (Bonnet and Mahieu, 2000; Blanchet et al., 2009), have all been used for these purposes. In some cases, dynamic microsimulation models have been used as an input for macro models such as in the case of the MOSART (Andreassen and Solli , 2000), DYNASIM2 and DARMSTADT models.

Dynamic microsimulation models can also be used to evaluate the future performance of various long-term programmes such as pensions, educational financing, and health and long-term care, by analysing future cross-sectional data. The governmental models such as 
DYNCAN (Morrison, 2000), POLISIM (McKay, 2003), PENSIM2 (Emmerson, 2004), the Sfb3 models (Galler and Wagner, 1986), MOSART (Andreassen et al., 1996), PENMOD (Shiraishi, 2008) and SESIM (Ericson, and Hussenius, 1999; Klevmarken et al., 2007) have been extensively used for this purpose. The existence of baseline projections allows the design of a new public policy by simulating the effect of potential reforms. Models such as LIAM (O'Donoghue, 2009), PRISM (Kennell and Sheils, 1990), the Belgian dynamic model (Joyeaux et al., 1996), the SfB3 population model (Galler and Wagner, 1986), LIFEMOD (Falkingham and Johnson, 1995) and Begium MIDAS (Dekkers et al., 2008; Dekkers and Belloni, 2009), have all been used to look at pension reform. A number of models such as DYNAMOD, the SfB3 cohort model (Hain and Hellberger, 1986), LIFEMD (Harding, 1993), and SAGE (Zaidi and Scott, 2001) have been used to examine changes to education finance, whereby education costs are to be paid for over an individual's lifetime. Fölster (1997) used a microsimulation model to examine reforms to social insurance utilising personal savings accounts.

By using longitudinal information created from dynamic microsimulation models, researchers can study the inter-temporal processes and behaviours at both the aggregate and individual levels. For example, CORSIM (Keister, 2000), DYNAMOD (Baekgaard, 1998), and MIDAS (Stroombergen et al., 1995) have all been used to look at wealth accumulation. Models such as DESTINIE1/2, LIAM, LifePaths, and IFSIM have been used to examine intergenerational transfers (Rowe and Wolfson, 2000; Bonnet and Mahieu, 2000; Blanchet et al., 2009; Baroni et al., 2009; O'Donoghue, 2009), whilst FAMSIM (Lutz, 1997) has been used to study the demographic behaviour of women, and MICROHUS (Klevmarken and Olovsson, 1996) examined the impact of a tax-benefit system on labour market mobility. Models that simulate these processes can be used to design policies to combat these problems, for example DYNASIM, was used to study the effect of teenage childbearing, while CORSIM has been used to look at dental health within the US population (Brown et al., 1992). The models FEM and POHEM were designed to evaluate the evolution of the population's health status and its budget implications for the US and Canada (Eugenio, 2010; Will et al., 2001), whist the LifePaths modelling framework has been used in Canada to examine time use issues (Wolfson and Rowe, 1998).

By combining spatial information with dynamic microsimulation models, the model can then be used to predict the geographical trend of certain social economic activities. This type of model is usually referred to as a dynamic spatial microsimulation model and although spatial models can focus only on small areas, e.g. MOSES (Wu et al., 2008), there are a number of models that attempt to analyse policy changes at the national level. For instance, the SVERIGE model simulates a number of demographic processes for policy 
analysis in Sweden (Vencatasawmy et al., 1999; Holm et al., 2006), whilst the SMILE model (Ballas et al., 2005a; O'Donoghue et al., 2011) analyses the impact of policy change and economic development on rural areas in Ireland. In addition to modelling economic policy, SimBritain (Ballas et al., 2005b) looks at the evolution of health at the national level while models such as HouseMod (Phillips and Kelly, 2006) and SustainCity (Morand et al., 2010) focus on the housing market within a dynamic setting.

Dynamic microsimulation models typically project samples of the population over time. If a full cross-section of the population is projected, then one can for example, examine future income distributions under different economic and demographic scenarios. DYNASIM2/3 (Wertheimer et al, 1986; Favreault and Smith, 2004), APPSIM (Harding 2007b), the SfB3 population model (Galler and Wagner, 1986), DYNAMITE (Ando et al., 2000), SADNAP (Van Sonsbeek, 2009) and DESTINIE1/2 (Bonnet and Mahieu, 2000; Blanchet et.al, 2009) have been used for these purposes. These models typically utilise macro-models or forecasts to align their own projections. However, occasionally the opposite has occurred, where dynamic microsimulation models have been used as input into macro models as in the case of MOSART (Andreassen and Solli, 2000), DYNASIM2 and the DARMSTADT models.

Table 2.1 Uses of Dynamic Microsimulation Models

\begin{tabular}{|c|c|c|}
\hline Model & Country & Uses \\
\hline ANAC & Italy & $\begin{array}{l}\text { Examines the effect of demographic changes on the Italian } \\
\text { saving rate and the reform of the pension system }\end{array}$ \\
\hline APPSIM & Australia & $\begin{array}{l}\text { Designed to provide answers regarding the future distributional } \\
\text { impact of policy change and other issues associated with policy } \\
\text { responses to population ageing }\end{array}$ \\
\hline BRALAMMO & Brazil & Models the Brazilian labour market for pension welfare analysis \\
\hline CAPP_DYN & Italy & Analyses the long term redistributive effects of social policies \\
\hline CBOLT & USA & $\begin{array}{l}\text { Analyses potential reforms to federal entitlement programmes } \\
\text { and quantifies the US nation's long-term fiscal challenges }\end{array}$ \\
\hline CORSIM & USA & $\begin{array}{l}\text { Models changes occurring within kinship networks, wealth } \\
\text { accumulation, patterns of intergenerational mobility, the } \\
\text { progressivity and the life course of the current social security } \\
\text { system, as well as potential reforms, household wealth } \\
\text { accumulation, health status, interstate migration, time and } \\
\text { income allocation, and international collaborations }\end{array}$ \\
\hline DEMOGEN & Canada & $\begin{array}{l}\text { Models distributional and financial impact of proposals to } \\
\text { include homemakers in the Canadian pension plan }\end{array}$ \\
\hline DESTINIE I/II & France & Models public pensions and intergenerational transfers \\
\hline DYNACAN & Canada & $\begin{array}{l}\text { Models the Canada Pension Plan and its impact on the } \\
\text { Canadian population }\end{array}$ \\
\hline
\end{tabular}




\begin{tabular}{|c|c|c|}
\hline Model & Country & Uses \\
\hline Dynamic Model & Ireland & $\begin{array}{l}\text { Models inter-temporal issues relating to the degree of } \\
\text { redistribution within the tax-benefit system }\end{array}$ \\
\hline $\begin{array}{l}\text { DYNAMIC } \\
\text { TUSCAN }\end{array}$ & Italy & $\begin{array}{l}\text { Simulates the demographic, social and economic characteristics } \\
\text { of the Tuscan population }\end{array}$ \\
\hline DYNAMITE & Italy & $\begin{array}{l}\text { Models microeconomic issues and the impact of } \\
\text { macroeconomic/institutional changes on the distribution of } \\
\text { income }\end{array}$ \\
\hline DYNAMOD I \& II & Australia & $\begin{array}{l}\text { Models life course policies such as superannuation, age, pensions } \\
\text { and education, long-term issues within the labour market, } \\
\text { health, aged care and housing policy, future characteristics of the } \\
\text { population and the projected impact of policy changes }\end{array}$ \\
\hline DYNASIM I \& II & USA & $\begin{array}{l}\text { Forecasts the population up to } 2030 \text { by employing different } \\
\text { assumptions regarding demographic and economic scenarios, } \\
\text { and analyses the cost of teenage childbearing to the public sector } \\
\text { under alternative policy scenarios, also includes a link to a macro } \\
\text { model }\end{array}$ \\
\hline DYNASIM III & USA & $\begin{array}{l}\text { Designed to analyse the long-term distributional consequences } \\
\text { of retirement and ageing issues }\end{array}$ \\
\hline FAMSIM & Austria & Models the demographic behaviour of young women \\
\hline FEM & USA & $\begin{array}{l}\text { A demographic and economic simulation model designed to } \\
\text { predict the future costs and health status of the elderly and to } \\
\text { explore what current trends or future shifts might imply for } \\
\text { policy, developed by RAND }\end{array}$ \\
\hline GAMEO & France & $\begin{array}{l}\text { Analyses and assesses the consequences of various higher } \\
\text { education policies }\end{array}$ \\
\hline HARDING & Australia & $\begin{array}{l}\text { Analysis of lifetime tax-transfer analysis, for analysis of policy } \\
\text { concerning the Higher Education Contribution Scheme and } \\
\text { redistributive impact of government health outlays over the } \\
\text { lifetime of an individual }\end{array}$ \\
\hline HouseMod & Australia & $\begin{array}{l}\text { Simulates the impacts of different policy options at the small } \\
\text { area level in Australia }\end{array}$ \\
\hline IFSIM & Sweden & $\begin{array}{l}\text { Studies intergenerational transfers and the interdependence } \\
\text { between demography and the economy }\end{array}$ \\
\hline IFS Model & UK & $\begin{array}{l}\text { Studies pensioner poverty under a variety of alternative tax and } \\
\text { benefit policies }\end{array}$ \\
\hline INAHSIM & Japan & $\begin{array}{l}\text { Simulates demographic and social evolution, simulates kinship } \\
\text { relationships in detail }\end{array}$ \\
\hline INFORM & UK & $\begin{array}{l}\text { Developed for forecasting of benefit caseloads and combinations } \\
\text { of receipt, designed to incorporate significant benefit reforms } \\
\text { planned over the coming years, based entirely on administrative } \\
\text { data }\end{array}$ \\
\hline Italian Cohort & Italy & Analyses lifetime income distribution issues \\
\hline Japanese Cohort & Japan & $\begin{array}{l}\text { Looks at the impact on household savings of changes in } \\
\text { demographic structure }\end{array}$ \\
\hline
\end{tabular}




\begin{tabular}{|c|c|c|}
\hline Model & Country & Uses \\
\hline LABORsim & Italy & $\begin{array}{l}\text { Simulates the evolution of the labour force over future decades } \\
\text { in Italy }\end{array}$ \\
\hline LIAM & Ireland & $\begin{array}{l}\text { Evaluates potential reforms to the Irish pensions system in terms } \\
\text { of changes to life-cycle incomes }\end{array}$ \\
\hline LIFEMOD & UK & Models the lifetime impact of a welfare state \\
\hline LifePaths & Canada & $\begin{array}{l}\text { Models health care treatments, student loans, time-use, public } \\
\text { pensions and generational accounts }\end{array}$ \\
\hline $\begin{array}{l}\text { Long Term Care } \\
\text { Model }\end{array}$ & UK & Models long term care reform options \\
\hline Melbourne Cohort & Australia & Analyses income inequality in a lifetime context \\
\hline MICROHUS & Sweden & $\begin{array}{l}\text { Models dynamic effects of changes to the tax-benefit system on } \\
\text { the income distribution and economic-demographic effects of } \\
\text { immigration }\end{array}$ \\
\hline MIDAS & Belgium & Analyses pension system and social security adequacy \\
\hline MIDAS & New Zealand & Models wealth accumulation and distribution \\
\hline MIND & Italy & $\begin{array}{l}\text { Simulates the economic impact resulting from alternative values } \\
\text { of the income growth rate and real interest rate }\end{array}$ \\
\hline MINT & USA & $\begin{array}{l}\text { Forecasts the distribution of income for the } 1931-1960 \text { birth } \\
\text { cohorts in retirement, MINT5 extends to the } 1926-2018 \text { birth } \\
\text { cohorts }\end{array}$ \\
\hline MOSART $1 / 2 / 3$ & Norway & $\begin{array}{l}\text { Models the future cost of pensions, undertakes micro level } \\
\text { projections of population, education, labour supply and public } \\
\text { pensions, incorporates overlapping-generations, models within a } \\
\text { dynamic microsimulation framework }\end{array}$ \\
\hline NEDYMAS & Netherlands & $\begin{array}{l}\text { Models intergenerational equity and pension reform, the } \\
\text { redistributive impact of social security schemes in a lifetime } \\
\text { framework }\end{array}$ \\
\hline PENMOD & Japan & Public pension system analysis \\
\hline PENSIM & UK & $\begin{array}{l}\text { Models the treatment of pensioners by the social security system } \\
\text { across the income distribution }\end{array}$ \\
\hline PENSIM2 & UK & $\begin{array}{l}\text { Estimates the future distribution of pensioner incomes to } \\
\text { analyse the distributional effects of proposed changes to pension } \\
\text { policy }\end{array}$ \\
\hline PENSIM & USA & $\begin{array}{l}\text { Analyses lifetime coverage and adequacy issues related to } \\
\text { employer-sponsored pension plans in the USA. }\end{array}$ \\
\hline Pensions Model & Belgium & $\begin{array}{l}\text { Analyses and forecasts the medium term impact of a change to } \\
\text { pension regulations }\end{array}$ \\
\hline POHEM & Canada & $\begin{array}{l}\text { A longitudinal microsimulation model of health and disease, it is } \\
\text { used to compare competing health intervention alternatives } \\
\text { within a framework that captures the effects of disease } \\
\text { interactions }\end{array}$ \\
\hline POLISIM & USA & $\begin{array}{l}\text { Demographic-economic and social security projection for US } \\
\text { social security administration }\end{array}$ \\
\hline PRISM & USA & Evaluates public and private pensions \\
\hline
\end{tabular}




\begin{tabular}{|c|c|c|}
\hline Model & Country & Uses \\
\hline PSG & USA & $\begin{array}{l}\text { Analyses the lifetime implications of social security policies for a } \\
\text { large sample of people born in the same year }\end{array}$ \\
\hline SADNAP & Netherlands & $\begin{array}{l}\text { Evaluates the financial and economic implications of the } \\
\text { problem of ageing }\end{array}$ \\
\hline SAGE & UK & Dynamic demographic/tax model for the UK \\
\hline SESIM & Sweden & $\begin{array}{l}\text { Models budget and distributional impact of inter-temporal } \\
\text { policy issues such as student grants, labour supply, savings } \\
\text { decisions and pensions }\end{array}$ \\
\hline SimBritain & UK & Simulates urban and regional populations within the UK \\
\hline SMILE & Ireland & Population projections with spatial details for Ireland \\
\hline $\mathrm{Sfb} 3$ & Germany & $\begin{array}{l}\text { Analyses pension reforms, the effect of shortening worker hours, } \\
\text { distributional effects of education transfers }\end{array}$ \\
\hline SustainCity & Switzerland & A dynamic model with a focus on land use simulations \\
\hline SVERIGE & Sweden & $\begin{array}{l}\text { Models human eco-dynamics (the impact of human cultural and } \\
\text { economic systems on the environment) }\end{array}$ \\
\hline Swedish Cohort & Sweden & $\begin{array}{l}\text { Models the replacement of social insurance by personal savings } \\
\text { accounts and the distribution of lifetime marginal effective tax } \\
\text { rates }\end{array}$ \\
\hline Tdymm & Italy & $\begin{array}{l}\text { Analyses the Italian labour market and pension system, with a } \\
\text { focus on pension adequacy and related distributional effects }\end{array}$ \\
\hline XEcon & Canada & $\begin{array}{l}\text { A model intended for theoretical exploration rather than } \\
\text { practical empirical application (developed for the eXperimental } \\
\text { Economy) }\end{array}$ \\
\hline
\end{tabular}

Sources: Andersson et al. (1992); Ando (1996); Ando and Nicoletti Altimari (1999); Ando et al. (2000);

Antcliffet al. (1993, 1996); Baldini (1997); Ballas et al. (2005a, 2005b); Baroni et al. (2009); Blanchet et al. (2009); Bonnet and Mahieu (2000); Brewer et al. (2007); Caldwell et al. (2000); Citro and Hanushek (1991a, 1991b); Courtioux et al. (2008); Curry (1996); Dekkers and Belloni (2009); Emmerson et al. (2004), Ericson and Hussenius (1998, 1999); Falkingham and Lessof (1991); Favreault and Smith (2004); Fölster (1997); Fredriksen (1998); Galler and Wagner (1986); Gault (2009); Hain and Hellberger (1986); Hancock (2000); Hancock et al. (1992); Harding (1993); Harding (2007b); Holmer (2009); Holmer et al. (2001); Inagaki (2010); INSEE (1999); Joyeaux et al. (1996); Kelly and Percival (2009); King et al. (1999a,1999b); Klevmarken and Olovsson (1996); Leombruni (2006); Lutz (1997); Maitino (2009); Mazzaferro and Morciano (2008); McKay (2003); Morand et al. (2010); Morrison (2000); Nelissen (1996); O'Donoghue (2001b); O'Donoghue et al. (2009); Oharra et al. (2004); Osberg and Lethbridge (1996); Panis and Lillard (1999); Phillips and Kelly (2006); Pudney (1992); Pylkkänen (2000); Rowe and Wolfson (2000); Shiraishi (2008); Smith et al. (2007); Stroombergen et al. (1995); Tedeschi (2011); Toder et al. (1999);Van de Ven (1998); Van Sonsbeek (2009); Vencatasawmy et al. (1999); Will (2001); Winder and Zhou (1999); Wolfson (1988); Zaidi and Rake (2001); Zaidi and Scott (2001); Zucchelli (2010); Zylberstajn et al. (2011)

Although Table 2.1 tries to cover as many known models as possible, it is nearly impossible to list all models as new ones are being developed every year. In addition, the list focuses more on the dynamic microsimulation models that are mainly used for social economic 
analyses at national level. Certain regional dynamic spatial models and transportation models are not included.

All these powerful dynamic microsimulation models come with the cost of high complexity. Compared with static microsimulation, dynamic microsimulation is much more costly to develop and also has more issues with the methodologies used. This chapter intends to discuss some of the methodological issues related to the construction of a dynamic microsimulation model, surveying current practice in the field around the world.

\subsection{Methodological Issues - Part I}

In this section, a number of methodological issues relating to the development of dynamic microsimulation models are discussed. There are many choices when constructing a dynamic microsimulation model and this chapter discusses these choices and the pros and cons of different practices. Given the number of issues covered in the chapter, the content is split into two parts; the first focuses more on general issues such as dataset and development, whilst the second pays more attention to the technical choices addressed in the models.

\subsubsection{Base Dataset Selection}

Base dataset selection is important in a microsimulation model as the quality of the input data determines the quality of the output. However, selection of a base dataset is not an easy task as hardly any micro dataset contains all the information required by a dynamic population microsimulation model and the difficulties of picking a base dataset have been discussed by Cassells et al. (2006) and Zaidi and Scott (2001). There are a number of different types of base data that a dynamic model can utilise and Table 2.2 describes the types used by different dynamic microsimulation models, including detailing of the data source and sample size. Typically, a dynamic microsimulation model starts with one or several of the following types of dataset according to their sources:

- Administrative Data

- Census Data

- Household Survey Data

- Synthetic Dataset

Administrative data often contains the most accurate information, as there is increased effort placed on data collection and as data is often collected for the whole population, sample sizes are usually much larger than survey samples. However, the data typically collected is only the information necessary for administrative purposes and, for this reason, 
countries who use administrative data often supplement information with extra survey data as in the SESIM and MICROHUS models.

Legal and privacy reasons may also prevent administrative data from being accessible. Models such as CORSIM, DYNACAN and DYNAMOD use census data and while census data typically has better coverage than household surveys, they often contain less information and have to be supplemented with imputed information from other sources.

Household survey data, e.g. the LII survey utilised in the LIAM model, is also frequently used as the base dataset because it is rich in the number of variables of interest and offers information on the dynamics of behaviour. However, household survey datasets may have the issues of smaller sample size and weights adjustment. The use of weights in a dynamic model adds complexity to many areas and can result in individuals being given different weightings at different points in their lives. One solution implemented in the DYNAMITE and ANAC models is to replicate households according to their nonresponse weights, so that consequently each household has the same weight.

Another type of base dataset is synthetic datasets. These are selected when either a longitudinal model is used, as in the case of DEMOGEN, HARDING, LIFEMOD and BALDINI, or where no data exists, as in the case of the NEDYMAS model, where a synthetic initial sample representative of the Dutch population in 1947 was generated. As synthetic datasets are artificially created, they often contain all the variables required and models based on synthetic datasets usually provide great tools in understanding a single policy in depth. However, adjustments are required before reporting the policy effects in real life.

For microsimulation models analysing the dynamics of elderly earnings or pensions, the dataset requirement is usually higher as it requires historical variables that affect the evolution of the elderly social economic status. This necessity implies that a long panel dataset containing rich demographic, employment, and pension data is required, something which is not readily available to most researchers. Hybrid sources of datasets are often used in such a scenario, whereby a combination of datasets from various sources, statistical matching and simulation techniques are utilised; for instance DYNASIM3 (Favreault and Smith, 2004) matches two survey datasets, namely, Survey of Income and Program Participation (SIPP) and Panel Study of Income Dynamics (PSID). CBOLT (Oharra et al., 2004) uses a similar approach to complement its main dataset with SIPP, PSID and data from the Current Population Survey (CPS). A new model Tdymm (Tedeschi, 2011), intends to match administrative records with the European Union Statistics on Income and Living Conditions (EU-SILC) dataset. For researchers without access to certain required data, simulation is used to impute the longitudinal history. The CORSIM model simulates part of the historical profile based on a historical cross-sectional dataset and matches the model output to historical aggregate information such as fertility 
and mortality rates (Caldwell, 1996), whilst LIAM simulates a historical profile by exploiting retrospective variables, previous censuses and other data sources ( $\mathrm{Li}$ and O’Donoghue, 2010).

Another issue in the base dataset selection is sample size; the larger the sample size, the more smaller consider groups can be considered. Sample sizes are more important for intertemporal analysis because here the number of dimensions is increased as similar individuals in a cross-sectional sample may in fact be very different due to the different paths taken to reach the same state. Regardless the source of the dataset, panel data is usually preferred as it records changes over time. Sample size also has an impact on run time of the model; the larger the samples size, the longer the run speed, resulting in a trade-off. Faster computer power does however reduce the impact of this trade-off.

Table 2.2 Base Dataset Selection of Dynamic Microsimulation Models

\begin{tabular}{|c|c|c|c|}
\hline Model & Country & Base Dataset & Observation \\
\hline ANAC & Italy & $\begin{array}{l}\text { Household Income and Wealth, } \\
1993\end{array}$ & 67000 households \\
\hline APPSIM & Australia & $\begin{array}{l}1 \% \text { census sample drawn from the } \\
2001 \text { Census }\end{array}$ & 188,013 individuals \\
\hline CAPP_DYN & Italy & $\begin{array}{l}\text { Survey of Households' Income and } \\
\text { Wealth (SHIW), } 2002\end{array}$ & $\begin{array}{l}21,148 \text { individuals and } \\
8,011 \text { households }\end{array}$ \\
\hline COBLT & USA & $\begin{array}{l}\text { Continuous Work History } \\
\text { Sample (CWHS), complemented } \\
\text { with SIPP, PSID and CPS datasets }\end{array}$ & 300,000 individuals \\
\hline CORSIM & USA & $\begin{array}{l}0.1 \% \text { sample drawn from the } 1960 \\
\text { census }\end{array}$ & 180,000 individuals \\
\hline DEMOGEN & Canada & Synthetic cohort aged 0 & $1,000-5,000$ individuals \\
\hline $\begin{array}{l}\text { DESTINIE I } \\
\& \text { II }\end{array}$ & France & Financial Assets Survey, 1991 & 37,000 individuals \\
\hline DYNACAN & Canada & $\begin{array}{l}1 \% \text { sample drawn from } 1971 \text { census, } \\
\text { public use file }\end{array}$ & 212,000 individuals \\
\hline $\begin{array}{l}\text { Dynamic } \\
\text { Model }\end{array}$ & Ireland & $\begin{array}{l}\text { LII survey, } 1994 \text { (Pop.), synthetic } \\
\text { cohort aged } 0 \text { (Cohort) }\end{array}$ & Around 4,500 households \\
\hline $\begin{array}{l}\text { DYNAMIC } \\
\text { TUSCAN }\end{array}$ & Italy & EU-SILC 2003 wave & \\
\hline DYNAMITE & Italy & $\begin{array}{l}\text { Household Income and Wealth, } \\
1993\end{array}$ & 67,000 households \\
\hline $\begin{array}{l}\text { DYNAMOD } \\
\text { I and II }\end{array}$ & Australia & $\begin{array}{l}\text { 1\% sample drawn from the } 1986 \\
\text { census }\end{array}$ & 150,000 individuals \\
\hline $\begin{array}{l}\text { DYNASIM I } \\
\& \text { II }\end{array}$ & USA & $\begin{array}{l}\text { CPS } 1973 \text { matched to Social Security } \\
\text { Administration (SSA) data }\end{array}$ & \\
\hline DYNASIM III & USA & SIPP panels 1990 to 1993 & $\begin{array}{l}100,000 \text { individuals and } \\
44,000 \text { households }\end{array}$ \\
\hline
\end{tabular}




\begin{tabular}{|c|c|c|c|}
\hline Model & Country & Base Dataset & Observation \\
\hline FAMSIM & Austria & $\begin{array}{l}\text { Family and Fertility Survey (Austria), } \\
1995-96\end{array}$ & 4,500 women \\
\hline FEM & USA & $\begin{array}{l}\text { Individual records drawn from the } \\
\text { Medicare Current Beneficiary Survey } \\
\text { (MCBS), 1992-1998 }\end{array}$ & 10,000 individuals \\
\hline GAMEO & France & $\begin{array}{l}\text { French Labour Force Survey (FLFS), } \\
2003-2005\end{array}$ & \\
\hline HARDING & Australia & Synthetic cohort aged 0 & 4,000 individuals \\
\hline IFSIM & Sweden & $\begin{array}{l}\text { Swedish micro dataset on the } \\
\text { Household Market and Non-market } \\
\text { Activities HUS, } 1996\end{array}$ & 3,000 individuals \\
\hline IFS Model & UK & $\begin{array}{l}\text { English Longitudinal Study of } \\
\text { Ageing (ELSA), 2002-2003 }\end{array}$ & 12,100 individuals \\
\hline INAHSIM & Japan & $\begin{array}{l}\text { Comprehensive Survey of the Living } \\
\text { Conditions of People on Health and } \\
\text { Welfare (CSLC), } 2004\end{array}$ & 127,687 individuals \\
\hline INFORM & UK & $\begin{array}{l}1 \% \text { sample drawn from Department } \\
\text { for Work and Pensions (DWP) } \\
\text { administrative data }\end{array}$ & 110,000 individuals \\
\hline $\begin{array}{l}\text { Italian Cohort } \\
\text { Model }\end{array}$ & Italy & Synthetic cohort aged 0 & 4,000 individuals \\
\hline $\begin{array}{l}\text { Japanese } \\
\text { Cohort Model }\end{array}$ & Japan & $\begin{array}{l}\text { Synthetic multiple cohorts (single } \\
\text { representative of each cohort type) }\end{array}$ & 4,000 individuals \\
\hline LABORsim & Italy & $\begin{array}{l}2003 \text { Rilevazione Trimestrale delle } \\
\text { Forze Lavoro (RTFL) }\end{array}$ & 50,000 individuals \\
\hline LIAM & Ireland & LII survey, 1994-2001 & 15,000 individuals \\
\hline LIFEMOD & UK & Synthetic cohort aged 0 & 4,000 individuals \\
\hline LifePaths & Canada & Synthetic cross-section & Varies \\
\hline $\begin{array}{l}\text { Long Term } \\
\text { Care Model }\end{array}$ & UK & $\begin{array}{l}\text { Family Expenditure Surveys, 1993- } \\
1996\end{array}$ & 1,770 individuals \\
\hline $\begin{array}{l}\text { Melbourne } \\
\text { Cohort Model }\end{array}$ & Australia & $\begin{array}{l}\text { Synthetic sample of } 20 \text { year olds in } \\
1970\end{array}$ & 50,000 males and families \\
\hline MICROHUS & Sweden & $\begin{array}{l}\text { HUS income distribution database, } \\
1984\end{array}$ & \\
\hline MIDAS & Belgium & $\begin{array}{l}\text { PSBH dataset for Belgium, 2002, } \\
\text { GSOEP dataset for Germany,2002, } \\
\text { ECHP dataset for Italy, } 2001\end{array}$ & \\
\hline MIDAS & $\begin{array}{l}\text { New } \\
\text { Zealand }\end{array}$ & $\begin{array}{l}\text { Synthetic cross-section based on } \\
1991 \text { Census }\end{array}$ & 10,000 individuals \\
\hline MIND & Italy & $\begin{array}{l}\text { ISTATA, IRP and SHIW Data, } \\
1995\end{array}$ & \\
\hline MINT & USA & $\begin{array}{l}\text { SIPP, 1990-93, matched to SSA data, } \\
\text { SIPP, 1990-96, matched to SSA data } \\
\text { for MINT5 }\end{array}$ & $\begin{array}{l}85,000 \text { individuals, } \\
\text { expanded in later versions }\end{array}$ \\
\hline
\end{tabular}




\begin{tabular}{|c|c|c|c|}
\hline Model & Country & Base Dataset & Observation \\
\hline $\begin{array}{l}\text { MOSART } \\
1 / 2 / 3\end{array}$ & Norway & $\begin{array}{l}1 \% \text { sample drawn from } \\
\text { administrative data, } 1989 \text {, version } 3 \\
\text { used a } 12 \% \text { sample drawn from } \\
\text { administrative data, } 1993\end{array}$ & $\begin{array}{l}40,000 \text { individuals, } \\
500,000 \text { observations in } \\
\text { version } 3\end{array}$ \\
\hline NEDYMAS & Netherlands & $\begin{array}{l}\text { Synthetic cross-section based on } \\
1947 \text { census }\end{array}$ & 10,000 individuals \\
\hline PENMOD & Japan & $\begin{array}{l}\text { Synthetic dataset based on the official } \\
\text { aggregate statistics }\end{array}$ & \\
\hline PENSIM & UK & $\begin{array}{l}\text { Retirement Survey, 1988, Social } \\
\text { Change and Economic Life Initiative } \\
\text { Survey, } 1986 \text { and Family } \\
\text { Expenditure Survey, } 1988\end{array}$ & 5,000 benefit units \\
\hline PENSIM2 & UK & $\begin{array}{l}\text { Family Resource Survey, British } \\
\text { Household Panel Survey and } \\
\text { Lifelong Labour Market Database, } \\
\text { 1999-2001 }\end{array}$ & \\
\hline PENSIM & USA & Synthetic cohort aged 0 & \\
\hline $\begin{array}{l}\text { Pensions } \\
\text { Model }\end{array}$ & Belgium & $\begin{array}{l}\text { Synthetic cross-section based on } \\
\text { survey data }\end{array}$ & \\
\hline POHEM & Canada & Administrative data & \\
\hline POLISIM & USA & $\begin{array}{l}\text { A subset (1-10\%) of the } 1960 \text { US } \\
\text { Census Bureau Public use Microdata } \\
\text { Sample (PUMS) }\end{array}$ & \\
\hline PRISM & USA & $\begin{array}{l}\text { CPS, March 1978, March and May } \\
\text { 1979, matched to SSA data }\end{array}$ & 28,000 adults \\
\hline PSG & USA & Mixed & 100,000 individuals \\
\hline SADNAP & Netherlands & $\begin{array}{l}\text { Administrative data from Statistics } \\
\text { Netherlands (CBS) }\end{array}$ & \\
\hline SAGE & UK & $\begin{array}{l}10 \% \text { sample drawn from the } \\
\text { Individual/Household, } 1991 \\
\text { anonymised records combined with } \\
\text { several survey datasets }\end{array}$ & 54,000 individuals \\
\hline SESIM & Sweden & $\begin{array}{l}\text { Household } \\
\text { Survey on Income (HINK), } 1992\end{array}$ & 30,000 individuals \\
\hline $\begin{array}{l}\text { Sfb3 } \\
\text { Population }\end{array}$ & Germany & $\begin{array}{l}\text { Integrated Micro Data File, } 1969 \\
\text { (Pop.), synthetic cohort aged } 0 \\
\text { (Cohort) }\end{array}$ & $\begin{array}{l}69,000 \text { households / 7,300 } \\
\text { individuals }\end{array}$ \\
\hline Sfb3 Cohort & Germany & $\begin{array}{l}\text { Integrated Micro Data File, } 1969 \\
\text { (Pop.), synthetic cohort aged } 0 \\
\text { (Cohort) }\end{array}$ & $\begin{array}{l}69,000 \text { households / 7,300 } \\
\text { individuals }\end{array}$ \\
\hline SimBritain & UK & UK Census and BHPS, 1991 & \\
\hline SMILE & Ireland & Census of Population of Ireland & \\
\hline
\end{tabular}

Source: See Table 2.1 
Microsimulation models are usually built for specific purposes and are thus custom developed, although there are a few packages that are often used in the development of dynamic microsimulation model. These packages can be grouped in to three main categories according to their development environments, each with their own advantages and disadvantages:

- General purpose programming language tool (C/C++/C\#/Java etc.)

- Statistical package (Stata/SAS/R/MatLab/Mathematica etc.)

- Simulation package (AnyLogic, Modgen, LIAM2 etc.)

Development using a general purpose programming language clearly enjoys the highest degree of flexibility and possibly also a speed advantage. The $\mathrm{C}$ language family appears to be most popular choice among all programming languages. Models like SAGE, DYNAMOD, LIAM, and DYNACAN were all developed using C++, whilst POLISIM used a mixture of $\mathrm{C}$ and $\mathrm{C}++$, and APPSIM and MOSART were programmed in C\#. Models have also been developed in Java (e.g. IFSIM). Evaluation based on the prototype microsimulation models by Percival (2007) suggested that there is a substantial speed gain by switching the prototype model from SAS to $\mathrm{C}++$; however, the cost of development is much higher when compared with other approaches, as all the potential numeric calculations and related data management need to be programmed. In practice, it is likely that policy modellers are not adequately proficient in programming, while professional programmers may not be able to fully understand the economic principles that are to be implemented.

The second approach is to develop microsimulation models based on existing statistical or mathematics packages, such as GAMEO, DYNASIM, and PENSIM2 which were built on SAS. Modern statistical packages are capable of executing computation commands in batch and the code of a model is commonly referred to as a "script", "do-file" or "syntax file" etc. The main advantage of this approach is a fast development time and easy access to the statistical power of the package. However, the speed of the model might be lower as script commands are usually interpreted at the time of analysis; the increased performance time is most obvious when large loops are being implemented.

Another tool with which to develop microsimulation models is the use of specific modelling packages. Software in this category ranges from generic purpose modelling software, e.g. AnyLogic etc. to microsimulation specific packages. Whilst agent based simulation modellers use more generic purpose packages, microsimulation modellers tend to use more specific software. The two most notable microsimulation packages are Modgen, developed by Statistics Canada, and the LIAM2 engine, which is being developed by the Federal Planning Bureau (FPB) in Belgium. Modgen provides a $\mathrm{C}++$ library in order for 
developers to incorporate required common actions and modules. It is often used to develop continuous microsimulation models, such as LifePath. In contrast, LIAM2 is a microsimulation scripting engine which is capable of reading its own syntax and microsimulation packages such as this one offer the great benefit of rapid development.

In practice, most models are based on a statistical package or a generic purpose programming language. However, it is not uncommon to see mixed combinations of environments in order to utilise the advantages of different software, especially for pre- or post-simulation analysis, e.g. DYNACAN, LIAM.

\subsubsection{Cohort Model or Population Model}

One issue that is closely related to the base dataset selection is the type of data structure that a model uses. Harding (1993) and others have categorised inter-temporal dynamic models into two types: cohort/longitudinal models that model a single cohort over their lifetime, and population/cross-section models that model a population cross-section over a defined period of time. In addition, some models focus only on adults (i.e. ignore children) and thus, although these models may contain a cross-section of the population, they do not represent the entire age spectrum. This flaw is also seen among models dedicated to pension analysis, e.g. IFS Model (2007).

From a model design perspective, the distinction between cohort and population model is less significant than the use that the model is put to. The distinction made in the literature from a historical viewpoint has more to do with computing power and data constraints rather than any major methodological differences. Cohort models were typically used because the computing costs required to simulate whole lifetimes for cross-sections with sufficient sample sizes to be able to examine specific cohorts were too high. Both types of models can be simulated in the same modelling environment: a cohort model is simply a model that ages a sample of unrelated individuals aged zero, while a population model ages a sample of individuals of different ages some of whom are related. Both samples are then passed through ageing procedures, to produce life event histories over the modelled period.

It is also possible to model both types using the same computing platform. The potentially larger size of the cohort modelled in dynamic cohort models allows life time income patterns for smaller population groups such as recipients of disability benefits or lone parents to be studied. Some cross-section models such as MOSART combine the advantages of both types of models due to access to a very large dataset. Access to administrative datasets that contain detailed labour market and life event histories for $1 \%$ of the population allows a model to be run over the lifetime of a particular cohort while comparing their position to other cohorts. 


\subsubsection{Model Complexity}

The complexity of a model is often guided by the potential policy questions that the model is required to answer. Models focusing on pension issues usually simulate detailed labour market behaviour for decades ahead, as a change in the pension system can only mature when the youngest cohort in the labour market retires. In contrast, short term tax policy models usually forward simulate 3 to 5 years and are typically limited to tax related variables only. If a model is being utilised to answer different research questions, then it usually needs to simulate more variables for a longer period of time, which involves higher levels of complexity.

An ideal microsimulation model should have the capacity to simulate details of all possibly related variables; however, the costs of building large models, both in terms of model validity and management needs to be taken into consideration. Dynamic microsimulation models have the reputation of being complex and the potential to run "out-of-spin" with regard to some aspects. Complex models, while having more power, are much more difficult to validate and may often contain bugs in their implementation. In addition, the complexity of the processes often means development takes longer than expected.

Large general purpose microsimulation models are usually built by large teams with access to large and complex datasets. These models usually simulate a wide variety of economic and demographic processes and can therefore be used for many different applications. These forecasting models usually incorporate alignment systems in order to keep the model in line with external forecasts or are in fact linked to macro-models. Models of this type include DYNASIM from the USA, the Canadian Pensions Program DYNACAN, the MOSART model in Norway and the APPSIM model in Australia etc.

Given the high cost of model development, Harding (2007a) suggested that developers "place a much greater importance on developing the simplest possible (but functioning) version of a model, on getting that well documented and on producing papers containing illustrative results within the project budget and timeframe". Some newer models, e.g. SustainCity (Morand et al., 2010), advocate this approach, especially during the initial development phase.

\subsubsection{Model Validation}

Given the increasing complexity of models, it is becoming increasingly important to validate the model in order to maintain its credibility. Unfortunately, only limited effort has been placed on validation matters and there is no international consensus on validation procedures. DYNACAN (Morrison, 2008) has published the most comprehensive validation process documentation which included:

- Context of Validation 
- Data/Coefficient/Parameter Validation

- Programmers/Algorithmic Validation

- Module-Specific Validation

- Multi-module Validation

- Policy Impact Validation

Expost analyses of previous periods can also be used to assess the reliability of a model and it is for this reason that a number of the major microsimulation projects have taken historic datasets as their starting population base for simulations. For example, the CORSIM and POLISIM models takes as their base a sub-sample of the 1971 and 1960 US Censuses respectively, and the DYNACAN model takes a sample of the 1970 Canadian Census as its base. By running the model forward to the present day, the model forecasts can be compared to what has actually happened (see for examples Morrison, 2000; Caldwell and Morrison, 2000). However, these models invariably incorporate historical information such as macro-aggregates into the model and as this information would not have been known to forecasters, this may produce better forecasts than would have otherwise been the case. One method to overcome this is to compare directly generated forecasts with what happened in reality, for example comparing forecasted labour participation rates with actual rates. Another method described by Caldwell (1996) is to use an indirect approach, known as a multiple module approach. An example cited by Caldwell is the case of validating the numbers of married persons with health insurance, when the directly simulated processes are marriage and medical insurance membership. Sources of error may result from errors in either or both direct processes, or because of misspecified interactions. However, some types of dynamic model may have no comparable source of validation. For example, models which solely look at a single cohort living in a steady state have nothing with which they can be validated as the model does not attempt to mimic real life, but merely a stylised version of it. Additionally, countries that have only recently developed their micro-data resources may not have alternative sources of data with which to validate, although this problem will become progressively less with time.

Recent developments in microsimulation methodology suggest an alternative validation method using a simplified model. Since no future data is available to validate a forecasting dynamic microsimulation model, Morrison (2007) suggests comparing a model's result to a trustworthy model's result. Dekkers (2010) argues that the general trend of certain indicators estimated by a simple model could be seen as a benchmark for more complicated microsimulation model as there is no black box in a simple model. The Belgium MIDAS model used this approach to validate against a "simple stylised" model, which is essentially a representative household style model with only demographic and pension indexation components. 


\subsection{Methodological Issues - Part II}

This section continues the discussion of methodological issues faced in constructing dynamic microsimulation models but focuses on the technical implementation and choices made in a model. Table 2.3 provides an overview of the technical choices discussed in this section.

Table 2.3 An overview of the technical choices made by dynamic microsimulation models

\begin{tabular}{|c|c|c|c|c|c|c|}
\hline Model & Country & $\begin{array}{l}\text { Base } \\
\text { Pop }\end{array}$ & $\begin{array}{c}\text { Type of } \\
\text { Time } \\
\text { Modelling }\end{array}$ & $\begin{array}{l}\text { Open } \\
\text { or } \\
\text { Closed } \\
\text { Model }\end{array}$ & $\begin{array}{c}\text { Use of } \\
\text { Alignment } \\
\text { Algorithms }\end{array}$ & $\begin{array}{c}\text { Use of } \\
\text { Behavioural } \\
\text { Equations }\end{array}$ \\
\hline ANAC & Italy & Cross & $\mathrm{D}$ & $\mathrm{C}$ & $\mathrm{Y}$ & $\mathrm{N}$ \\
\hline APPSIM & Australia & Cross & $\mathrm{D}$ & $\mathrm{C}$ & Y & $\mathrm{N}$ \\
\hline CAPP_DYN & Italy & Cross & $\mathrm{D}$ & $\mathrm{C}$ & Y & $\mathrm{N}$ \\
\hline CORSIM & USA & Cross & $\mathrm{D}$ & $\mathrm{C}$ & Y & $\mathrm{N}$ \\
\hline DEMOGEN & Canada & Cohort & $\mathrm{D}$ & $\mathrm{O}$ & $\mathrm{N}$ & $\mathrm{N}$ \\
\hline DESTINIE I \& II & France & Cross & $\mathrm{D}$ & $\mathrm{C}$ & $\mathrm{Y}$ & $\mathrm{N}$ \\
\hline DYNACAN & Canada & Cross & $\mathrm{D}$ & $\mathrm{C}$ & $\mathrm{Y}$ & $\mathrm{N}$ \\
\hline Dynamic Model & Ireland & Both & $\mathrm{D}$ & $\mathrm{C}$ & $\mathrm{Y}$ & $\mathrm{Y}$ \\
\hline $\begin{array}{l}\text { DYNAMIC } \\
\text { TUSCAN }\end{array}$ & Italy & Cross & $\mathrm{D}$ & & & $\mathrm{N}$ \\
\hline DYNAMITE & Italy & Cross & $\mathrm{D}$ & $\mathrm{C}$ & Y & $\mathrm{N}$ \\
\hline DYNAMOD I \& II & Australia & Cross & $\mathrm{C} / \mathrm{D}$ & $\mathrm{C}$ & Y & $\mathrm{N}$ \\
\hline DYNASIM I \& II & USA & Cross & $\mathrm{C} / \mathrm{D}$ & $\mathrm{C}$ & Y & $\mathrm{N}$ \\
\hline DYNASIM III & USA & Cross & $\mathrm{D}$ & $\mathrm{C}$ & Y & $\mathrm{Y}$ \\
\hline FAMSIM & Austria & Cross & $\mathrm{D}$ & $\mathrm{C}$ & $\mathrm{N}$ & $\mathrm{N}$ \\
\hline FEM & USA & Cross & $\mathrm{D}$ & & $\mathrm{N}$ & $\mathrm{N}$ \\
\hline GAMEO & France & Cross & $\mathrm{D}$ & & $\mathrm{Y}$ & \\
\hline HARDING & Australia & Cohort & $\mathrm{D}$ & C & $\mathrm{N}$ & $\mathrm{N}$ \\
\hline IFSIM & Sweden & Cross & $\mathrm{D}$ & $\mathrm{C}$ & Partial CGE & \\
\hline IFS Model & UK & $\begin{array}{l}\text { Partial } \\
\text { Cross }\end{array}$ & $\mathrm{D}$ & C & $\mathrm{Y}$ & Y \\
\hline INAHSIM & Japan & Cross & $\mathrm{D}$ & $\mathrm{C}$ & Y & $\mathrm{N}$ \\
\hline INFORM & UK & Cross & $\mathrm{D}$ & & Y & \\
\hline $\begin{array}{l}\text { Italian Cohort } \\
\text { Model }\end{array}$ & Italy & Cohort & $\mathrm{D}$ & C & $\mathrm{N}$ & $\mathrm{N}$ \\
\hline $\begin{array}{l}\text { Japanese Cohort } \\
\text { Model }\end{array}$ & Japan & Cohort & $\mathrm{D}$ & C & $\mathrm{Y}$ & Y \\
\hline LABORsim & Italy & Cohort & $\mathrm{C}$ & C & Y & $\mathrm{N}$ \\
\hline LIAM & Ireland & Cross & D & C & Y & Y \\
\hline
\end{tabular}




\begin{tabular}{|c|c|c|c|c|c|c|}
\hline Model & Country & $\begin{array}{l}\text { Base } \\
\text { Pop }\end{array}$ & $\begin{array}{c}\text { Type of } \\
\text { Time } \\
\text { Modelling }\end{array}$ & $\begin{array}{c}\text { Open } \\
\text { or } \\
\text { Closed } \\
\text { Model }\end{array}$ & $\begin{array}{c}\text { Use of } \\
\text { Alignment } \\
\text { Algorithms }\end{array}$ & $\begin{array}{c}\text { Use of } \\
\text { Behavioural } \\
\text { Equations }\end{array}$ \\
\hline LIFEMOD & UK & Cohort & $\mathrm{D}$ & $\mathrm{C}$ & $\mathrm{N}$ & $\mathrm{N}$ \\
\hline LifePaths & Canada & Cross & $\mathrm{C}$ & $\mathrm{O}$ & & $\mathrm{N}$ \\
\hline $\begin{array}{l}\text { Long Term Care } \\
\text { Model }\end{array}$ & UK & Cross & $\mathrm{D}$ & $\mathrm{C}$ & $\mathrm{Y}$ & $\mathrm{N}$ \\
\hline $\begin{array}{l}\text { Melbourne Cohort } \\
\text { Model }\end{array}$ & Australia & Cohort & $\mathrm{D}$ & $\mathrm{O}$ & & $\mathrm{N}$ \\
\hline MICROHUS & Sweden & Cross & $\mathrm{C}$ & $\mathrm{C}$ & $\mathrm{N}$ & $\mathrm{Y}$ \\
\hline MIDAS & Belgium & Cross & $\mathrm{D}$ & $\mathrm{C}$ & $\mathrm{Y}$ & $\mathrm{Y}$ \\
\hline MIDAS & New Zealand & Cross & $\mathrm{D}$ & $\mathrm{C}$ & & $\mathrm{N}$ \\
\hline MIND & Italy & Cross & & $\mathrm{O}$ & $\mathrm{Y}$ & \\
\hline MINT & USA & Cross & $\mathrm{C} / \mathrm{D}$ & $\mathrm{O}$ & $\mathrm{Y}$ & $\mathrm{N}$ \\
\hline MOSART $1 / 2 / 3$ & Norway & Cross & $\mathrm{D}$ & $\mathrm{C}$ & $\mathrm{Y}$ & $\mathrm{N}$ \\
\hline NEDYMAS & Netherlands & Cross & $\mathrm{D}$ & $\mathrm{C}$ & $\begin{array}{l}\text { Limited } \\
\text { CGE }\end{array}$ & $\mathrm{Y}$ \\
\hline PENSIM & UK & Cross & $\mathrm{C}$ & $\mathrm{C}$ & $\mathrm{Y}$ & $\mathrm{N}$ \\
\hline PENSIM2 & UK & Cross & $\mathrm{D}$ & $\mathrm{C}$ & $\mathrm{Y}$ & $\mathrm{Y}$ \\
\hline PENSIM & USA & Cohort & $\mathrm{C} / \mathrm{D}$ & $\mathrm{O}$ & $\mathrm{N}$ & $\mathrm{N}$ \\
\hline Pensions Model & Belgium & Cross & $\mathrm{D}$ & $\mathrm{C}$ & & $\mathrm{N}$ \\
\hline POHEM & Canada & Cohort & $\mathrm{C}$ & & $\mathrm{N}$ & $\mathrm{N}$ \\
\hline POLISIM & USA & Cross & $\mathrm{D}$ & $\mathrm{C}$ & $\mathrm{Y}$ & $\mathrm{Y}$ \\
\hline PRISM & USA & Cross & $\mathrm{D}$ & $\mathrm{C}$ & $\mathrm{Y}$ & $\mathrm{Y}$ \\
\hline PSG & USA & Cohort & $\mathrm{C}$ & $\mathrm{O}$ & $\mathrm{N}$ & $\mathrm{N}$ \\
\hline SADNAP & Netherlands & Cross & $\mathrm{D}$ & $\mathrm{C}$ & $\mathrm{Y}$ & $\mathrm{Y}$ \\
\hline SAGE & UK & Cross & $\mathrm{D}$ & $\mathrm{C}$ & $\mathrm{Y}$ & $\mathrm{Y}$ \\
\hline SESIM & Sweden & Cross & $\mathrm{D}$ & $\mathrm{C}$ & $\mathrm{N}$ & $\mathrm{Y}$ \\
\hline SustainCity & Switzerland & Cross & $\mathrm{D}$ & C & & $\mathrm{Y}$ \\
\hline Sfb3 Population & Germany & Cross & $\mathrm{D}$ & $\mathrm{C}$ & $\mathrm{Y}$ & $\mathrm{N}$ \\
\hline Sfb3 Cohort & Germany & Cohort & $\mathrm{D}$ & $\mathrm{O}$ & $\mathrm{N}$ & $\mathrm{N}$ \\
\hline SVERIGE & Sweden & Cross & $\mathrm{D}$ & $\mathrm{C}$ & $\mathrm{Y}$ & $\mathrm{N}$ \\
\hline $\begin{array}{l}\text { Swedish Cohort } \\
\text { Model }\end{array}$ & Sweden & Cohort & $\mathrm{D}$ & $\mathrm{C}$ & $\mathrm{N}$ & $\mathrm{N}$ \\
\hline Tdymm & Italy & Cross & $\mathrm{D}$ & $\mathrm{C}$ & $\mathrm{Y}$ & $\mathrm{Y}$ \\
\hline
\end{tabular}

Source: See Table 2.1

Key: Cross, cross-sectional; $C$, continuous; $D$, discrete; $Y$, yes; $N, N o$

\subsubsection{Static and Dynamic Ageing}

"Ageing" within dynamic microsimulation refers to the process of changing characteristics of micro units over time. There are two types of ageing processes; static ageing and dynamic 
ageing. Static ageing involves adjusting the weights of the observations so that the simulated population distribution matches the macro aggregates. For example, in order to simulate an ageing society, the weighting of young people gradually decreases over time while the weighting of elderly people would increase; however, there is no change to the attributes of these individuals. Dynamic ageing by contrast, changes the attributes of the individuals instead of altering their weights. In the same example of simulating an ageing society, models with dynamic ageing will update the age and other related attributes of individuals over time instead of changing their weights.

While static ageing can ideally produce the same population representative cross-sectionals as models with dynamic ageing, it has the benefit of having a simpler simulation engine as the only variable that needs to be changed over time is the weight of the observations. Dekkers and Van Camp (2011) noted that this might be attractive for modellers who already have a static microsimulation model, however, static ageing also has a number of disadvantages. Klevmarken (1996) highlighted that whereas static ageing may avoid some problems of drift in the projected cross-section associated with dynamic ageing because of misspecification in dynamic equations, it cannot account for mobility between states. In addition, he pointed out that from a statistical point of view, it is inefficient not to use all available historical information to project into the future. A consequence of not modelling the mobility of individuals between points in time is that it reduces the type of analyses that can be undertaken by a microsimulation model, for example, it is not possible to conduct analyses that require life event histories such as the simulation of pensions. Furthermore, future weights need to be forecast in order to age a dataset. Although macro models or other forecasting devices can be used they may not forecast weights at the level of detail required. Besides, the weight calculation may be further complicated when the target distribution involves more than one variable ${ }^{2}$. Generally speaking, static ageing cannot be used where there are no individuals in the sample in a particular state. If there are a small number of cases in a particular household category, then a very high weight may have to be applied, resulting in unstable predictions. As a result, static ageing procedures are mostly used in short to medium term forecasts of approximately 3-5 years, where it can be expected that large changes have not occurred in the underlying population. However, it may be more difficult to use static ageing over longer periods of time due to changing characteristics of the population.

\footnotetext{
${ }^{2}$ For some examples of the multi-dimensional reweight algorithm, see Deville et al. (2003), Tanton et al. (2011) etc.
} 
Dynamic ageing can consistently estimate characteristics of future income distributions under ideal circumstances in which all transition probabilities and state specific expectations can themselves be estimated consistently. This may be possible in a simple model with a small number of processes; however, in a fully dynamic model of work and life histories, many more processes need to be jointly estimated, a formidable requirement given the available data. Therefore, it is necessary to assume that the marginal distributions of different processes are independent. In addition, projections over time at the micro-level are particularly susceptible to misspecification error as modelling at this level involves more detail than in macro models, also current knowledge regarding micro-behaviour is not good enough to specify a fully dynamic model. As a result, dynamic ageing combined with an alignment (calibration) mechanism to keep aggregate outputs in line with predictions from macro models is more commonly used. This procedure combines the best of both static and dynamic ageing as it allows individual transitions to be simulated as well as ensuring that aggregate outputs track macro forecasts (see, for examples, Chénard 2000a, 2000b).

\subsubsection{Discrete or Continuous Time Modelling}

Another choice in the development of dynamic microsimulation models is the treatment of time. Discrete time models simulate which individuals experience particular events in given time intervals while continuous time models treat time as a continuous variable and determine the exact time that an event occurs (Willekens, 2006).

Discrete time microsimulation models usually incorporate a probability model or a transition matrix, for example the demographic module. Demographic modules in dynamic models are often constructed using annual transition probability matrices. Individuals are passed through a collection of transition matrices in each time period of the simulation (usually a year) to determine their simulated life paths, e.g. death. This method assumes that life events are independent of each other, however in reality they may be interdependent as in the example given above and consequently the order in which the transition matrices are applied is very important. In the example given above, if marriage is determined first, then the potential fertility rate changes and similarly, a pre-marital pregnancy will increase the probability of getting married. Galler (1997) discussed a number of options in this situation including the procedure of random ordering as used by the DARMSTADT (Heike et al., 1987) and Hungarian models (Csicsman et al., 1987).

There are a number of other problems with this type of approach. Firstly transitions are assumed to take place at a single point in each time period and the duration of the event must last at least one time period (typically a year, but may be of shorter duration). For example if the time period is a year, then this approach rules out transitions in and out of unemployment over the course of a year, which is unrealistic, as many people will have 
unemployment transitions for periods of less than one year as in the case of seasonal workers. Therefore, the discrete time transitions simulate net transitions (see Galler, 1997) at discrete points in time, ignoring the transition path taken to reach the end state.

Continuous time microsimulation models usually use survival models to simulate the time of events. Rather than simulating annual transition probabilities, survival functions model the length of time an individual will face in his/her current state, e.g. DYNAMOD and SOCSIM (Hammel, 1990) and this method was extensively discussed by Willekens (2006). Once a referencing event has occurred such as marriage, an individual is passed through each survival function that, given their current states, they are eligible for. For example, once an individual is married, then they become eligible for divorce, the event given their current state with the nearest event time is selected and then repeated until death.

Although the continuous time model does have some theoretical advantages, it also has considerable practical limitations. The estimation of competing risks and survival functions place very high requirements on the data that are rarely matched by the actual data available (Zaidi and Rake, 2001). Given that most base datasets were collected on an annual timeframe, it is therefore easier to incorporate a discrete time model. In addition, the potential interdependence of transitions for members (e.g. family) further raises the complexity of implementation. Alignment for continuous models is more difficult as crosssectional adjustments would erode the advantages of duration models, and the potential computation cost of alignment is much higher in continuous time models.

\subsubsection{Behavioural Equations or Probabilistic Based Modelling}

Microsimulation models could use probabilistic based modelling, behavioural equations or a mix of two to simulate changes. Behavioural models are grounded in economic theory, in the sense that changes to institutional or market characteristics result in a change in the behaviour of agents within the model. In contrast, probabilistic models aim to reproduce observed distributional characteristics in sample surveys without necessarily having a theoretical underpinning. Depending on how they are constructed, probabilistic models may or may not be able to respond to external market and institutional characteristics dynamically.

Probabilistic based modelling is often used to simulate mortality, fertility, family formation, labour market transitions etc. Although not necessarily grounded in microeconomic theory, they are based instead on a probability-based matrix and do not depend on policy parameters within the model. In practice, many transitions are based on only a small number of factors such as age and sex. This method is commonly used in static tax benefit microsimulation models as well as some dynamic models such as POLISIM. 
In a behavioural model, individual behaviour changes are as a result of changing policies, therefore the policy parameters must have a direct or indirect impact on the model. An example is a labour supply model that responds to changes in the tax-benefit system, not normally the case in a probabilistic method. A requirement of behavioural models is the stability of the parameters. Klevmarken (1997) outlined three criteria for choosing what types of behavioural equations should be included in a microsimulation model in general:

- They should be relevant for the objectives of the model

- There should be major behavioural adjustments to the policy changes the model is built to analyse

- Behaviour that influences the fiscal balance should be included

Examples of behavioural responses that fit these requirements include labour supply, retirement decisions, the effect of income and price changes on consumption, fertility and marital decisions, the take-up of social benefits etc. In the case of labour supply models, behaviour simulation models typically consist of three subcomponents: an arithmetic tax benefit model to estimate budget constraints, a quantifiable behaviour model using variables that can be simulated, and a mechanism to predict the labour supply under a new policy environment (Creedy and Duncan, 2002).

Compared with earlier microsimulation models, more models today have incorporated behavioural responses into their design although these responses are often limited to labour market simulations. Models such as MICROHUS, PRISM, SESIM, NEDYMAS, SAGE and LIAM all incorporate labour supply behavioural responses to the tax-benefit system, while DYNAMITE, ANAC and SADNAP model retirement decisions depending on the social security system. However, there is still only limited implementation in life-cycle models and Pudney and Sutherland $(1994,1996)$ have found that predictions based on behavioural models have very wide confidence intervals. In addition, certain behaviour models, e.g. a labour supply model based on policy independent personal characteristics (usually logit/probit), contain the implicit assumptions that the policy remains the same. This type of model is not suitable for reform analysis, and is often restricted to simulating status quo only.

\subsubsection{Open vs. Closed Model}

A decision dynamic microsimulation model builder has to consider is whether the model should be open, closed or a mixture of the two. A model is defined as closed if, except in the case of new born and new migrants, the model only uses a fixed set of individuals. Thus, if an individual is selected to be married, then their spouse is selected from within the existing population of the model. In contrast, an open model starts with a base population and if spouses are required, then new individuals are generated. This has the advantage that simulations for individuals (and their immediate families) can be run independently of 
other individuals, and thus allows the model to be run in parallel on different computer processors, allowing overall run times to be reduced.

Open models, for instance, PENSIM and LifePaths, have the advantage of having simpler interaction models, e.g. a newly married partner can be created artificially to fit the social economic characteristics of an individual. However, an open model is more difficult for alignment as the sample may not stay representative of the population as new individuals are created. Although possible, it is a non-trivial task to align a varying population with macro-aggregates, as the weights would require constant dynamic reweighting and in the case of heavy alignments, the benefits of running the model in parallel might be lost. As a result, most dynamic models in use utilise a closed model method.

Despite this, most models have to incorporate a degree of openness because of migration. While immigration requires the generation of new individuals, it has little effect on alignment as macro-aggregates are typically based on a partially open population.

\subsubsection{Alignment with Projections}

As statistical models are typically estimated using historical datasets with specific characteristics and period effects, projections of the future may therefore contain errors or may not correspond to exogenous expectations of future events. In addition, the complexity of micro behaviour modelling may mean that simulation models may over or under predict the occurrence of a certain event, even in a well-specified model (Duncan and Weeks, 1998). Because of these issues, methods of calibration known as alignment have been developed within the microsimulation literature to correct for issues related to the adequacy of micro projections.

Scott (2001) defines alignment as "a process of constraining model output to conform more closely to externally derived macro-data ('targets')". Clearly, in an ideal world, a system of equations would be estimated that could replicate reality and give effective future projections without the need for alignment. However, as Winder (2000) stated, "microsimulation models usually fail to simulate known time-series data. By aligning the model, goodness of fit to an observed time series can be guaranteed." Some modellers suggest that alignment is an effective pragmatic solution for highly complex models (O’Donoghue, 2010), as it offers a limited connection between micro and macro data.

Over the past decade, despite this controversy, aligning the output of a microsimulation model to exogenous assumptions has become standard. As Anderson (2001) noted, almost all existing dynamic microsimulation models are adjusted to align to external projections of aggregate or group variables when used for policy analysis. Continuous variables such as earnings are typically aligned with a fix ratio in order to meet the projected average or distribution, whilst binary variables, such as working status, are aligned with various 
methods, including multiplicative scaling, sidewalk, sorting based algorithms etc. (See Morrison, 2006). Microsimulation models using historical datasets, e.g. CORSIM, align their output to historical data to create a more credible profile (SOA, 1997), while Models that work prospectively, e.g. APPSIM, also utilise the technique to align their simulations with external projections (Kelly and Percival, 2009).

Alignment also has its downsides, as highlighted by Baekgaard (2002). Concerns raised regarding alignment include the issue of consistency within the estimates and the level of disaggregation at which this should occur. It has been suggested that equations should be reformulated rather than constrained ex post. The existence of an alignment mechanism may constrain model outputs to always hit aggregate targets even if there has been an underlying behavioural or structural change. An example would be if education levels rose, as this would be expected to reduce mortality rates and increase female labour force participation. If the alignment mechanism for each process did not incorporate the impact of educational achievement, then an increase in the education level would have no effect on these aggregates. In most cases, alignment methods are only documented briefly as a minor technical part of the main model. Currently, there is a lack of studies analysing how projections and distributions change as a result of the use of different alignment methods.

\subsubsection{Link between Micro and Macro Models}

Microsimulation models increasingly meet the need to interact with macro economy through either an alignment process or computational general equilibrium (CGE) feedback. Alignment, as discussed in earlier, offers a simple but limited way to enforce the aggregate statistics within a simulation; however, it is usually limited to very specific variables and does not change based on the feedback from simulated micro data. Besides alignment, there is also a growing interest in using CGE models to link macro, meso and micro models (see Ahmed and O’Donoghue, 2007; Davies 2004). CGE models offer a potential opportunity to allow macro models interact with micro models via prices in different markets, which is particular useful for analysing large scale macroeconomic shock. For instance, IFSIM links a microsimulation model with a simple CGE model assuming a single sector economy.

There are a few papers discussing the potential methods of linking a microsimulation model and a CGE model. Cockburn (2001) used an integrated approach to link a survey dataset within a CGE framework, where the main concept was to replace the traditional unit of analysis in CGE, representative household, with a real household. Another approach is to separate macro and micro components while allowing the result of the micro or macro models is fed into the other models. Depending on the direction of the output feeding and the number of iterations, this approach was further subcategorised into “Top-Down”, “Bottom-Up”, “Top-Down Bottom-Up” and "Iterated Top-Down Bottom- 
Up” approaches (Galler, 1990; Baekgaard, 1995; Savard, 2003). Colombo (2010) compared several CGE microsimulation linkage methods and suggested the "Iterated TopDown Bottom-Up" as the currently most complete approach. However, with only few exceptions like NEDYMAS (Dekkers et al., 1993) which used the iterated approach, most macro-micro linking attempts in dynamic microsimulation models are limited to one-way only.

At the current stage, the integration of CGE or partial equilibrium with microsimulation is still limited at the current stage (Ahmed and O'Donoghue, 2007), and is mostly found in static models, e.g. IZAYMOD. This might be the result of several factors, including modelling complexity, data issues, model stability and computational costs. Robilliard and Robinson (2003) indicated that current approaches in linking micro-macro may still need to be refined before addressing distributional issues. In addition, linking with CGE requires decent quality of household income and expenditure data, which is not widely available. Furthermore, the integration between CGE and dynamic microsimulation could potentially exaggerate the uncertainty introduced in the results due to the complexities in interactions of different social economic variables and consequently result in a greatly increased computation time.

\subsubsection{Links and Integrations with Agent Based Models}

Although this study mostly focuses on the development of dynamic microsimulation models, it is also worth to note that microsimulation is closely related to two other individual level modelling approaches, cellular automata and agent based models (Williamson, 2007). In particular, agent based models are also used in social science to analyse macro level phenomena gathered from micro units. An agent based model (ABM) typically consists of a set of autonomous decision-making entities (agents), a set of agent relationships and methods of interaction, and the agents' environment (Macal and North, 2010). It is often used to show how macro level properties such as spatial patterns and levels of cooperation emerge from adaptive behaviours of individuals.

Traditionally, agent based models are highly abstract and theoretical without many direct empirical applications (Boero and Squazzoni, 2005; Janssen and Ostrom, 2006). In recent years, however, there is a growing interest in $\mathrm{ABM}$ literature of injecting empirical data in an attempt to simulate some real-world phenomenon (Parker et al., 2003; Hassan et al., 2008). From a practical point of view, when agent based models add more social economic attributes to the agents and when microsimulation models add more behaviour rules and interactions, they are moving toward to a common ground (Williamson, 2007).

Agent based models cover an important aspect of social economic modelling, network effects, which has long been discussed by sociologists and economists but hardly exists in 
microsimulation beyond household effects and spouse matching. Microsimulation modellers often implicitly assume that the effects of social pressures and peer effects are already embedded in the existing distribution and they are likely to keep constant, i.e. there is no need to update the model as time passes. While this assumption might be acceptable for some research, such as tax reform analysis, it might be too strong for some other types of research, e.g. evaluating alternative health intervention policy. Agent based models, on the other hand, often explicitly model these interactions and allow certain social factors to change as the population evolves.

With the growing number of social networking data, it is theoretically possible to integrate the adaptive behaviours from $\mathrm{ABM}$ into microsimulation models to produce a more realistic model. The potential introduction of network effects could benefit a set of microsimulation models, e.g. health simulation models, in which the social factors may play a role. In addition, peer effects may also help to model the evolution of marriage/fertility patterns, the formations and dissolutions of neighbourhoods in a spatial microsimulation model etc.

It should also be noted that the benefit of this potential integration may also bring some disadvantages. The implementations of micro interactions would greatly increase the computational cost and complexity, thus makes the model more difficult to understand and validate. Besides, the current base datasets of the microsimulation models are often standard surveys or census data that do not cover extensive network attributes. At the current stage, the implementation of extensive interactions like ABM in microsimulation models is still at its infancy, the existing attempts are limited to the introduction of simple behaviour rules, e.g. copying consumption habits as in Lawson (2011).

\subsection{Conclusion}

This chapter has discussed some of main issues involved in constructing a dynamic microsimulation model and described some of the choices made by different models in use worldwide. The main issues discussed have covered some of the general model development issues, such as base dataset selection, cohort or population based model structure, programming environment, and model validation. The chapter has also discussed some of the technical choices made in model implementation, such as whether the model should be open or closed, whether alignment algorithms should be used, whether the model should incorporate behavioural response to policy changes, and links to the agent based models etc.

Over the past decades, microsimulation models have been applied to many different policy areas and a comparison of models as given in Table 2.1 illustrates the scope of application of dynamic microsimulation models. Most dynamic microsimulation models listed can be 
categorised as discrete cross-sectional models using dynamic ageing. For newer models, alignment has become a standard component allowing interactions with macro aggregates and more recently, simulation packages that are dedicated solely to microsimulation have become a viable option in model development. These packages, together with increased cooperation through meetings and code sharing (e.g. LIAM, Modgen model series), could significantly increase the development process.

The increasing use of microsimulation models has raised many challenges to meet the needs of more complex and accurate policy analyses. For instance, there is a growing interest in integrating CGE into microsimulation models, although the actual implementations of CGE-microsimulation are at this stage restricted due to data and technical limitations. Behavioural responses in microsimulation could also be further improved and there is only limited implementation in life-cycle models when simulating inter-temporal choices. Microsimulation could potentially implement some elements from ABM to allow dynamic behaviour changes. In addition, the documentation of many models is largely insufficient, with the exceptions of a few models, e.g. DYNACAN. Finally, certain practices within the simulations, such as multinomial alignment and error term simulation, have not yet been thoroughly studied. 


\subsection{References}

Ahmed, V. and O' Donoghue, C., 2007. CGE-Microsimulation Modelling: A Survey. MPRA Paper

Andersson, I., Brose, P., Flood, L., Klevmarken, N.A., Olovsson, P. \& Tasizan, A., 1992. MICROHUS - A microsimulation model of the Swedish household sector, International Symposium on Economic Modelling, Gothenburg.

Anderson, JM., 2001. Models for Retirement Policy Analysis, Report to the Society of Actuaries, USA

Ando A., 1996. Microsimuation Analysis of Aggregate Savings Behaviour in Japa: Effects of Aging Population on Aggregate Savings and Design of Policies on Savings in Japan, Tokyo: National Institute for Research Advancement.

Ando, A. A. Moro, 1995. "Deomgraphic Dynamics, Labor Force Participation and Household Asset Accumulation: Case of Japan”, NBER Working Paper 5261. Cambridge MA: National Bureau of Economic Research.

Ando, A. and S. Nicoletti Altimari, 1999. “A Micro Simulation Model of the Italian Household Sector”, Mimeo, University of Pennsylvania, Department of Economics.

Ando, A., A. Brandolini, G. Bruno, L. Cannari, P. Cipollone, G. D’Alessio, I., Faiella, L. Forni, M.R. Marino and S. Nicoletti Altimari, 2000. “The Bank of Italy's DYNAMITE: Recent Developments”. Mimeo, Rome: Bank of Italy.

Andreassen L., and I. Solli, 2000. "Incorporating overlapping-generations modelling in a dynamic microsimulation framework", Paper Presented to the 6th Nordic Workshop on Microsimulation, Copenhagen, June.

Andreassen L., D. Fredriksen and O. Ljones, 1996. "The Future Burden of Public Pension Benefits: A Microsimulation Study”, in Harding A. (ed.) Microsimulation and Public Policy, Amsterdam: Elsevier.

Antcliff S., M. Bracher, A. Gruskin, A. Hardin, C. Kapuscinski, 1996. “Development of DYNAMOD 1993 and 1994”, NATSEM, Canberra: DYNAMOD Working Paper No. 1.

Antcliff, S., 1993. "An introduction to DYNAMOD: A Dynamic microsimulation Model”, NATSEM, Canberra: DYNAMOD Technical Paper No. 1.

Baekgaard, H. 1995. Integrating Micro and Macro Models: Mutual Benefits, National Centre for Social and Economic Modelling (NATSEM), University of Canberra, Australia.

Baekgaard, H., 1998. Simulating the Distribution of Household Wealth in Australia: New Estimates for 1986 and 1993. Technical Paper No. 14 - June, National Centre for Social and Economic Modelling (NATSEM), University of Canberra, Australia.

Baekgaard, H. 2002. Micro-macro linkage and the alignment of transition processes : some issues, techniques and examples, National Centre for Social and Economic Modelling Technical paper

Baldini M., 1997. Diseguaglianza e Redistribuzione nel Ciclo di Vita, Bologna: Il Mulino.

Ballas, Dimitris, Graham Philip Clarke, and Emily Wiemers. 2005a. Building a dynamic spatial microsimulation model for Ireland. Population, Space and Place 11, no. 3 (May): 157-172. doi:10.1002/psp.359.

Ballas, D., Clarke, G., Dorling, D., Eyre, H., Thomas, B., Rossiter, D., 2005b. SimBritain: a spatial microsimulation approach to population dynamics. Population, Space and Place 11, 13-34. 
Bardaji, J., B. Sédillot and E. Walraet. 2003. Un outil de prospective des retraites: le modèle de microsimulation Destinie, Économie et prévision pp. 193-214.

Baroni, E., J. Žamac and G. Öberg, 2009, IFSIM Handbook. Arbetsrapport.

Blanchet, D., et al., 2009. The Destinie 2 microsimulation model: increased flexibility and adaptation to users' needs. IMA Conference Paper.

Boero, R., Squazzoni, F., 2005. Does empirical embeddedness matter? Methodological issues on agent-based models for analytical social science. Journal of Artificial Societies and Social Simulation 8, 6.

Bonnet, C. and R. Mahieu, 2000. "Public pensions in a dynamic microanalytic framework: the case of France", in Mitton et al. (eds.) Microsimulation in the New Millennium, Cambridge: Cambridge University Press.

Brewer, M., Browne, J., Emmerson, C., Goodman, A., Muriel, A. and Tetlow, G., 2007. Pensioner poverty over the next decade: what role for tax and benefit reform, The Institute for Fiscal Studies

Brown, R.J., S.B. Caldwell and S.A. Eklund 1992, "Microsimulation of dental conditions and dental service utilisation" in J.G. Anderson (ed.), Proceedings of the Simulation in Health Care and Social Services Conference, Society for Computer Simulation, San Diego.

Caldwell S. and R. Morrison, 2000. "Validation of longitudinal microsimulation models: experience with CORSIM and DYNACAN", in Mitton et al. (eds.) Microsimulation in the New Millennium, Cambridge: Cambridge University Press.

Caldwell S.B., 1996, "Health, Wealth, Pensions and Life Paths: The CORSIM Dynamic Microsimulation Model”, in Harding A. (ed.) Microsimulation and Public Policy, Amsterdam: Elsevier.

Cassells, R., et al., 2006. Problems and Prospects for Dynamic Microsimulation: A Review and lessons for APPSIM. NATSEM Discussion Papers no. 63.

Chénard D. 2000a. "Individual alignment and group processing: an application to migration processes in DYNACAN", in Mitton et al. (eds.) Microsimulation in the New Millennium, Cambridge: Cambridge University Press.

Chénard D. 2000b. "Earnings in DYNACAN: distribution alignment methodology", Paper Presented to the 6th Nordic Workshop on Microsimulation, Copenhagen, June.

Citro C.F. and E.A. Hanushek (eds.), 1991a. The uses of Microsimulation Modelling, Volume 1, Review and Recommendations. Washington National Academy Press.

Citro C.F. and E.A. Hanushek (eds.), 1991b. The uses of Microsimulation Modelling, Volume 2, Technical Papers. Washington National Academy Press.

Cockburn, J. 2001. Trade Liberalization and Poverty in Nepal: A Computable General Equilibrium Microsimulation Approach, Working Paper 01-18, CRÉFA, Université Laval.

Colombo, G. 2010. Linking CGE and Microsimulation Models: A Comparison of Different Approaches, International Journal of Microsimulation.

Courtioux, P., S. Gregoir and D. Houeto, 2008, The Simulation of the Educational Output over the Life Course: The GAMEO Model, 34 .

Creedy, J., Duncan, A., Harris, M. and Scutella, R. 2002. Microsimulation Modelling of Taxation and the Labour Market: the Melbourne Institute Tax and Transfer Simulator, Edward Elgar Publishing, Cheltenham 
Csicsman, N. and N. Pappne, 1987. "The Software Developed for the Hungarian Micro-simulation System", Proceedings of International Workshop for Demographic Microsimulation, International Institute for Applied Systems Analysis, Budapest, Hungary, November.

Curry C. 1996. "PENSIM: A Dynamic Simulation Model of Pensioners' Incomes". London: Department of Social Security.

Davies, J.B., 2004. Microsimulation, CGE and Macro Modelling for Transition and Developing Economies. UNU/WIDER research paper

Dekkers, G.J.M., Nelissen J.H.M. and Verbon H.A.A., 1993. The Macro Model Programme Sector of the Microsimulation Model NEDYMAS, WORC paper 93.08.016/2, Katholieke Universiteit Brabant, Tilburg

Dekkers, Gijs, Hermann Buslei, Maria Cozzolino, Raphael Desmet, Johannes Geyer, Dirk Hofmann, Michele Raitano, et al. 2008. What are the consequences of the AWG-projections for the adequacy of social security pensions ? An application of the dynamic micro simulation model MIDAS for Belgium, Italy and Germany Report of the Work Package 4 of The AIM project Federaal Planbureau. Economica.

Dekkers, G., Belloni, M., 2009. Micro simulation, pension adequacy and the dynamic model MIDAS: an introduction.

Dekkers, G. 2010. On the impact of indexation and demographic ageing on inequality among pensioners . European Workshop on Dynamic microsimulation modelling.

Dekkers G. and Van Camp G. 2011. The simulation properties of microsimulation models with static and dynamic ageing - a guide into choosing one type of model over the other, International Journal of Microsimulation

Deville, J. C., Sarndal, C. E., and Sautory, O. 1993. Generalized raking procedures in survey sampling, Journal of the American Statistical Association 88, pp. 1013-1020.

Emmerson, C., H. Reed and A. Shephard, 2004. An assessment of PenSim2.

Ericson, P. and J. Hussenius, 1998. "A note about SESIM - a dynamic microsimulation model", mimeo, Stockholm: Swedish Ministry of Finance.

Ericson, P. and J. Hussenius, 1999. "Distributional Effects of Public Student Grants in Sweden - a Presentation and an Application of the Dynamic Microsimulation Model SESIM", paper presented to the APPAM seminar Public Policy Analysis and Management: Global and Comparative Perspectives”, Washington D.C., November.

Falkingham J. and C. Lessof, 1991. "LIFEMOD: The Formative Years”. London: Research Note No. 24. London School of Economics.

Falkingham J. and P. Johnson, 1995. "A Unified Funded Pension Scheme (UFPS) for Britain", in Falkingham and Hills (eds.) The Dynamic of Welfare: The Welfare State and the Life Cycle. New York: Prentice-Hall.

Favreault, M., Smith, K., 2004. A Primer on the Dynamic Simulation of Income Model (DYNASIM3) The Urban Institute Discussion Paper.

Flood, L. 2007. Can we Afford the Future? An evaluation of the new Swedish pension system, Modelling our future: population ageing, social security and taxation pp. 33 .

Fölster S., 1997.“Social Insurance Based on Personal Savings Accounts”, European Economy, No. 1997/4.

Fredriksen D., 1998. Projections of Population, Education, Labour Supply and Public Pension Benefits: Analyses with the Dynamic Microsimulation Model MOSART. Social and Economic Studies. Oslo: Statistics Norway 
Galler, H.P. and G. Wagner, 1986. "The microsimulations model of the Sfb3 for the analysis of Economic and Social Policies”, in Orcutt G.H., J. Merz and H. Quinke, Microanalytic Simulation Models to support Social and Financial Policy Amsterdam: North-Holland.

Galler, H.P., 1990. Microsimulation of tax-transfer systems", in: J.K. Brunner and H.G. Petersen, eds., Simulation Models in Tax and Transfer Policy (Campus, Frankfurt/M., New York), 279-300.

Galler, H.P., 1997. "Discrete-time and continuous-time approaches to dynamic microsimulation reconsidered" Discussion Paper, NATSEM, University of Canberra

Gault, S., 2009. Benefit reform - a dynamic microsimulation approach using administrative data. IMA Conference Paper.

Hassan, S., Pavon, J., Gilbert, N., 2008. Injecting data into simulation: Can agent-based modelling learn from microsimulation.

Hain W. and C. Helberger, 1986. "Longitudinal Simulation of Lifetime Income”, in Orcutt G., J. Merz and H. Quinke (eds.) Microanalytic Simulation Models to support Social and Financial Policy. New York: NorthHolland.

Hammel, E.A., 1990. "SOCSIM II", Working Paper No. 29, Graduate Group in Demography, Berkeley: University of California at Berkeley.

Hancock R., 2000. “Charging for Care in later life: an exercise in dynamic microsimulation” in Mitton et al. (eds.) Microsimulation in the New Millennium, Cambridge: Cambridge University Press.

Hancock R., J. Mallender and S. Pudney, 1992. "Constructing a Computer model for Simulating the Future Distribution of Pensioner's Incomes for Great Britain”, in Hancock R and H. Sutherland (eds.) Microsimulation Models for Public Policy Analysis: New Frontiers.

Harding A. 1993. Lifetime Income Distribution and Redistribution: applications of a microsimulation model, Contributions to Economic Analysis, Vol 221, Amsterdam: North Holland.

Harding, A., 2007a. Challenges and Opportunities of Dynamic Microsimulation Modelling

Harding, A., 2007b. APPSIM: The Australian Dynamic Population and Policy Microsimulation Model.

Heike, H.D., O. Hellwig and A. Kaufmann, 1987. "Experiences with the Darmstadt microsimulation model (DPMS)", Proceedings of International Workshop for Demographic Microsimulation, International Institute for Applied Systems Analysis, Budapest, Hungary, November.

Holmer, M. and A. Janney and B. Cohen, 2001. Overview of PENSIM/2, mimeo. Washington D.C.: Policy Simulation Group.

Holm, E., Holme, K., Mäkilä, K., Mattsson-Kauppi, M., Mörtvik, G., 2006. The SVERIGE spatial microsimulation model, pp. 8-9.

Holmer, M., 2009. Projecting Future US Pension Benefits.

Inagaki, S., 2010. Overview of INAHSIM: A Microsimulation Model for Japan. PIE/CIS Discussion Paper 468.

INSEE, 1999. "La modèle de microsimulation dynamique, DESTINIE", Documents de Travail de la Direction des Etudes et Synthèses Économiques”, No. G9913. Paris: Institut National de la Staistique et des Études Économiques.

Janssen, M.A., Ostrom, E., 2006. Empirically based, agent-based models. Ecology and Society 11, 37. 
Joyeux, C., R. Plasman and B. Scholtus, 1996. "A Model of the Evolution of Pensions Expenditures in Belgium", paper presented to a meeting of the European HCM Network on Socio-Economic Modelling, June, 1996, Cambridge.

Lawson, T., 2011. An Agent-based Model of Household Spending Using a Random Assignment Scheme, IMA Conference, Stockholm.

Macal, C.M., North, M.J., 2010. Tutorial on agent-based modelling and simulation. Journal of Simulation 4, 151162.

Keister, L. 2000. Wealth in America: Trends in Wealth Inequality. Cambridge: Cambridge University Press.

Kelly S and A. King, 2001. "Australians over the coming 50 years: providing useful projections" in Brazilian Electronic Journal of Economics, this issue.

Kelly, S., Percival, R., 2009. Longitudinal benchmarking and alignment of a dynamic microsimulation model. IMA Conference Paper.

Kennell D.L. and J.F. Sheils, 1990. "PRISM: Dynamic Simulation of Pension and Retirement Income”, in Lewis G. H. and R.C. Michel (eds.) Microsimulation Techniques for Tax and Transfer Analysis. Washington D.C.: The Urban Institute Press.

King A., H. Baekgaard and M. Robinson, 1999a. "DYNAMOD-2: An Overview”. Technical Paper No. 19, National Centre for Social and Economic Modelling (NATSEM), University of Canberra, Australia.

King A., H. Baekgaard and M. Robinson, 1999b. "The Base Data for DYNAMOD-2". Technical Paper No. 20, National Centre for Social and Economic Modelling (NATSEM), University of Canberra, Australia.

Klevmarken N.A., 1997. "Modelling behavioural response in EUROMOD”, Paper presented to Conference of European Microsimulation, Brussels, April 18th.

Klevmarken, N.A. \& Olovsson, P., 1996, "Direct and behavioural effects of income tax changes - simulations with the Swedish model MICROHUS”, in Microsimulation and Public Policy, ed. by Ann Harding, Elsevier Science Publishers, Amsterdam.

Klevmarken, N. A., Bolin, K., Eklöf, M., Flood, L., Fransson, U., Hallberg, D., Höjgård, S., Lindgren, B., Mitrut, A. And Lagergren, M. 2007. Simulating the future of the Swedish baby-boom generations, Working Paper No. 26. Uppsala University, Department of Economics.

Li, J., O'Donoghue, C., 2010. Simulating Histories for Dynamic Microsimulation Models, in: O’Donoghue, C. (Ed.), Life-Cycle Microsimulation Modelling: Constructing and Using Dynamic Microsimulation Models. LAP LAMBERT Academic Publishing.

Leombruni, R., Richiardi, M., 2006. LABORsim: An Agent-Based Microsimulation of Labour Supply-An Application to Italy. Computational Economics. 27, 63-88.

Lutz W., 1997. FAMSIM Austria: Feasibility Study for A Dynamic Microsimulation Model for Projections and the Evaluation of Family Policies Based on the European Family and Fertility Survey. Vienna: Austrian Institute for Family Studies.

Maitino, M. L., Sciclone, N., 2009. DYNAMIC TUSCAN. IMA Conference Paper.

Mazzaferro, C., and Morciano, M. 2008. CAPP_DYN: A Dynamic Microsimulation Model for the Italian Social Security System. Center for the Analysis of Public Policies (CAPP)

McKay, S., 2003. Dynamic microsimulation at the US Social Security administration, International Conference on Population Ageing and Health: Modelling Our Future, Canberra, pp. 7-12. 
Morand, E., L. Toulemon, S. Pennec, R. Baggio, and F. Billari 2010. Demographic modelling: the state of the art, Sustain City Working Paper, 2.1a, Ined, Paris.

Morrison R. 2000. “Assessing the Quality of DYNACAN's Synthetically-Generated Earnings Histories”, Paper Presented to the 6th Nordic Workshop on Microsimulation, Copenhagen, June.

Morrison, Rick, 2008. Validation of Longitudinal Microsimulation Models: DYNACAN Practices and Plans, DYNACAN Team Working Paper No. 8

Nelissen, J.H.M., 1996a. The modelling of institutional households by means of microsimulation., Tilburg University Press, Tilburg, 166 p.

Nelissen, J.H.M., 1996b. Social security and lifetime income redistribution: A microsimulation approach. In A. Harding (Ed.) Microsimulation and public policy (pp. 267-292). Amsterdam: North-Holland.

Nelissen, J.H.M., 1996c. Annualized versus non-annualized lifetime income redistribution. Applied Economics Letters, $3533-536$.

O’Donoghue C. 2001a, “Dynamic Microsimulation: A Survey”, Brazilian Electronic Journal of Economics.

O'Donoghue C. 2001b. Redistribution in the Irish Tax-Benefit System, unpublished PhD, London School of Economics.

O'Donoghue, C., J. Lennon and S. Hynes, 2009, The Life-Cycle Income Analysis Model (LIAM): A Study of a Flexible Dynamic Microsimulation Modelling Computing Framework. CeRP Working Papers.

O'Donoghue, C., Loughrey, J. and Morrissey, K., 2011. Modelling The Impact of the Economic Crisis on Inequality in Ireland, IMA 2011 conference paper

Oharra, J., Sabelhaus, J., Simpson, M., 2004. Overview of the Congressional Budget Office Long-Term (CBOLT) Policy Simulation Model. Congressional Budget Office. Washington DC.

Orcutt, G., 1957. A new type of socio-economic system. The Review of Economics and Statistics 39, 116-123.

Osberg, Lars and Lethbridge, Lynn, 1996. "Labour Market Modeling in DYNACAN - Final Report.", DYNCAN Project Consulting Report, May.

Panis C. and L. Lillard, 1999. Near Term Model Part II, Final Report. Santa Monica: Rand Corp.

Parker, D.C., Manson, S.M., Janssen, M.A., Hoffmann, M.J., Deadman, P., 2003. Multi Agent Systems for the Simulation of Land Use and Land Cover Change: A Review. Annals of the Association of American Geographers 93, 314-337.

Peichl, A., Schneider H. and Siegloch S. 2010. Documentation IZAYMOD: The IZA Policy Simulation Model, IZA working paper 4865

Percival, R. 2007. APPSIM - Software Selection and Data Structures, NATSEM working paper

Phillips, B. and Kelly, S., 2006. HouseMod: A regional Microsimulation Projection Model of Housing in Australia, Australian Housing Research Conference Paper 2006

Pudney S.E., 1992. “Dynamic Simulation of Pensioner's incomes: methodological issues and a model design for Great Britain”, Dept. of Applied Economics Microsimulation Unit Discussion paper no. MSPMU 9201, University of Cambridge.

Pudney, S. and Sutherland, H. 1994, "The statistical reliability of micro-simulation estimates: Results fora UK tax-benefit model", Journal of Public Economics, 53, 327-365. 
Pudney S and Sutherland H., 1996. "Statistical reliability in microsimulation models with econometricallyestimated behavioural responses" in A Harding (ed.) Microsimulation and public policy, Elsevier, Amsterdam, 473-504.

Robilliard, Anne-Sophie and Robinson, Sherman, 2003. Reconciling Household Surveys and National Accounts Data Using a Cross Entropy Estimation Method. Review of Income and Wealth, Vol. 49, pp. 395-406.

Rowe, G. and M. Wolfson, 2000. "Public Pensions - Candian Analyses Based on the LifePaths Generational Accounting Framework", paper prepared for the Nordic Microsimulation Workshop, Copenhagen.

Savard, L. 2003. Poverty and Income Distribution in A CGE-Household Micro-Simulation Model: TopDown/Bottom-Up Approach, CIRPÉE Working Paper 03-43.

Shiraishi, K. 2008. "The Use of Microsimulation Models for Pension Analysis in Japan," CIS Discussion Paper No.409, Center for Intergenerational Studies, Institute of Economics, Hitotsubashi University.

Smith, K.E., Favreault, M.M., Ratcliffe, C., Butrica, B., Toder, E., Bakija, J., 2007. Modeling Income in the Near Term 5. Urban Institute.

SOA 1997. Chapter 5 on CORSIM, Society of Actuaries, http://www.soa.org/files/pdf/Chapter_5.pdf

Stroombergen A., D. Rose and J. Miller, 1995. Wealth Accumulation and Distribution: Analysis with a Dynamic Microsimulation Model. Wellington: Business and Economic Research Ltd.

Tanton, R., Vidyattama, Y., Nepal, B., McNamara, J., 2011. Small area estimation using a reweighting algorithm. Journal of the Royal Statistical Society: Series A (Statistics in Society).

Tedeschi , S. 2011. T-DYMM: Background and Challenges, Intermediate Conference

Toder E., C. Uccelllo, J. O’Hare, M. Favreault, C. Ratcliffe, K. Smith, G. Burtless and B. Bosworth. 1999. Modeling Income in the Near Term - Projections of Retirement Income Through 2020 for the 1931-60 Birth Cohorts. Final Report. Washington DC: Urban Institute.

van de Ven J., 1998. "A Dynamic Cohort Microsimulation Model“, University of Melbourne - Department of Economics Working Paper, No. 637.

van Soest A., (1995): Structural models of family labor supply: a discrete choice approach, Journal of Human Resources, 30(1), 63-88.

Van Sonsbeek, J., 2009, Micro Simulations on the Effects of Ageing-Related Policy Measures: The Social Affairs Department of the Netherlands Ageing and Pensions Model.

Vencatasawmy, C.P., E. Holm, T. Rephann, J. Esko, N Swan, M. Ohman, M. Astrom, E. Alfredsson, K. Holme and J. Siikavaara, 1999. "Building a spatial microsimulation model", SMC Internal Discussion Paper. Kiruna: Spatial Modelling Centre.

Wertheimer, R., S.R. Zedlewski, J. Anderson and K. Moore, 1986, "DYNASIM in comparison with other microsimulation models” in G. Orcutt, J. Merz and H. Quinke (eds.) Microanalytic Simulation Models to Support Social and Financial Policy. Amsterdam: North-Holland.

Will, B., J. Berthelot, K. Nobrega, W. Flanagan and W. Evans, 2001, Canada's Population Health Model (POHEM) a tool for performing economic evaluations of cancer control interventions. European Journal of Cancer 37, 1797-1804.

Willekens, F. 2006, Description of the micro-simulation model (Continuous-time micro-simulation). Deliverable D8 (first part), MicMac Bridging the micro-macro gap in population forecasting, NIDI, The Netherlands 
Williamson, P., 2007. The Role of The International Journal Of Microsimulation. International Journal of Microsimulation.

Winder, N. and Y Zhou, 1999. "Predicting the annual income of Swedish individuals", SMC Internal Discussion Paper. Kiruna: Spatial Modelling Centre.

Wolfson M. and G. Rowe, 1998. "LifePaths - Toward an Integrated Microanalytic Framework for SocioEconomic Statistics”, paper presented to the 26th General Conference of the International Association for Research in Income and Wealth, Cambridge, UK.

Wolfson M., 1988. "Homemaker Pensions and lifetime redistribution”, Review of Income and Wealth, Vol. 34, No. 3, pp. 221-250.

Wu, B., Birkin, M., Rees, P., 2008. A spatial microsimulation model with student agents. Computers, Environment and Urban Systems 32, 440-453.

Zaidi, A. and A. Scott, 2001, Base dataset for the SAGE model, (Sage Technical Note).

Zaidi, A., Rake, K., 2001. Dynamic microsimulation models: a review and some lessons for SAGE. The London School of Economics, Simulating Social Policy in an Ageing Society (SAGE), Discussion Paper. 2.

Zucchelli, E., A. Jones and N. Rice, 2010, The evaluation of health policies through microsimulation methods. Health, Econometrics and Data Group (HEDG) Working Papers.

Zylberstajn E., Zylberstajn H., and Afonso L. 2011. BRALAMMO: A dynamic labor market microsimulation model for Brazil 



\section{[3] Simulating Histories within Dynamic Microsimulation Models ${ }^{3}$}

\footnotetext{
${ }^{3}$ Acknowledgement: For their helpful discussions and comments, the authors wish to thank Elisa Baroni, Gijs Dekkers, two anonymous referees, and the participants of the 2010 European workshop on dynamic microsimulation modelling in Brussels.

A shorter version of this chapter is available as: Li, J. and O'Donoghue, C., 2010. Simulating Histories for Dynamic Microsimulation Models, in: O’Donoghue, C. (Ed.), Life-Cycle Microsimulation Modelling: Constructing and Using Dynamic Microsimulation Models. LAP LAMBERT Academic Publishing

The chapter is available as: Li, J. and O'Donoghue, C., 2011 (forthcoming). Simulating Histories within Dynamic Microsimulation Model, International Journal of Microsimulation
} 


\subsection{Background}

Many countries today are facing the prospect of rapid demographic change in the decades ahead and numerous research papers have been devoted to the analysis of the implications of an ageing population. A number of microsimulation models have been developed to study this issue linked with social security, retirement incomes, and pension reforms. In order to generate an accurate and stable projection for elderly earnings and pensions, it is essential to include some historical information in the dataset, a luxury that many modellers do not have.

Microsimulation models are usually categorised as either "static" or "dynamic". Static models, e.g. EUROMOD (Mantovani et al., 2007), are mostly arithmetic models that evaluate the immediate distributional impact upon individuals/households of possible policy changes, whilst Dynamic models, e.g. DESTINIE, PENSIM, SESIM (Bardaji et al., 2003; Curry, 1996; Flood, 2007), extend the static model by allowing individuals to change their characteristics as a result of endogenous factors within a model (O'Donoghue, 2001). Dynamic microsimulation models in theory, could offer more insights than static models as they usually integrate long-term projections and behaviour simulations; however, they are costly to develop and require a baseline dataset that is both rich in variables and historical information. These demanding requirements unfortunately are rarely matched by the existing data availability (Harding, 2007) and therefore compromises are often made in order to make the simulation possible.

This paper investigates longitudinal data availability issues in microsimulation and proposes a viable alternative by simulating a plausible and consistent history using a typical household survey panel from Ireland. The following section discusses the base dataset issues in dynamic microsimulation models and the potential alternatives. Section 3 describes the dataset used in the back simulation and section 4 explains the modelling procedure of the back simulation, and followed by a description of the alignment technique used in section 5. The three sections following report the results of the back simulation together with the validations, for employment status, pension memberships and earnings, respectively. A conclusion and discussion are provided in the final section of this paper.

\subsection{Base Dataset Issues in Dynamic Microsimulation}

\subsubsection{Base Dataset Selection}

Base dataset selection is important for a microsimulation model as the quality of the input data determines the quality of the output, yet this is not an easy task, as hardly any micro datasets contain all the information required by a dynamic microsimulation model that can be used to project the whole population. The difficulties of picking a base dataset have 
been discussed in several papers (Cassells et al., 2006; Zaidi and Scott, 2001). Typically, a dynamic microsimulation model starts with one or several of the following types of dataset:

- Cross-sectional Household Survey Data

- Cross-sectional Administrative data

- Census Data

- Panel Household Survey Data

- Panel Administrative data

Panel data is generally preferred over cross-sectional data as it records changes over time, a useful component in statistical modelling. Household survey data, e.g. EU-SILC data in EUROMOD (Figari and Sutherland, 2007), is frequently used as the basis of the base dataset, because it is rich in the number of variables of interests and offers information on the dynamics of behaviours. However, the time period in these survey datasets may be insufficient to provide certain historical information required for life-cycle modelling and analysis. Administrative data, although typically consisting of a more limited range of contextual variables, often provides a longer history and contains relatively high quality information for certain variables, e.g. tax, and in most cases, a higher number of observations. Some Scandinavian country models, e.g. the MOSART model in Norway (Fredriksen, 2003), are based on extensive and detailed register information. However, access to administrative records is typically fairly limited even from within a government.

For microsimulation models analysing the dynamics of elderly earnings or pensions, it is essential to have historical social economics variables that could be used to reconstruct the career trajectories of today's elderly workers. This implies that an ideal dynamic microsimulation base dataset should contain the following information for each individual from birth:

- Demographic information, which contains age, education, marriage, birth of children, household (or tax unit) formation and dissolution

- Employment trajectory information, which contains labour force participation records, historical earnings, types of job etc.

- Pension membership and entitlement information, which contains the record of various pension schemes participation (including state, occupational, and private pension)

To meet these requirements a long panel dataset containing rich demographic, employment, and pension data is required; unfortunately, a dataset that matches the above description is not readily available to most researchers. Certain models (e.g. DYNASIM, CORSIM) as a result, have experimented with alternative methods such as statistical matching and simulation. 
The first method, statistical matching, involves filling in the missing information required from a different but comparable dataset compiled within a similar time frame. For example, a microsimulation model based on a household survey dataset may need some historical earning records that are only available from another income study dataset. Under such a circumstance, a matching method may be used to fill in the information gaps based on a statistical model using available social economic characteristics shared by both datasets. The DYNASIM model was one of the pioneers in this area and uses Current Population Survey (CPS) as the base dataset matched with social security earnings records from administrative data. In DYNASIM3 (Favreault, 2004), the statistical matching was undertaken between two survey datasets, namely, Survey of Income and Program Participation (SIPP) and Panel Study of Income Dynamics (PSID), while PENSIM2 matches Family Resource Survey (FRS) and British Household Panel Survey (BHPS) to the Lifelong Labour Market Database (LLMDB) to incorporate household contextual data (Emmerson et al., 2004). In addition, statistical matching also occurs between survey and census datasets, e.g. SAGE matches survey data to their base census sample data to obtain the additional information required (Evandrou, 2004).

The second method used is to generate a synthetic historical panel using information from the base dataset itself. Unfortunately, the methodology of simulating histories is not as widely discussed as simulating future characteristics in the microsimulation field. There are many challenges in attempting to "back-cast" or "back simulate" historical earnings (and other characteristics) earlier in life (Harding, 2007). The DYNANCAN model uses a limited back simulation technique by imputing the historical earning profiles between 1966 and 1969 with limited retrospective consistency (Morrison, 1997;1998), whilst the CORSIM model simulates part of the historical profile based on a historical cross-sectional dataset, matching the model output to historical aggregate information such as fertility and mortality rates (Caldwell, 1997). Nevertheless, the existing methods only impute the history for a limited number of years and they usually suffer from the inconsistency issues. While certain variables match the historical data at cross-sectional level, the longitudinal consistencies are typically ignored and variables covered are not extensive enough to support life cycle analyses and pension simulations.

There are advantages and disadvantages to both methods described above. Statistical matching can be used when there are sufficient matching variables in a comparable dataset and this method has the desirable feature of having a "real-world" value, although the quality of matching may vary substantially depending on the quality and quantity of matching variables. In some cases, certain variables, e.g. historical earning records, may not exist in any dataset or access is restricted due to legal restrictions. If these variables are needed within the model, then the only option available is simulation. Synthetic simulation has the advantage of flexibility but longitudinal consistency may be an issue due to the limited information available. 


\subsection{2}

LIAM is a dynamic microsimulation model designed to evaluate potential reforms of the Irish pensions system and other policies in terms of changes to life-cycle incomes, particularly on old age income replacement rates, poverty and inequality measures (O’Donoghue et al., 2009). Given the nature of the model, it requires a pension module which is able to simulate:

- Life-cycle income distribution under a given pension system

- Public and/or private pension fund accumulation and dissipation over individuals' lifecycles, under a given pension system and alternatives

- Effects of reforms of a given system on life-cycle income distribution, costs, and other redistributive measures

Since the model aims to evaluate the impact of policy change for those "at risk", i.e. potential pensioners, an ideal historical panel would start in the year in which the oldest potential retiree in the dataset was born. However, one practical issue of alignment prevents generating meaningful values in the very early years when few individual exists in the dataset. As alignment is necessary to ensure the cross-sectional consistency with the historical values, it is necessary to keep a minimum number of the observations for each year that the alignment is applied. Therefore, the study sets the starting year of the historical panel in 1939, the year when the youngest retirees in 1994 (age 55) were born and the elder retirees in 1994 (age 75+) just entered the labour market for no more than a few years.

Furthermore, in order to simulate the potential pension income, it is necessary to include a set of important social economic variables, covering demography, employment, and pension information. These include:

- Demographic data includes gender, age, marital status, number of children and education attainment

- Employment data covers employment status (working or not), employment type (employee or self-employed), employment sector (public or private) and job income

- Pension data includes the pension contribution to occupational pension and private pension, the fund size of the defined-contribution (DC) pension, and the type of pension claimed after retirement

LIAM ideally, should select a base dataset which has a long social economic history, i.e. a panel that looks like an extended version of the US PSID or certain administrative datasets available in Sweden/UK etc. Unfortunately, long historical panels do not exist for Ireland, neither in the form of survey datasets nor as administrative records, yet this missing information is crucial to life cycle modelling and analysis, as some forward simulation 
components, such as pension eligibilities, are built on the individual labour trajectory. Given these constraints, simulation is therefore the best tool for obtaining histories for LIAM. Compared with earlier works on the historical recreation in microsimulation model (e.g. CORSIM and DYNACAN), the model could reconstruct a much longer time period and focuses on the consistencies at both cross-sectional and longitudinal levels.

This paper, as part of the work developing LIAM, proposes a microsimulation algorithm which could generate a plausible, consistent and comprehensive historical panel based on a household survey dataset by extrapolating the retrospective variables concerning past employment history. Variables such as years of working and pension eligibilities are registered in the household survey and could be used to model a plausible working history for all individuals when taken together with information generated from some external statistics.

\subsection{Data}

This back simulation module is primarily modelled based on the 1994-2001 Living in Ireland Survey (LII) dataset along with some external statistics extracted from the pension questionnaire section of the 2002 Quarterly Household National Survey (QHNS), and the Irish census reports since 1930s.

The LII survey constitutes the Irish component of the European Community Household Panel (ECHP) and is a representative household panel survey that was conducted yearly on the Irish population between 1994 and 2001 (eight waves). The data contains panel information on demographics, employment, and other social economic characteristics for around 3500 households in each wave. In 2000, an additional 1500 households were brought into the dataset to compensate for the attrition since 1994. Table 3.1 lists some descriptive information of key demographic and employment variables in the LII dataset.

Besides the LII survey, the back simulation module also uses the information gathered from the QHNS survey, which is a nationwide household survey, designed to produce quarterly labour force estimates in Ireland since 1997. In the first quarter of 2002, a special module dedicated to pension savings was added to the survey. QHNS is used in the back simulation mostly for alignments when estimating occupational and private pensions. Census reports prior to 1994 were used in the back simulation module in order to align certain important history aggregates.

\subsubsection{Demographic Base Data}

Demographic data is the foundation of a population-based simulation. The back simulation module extracts demographic information from the LII survey and surmises some data, for example the time of birth of each individual is calculated from age 
information in the survey and marriage status is derived from the reported age of marriage. In the case where a missing value is spotted and no historical data is readily available, some assumptions are made, e.g. it is assumed that an individual would get married at 25 , the average age of marriage in Ireland in the1990s when no other information is available. Divorce and remarriage is not simulated for in the current history panel for complexity reasons, and education level is assumed constant once an individual has left the reported schooling period ${ }^{4}$.

Table 3.1 An Overview of LII Survey

\begin{tabular}{l|cc}
\hline Variable & Mean & s.d. \\
\hline Age & 34.15 & 21.86 \\
Gender & 0.50 & 0.50 \\
Married (\%) & $38.91 \%$ & 0.49 \\
Average household size & 4.31 & 1.86 \\
Working population (\%) & $38.18 \%$ & 0.49 \\
Public Sector worker (\%) & $7.81 \%$ & 0.27 \\
Self-employed (\%) & $7.73 \%$ & 0.27 \\
Retired (\%) & $6.85 \%$ & 0.25 \\
Unemployed (\%) & $5.40 \%$ & 0.23 \\
Percentage of the population with college education & $17.46 \%$ & 0.38 \\
Average reported years of work & 13.66 & 15.20 \\
\hline Total number of household & \multicolumn{2}{|c}{7529} \\
Total number of individuals & \multicolumn{2}{|c}{23955} \\
Total number of observations & \multicolumn{2}{|c}{100639} \\
\hline
\end{tabular}

In the current version of the back simulation, cohorts that died before 1994 were not simulated, as the primary goal for the back simulation is to complete the career trajectory for the potential living pensioners. This simplification helps to reduce uncertainties within the history panel and lowers the modelling difficulties by avoiding potential complex interactions and consistency concerns of the synthetic population. One drawback of this simplification is that it raises the bar for alignment, as the simulated data will not be able to compare with the historical aggregate indicators. Fortunately, the Irish census data contains detailed information for each age gender subgroup. As a result, all alignments described in this paper can be performed at cohort level to ensure the consistency between simulated values and historical census data.

\footnotetext{
${ }^{4}$ It is possible to release these assumptions by incorporating a refined household formation and dissolution model. However, it is not included in the current version of the back simulation model to reduce the model complexity.
} 


\subsubsection{Exploiting the Retrospective Variable}

The LII survey contains certain retrospective questions similar to many household survey datasets. These questions are helpful in history re-creation as they can pinpoint the time when certain events happened in an individual's history, e.g. birth, marriage etc. In the LII survey, retrospective variables provide information for

- the year when an individual started their current job and their job's duration

- the year when an individual first entered the labour market

- the number of years spent in full-time education, employment (including selfemployment and farming), unemployment (seeking a job), illness or disability,

- home caring or retirement duration since the age of 10

- the duration of unemployment, if currently unemployed

While the information collected is highly relevant for back simulation, these retrospective variables may not contain high quality data. Missing values and inconsistencies are sometimes spotted across differing years of the LII survey, for example the declared number of years in school varying without engaging in education. This type of error could hamper the quality of the simulated histories severely, as there would be no reliable reference to constrain the shape of the career trajectory.

In order to mitigate the impact of lower quality data, it is useful to correct obvious mistakes in the data collection and impute the missing values to expand the base on the dataset. Adjustments are applied to enforce the consistencies with key variables (e.g. age) and avoid basic mistakes such as assigning college degrees to children. Since most retrospective values (more than $90 \%$ of the individuals) are not updated once collected in the base year, it is necessary to recalibrate the values from second wave onwards to ensure the consistencies with the recorded labour market activity in the previous year. For example, if the individual worked full time in 1994, the accumulated years of employment should increase by one in 1995. Same principle applies to other variables like years of education etc.

Table 3.2 presents an overall summary on the outcome of the retrospective variable adjustments and highlights the difference between the original data and the adjusted data in the base year (1994) when the retrospective data was first collected. This adjustment increases the usability of these variables by improving its internal consistency. The table does not include missing values, which are imputed in the next step.

Missing values are imputed via a set of ordinary least squared (OLS) equations, where the number of years spent in certain employment conditions are estimated using a vector for personal characteristics. Imputed values are checked for consistencies with other variables like age, education and adjusted in case of conflicts. Table 3.3 describes what variables are imputed using this specification and what personal characteristics are included in the 
vector $X$. Models are separately estimated for males and females. Appendix 3.B and C report the estimates obtained in the imputation equations.

Table 3.2 Retrospective Variables Adjustment in the LII survey (base year)

\begin{tabular}{|c|c|c|c|c|c|}
\hline \multirow{2}{*}{ Variable Description } & \multicolumn{2}{|c|}{ Original } & \multicolumn{2}{|c|}{ Adjusted } & \multirow{2}{*}{$\begin{array}{l}\text { Observations } \\
\text { Adjusted (\%) }\end{array}$} \\
\hline & Mean & s.d. & Mean & s.d. & \\
\hline \multicolumn{6}{|l|}{ (Male) } \\
\hline $\begin{array}{l}\text { Years in full-time education or } \\
\text { training }\end{array}$ & 6.83 & 2.67 & 6.67 & 2.85 & $2.28 \%$ \\
\hline $\begin{array}{l}\text { Years in employment, self- } \\
\text { employment or farming }\end{array}$ & 19.38 & 17.88 & 19.32 & 17.88 & $0.40 \%$ \\
\hline Years in unemployment & 1.11 & 3.24 & 1.11 & 3.24 & $0.14 \%$ \\
\hline Years of illness/disabled & 0.39 & 2.88 & 0.39 & 2.88 & $0.02 \%$ \\
\hline Years spent on home duties & 0.21 & 3.30 & 0.14 & 2.63 & $0.23 \%$ \\
\hline Years in retirement & 1.01 & 3.44 & 1.00 & 3.42 & $0.07 \%$ \\
\hline \multicolumn{6}{|l|}{ (Female) } \\
\hline $\begin{array}{l}\text { Years in full-time education or } \\
\text { training }\end{array}$ & 6.92 & 2.36 & 6.77 & 2.57 & $2.23 \%$ \\
\hline $\begin{array}{l}\text { Years in employment, self- } \\
\text { employment or farming }\end{array}$ & 9.17 & 10.68 & 9.10 & 10.64 & $0.51 \%$ \\
\hline Years in unemployment & 0.32 & 1.58 & 0.32 & 1.58 & $0.09 \%$ \\
\hline Years of illness/disabled & 0.27 & 2.39 & 0.25 & 2.26 & $0.05 \%$ \\
\hline Years spent on home duties & 12.76 & 17.21 & 12.70 & 17.14 & $0.17 \%$ \\
\hline Years in retirement & 0.34 & 2.43 & 0.33 & 2.39 & $0.05 \%$ \\
\hline \multicolumn{6}{|l|}{ (Total) } \\
\hline $\begin{array}{l}\text { Years in full-time education or } \\
\text { training }\end{array}$ & 6.87 & 2.52 & 6.72 & 2.71 & $2.26 \%$ \\
\hline $\begin{array}{l}\text { Years in employment, self- } \\
\text { employment or farming }\end{array}$ & 14.29 & 15.59 & 14.22 & 15.58 & $0.45 \%$ \\
\hline Years in unemployment & 0.72 & 2.58 & 0.72 & 2.58 & $0.11 \%$ \\
\hline Years of illness/disabled & 0.33 & 2.65 & 0.32 & 2.59 & $0.03 \%$ \\
\hline Years spent on home duties & 6.48 & 13.88 & 6.41 & 13.77 & $0.20 \%$ \\
\hline Years in retirement & 0.68 & 3.00 & 0.67 & 2.97 & $0.06 \%$ \\
\hline
\end{tabular}

Table 3.3 Imputed Variables

\begin{tabular}{ll}
\hline Imputed Variables & Personal Characteristics used $(X)$ \\
\hline Years in full-time education or training & Education, age, current employment status, \\
Years in employment, self-employment or farming & chronic illness, retirement status, number \\
Years in unemployment & of children in different age groups \\
Years of illness/disability & \\
Years spent on home duties & \\
Years in retirement & \\
\hline
\end{tabular}




\subsection{Methodology I: Modelling the Histories}

This section describes the methodology used in the back simulation. While a back simulation model may use some historical information to refine the outcome, it also has a higher requirement on the output quality. Since the main purpose of this back simulation model is to recreate each individual career trajectory, it demands a high accuracy of the model prediction as the pension eligibility is highly sensitive to the past employment status. In a forward microsimulation model, one would typically use some kind of aggregated values (e.g. mean, standard deviation of the distribution) to evaluate the quality of the simulation. The predicted value does not need to be correct at the individual level as long as the distributions are reasonable. Nonetheless, in the case of backward simulation, one needs to ensure that the values are sensible at the individual level due to the longitudinal consistency requirement while maintaining the reasonable distribution shape at each crosssectional level.

Compared with a forward dynamic microsimulation model, a back simulation model could be more complex as it is designed to exploit more information both from historical values and retrospective information. In order to create a panel dataset that is as close as possible to the real history, three methodologies are used in back simulations:

- Deterministic simulation

- Semi-stochastic simulation

- Stochastic simulation

The deterministic simulation generates the part of the history that is directly determined by retrospective variables and ensures that the generated history is perfectly consistent with the reported values. For instance, if an individual reports starting work at age 20, it is safe to assume that this individual was in work that particular year. The variables used in deterministic simulation include the age when an individual begins to work, the year in which an individual quit their previous job, the number of years spent in their current employment status (e.g. length of current job, unemployment etc.) and the number of years spent in each employment status.

Semi-stochastic simulation recreates certain historical events from retrospective variables in conjunction with some reasonable assumptions. While the deterministic simulation pinpoints the timing of some major events in history, it gives only incomplete information regarding employment trajectory. Semi-stochastic simulation is still largely based on the reported retrospective variables but might involve some assumptions. For instance, since most women take maternity leave when giving birth, it is reasonable to simulate a career profile interrupted in the year of childbirth with a high probability. Another example would be "back to work" social welfare benefit, which usually implies a period of unemployment for the years preceding claiming the benefit. 
Stochastic simulation is designed to fill the parts of the history that cannot be inferred from deterministic and semi-stochastic processes and it recreates the history through the predictions of estimated econometric models with random components. This method is similar to a regular dynamic microsimulation model, such as DYNAMOD2 and SAGE (King et al., 1999; Zaidi, 2004), with the difference being that the back simulation model ages the population in a reversed direction and is subject to a much more restricted alignment procedure for consistency reasons. An outline of the simulation steps are provided in the Appendix 3.A.

\subsubsection{Discrete Variable Simulation}

Discrete variables include both binary variables, such as pension membership and categorical variables, such as job position. Since the pension, membership calculation only requires basic employment status and the technical issues in alignment, the current version of the back simulation only simulate binary variables. Binary variables such as employment status, pension membership etc. are modelled using logit models that produce a probability of an event occurring as the output. These binary variables could be modelled in the following generic form

$$
\operatorname{logistic}\left(p_{i}\right)=\alpha+\beta X_{i}+\varepsilon_{i}
$$

$X_{i}$ is the vector of personal characteristics. The error term can be decomposed into specific individual effects $u_{i}$ and an i.i.d. stochastic term $v$. While there are a few methods that can be adopted for controlling individual heterogeneity, this current version of the back simulation uses a simple logistic implementation for the program compatibility and the speed reason. Assuming that the stochastic term $v_{i t}$ is i.i.d. with mean zero, the average of

the error terms for each individual is an unbiased estimate for individual effects $\left(u_{i}\right)$. It then becomes possible to re-estimate the model using calculated individual effects and apply them to the simulation. Therefore, the final model applies can be described as

$$
\operatorname{logistic}\left(p_{i t}\right)=\alpha+\beta X_{i t}+u_{i}+v_{i t}
$$

The method is essentially an adjusted "fixed-effects" logit model, which is a logit variation of the specification suggested by Mundlak (1978). It yields a higher predictive power as parts of the unobserved heterogeneities are modelled. Table 3.4 lists the variables included for each logit model. Models are estimated separately for male and females.

\subsubsection{Continuous Variable Simulation}

Income $y_{i t}$ is modelled as an extended Mincer type earning equation (Mincer and Jovanovic, 1981). It consists of a deterministic component (representing the dependence 
of income on current state variables), a random effect $u_{i}$ (to account for unobserved individual heterogeneity), and a stochastic component $\varepsilon_{i t}$ (which represents random variation over time, in addition to variation from state changes). The statistical form looks like:

$$
y_{i t}=\alpha+\beta X_{i}+u_{i}+\varepsilon_{i t}
$$

Where $X_{i}$ includes education attainment, labour market experience and unemployment experience in the equations. Earnings are estimated using a random effect specification and coefficients are reports in Appendix 3.D.

Table 3.4 Components of the Employment Status Equations

\begin{tabular}{l|ccccc}
\hline \multirow{2}{*}{$\begin{array}{l}\text { Variables Included in the } \\
\text { Equations }\end{array}$} & \multicolumn{5}{|c}{ Equations } \\
\cline { 2 - 6 } & In-Work & $\begin{array}{c}\text { Self- } \\
\text { employment }\end{array}$ & $\begin{array}{c}\text { Job } \\
\text { Sector }\end{array}$ & $\begin{array}{c}\text { Occupational } \\
\text { Pension } \\
\text { Membership }\end{array}$ & $\begin{array}{c}\text { Private } \\
\text { Pension } \\
\text { Membership }\end{array}$ \\
\hline Age or Age group & Yes & Yes & Yes & Yes & Yes \\
Age Squared & Yes & Yes & Yes & & \\
$\begin{array}{l}\text { Age 65 or above } \\
\text { Education }\end{array}$ & Yes & Yes & Yes & Yes & Yes \\
$\begin{array}{l}\text { Gender } \\
\text { Work Experience }\end{array}$ & Yes & Yes & Yes & Yes & Yes \\
$\begin{array}{l}\text { Gave Birth to a Child in the } \\
\text { current year }\end{array}$ & Yes & Yes & Yes & & \\
$\begin{array}{l}\text { Work in the Public Sector } \\
\text { or Not }\end{array}$ & & & & & Yes \\
$\begin{array}{l}\text { Job Industry } \\
\text { Job Occupation }\end{array}$ & & & & Yes & Yes \\
$\begin{array}{l}\text { Lagged variables } \\
\text { Mean value of residuals }\end{array}$ & & & & Yes & Yes \\
\hline
\end{tabular}

\subsection{Methodology II: Alignment and Adjustment in the Simulation}

Alignment is a commonly used method for calibrating microsimulation models so that aggregate outputs from the model match the external projections or values. This is partially due to insufficient knowledge regarding micro-behaviour to specify a fully dynamic model. Simulation models, if unbounded, may over or under predict the occurrence of a certain event, even in a well-specified discrete model (Duncan and Weeks, 2000). Therefore, although in theory alignment might be controversial (as a perfectly specified model with 
perfect data should not need any alignment), it is a de facto common practice for microsimulation models (see for example DYNACAN, CORSIM, and LIAM).

In the back simulation module, alignment shapes the earnings and the distribution of employment status in a way that is both consistent with historical census information and retrospective information. There are two types of alignments applied in this model; one is a cross-sectional alignment and the other a longitudinal alignment.

\subsubsection{Cross-sectional Alignment}

Depending on whether the variable is continuous or discrete, the alignment technique applied is different. Continuous variables such as earnings were aligned to the same level for the first year of the survey in 1994 for each age, gender, and education group and wage growth was assumed to be equivalent to consumer price index (CPI) growth rate. The alignment is a proportional adjustment, which has been used in several models, e.g. Chénard (2000a, 2000b).

For binary variables such as employment status variables, the alignment matches the proportion of the population which has a certain employment status (e.g. working or not), to the external census values, or estimated historical values, for each age, sex and education group in a given year. The alignment is based on the probability predicted by the logit model, i.e. individuals with the highest predicted probabilities (with the stochastic term) would be selected. The method is described in details by O'Donoghue (2010).

One issue with the alignment usage in this particular study is the incomplete population. While the dataset is population representative between year 1994-2001, the lack of the deceased population makes the dataset biased in early years. To address this problem, cross sectional alignments are only applied at the sub population level, i.e. alignment by age, gender, education status etc. rather than at the whole population level.

\subsubsection{Longitudinal Alignment}

Besides the cross-sectional alignment, the back simulation also requires consistency in the retrospective variables, which is crucial to the quality of the generated historical dataset, as one of the main purposes of a long panel dynamic microsimulation is life-cycle analysis (e.g. pension). Currently there are hardly any simulation models applying a longitudinal alignment, as most have been developed for forward simulation, where there is no benchmark with which to align the results. In the back-simulation module, longitudinal alignments are implemented for the following reasons:

- The simulated life path should be consistent with the reported retrospective variables such as date of marriage, year when started working, education, childbirth etc. 
- The simulated number of years spent in a certain employment category (e.g. total years of work/unemployment) should be consistent with reported values in the LII dataset

- The state, occupational and private pension eligibilities should be consistent with the simulated labour force trajectory

As discussed earlier, major life events are determined before the stochastic simulation to ensure consistency. The reported number of years spent within a certain employment category, as presented in the LII dataset, is taken into account during the cross-sectional alignment design process. Together with the deterministic simulation, it is possible to identify how many working years are left undetermined. Individuals without any "working years" left would be assigned as out of a job during the cross-sectional alignment procedure. Some small adjustments were applied after the panel was created to eliminate small gaps experienced during public sector employment.

The alignment for the state contributory pension eligibility is a bit more complicated. Ireland introduced a state pension system in 1953 and in order to be eligible for an Irish state pension, an individual has to contribute for at least $19.52 \%(10 / 52)$ of the time between their first eligible job and age 65. Self-employed jobs were not deemed eligible until 1988. Given this information, it is possible to influence the pension entitlement by modifying two factors within a career profile: the years of contribution and the density of contribution. For example, if an individual is not eligible for a state pension but the simulation gives an opposite result (a type I error), it is most likely that the model oversimulated the number of years worked with a pension eligible job, or that the starting year is too late. In this case, it is possible to improve the consistency by removing the years of working experience in eligible jobs and replace them with non-eligible activities. Meanwhile, a reverse correction procedure can be applied to type II error individuals (the ones with pension eligibility but without simulated eligibility).

A simplified case below demonstrates this algorithm (Table 3.5 and Table 3.6). Assuming there are three individuals in the dataset: A, B and C. They reported that they have worked 3, 4, 3 years in total in their lifetime respectively, and in 1994, B and C received state pensions. Based on the reported total years of work and the yearly aggregate alignment, the back simulation module may generate an output as below, where a black dot [•] means that an individual is working in that year and a white dot [o] indicates that the individual is out of work. As seen below, the simulation is able to reconstruct a history with a controlled yearly aggregate and consistent total years worked.

As shown above in Table 3.5, individual A has a type I error and individual C has a type II error. In order to correct the eligibility while preserving the total years of work and yearly aggregate, one solution is to swap jobs. In this case, individual A's job in 1951 has been swapped with the 1973 job, while individual C's job in 1973 has been swapped with the 
1951 job. Given the symmetric nature of the process, there is no change in the yearly aggregate and total years of work.

Table 3.5 Simulated Profile without Adjustment

\begin{tabular}{|c|c|c|c|c|c|c|c|c|c|c|}
\hline Year & 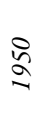 & 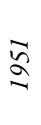 & ๙ू & $\hat{N}$ & $\stackrel{N}{2}$ & $\stackrel{n}{n}$ & $\begin{array}{c}\text { Total } \\
\text { Years of } \\
\text { Work }\end{array}$ & Rate & $\begin{array}{l}\text { Simulated } \\
\text { Eligibility }\end{array}$ & $\begin{array}{c}\text { Actual } \\
\text { Eligibility }\end{array}$ \\
\hline Individual A & $\bullet$ & $\circ$ & $\bullet$ & $\circ$ & $\circ$ & $\bullet$ & 3 & $33.3 \%$ & Yes & No \\
\hline Individual B & $\bullet$ & ० & $\bullet$ & $\bullet$ & $\circ$ & $\bullet$ & 4 & $66.7 \%$ & Yes & Yes \\
\hline Individual C & $\bullet$ & $\bullet$ & $\bullet$ & ○ & $\circ$ & $\circ$ & 3 & $0.00 \%$ & No & Yes \\
\hline Yearly Aggregate & 3 & 1 & 3 & 1 & 0 & 2 & & & \multicolumn{2}{|c|}{$(1 / 3$ correct $)$} \\
\hline
\end{tabular}

Table 3.6 Simulated Profile with Adjustment

\begin{tabular}{|c|c|c|c|c|c|c|c|c|c|c|}
\hline Year & $\stackrel{2}{\approx}$ & $\stackrel{\pi}{\sim}$ & $\underset{\Omega}{\Omega}$ & $\widehat{\widehat{N}}$ & $\underset{\Omega}{2}$ & 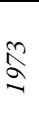 & $\begin{array}{c}\text { Total } \\
\text { Years of } \\
\text { Work }\end{array}$ & Rate & $\begin{array}{l}\text { Simulated } \\
\text { Eligibility }\end{array}$ & $\begin{array}{c}\text { Actual } \\
\text { Eligibility }\end{array}$ \\
\hline Individual A & $\bullet$ & $\bullet$ & - & $\circ$ & ० & ○ & 3 & $0.0 \%$ & No & No \\
\hline Individual B & - & o & - & - & $\circ$ & - & 4 & $66.7 \%$ & Yes & Yes \\
\hline Individual C & $\bullet$ & $\circ$ & - & $\circ$ & 0 & $\bullet$ & 3 & $33.3 \%$ & Yes & Yes \\
\hline Yearly Aggregate & 3 & 1 & 3 & 1 & 0 & 2 & & & \multicolumn{2}{|c|}{ ( $3 / 3$ correct $)$} \\
\hline
\end{tabular}

This method is essentially a swapping algorithm that works when the longitudinal inconsistency is found. This procedure, however, might break the cross-sectional alignment introduced earlier in some cases when there is no individual consistency that could be improved without breaking another one. In order to avoid this undesired consequence or alleviate the impact, employment statuses are added or removed only in carefully selected year(s) based on the difference between simulated labour market statistics and the census values. For instance, if the labour force participation is lower than the census value for a specific simulated year, then the model will not be allowed to remove employment statuses from that particular year, instead, it will put a higher priority on employment creation for that particular year.

Since the LII is a panel dataset, the simulated history should be consistent with not only the first year, but with all the waves. Therefore, this alignment procedure takes several iterations; the model first aligns the history with the last wave in the survey, and then gradually moves to the first wave in a loop. It should be noted that this method does not guarantee perfect consistency but it does offer a reasonable result with some important insights into the life paths of individuals. 


\subsubsection{Data Quality and Alignment}

Apart from computational algorithm defects in alignments, there is another important factor affecting the consistencies of simulated history: the quality of the data. The retrospective information collected in the survey dataset can suffer from various recall or measurement biases and it is rare not to spot inconsistencies. An individual aged 67 in 1994 might report he/she received his/her state pension in that year, while claiming that he/she had only worked for 2 years during his/her lifetime. Sometimes, the inconsistency may not be as obvious as in this previous example, especially when dealing with crossvariable consistencies. Certain data quality issues might be difficult to spot beforehand and make longitudinal alignment difficult. Therefore, it may sometimes be necessary to allow for a small deviation from the reported values.

\subsection{Results I: Back Simulating Employment Status}

This section evaluates the back-simulation of discrete (mainly employment status) variables. It recreates labour force participation and job nature (public or private sector, employed or self-employed), crucial information for future pension projection. Figure 3.1 illustrates their simulation order within the module. Among the discrete variables, the module simulates:

- In-work, Employment Sector (Public/Private)

- Self-employment

- Various pension memberships

The simulations are based on the complete sample of the 1994 population in the LII survey. Since the model does not generate historical profiles for people who have died before 1994, the simulated sample is not representative of the population prior to 1994 . This implies that the average age in the earlier years of the simulation is significantly lower than the average age in the sample. Therefore, outputs are presented mostly by age group or cohort group in order to avoid misunderstandings. 
Figure 3.1 Simulation Flowchart for the Employment Status Variables

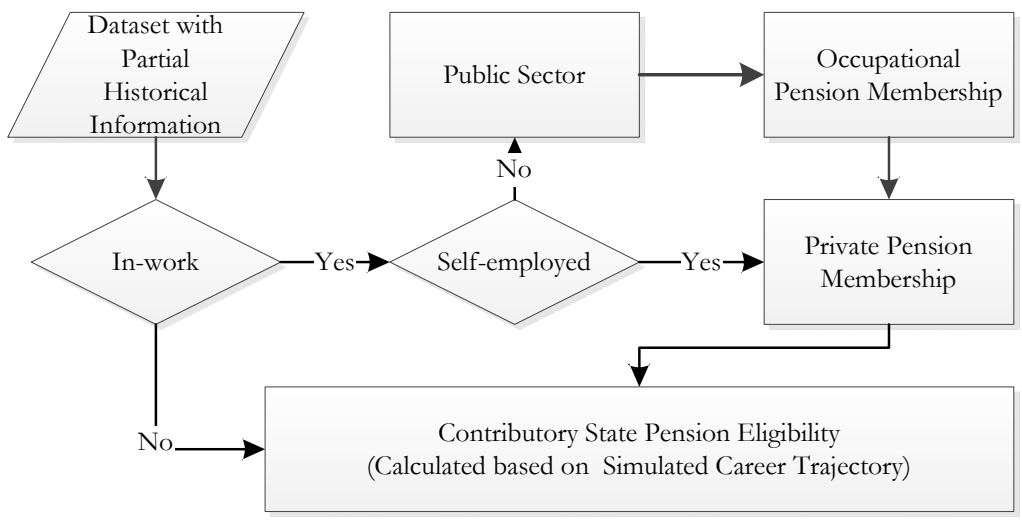

As discussed in the earlier section, the main goal of the back simulation model is to recreate a sensible history for all individuals in the dataset. Therefore, it is essential that the model output can replicate what actually happened. In an ideal world, the model output should be compared with the actual data to see how well the model performs. However, the lack of real historical data is the very reason that the back simulation is required. In addition, it is not feasible to compare the model with other back simulation approaches, e.g. statistical matching method, in this particular case, as synthetic history recreation is the only option due to the data limitation. Therefore, the results of the model are mainly compared with the known benchmarks: the census reports and the pension eligibilities. A success replication of this information would suggest the simulated historical profiles are sensible at both aggregate and individual level.

\subsubsection{In-work Ratio}

The evolution of the in-work ratio is reproduced in Figure 3.2 and Figure 3.3. As the graphs show, the male employment rate alters little over time except for a gradual fall of late career employment since the introduction of the retirement pension system in the 1970s. The female employment rate is $40 \%$ 50\% lower than the male employment rate throughout the simulated history. The simulation indicates that the female labour participation rate is much higher before the age of 35 than for other age groups. 
Figure 3.2 Simulated Historical In-Work Ratio for Male by Age

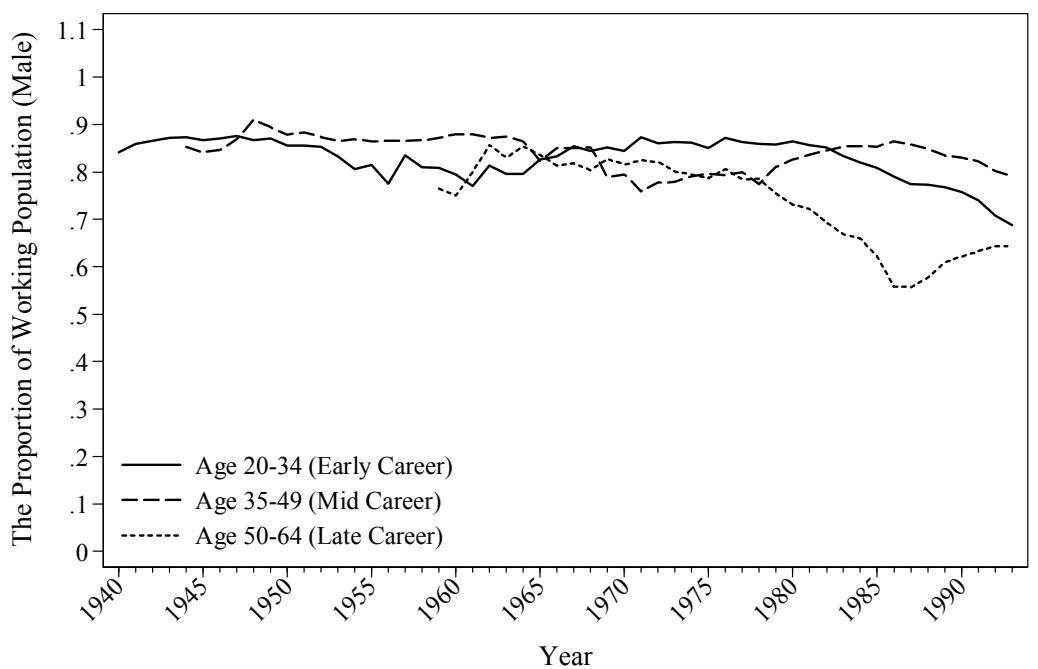

Figure 3.3 Simulated Historical In-Work Ratio for Female by Age

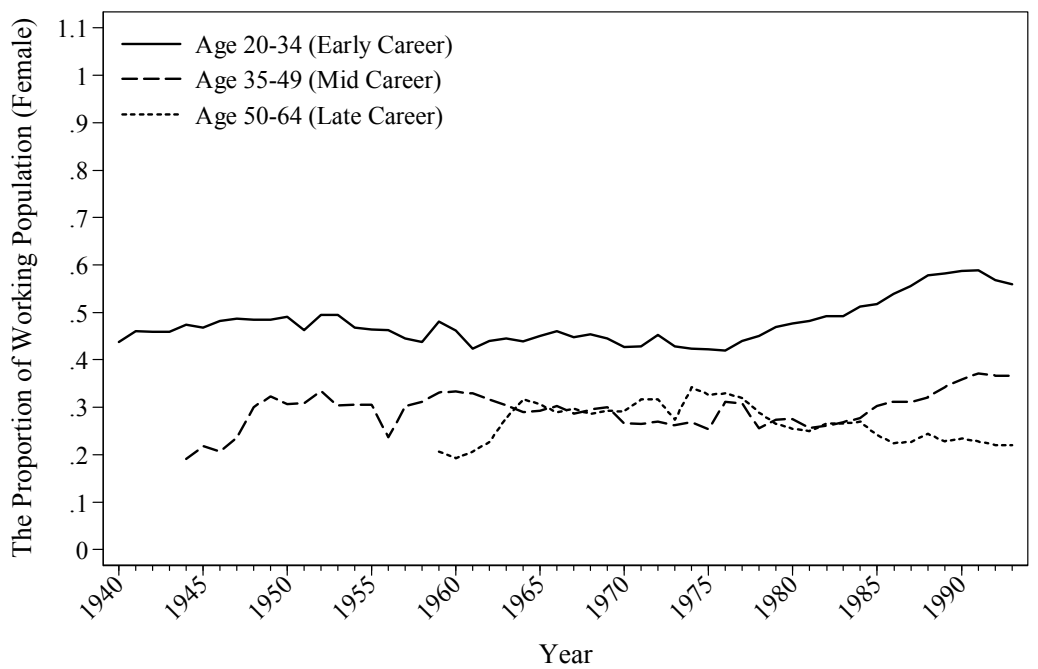

Figure 3.4 and Figure 3.5 further examine the simulated historical in-work proportion and offer a comparison with the census values to validate the simulation. As discussed earlier, the cross-sectionals in the simulated period are not population representative due to the missing values of deceased individuals. Therefore, census values were adjusted based on the 
sample's demographic features. In order to isolate the change of demographic composition, graphs are presented by cohorts.

Figure 3.4 Simulated Historical In-Work Ratio for Male by Cohorts

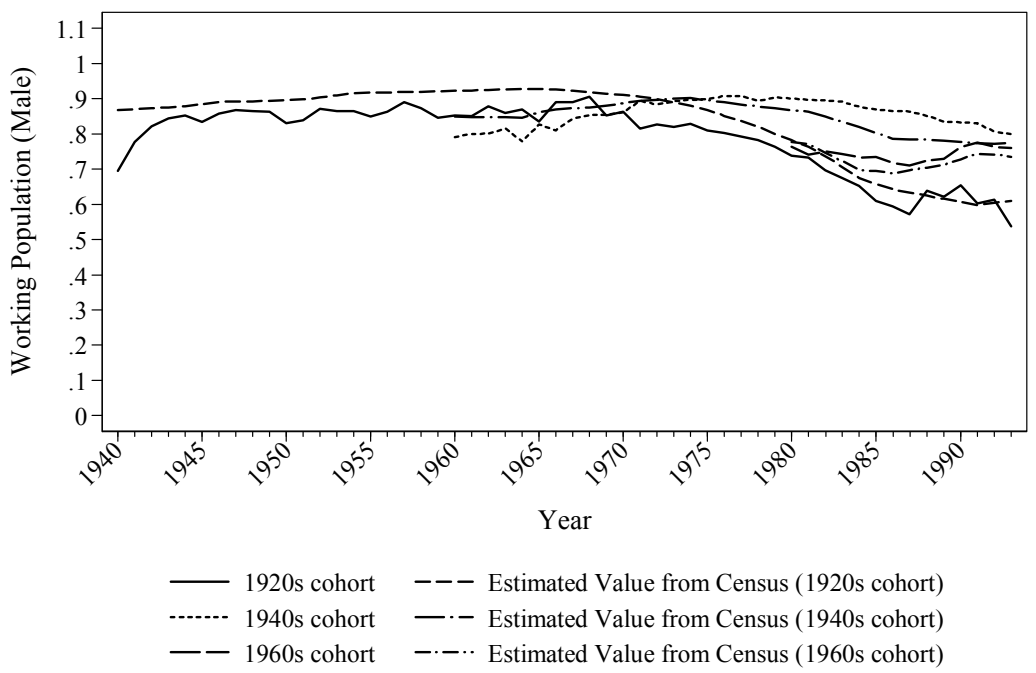

Figure 3.5 Simulated Historical In-Work Ratio for Female by Cohorts

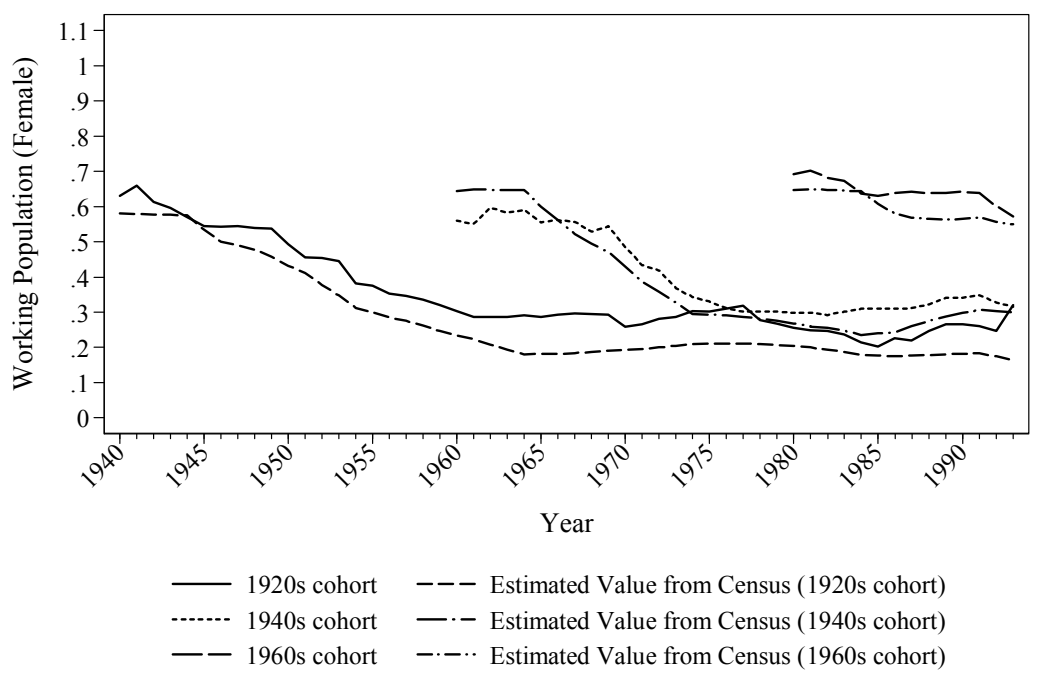


The figures confirm that the simulated values roughly match the estimations from the census data with a deviation of around 5 percentage points on average. The simulation seems to work better for later cohorts than the earlier ones, however this difference may partially be caused by the longitudinal alignment procedure where the adjustments may not be perfectly balanced, and the inconsistencies in retrospective variables, where the data quality declines as age increases. Nonetheless, it is safe to say that the simulated ratios move in the same direction as the census values.

The back simulation module not only aims at providing a reasonable profile at the crosssectional level, but also a historical trajectory that is consistent with retrospective variables. Figure 3.6 illustrates the difference between the simulated number of years in work and the reported values. As shown, the longitudinal inconsistency in the simulation is well controlled; in total, over $83 \%$ of the individuals were simulated with an error no greater than 1 year, and over $89 \%$ of the observations have a difference of less than 2 years. A few extreme cases are also spotted with an error greater than 10 years. These observations typically report no working history but with old age pension entitlement. In this case, the model overrides the report of zero working year in favour of the observed pension eligibilities.

On average, the absolute simulation errors for males are slightly larger than those for females. A possible reason is that males generally have longer career trajectories, which increase the computation complexity in balancing the cross-sectional and longitudinal alignments. The longer career trajectory also implies that the measurement error of the retrospective values like reported years of work might be bigger for males. As a result, the quality of the simulation could be negatively affected due to the inconsistent reported values.

\subsubsection{Employment Sectors and Self-employment}

Figure 3.7 and Figure 3.8 depict the historical evolution of public sector employment by age. As shown, there is a gradual growth of public sector workers for all age groups, a trend that is consistent for both males and females. However, the increase of females working in the public sector is faster compared with male workers, especially for workers in their early and mid-career stages. 
Figure 3.6 Difference between Simulated Years of Work and Reported Value

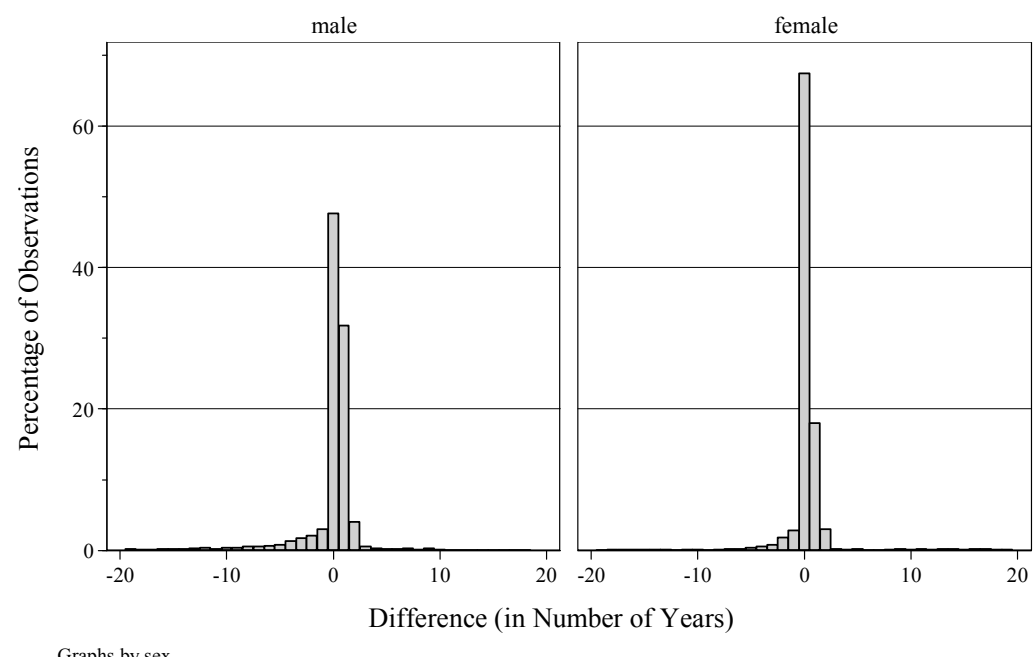

Figure 3.7 Simulated Public Sector Employment for Male

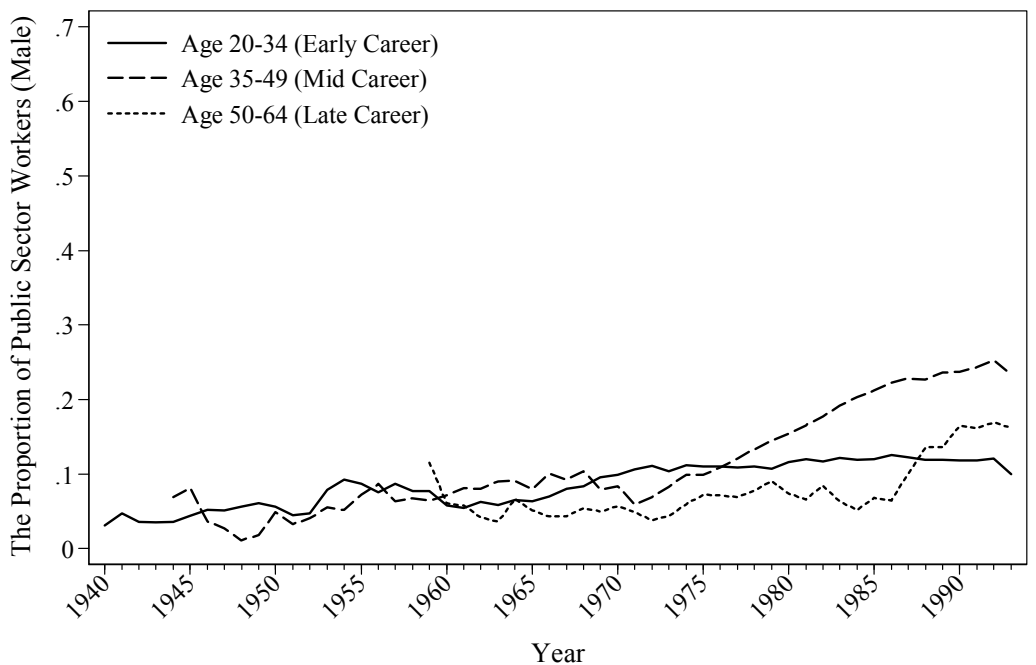


Figure 3.8 Simulated Public Sector Employment for Female

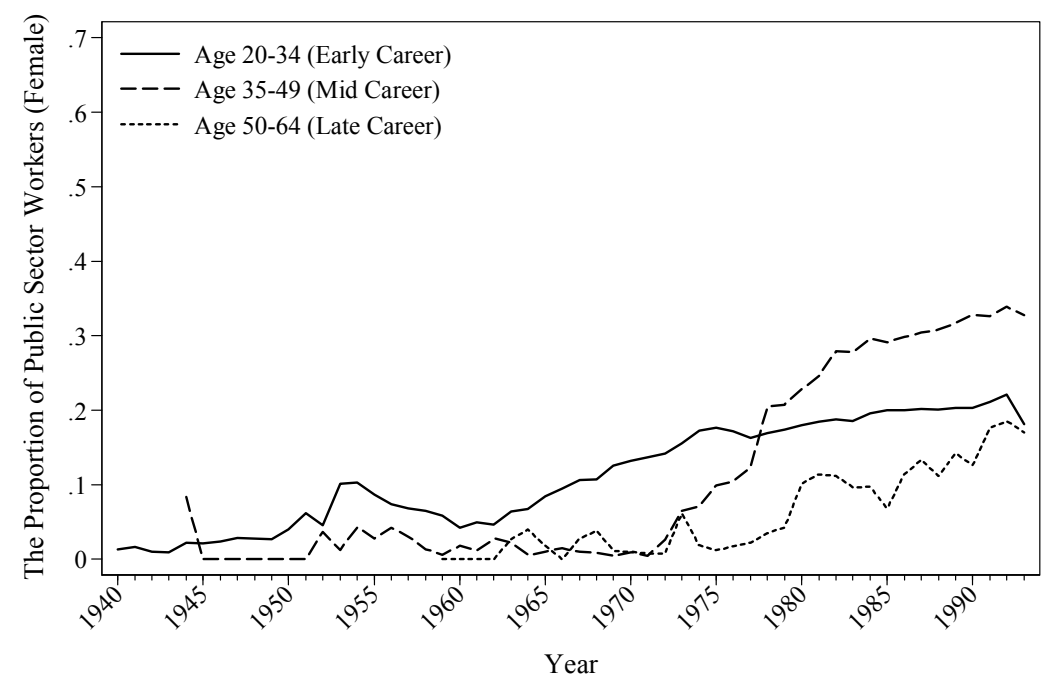

Regarding the self-employed, Figure 3.9 and Figure 3.10 reveal the different preferences amongst different age groups. From the graphs it can be seen that the self-employment rates increase dramatically for males above the age of 35 over time and this stabilises around $30 \%$, while the self-employment rate for males under 35 is just above $12 \%$ most of the time. The raise slope of the curve in the earlier part of the history may be contributed to by the limited number of observations for the age group. For females, the self-employment ratio is more or less stable within each age group except for a moderate decline for workers over 50 years old. Despite the drop, this late-career age group has a self-employment rate of around $30 \%$, which is more than 20 percentage points higher compared with other groups. The differences are mainly due to the dropped female labour participation at later ages. Since the average age of retirement for female employee is lower than the male counterparts, the proportion of the self-employed workers increases after age 50 . The graphs demonstrate that workers under the age of 35 have the least preference towards selfemployment, a preference which is observed in both the simulated histories and the original dataset. 
Figure 3.9 Simulated Male Self-Employed Ratio by Age

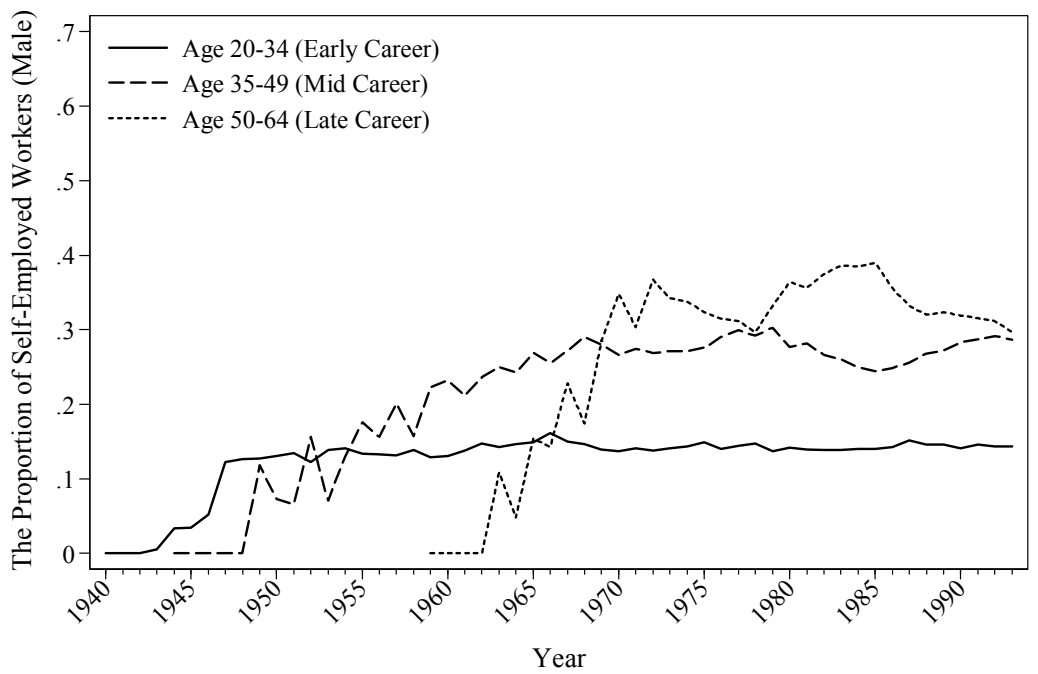

Figure 3.10 Simulated Female Self-Employed Ratio by Age

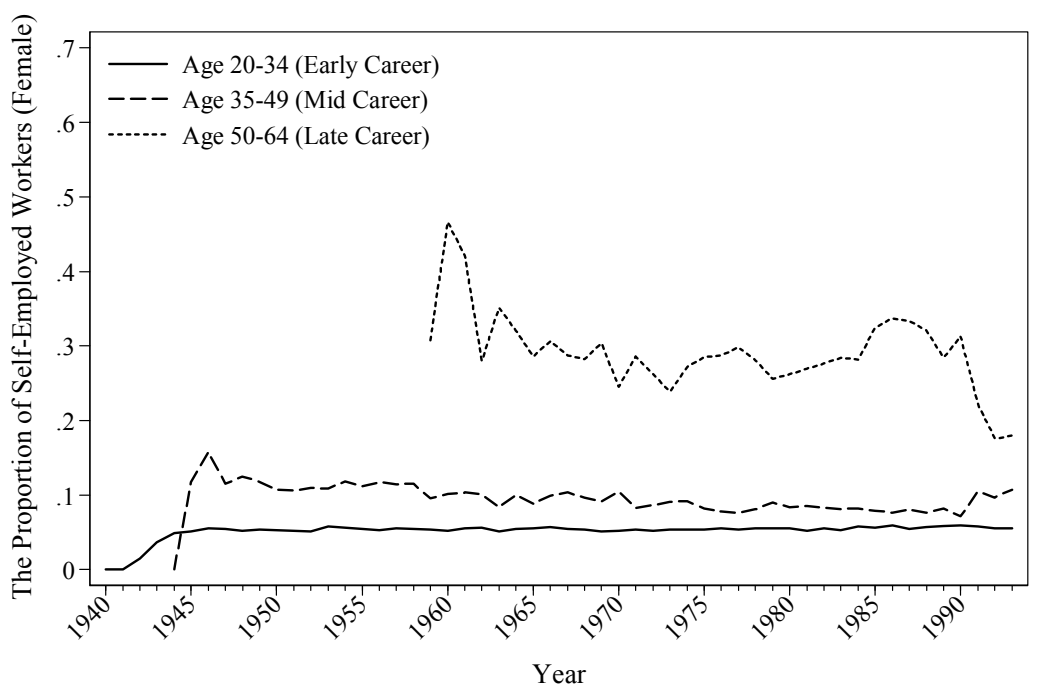




\subsection{Results II: Pension Memberships and Eligibilities}

According to Irish pension regulations, individuals retiring at the age of 65 or later are entitled to a retirement or old age social welfare pension (RP and OAP, respectively), which can either be contributory or means-tested. The state pension system consists of a social insurance pension introduced for those aged 70+ in 1961 and a retirement pension for those aged 65 introduced in 1970 (O'Donoghue, 2002). Individuals may be entitled to additional pensions depending on their jobs and personal choices. The back simulation module replicates the pension system by simulating each individual's participation in pension schemes and calculating their eligibility for a state pension once an individual retires.

\subsubsection{State Pension Eligibilities}

State pension eligibility is calculated from the simulated contribution history, which means that an output consistent with observed pension eligibility requires the complete working trajectory (employment status/type/sector) to be within a plausible and restricted range. Therefore, the consistency of pension eligibilities could be seen as an important indicator of overall simulation quality.

Table 3.7 lists the accuracies of different simulated pension eligibilities. Overall, the back simulation module developed in this paper is able to simulate the eligibility with an error of less than $5 \%$ for any pension type. This result is obtained after the longitudinal alignment procedure, which improved the accuracy of simulated eligibility by more than 25 percentage points in the exercise ${ }^{5}$.

Table 3.7 Percentage of correctly Simulated Eligibility

\begin{tabular}{lcc}
\hline Pension Type & Correctly Simulated & Number of Observations ${ }^{*}$ \\
\hline Contributory State Pension & $96.08 \%$ & 9343 \\
Occupational Pension & $98.25 \%$ & 10030 \\
Private Pension & $97.36 \%$ & 1706 (Year 2000 onwards) \\
\hline${ }^{*}$ Only those aged 66+ are included for state pension and those aged 65+ for occupational \\
and private pension
\end{tabular}

\footnotetext{
${ }^{5}$ The effectiveness of the longitudinal alignment is determined by a number of factors, which include the number of iterations used, the balancing parameters between the cross-sectional accuracy and the longitudinal consistency, models used in the back simulation, and stochastic terms. The number illustrated here only reflects the efficiency of one particular run that produces the back simulation results in this paper.
} 


\subsection{2}

Occupational and private pensions are simulated through well-specified logit models and the results are aligned with the information extracted from the QNHS and LII survey. Figure 3.11 describes the development of occupational pension membership by cohorts. It seems that later cohorts are more willing to participate in occupational pension schemes, which might imply an increase in the occupational pension coverage in Ireland over time, which in turn is consistent with the history of Irish pension reforms.

Figure 3.11 Occupational Pension Participation by Cohort

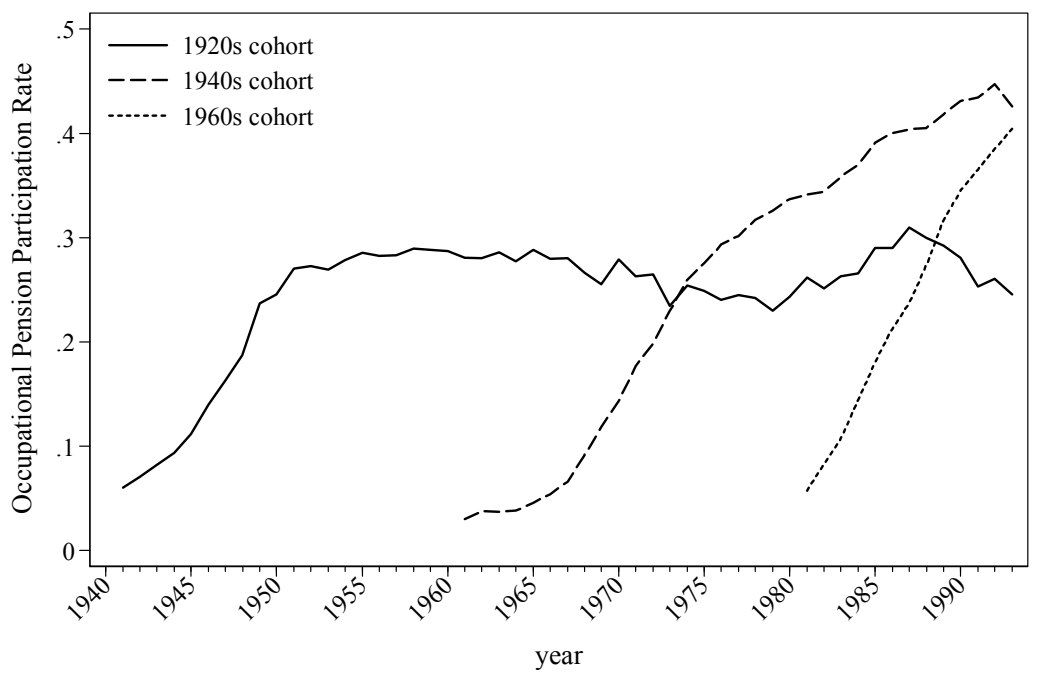

Analysing the trend for the cohort prospectively shows the dynamics of pension participation across time for the different cohort groups. Nonetheless, it does not reveal the dynamics of age preference, which is tightly linked with career development. Figure 3.12 discloses the shift of preference of same age groups across time. As suggested, midcareer individuals appear to be participating more actively then those in other groups. It seems that the age group closest to retirement has the lowest participation rate, which

\footnotetext{
${ }^{6}$ Using contemporary data for alignment might lead to overestimated pension participations. A better solution would involve gathering historical data and using it together with pension income, which could then potentially reveal the length of contributions. However, such an improved alignment is not possible in the current model given the availability of data.
} 
could due to the differences in career trajectories, availability of the pension options for this cohort and other reasons.

Figure 3.12 Occupational Pension Participation by Age Group

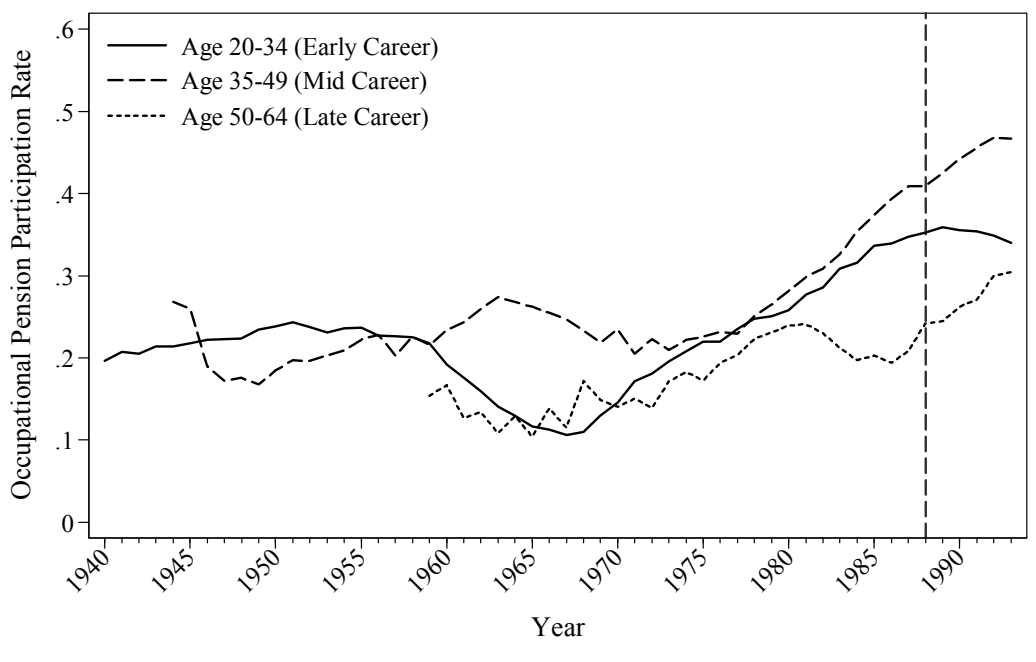

1988 is the year when the last major state pension reform took place during the simulated time period

\subsection{Results III: Income Variables}

In addition to employment statuses, the back simulation module also provides monetary income histories for all individuals. Labour earnings are simulated using the models mentioned in section 4, while other non-labour income is assumed stable over time as they do not affect pension memberships. Figure 3.13 and Figure 3.14 demonstrate the dynamics of the average labour income over lifetime in this back simulation by analysing the earnings of three different cohorts. The average earning curve, as shown by the earlier cohorts, has the distinctive shape of a quadratic function, which matches the expectation of classic human capital theory. Female earnings seem to have a more flat mid-career profile, which may be due to the career interruption caused by maternity leave.

Figure 3.15 and Figure 3.16 give an overview of the evolution of earnings across the different age groups. As can be seen, average earnings increase steadily due to the increasing level of education. This is also confirmed by the cohort graphs shown earlier, where the younger cohorts demonstrate higher peak values. Male earnings are substantially different depending on the stage of their career. The average earnings by age 50 or above can be more than $50 \%$ higher compared to a male aged $20-35$, but the difference is a lot smaller for female workers. 
Figure 3.13 Average Male Earnings $(£)$ by Cohort

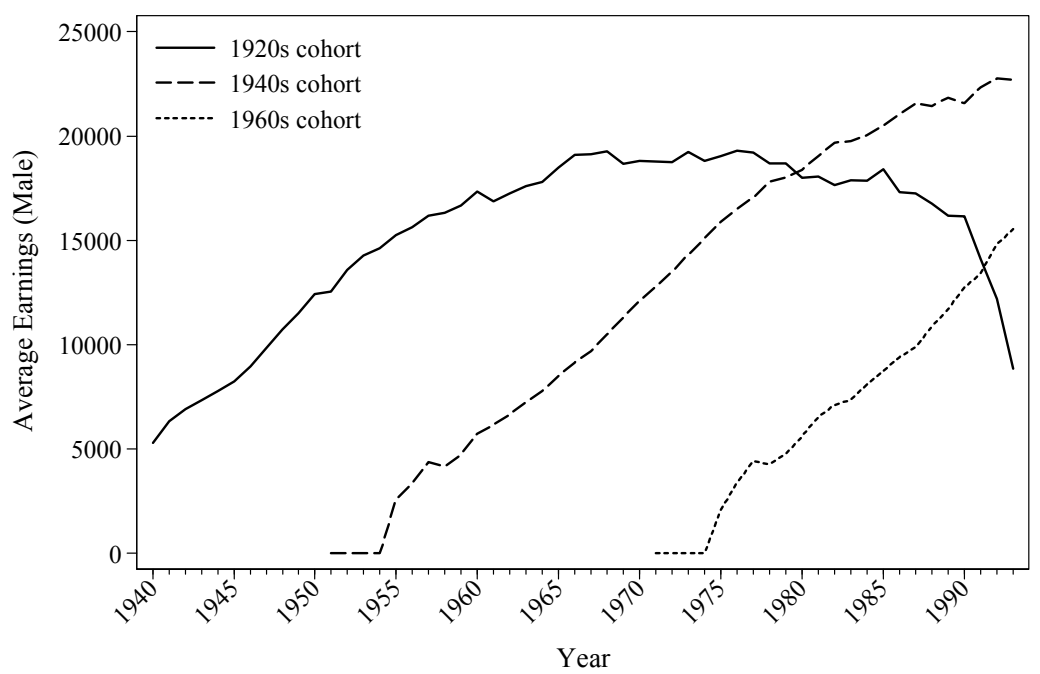

Figure 3.14 Average Female Earnings $(£)$ by Cohort

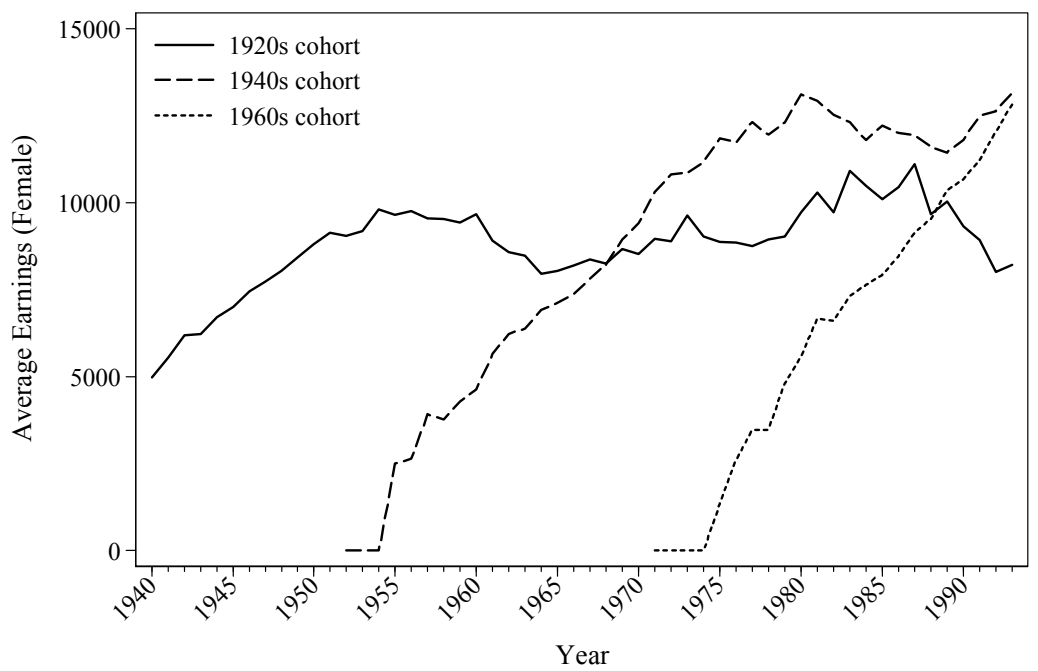


Figure 3.15 Average Male Earnings $(£)$ by Age

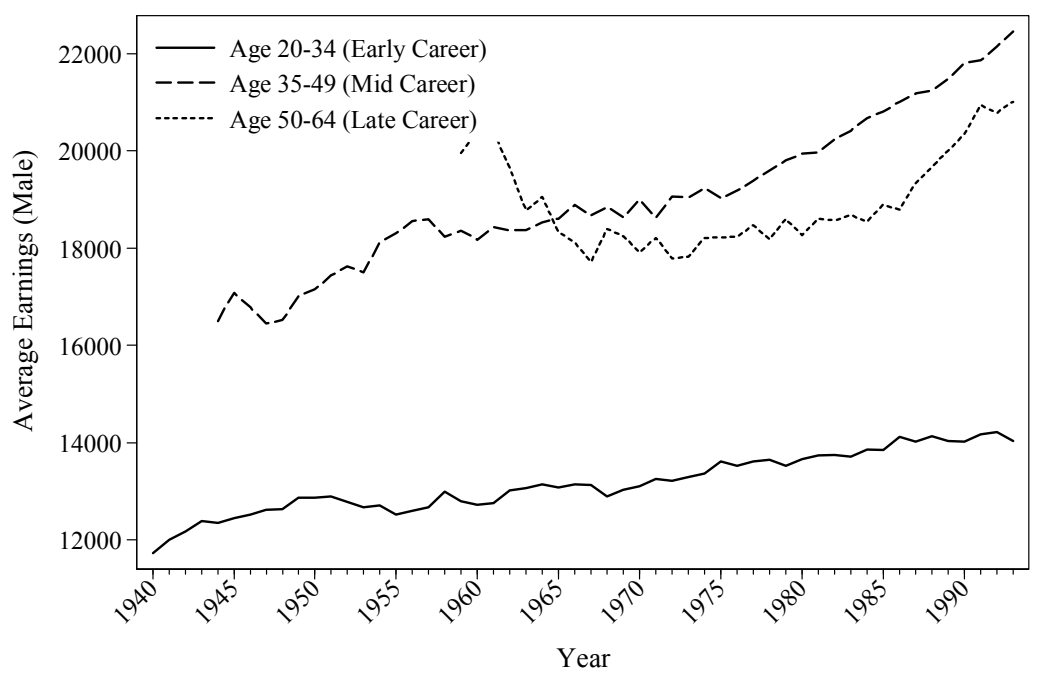

Figure 3.16 Average Female Earnings $(£)$ by Age

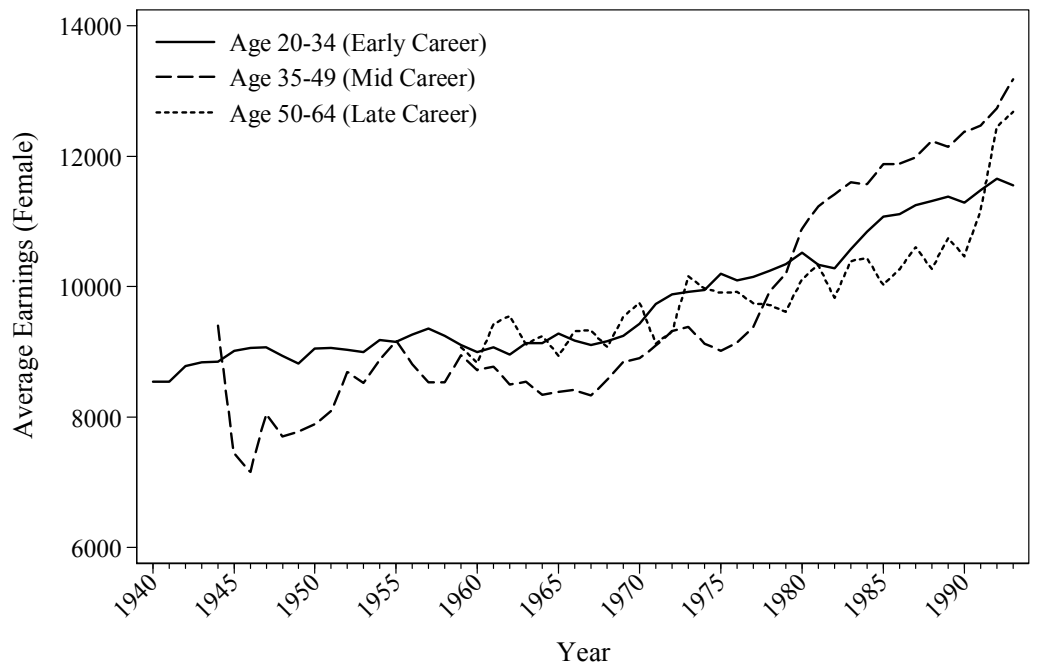

\subsection{Conclusions}

As discussed above, the preparation of the base dataset is one of the most important elements in every dynamic microsimulation model. However, finding a long historical 
panel dataset with all the necessary variables is often infeasible. This paper develops an algorithm to simulate a historical panel for the LII dataset to fill in the missing history.

The back simulation module extracts retrospective information from the LII survey and applies a dynamic microsimulation in a reversed direction to simulate population histories. Due to the nature of historical simulation, the longitudinal consistency requirement is high and difficult to achieve when compared with a forward dynamic microsimulation. The method proposed in this paper solves this problem by introducing extra calibrations and alignments at both the cross-sectional and longitudinal levels. The overall result of the simulated panel, as described in the earlier sections, matches the labour market history to a fairly high degree based on the macro statistics calculated. The simulated values follow the observed trend quite closely, and are able to pick up the dynamics of different types of pension eligibility across time and cohorts. Nevertheless, further validation of the longterm trajectories of the employment and earnings produced by the model might be necessary, although there is little reliable data to compare the results with for the earlier half of 20 th century.

The back simulation method could potentially offer many benefits for microsimulation modellers. By expanding the longitudinal information while maintaining consistencies with a panel dataset with limited waves, it offers a viable alternative to the dilemma of base dataset choice as described by Cassells et al. (2006) and Zaidi and Scott (2001). The generated historical panel could consequently enhance the accuracy and stability of the forward dynamic simulation by feeding in information on career trajectory. Given the extensive retrospective information modelled, the back simulated panel has a much higher data quality than a simple synthetic panel. Since only standardized survey questions and macro statistics are used in the simulation, this proposed back simulation method could be potentially replicated in other datasets that include retrospective questions, e.g. ECHP, BHPS, German Socio-Economic Panel (GSOEP), FFS. The method could help modellers to run a life-cycle based simulation without using a scarce long panel. In addition, the historical panel provides many important insights, e.g. the dynamics of career trajectories, which would otherwise be easily overlooked in the original dataset.

The exploration of a back simulation method as described in this paper is still in its early stages and the current algorithm could be further improved. Future work is planned to improve the following aspects of the back simulation model:

- Simulation of the deceased cohort of the population in order to align historical statistics more accurately, as the current version does not generate a representative historical population.

- Develop an improved algorithm for the cross-sectional/longitudinal alignment to alleviate the impact of inaccurate responses for retrospective questions. 
- Understand the robustness of the model and the standard errors of the results. Further analysing the variations in the model would enhance the credibility of the model, especially when stochastic components are used.

In spite of the shortcomings inherent in the current version of this model, this paper shows that reconstructing historical information is feasible based on standard household survey dataset and census information, providing there is some retrospective information in the dataset that can be used for modelling. From a practical point of view, the simulated panel is the only available historical panel dataset for Ireland, which offers the possibilities of investigating life-cycle income profiles together with a dynamic microsimulation model. 


\subsection{References}

Bardaji, J., B. Sédillot and E. Walraet., 2003. Un outil de prospective des retraites: le modèle de microsimulation Destinie, Économie et prévision pp. 193-214.

Caldwell, Stephen B. 1997. CORSIM 3.0 User and Technical Documentation. Ithaca, NY: Cornell University.

Cassells, R., A. Harding and S. Kelly., 2006. "Problems and Prospects for Dynamic Microsimulation: A Review and lessons for APPSIM": NATSEM Discussion Paper.

Chénard, D., 2000a. Earnings in DYNACAN: distribution alignment methodology, DYNACAN Project Document.

Chénard, D., 2000b. Individual alignment and group processing: an application to migration processes in DYNACAN, OCCASIONAL PAPERS-UNIVERSITY OF CAMBRIDGE DEPARTMENT OF APPLIED ECONOMICS pp. 238-250.

Curry, C., 1996. "PENSIM: A Dynamic Simulation Model of Pensioners' Income " in Government Economic Service Working Paper No. 129, London: Analytical Services Division, Department of Social Security.

Duncan, A. and M. Weeks., 2000. "Simulating Transitions Using Discrete Choice Models" in Microsimulation Modelling for Policy Analysis: Challenges and Innovations by L. Mitton, H. Sutherland and M. Weeks Ed., Cambridge: Cambridge University Press.

Emmerson, C., H. Reed and A. Shephard., 2004. An assessment of PenSim2.

Evandrou, M. 2004, Imputing pension and caring histories to the base data in the SAGE dynamic microsimulation model, SAGE Technical Note No 8.

Favreault, M., 2004. A Primer on the Dynamic Simulation of Income Model (DYNASIM3)

Figari, F., H. Levy and H. Sutherland., 2007. Using The Eu Silc For Policy Simulation: Prospects, Some Limitations And Suggestions, EUROMOD Working Papers.

Flood, L., 2007. Can we Afford the Future? An evaluation of the new Swedish pension system, Modelling our future: population ageing, social security and taxation pp. 33 .

Fredriksen, D., 2003. "The MOSART model-a short technical documentation".

Harding, A., 2007. Challenges and Opportunities of Dynamic Microsimulation Modelling

King, A., H. Bækgaard and M. Robinson., 1999. DYNAMOD-2: An overview, Technical Paper, Vol. 19.

Mantovani, D., F. Papadopoulos, H. Sutherland and P. Tsakloglou., 2007. Pension incomes in the European Union: policy reform strategies in comparative perspective, Micro-simulation in action: policy analysis in Europe using EUROMOD pp. 27.

Mincer, J. and B. Jovanovic., 1981. Labor mobility and wages, Studies in Labor Markets pp. 21-64.

Morrison, R., 1997., "DYNACAN, the Canadian pension plan policy model: demographic and earnings components", Proceedings of the Microsimulation Section at the International Conference on Information Theory, Combinatorics, and Statistics, Portland, Maine, July 1997.

Morrison, R., 1998, “Overview of DYNACAN, a full-fledged Canadian actuarial stochastic model designed for the fiscal and policy analysis of social security schemes"

Mundlak, Y., 1978. On the pooling of time series and cross section data, Econometrica, Vol. 46 pp. 69-85. 
O’Donoghue, C., 2001. Dynamic microsimulation: a methodological survey, Brazilian Electronic Journal of Economics, Vol. 4 pp. 77.

O'Donoghue, C., 2002. Redistribution in the Irish tax benefit system, University of London.

O’Donoghue, C., J. Lennon and S. Hynes., 2009. The Life-Cycle Income Analysis Model (LIAM) : A Study of a Flexible Dynamic Microsimulation Modelling Computing Framework, International Journal of Microsimulation $\operatorname{Vol} 2(1)$

O’Donoghue, C., 2010. Life-Cycle Income Analysis Modelling - 2010 Lambert Academic Publishing AG \& CO.KG

Zaidi, A., 2004. Estimation of earnings in the SAGE dynamic microsimulation model: London, ESRC-Sage Technical Note.

Zaidi, A. and A. Scott., 2001. "Base dataset for the SAGE model": Sage Technical Note. 


\subsection{Appendices}

Appendix 3.A: Steps of Back Simulation

1. Estimate models

a. Employment (in-work/out-of-work) model

b. Self-employed model

2. Impute social economic status variables for each year in the original dataset (19942001)

a. Impute the number of years in education, employment, sickness, home care duties and retirement using regression in 1994 by sex group

b. Update these variables to 1995-2001

c. Consistency check for major social economic variables during the years 19942001

3. Generate historical data using known information

a. Demographic information (e.g. year of birth)

b. Maternity information (based on child age)

c. Job information (e.g. year of starting first job, last job, total number of years worked etc.)

d. Pension information (e.g. total pension contribution, pension entitlements)

e. Others (e.g. school, geographic information)

4. Deterministic back simulation (in/out work)

a. Create age information

b. Infer working status from retrospective variables

i. Must be out of work before year of starting work

ii. Must be in work in the year of starting work

iii. Must be in work since the current job started

iv. Must be in work in the year of quitting previous job

v. Must be unemployed since current unemployment started

5. Semi-stochastic back simulation

a. Assuming a 75\% chance that a woman will be "out of work" in the year of giving birth to a child

b. State pensioners must start work before the age of 56

c. "Back to work" beneficiaries must have been unemployed for 2 years

6. Fill the gap of unallocated working status for history using stochastic simulation

a. Replace the unknown working status to "in work" if the number of known working years is lower than the total work years 
i. Error term is stochastic. The ranking is based on the sum of the error terms and the personal effect in the model

ii. The status is aligned with census data by interacting with the ranking

b. Impute the working status if there is still a gap between the reported number of years in work and the simulated years of in work

c. Set the rest of the employment statuses to "not in work" if the simulated number of years in work is consistent with the reported values

d. Adjust any differences

7. Simulate/Generate the variables that LIAM will use

a. Demographic information (age, alive, maternity)

b. Education information (based on the age of leaving full time education)

c. Marriage information

i. Calculate the year in which an individual married

ii. Assume that an individual married at age 25 if there is no other information available

d. Prepare employment information

i. Self-employment

1. Estimate the probability of being self-employed (1994-2001)

2. Read the historical values of self-employment and smooth the curve using moving average method

3. Use the stochastic term and personal effect to predict the probability of self- employment, align data with estimates.

ii. Public sector

1. Assume that people stick with the same sector as reported in 1994

2. Do not allow for small gaps in public sector employment

3. Store alignment data by sex education and cohort

4. Use stochastic term and personal effect to predict the probability of staying within the public sector, and align the data using saved values

iii. Final adjustments to smooth labour participation history

8. Calculation for pay related social insurance (PRSI) pension entitlement

a. Create a variable for the contributory class in the PRSI system for state pensions

i. Public servants are treated as employees if they joined the job after 1995

ii. Public servant pensions are eligible for those who joined the work before 1995

b. Calculate the eligibility for a PRSI pension for the rest

i. $\quad$ Self-employed are assumed to only be insured after 1988

ii. Public sector are assumed to only be insured after 1995

iii. Calculate the pension credit 


\section{Longitudinal Alignment}

a. Compare simulated PRSI pension entitlement with the actual entitlement

b. Modify the history while keeping the cross-sectional alignment of the labour market participation, self-employed and pension coverage ratio stable

c. Repeat the above procedure several times until the consistency is satisfactory

10. Simulate earnings (for employees and self-employed)

a. Estimate the wage model (random effect model)

b. Record the standard deviation of random effects and the error term

c. Simulate the wage for each group with a stochastic term that shares the standard deviation of estimated random effects

d. Align the average earnings by sex, education level and age group to the year 2000 values

11. Simulate occupational pension membership using the equation estimated using the 1994-2001 data and calibrated using the QNHS samples.

a. Calculate the probability of receiving an occupational pension, employee personal pension and self-employed personal pension for each age and sex group

b. Estimate the occupational/self-employed/personal pension model using existing data

c. Align it with the probability breakdown calculated from the QHNS sample for both the existing dataset (LII) values and the simulated historical values

d. Correction for the unlikely event of an inconsistency between the occupational pension status and the employment status

e. Final adjustment and alignment

12. Calculate the value of the DC Occupational pension fund

a. Model contribution in a similar manner as wages and align with observed contribution rate (split into two rates, pre-1995 and post-1995)

b. Calculate the pension fund value from the 1930s using assumed interest rates

c. Calculate the contributions for each pension type 


\begin{tabular}{|c|c|c|c|c|}
\hline \multirow{3}{*}{ Variables } & \multicolumn{4}{|c|}{ Equations } \\
\hline & \multicolumn{2}{|c|}{$\begin{array}{l}\text { Years in full-time } \\
\text { education or training }\end{array}$} & \multicolumn{2}{|c|}{$\begin{array}{l}\text { Years in employment, } \\
\text { self-employment or } \\
\text { farming }\end{array}$} \\
\hline & Coefficient & s.e. & coefficient & s.e. \\
\hline College Education & 4.22 & 0.07 & -3.43 & 0.21 \\
\hline Secondary Education & 2.17 & 0.07 & -1.66 & 0.21 \\
\hline Age & 0.00 & 0.02 & 0.36 & 0.05 \\
\hline Is Working & -1.02 & 0.13 & 7.37 & 0.37 \\
\hline Illness & 0.16 & 0.14 & -1.99 & 0.42 \\
\hline In education & -0.89 & 0.14 & 2.85 & 0.41 \\
\hline Unemployed & -1.28 & 0.14 & 1.03 & 0.40 \\
\hline Retired & -1.05 & 0.17 & 4.30 & 0.51 \\
\hline Number of Children under Age 3 & -0.06 & 0.06 & 0.16 & 0.19 \\
\hline Number of Children between Age 4 and 11 & -0.10 & 0.03 & 0.09 & 0.10 \\
\hline Number of Children between Age 12 and 15 & -0.09 & 0.04 & 0.06 & 0.12 \\
\hline Cohort Dummies & Yes & Yes & Yes & Yes \\
\hline Number of Observations & \multicolumn{2}{|c|}{5738} & \multicolumn{2}{|c|}{5738} \\
\hline Adjusted R-square & \multicolumn{2}{|c|}{0.48} & \multicolumn{2}{|c|}{0.90} \\
\hline
\end{tabular}

\begin{tabular}{|c|c|c|c|c|}
\hline \multirow{3}{*}{ Variables } & \multicolumn{4}{|c|}{ Equations } \\
\hline & \multicolumn{2}{|c|}{$\begin{array}{c}\text { Years in } \\
\text { unemployment }\end{array}$} & \multicolumn{2}{|c|}{ Years of illness/disablec } \\
\hline & coefficient & s.e. & coefficient & s.e. \\
\hline College Education & -1.05 & 0.11 & $\begin{array}{l}-0.02 \\
\end{array}$ & 0.10 \\
\hline Secondary Education & -0.79 & 0.11 & -0.03 & 0.10 \\
\hline Age & -0.01 & 0.02 & 0.05 & 0.02 \\
\hline Is Working & -0.04 & 0.19 & -0.80 & 0.18 \\
\hline Illness & -1.33 & 0.21 & 3.78 & 0.20 \\
\hline In education & 0.61 & 0.21 & -0.23 & 0.20 \\
\hline Unemployed & 3.91 & 0.21 & 1.17 & 0.19 \\
\hline Retired & 1.01 & 0.26 & -1.46 & 0.24 \\
\hline Number of Children under Age 3 & -0.03 & 0.10 & 0.07 & 0.09 \\
\hline Number of Children between Age 4 and 11 & 0.06 & 0.05 & -0.04 & 0.05 \\
\hline Number of Children between Age 12 and 15 & 0.10 & 0.06 & -0.13 & 0.06 \\
\hline Cohort Dummies & Yes & Yes & Yes & Yes \\
\hline Number of Observations & \multicolumn{2}{|c|}{5738} & \multicolumn{2}{|c|}{5738} \\
\hline Adjusted R-square & \multicolumn{2}{|c|}{0.23} & \multicolumn{2}{|c|}{0.15} \\
\hline
\end{tabular}




\begin{tabular}{|c|c|c|c|c|}
\hline \multirow{3}{*}{ Variables } & \multicolumn{4}{|c|}{ Equations } \\
\hline & \multicolumn{2}{|c|}{$\begin{array}{c}\text { Years spent on home } \\
\text { duties }\end{array}$} & \multicolumn{2}{|c|}{ Years in retirement } \\
\hline & coefficient & s.e. & coefficient & s.e. \\
\hline College Education & 0.43 & 0.12 & 0.00 & 0.07 \\
\hline Secondary Education & 0.40 & 0.12 & -0.01 & 0.07 \\
\hline Age & -0.12 & 0.03 & 0.03 & 0.02 \\
\hline Is Working & -2.35 & 0.21 & -0.25 & 0.12 \\
\hline Illness & 0.62 & 0.24 & -0.05 & 0.13 \\
\hline In education & -2.20 & 0.24 & -0.22 & 0.13 \\
\hline Unemployed & -2.28 & 0.23 & -0.20 & 0.13 \\
\hline Retired & -2.42 & 0.29 & 5.65 & 0.16 \\
\hline Number of Children under Age 3 & 0.20 & 0.11 & -0.01 & 0.06 \\
\hline Number of Children between Age 4 and 11 & -0.06 & 0.06 & -0.03 & 0.03 \\
\hline Number of Children between Age 12 and 15 & 0.04 & 0.07 & -0.02 & 0.04 \\
\hline Cohort Dummies & Yes & Yes & Yes & Yes \\
\hline Number of Observations & \multicolumn{2}{|c|}{5738} & \multicolumn{2}{|c|}{5738} \\
\hline Adjusted R-square & \multicolumn{2}{|c|}{0.03} & \multicolumn{2}{|c|}{0.74} \\
\hline
\end{tabular}




\begin{tabular}{|c|c|c|c|c|}
\hline \multirow{3}{*}{ Variables } & \multicolumn{4}{|c|}{ Equations } \\
\hline & \multicolumn{2}{|c|}{$\begin{array}{l}\text { Years in full-time } \\
\text { education or training }\end{array}$} & \multicolumn{2}{|c|}{$\begin{array}{l}\text { Years in employment, } \\
\text { self-employment or } \\
\text { farming }\end{array}$} \\
\hline & coefficient & s.e. & coefficient & s.e. \\
\hline College Education & 3.47 & 0.07 & -0.54 & 0.29 \\
\hline Secondary Education & 2.01 & 0.06 & -0.06 & 0.26 \\
\hline Age & 0.02 & 0.01 & 0.05 & 0.06 \\
\hline Is Working & 0.34 & 0.06 & 8.34 & 0.28 \\
\hline Illness & -0.32 & 0.12 & 0.06 & 0.53 \\
\hline In education & 0.21 & 0.11 & 2.79 & 0.48 \\
\hline Unemployed & 0.96 & 0.13 & 4.00 & 0.55 \\
\hline Retired & 0.53 & 0.13 & 26.78 & 0.59 \\
\hline Number of Children under Age 3 & -0.07 & 0.05 & 1.26 & 0.23 \\
\hline Number of Children between Age 4 and 11 & -0.03 & 0.03 & 0.27 & 0.13 \\
\hline Number of Children between Age 12 and 15 & -0.06 & 0.04 & -0.75 & 0.16 \\
\hline Cohort Dummies & Yes & Yes & Yes & Yes \\
\hline Number of Observations & & & 57 & \\
\hline Adjusted R-square & & & 0.5 & \\
\hline \multirow{3}{*}{ Variables } & \multicolumn{4}{|c|}{ Equations } \\
\hline & \multicolumn{2}{|c|}{ Years in unemployment } & \multicolumn{2}{|c|}{$\begin{array}{c}\text { Years of } \\
\text { illness/disabled }\end{array}$} \\
\hline & coefficient & s.e. & coefficient & s.e. \\
\hline College Education & -0.37 & 0.06 & -0.25 & 0.09 \\
\hline Secondary Education & -0.30 & 0.05 & -0.26 & 0.08 \\
\hline Age & 0.01 & 0.01 & -0.03 & 0.02 \\
\hline Is Working & 0.18 & 0.06 & -0.26 & 0.09 \\
\hline Illness & -0.20 & 0.11 & 2.55 & 0.17 \\
\hline In education & 0.16 & 0.10 & -0.10 & 0.15 \\
\hline Unemployed & 1.74 & 0.12 & 0.30 & 0.17 \\
\hline Retired & 0.65 & 0.12 & 0.27 & 0.19 \\
\hline Number of Children under Age 3 & 0.03 & 0.05 & -0.02 & 0.07 \\
\hline Number of Children between Age 4 and 11 & -0.03 & 0.03 & -0.11 & 0.04 \\
\hline Number of Children between Age 12 and 15 & 0.00 & 0.03 & -0.24 & 0.05 \\
\hline Cohort Dummies & Yes & Yes & Yes & Yes \\
\hline Number of Observations & \multicolumn{2}{|c|}{5725} & \multicolumn{2}{|c|}{5725} \\
\hline Adjusted R-square & \multicolumn{2}{|c|}{0.06} & \multicolumn{2}{|c|}{0.05} \\
\hline
\end{tabular}




\begin{tabular}{|c|c|c|c|c|}
\hline \multirow{3}{*}{ Variables } & \multicolumn{4}{|c|}{ Equations } \\
\hline & \multicolumn{2}{|c|}{$\begin{array}{c}\text { Years spent on home } \\
\text { duties }\end{array}$} & \multicolumn{2}{|c|}{ Years in retirement } \\
\hline & coefficient & s.e. & coefficient & s.e. \\
\hline College Education & -1.87 & 0.34 & -0.10 & 0.07 \\
\hline Secondary Education & -1.03 & 0.30 & -0.04 & 0.06 \\
\hline Age & 0.22 & 0.07 & 0.03 & 0.02 \\
\hline Is Working & -8.58 & 0.32 & 0.01 & 0.07 \\
\hline Illness & -1.65 & 0.62 & 0.05 & 0.13 \\
\hline In education & -5.04 & 0.56 & -0.01 & 0.12 \\
\hline Unemployed & -7.31 & 0.64 & -0.02 & 0.13 \\
\hline Retired & -34.35 & 0.69 & 8.96 & 0.14 \\
\hline Number of Children under Age 3 & -0.66 & 0.27 & -0.03 & 0.06 \\
\hline Number of Children between Age 4 and 11 & -0.03 & 0.15 & 0.03 & 0.03 \\
\hline Number of Children between Age 12 and 15 & 0.42 & 0.18 & -0.05 & 0.04 \\
\hline Cohort Dummies & Yes & Yes & Yes & Yes \\
\hline Number of Observations & \multicolumn{2}{|c|}{5725} & \multicolumn{2}{|c|}{5725} \\
\hline Adjusted R-square & \multicolumn{2}{|c|}{0.75} & \multicolumn{2}{|c|}{0.46} \\
\hline
\end{tabular}


Appendix 3.D: Estimates for Earnings

\begin{tabular}{l|ccc}
\hline \multicolumn{1}{c|}{ Variables } & $\begin{array}{c}\text { Male Employee } \\
\text { Earnings }\end{array}$ & $\begin{array}{c}\text { Female Employee } \\
\text { Earnings }\end{array}$ & $\begin{array}{c}\text { Self-employment } \\
\text { Earnings }\end{array}$ \\
\hline College Education & 0.56 & 0.81 & 0.72 \\
Secondary Education & $(0.03)$ & $(0.03)$ & $(0.06)$ \\
& 0.31 & 0.49 & 0.31 \\
Work Experience (Years) & $(0.03)$ & $(0.03)$ & $(0.06)$ \\
& 0.09 & 0.05 & 0.03 \\
Work Experience (Squared) & $(0.00)$ & $(0.00)$ & $(0.00)$ \\
& 0.00 & 0.00 & 0.00 \\
Years of Unemployment) & $(0.00)$ & $(0.00)$ & $(0.00)$ \\
& 0.04 & 0.01 & 0.01 \\
Gender (Male=1) & $(0.00)$ & $(0.00)$ & $(0.00)$ \\
& & & 0.44 \\
Total Number of Observation & 13678 & 10231 & $(0.06)$ \\
\hline
\end{tabular}

(standard errors are reported in parentheses) 


\section{[4] An Evaluation of Binary Alignment Methods in Microsimulation Models ${ }^{7}$}

\footnotetext{
${ }^{7}$ An earlier version of this chapter is available as: Li, J. and O’Donoghue C. 2011, Evaluating Alignment Methods in Dynamic Microsimulation Models, International Microsimulation Association Conference 2011 Paper

Acknowledgement: The authors are grateful to Rick Morrison, Howard Redway and Steven Caldwell for helpful discussions over time in relation to alignment in microsimulation models.
} 


\subsection{Introduction}

Microsimulation is a technique used to model complex real life events by simulating the actions and impact of policy change on the individual micro unit (Harding, 2007). Microsimulation models are usually categorised as either "static" or "dynamic". Static models, e.g. EUROMOD (Mantovani et al., 2007), are often arithmetic models that evaluate the immediate distributional impact upon individuals/households of possible policy changes, whereas dynamic models, e.g. DESTINIE, PENSIM, SESIM (Bardaji et al., 2003; Curry, 1996; Flood, 2007), extend the static model by allowing the individuals to change their characteristics as a result of endogenous factors within the model (O’Donoghue, 2001). Using this method, it is possible to generate new simulated populations that can be used for policy and scenario analysis.

Dynamic microsimulation models typically simulate behavioural processes such as demographics (e.g. marriage), the labour market (e.g. unemployment) and income characteristics (e.g. wages). This method uses statistical estimates for a system of equations and then applies Monte Carlo simulation techniques to generate new populations, typically over time, both into the future and when creating histories with partial data, into the past.

As statistical models are typically estimated on historical datasets with specific characteristics and period effects, projections of the future may therefore contain errors or may not correspond to exogenous expectations of future events. In addition, the complexity of micro behaviour may mean that simulation models may over or under predict the occurrence of a certain event, even in a well-specified model (Duncan and Weeks, 1998). Because of these issues, methods of calibration known as alignments have been developed within the microsimulation literature to correct for issues related to the adequacy of micro projections.

Scott (2001) defines alignment as "a process of constraining model output to conform more closely to externally derived macro-data ('targets')" and there are arguments both for and against the use of alignment procedures (Baekgaard, 2002). Concerns directed towards the use of alignment mainly focus on the consistency issue within the estimates and the level of disaggregation at which this should occur, and it is suggested that equations should be reformulated rather than constrained ex post. Clearly in an ideal world, attempts would be made to estimate a system of equations that could replicate reality and give effective future projections without the need for alignment. However, as Winder (2000) stated, "microsimulation models usually fail to simulate known time-series data. By aligning the model, goodness of fit to an observed time series can be guaranteed." Alignment has been suggested by some modellers as an effective pragmatic solution for highly complex models (O’Donoghue, 2010). 
Over the past decade, aligning the output of a microsimulation model to exogenous assumptions has become standard despite the surrounding controversy. In order to meet the need of alignment, various methods, e.g. multiplicative scaling, sidewalk, sorting based algorithm etc., have been experimented with along with the development of microsimulation models (see Morrison, 2006). Microsimulation models using historical datasets, e.g. CORSIM, align their output to historical data to create a more credible profile (SOA, 1997). Similarly, models that work prospectively, e.g. APPSIM, also utilise the technique to align their simulation with external projections (Kelly and Percival, 2009).

Nonetheless, the understanding of the simulation properties of alignment in microsimulation models is very limited and literature on this topic is scarce, with a few exceptions (Anderson, 1990; Caldwell et al., 1998; Neufeld, 2000; Chénard, 2000a, 2000b; Johnson, 2001; Baekgaard, 2002; Morrison, 2006; Kelly and Percival, 2009; O'Donoghue, 2010). Although some new alignment methods have been developed in an attempt to address some of the theoretical and empirical deficiencies of earlier methods, discussions on empirical simulation properties of different alignment algorithms are almost non-existent.

This chapter aims to fill this gap and to better understand the simulation properties of alignment algorithms used in microsimulation. It evaluates all major binary alignment methods using a simple microsimulation model with a set of synthetic datasets and a real life dataset. It then compares the alignment processes, probability transformations, and the statistical properties of alignment outputs in transparent and controlled setups. In addition, a real life panel dataset from the LII survey, is used together with a simplified microsimulation model to evaluate the alignment performances in a typical microsimulation project setup. Alignment performances are tested using various evaluation criteria, including those outlined by Morrison (2006).

This chapter is divided into six sections. In the next section, the background to the alignment methodology used in microsimulation will be reviewed and a summary of existing algorithms used in various models given. Section 4.3 will discuss the objectives of alignment and the method of algorithm evaluation, whilst section 4.4 will describes the detail of the datasets used in the evaluation process and some key statistics. The results of the evaluation are presented in section 4.5, and conclusions are drawn together in the final section. 


\subsection{Alignment in Microsimulation}

\subsubsection{The Purpose of Alignment}

This section discusses the purpose of alignment in a microsimulation model and the common practice used for their statistical implementation. Baekgaard (2000) suggests two broad categories for alignment: parameter alignment, whereby the distribution function is changed by adjustment of its parameters; and ex post alignment, whereby alignment is performed on the basis of unadjusted predictions or interim output resulting from a simulation.

This chapter primarily focuses on the ex post alignment methods, as they are the most common form of alignments used in microsimulation. Models of continuous events such as the level of earnings or investment incomes utilise statistical regressions with continuous dependent variables and produce a distribution of continuous values. However, the prediction of the statistical model may deviate from the expectation, for example due to an expected change in distribution or productivity, or may need to be adjusted for scenario analysis. This raises the need for alignment, which often may be an adjustment of multiplicative applied continuous variables or via adjusting the error distribution (Chénard, 2000a).

For binary variables however, the same method cannot be applied as binary variable simulation uses discrete choice models such as logit, probit or multinomial logit models, and the outputs cannot be adjusted in the same manner as continuous variables. As the majority of processes, e.g. in-work, employment, health, retirement, etc., in dynamic microsimulation models are by their nature binary choices, this chapter focuses its attention on the alignment of binary choice models.

Models of discrete events such as in-work, employment status, disability status etc. typically produce probabilities of an event occurring as an output. These models can be expressed in the following generic form:

$$
f\left(p_{i}\right)=\alpha+\beta X_{i}+\varepsilon_{i}
$$

The equation can be divided into a deterministic component $\alpha+\beta X_{i}$ and a stochastic component $\varepsilon_{i}$. In a simple Monte Carlo simulation, the random number $\varepsilon_{i}^{*}$ is generated to adjust the model for endogenous changes in the explanatory variables to produce a new deterministic component $\alpha+\beta X_{i}^{*}$ and simulate a new dependent variable. 
In the case of a binary choice this produces ${ }^{8}$ :

$$
f\left(p_{i}^{*}\right)=\alpha+\beta X_{i}^{*}+\varepsilon_{i}^{*}
$$

The dependent variable is predicted to have a value of 1 if $f\left(p_{i}^{*}\right) \geq 0$ alternatively it has a value of $0^{9}$. In most cases, a microsimulation model applies this prediction process to all observations individually without interaction. However, this may lead to a potential side effect: The output of the predication, although it may look reasonable at each individual level, may not meet the modeller's expectation at the aggregate level. For instance, the simulated average earning might be higher or lower than the assumption, or the in-work rate beyond expectation. Therefore, alignment is introduced as the step after the initial prediction in order to correct this "error".

Although the theoretical debate of alignment has not been completed, alignment is de facto widely adopted in the models built or updated within the last decade, e.g. DYNACAN (Neufeld, 2000), CORSIM (SOA, 1997), APPSIM (Bacon, 2009). Many papers (Baekgaard, 2002; Bacon, 2009; O’Donoghue, 2010), have discussed the main reasons for alignment, and summarise them as follows:

- Alignment may be used to "repair" the unfortunate consequences of insufficient estimation data by incorporating additional information in the simulations. Since no country has an ideal dataset for estimating all the parameters needed for microsimulation, modellers often make compromises which adversely affect the quality of the output. Alignment can be used to fix some of these errors.

- Alignment can be used to adjust for poor predictive performance of the micro model or its misspecification. Even with perfect data, relationships between dependent variables and explanatory variables may change considerably in countries where substantial structural changes are taking place. Alignment allows the correction of these issues and makes the simulation consistent with holistic projection assumptions.

- Alignment provides an opportunity for producing scenarios based on different assumptions. Examples include the simulation of alternative recession scenarios on

${ }^{8}$ Note $f\left(\dot{p}_{i}^{*}\right)$ in the case of a logit model is defined as $f\left(p_{i}^{*}\right)=\ln \left(\frac{p_{i}^{*}}{1-p_{i}^{*}}\right)$

${ }^{9}$ A more detailed description of logit based discrete models in microsimulation can be found in O'Donoghue (2010). 
employment with different impacts on different social groups (e.g. sex, education or occupation)

- Alignment is instrumental in establishing links between microsimulation models of the household sector and macro models. It is a crucial step required in order to reach a consistent Micro-Macro simulation model (see Davies 2004).

- Alignment can be used to reduce the Monte Carlo variability through its deterministic calculation (Neufeld, 2000). This is particularly useful for small samples in order to confine the variability of aggregate statistics.

\subsubsection{Alignment Methods}

In order to calibrate a simulation of a binary variable, a method is required that can adjust the outcome of a logit or probit model to produce outcomes that are consistent with the external total. Currently, there is no standardised method for implementing an alignment in a microsimulation. Given that different modellers may have different views or needs, it is therefore not surprising that various binary alignment methods have been proposed.

Papers by Neufeld (2000), Morrison (2006) and O'Donoghue (2010) provide descriptions of some popular options for alignment used within the literature. Existing documented alignment methods include:

- Multiplicative Scaling

- Sidewalk Shuffle, Sidewalk Hybrid and their derivatives

- Central Limit Theorem Approach

- Alignment by Sorting (with different sorting variables)

Multiplicative scaling, described by Neufeld (2000), involves undertaking an unaligned simulation using Monte Carlo techniques and then comparing the proportion of transitions with the external control total. The ratio between the desired transition and the actual transition is calculated and multiplied to each simulated probabilities in the second pass. This method maintains the relative magnitudes of the probabilities and ensures that the mean of simulated probabilities equals to the desired rate. However, this method is criticized by Morrison (2006) as probabilities are not limited to the $0-1$ range, although the problem is rare in practice as the multiplicative ratio tends to be small. Neufeld (2000) suggests solutions to this may include using a nonlinear adjustment.

The sidewalk method was first introduced by Neufeld (2000) as a variance reduction technique, which was also used as an alternative to pure Monte Carlo simulation. It essentially uses the cumulative sum of the probabilities to determine the event occurrence. It involves an accumulating counter that tracks the sum of predicted probabilities during simulation, and once the integer part of the sum changes, a transition occurs. This reduces the possibility of unlikely simulated outcomes because of random numbers. Since the 
method does not involve complex transformations like sorting, it could potentially be very effective in computation, which is a crucial requirement when it was first introduced. The original method, however, does not align the simulated data to an external control and can serve as a variance reduction technique. In addition, this method has some difficulties in output replications when the order of the observations changes, for example the deletion of an observation (e.g. death) or other changes. Serial correlation within families (or other clustering unit) is also an issue as people within a cluster are simulated in order. It is therefore unlikely for two people within a family to be simulated to make a transition in one year if the transitional probabilities are low.

Neufeld (2000) further developed an alignment method that he characterized as a hybrid of the independent Monte Carlo simulation and the sidewalk method. DYNACAN adopted this method with a non-linear adjustment to the probabilities by adding a constant term to the equation. The method calibrates probabilities through the logit transformation rather than by using probabilities directly, thus assuring the values are bounded between 0 and 1 (SOA, 1998). The addition of the constant term also shifts the mean value of predicted probability to the target rate. Additionally, DYNACAN implements a small algorithm adjustment in sidewalk, where the resulting probabilities are modified with a small constant $\lambda$ depending on whether the number of simulated events exceed or fall behind the target by a set parameter $\eta$ (Neufeld, 2000; Morrison, 2006). These two parameters determine how similar the output is to a standard Monte Carlo or standard sidewalk method.

The central limit theorem approach was described by Morrison (2006). The method adjusts simulated probabilities with a multiplicative factor to ensure the expected number of events equals to the target. It is similar to multiplicative scaling, except that the multiplicative factor is recalculated each time an individual event is simulated. The continuous adjustment used in this method ensures the simulated number of events can match the target. A more detailed description of the method can be found in Morrison (2006).

Alignment by sorting was first documented by O'Donoghue (2001) and Johnson (2001). It involves sorting of the predicted probability adjusted with a stochastic component, and selects a desired number of events according to the sorting order. It is seen as a more "transparent" method (O'Donoghue, 2010), although computationally it is more intensive due to the sorting procedure. Many variations of this method have been used in recent years and the most widely used three algorithms will be discussed in this chapter:

- Sort by predicted probability (SBP),

- Sort by the difference between predicted probability and random number (SBD), and 
- Sort by the difference between logistic adjusted predicted probability and random number (SBDL).

Sort by predicted probability (SBP)

Assuming that the predicted probability from a logit model can be defined as:

$$
p_{i}^{*}=\frac{\exp \left(\alpha+\beta X_{i}^{*}\right)}{1+\exp \left(\alpha+\beta X_{i}^{*}\right)}
$$

Where $p_{i}^{*}$ is the predicted probability and both $\alpha$ and $\beta$ are estimated coefficients. This method essentially picks up the observations with the highest $p_{i}^{*}$ in each alignment pool. However, one consequence is that those with the highest risk are always selected for transition. For the example of in-work, the higher educated individuals, all other things being equal would be selected to have a job. In reality those with the highest risk will on average be selected more than those with lower risk, but not always and as a result, some variability needs to be introduced. Kelly and Percival (2009) proposed a variant of this method, where a proportion (typically $10 \%$ of the desired number) are selected when the sorting order is inverted, thereby allowing low risk units to make a transition.

\section{Sort by the difference between predicted probability and random number (SBD)}

Given the shortcoming of the simple probability sorting, Baekgaard (2002) uses another method, which sorts by differences between predicted probability and a random number. Instead of sorting the probability $p_{i}^{*}$ directly, this method sorts $r_{i}$, which is equal to the difference between $p_{i}^{*}$ and a random number $u_{i}$, a number that is uniformly distributed between 0 and 1 . Mathematically, this sorting variable can be defined as follows:

$$
r_{i}=\operatorname{logit}^{-1}\left(\alpha+\beta X_{i}\right)-u_{i}=\frac{\exp \left(\alpha+\beta X_{i}\right)}{1+\exp \left(\alpha+\beta X_{i}\right)}-u_{i}
$$

A concern raised regarding this method is that the range of possible sorting values is not the same for each point. In other words, because the random number $u_{i} \in[0,1]$ is subtracted from the deterministically predicted $p_{i}^{*}$, and the sorting value takes the range $r_{i} \in[-1,1]$. For each individual, $\mathrm{r}$ can only take a possible range of $r_{i} \in\left[u_{i}-1, u_{i}\right]$ and as a result, when $p_{i}^{*}$ is small, say 0.1 , the range of possible sorting values is $[-0.9,0.1]$. At the other extreme if $p_{i}^{*}$ is large, say 0.9 , then the range of possible sorting values is $[-0.1,0.9]$. Thus, because there is only a small overlap for these extreme points, an individual with a small $p_{i}^{*}$ will have a very low chance of being selected even if a low value random number is paired with the observation. Ideally the range of possible sorting values should be the same, 
so that for each individual, $r_{i} \in[a, b]$, with individuals with a low $\dot{p}_{i}^{*}$ being clustered towards the bottom and those with a high $p_{i}^{*}$ being clustered towards the top.

Sort by the difference between logistic adjusted predicted probability and random number $(S B D L)$

An alternative method described by Flood et al. (2005), Morrison (2006) and O'Donoghue et al. (2008) mitigates the range problem of SBD by using logistic transformation. This method takes a predicted logistic variable from a logit model, $\operatorname{logit}\left(p_{i}\right)=\alpha+\beta X_{i}$ combined with a random number $\varepsilon_{i}$ that is drawn from a logistic distribution to produce a randomised variable:

$$
p_{i}=\operatorname{logit}^{-1}\left(\alpha+\beta X_{i}+\varepsilon_{i}\right)
$$

$p_{i}$ is then used to sort individuals and similarly the top $n_{j}$ of households are selected. The sorting variable can therefore be described as follows:

$$
r_{i}=\operatorname{logit}^{-1}\left(\alpha+\beta X_{i}+\varepsilon_{i}\right)=\frac{\exp \left(\alpha+\beta X_{i}+\varepsilon_{i}\right)}{1+\exp \left(\alpha+\beta X_{i}+\varepsilon_{i}\right)}
$$

Where $\varepsilon_{i}$ is a logistically distributed random number with a mean value 0 and a standard error of $\pi / \sqrt{3}$. Since the random number is not uniformly distributed as $u_{i}$ in the previous method, it therefore produces a different sorting order.

\subsection{Methods of Evaluating Alignment Algorithms}

In order to evaluate the simulation properties of all alignment algorithms, it is important to define what needs to be compared and what the criteria are. Although different alignment methods have been briefly documented in a few papers, there is little discussion on the actual performance differences among these methods. Implementations vary from model to model, but to date, no paper validates the alignment methods. This chapter evaluates different algorithms and compares how they perform under different scenarios.

\subsubsection{Objectives of Alignment}

The objectives of alignment as discussed by Morrison (2006) and O'Donoghue (2010), serve as the basis of the evaluation criteria used here. From a practical point of view, a "good" alignment algorithm should be able to: 
a) Replicate as close as possible the external control totals for the alignment totals. This is one of the main reasons why alignment is implemented in microsimulation and the common goal of all alignment methods as discussed by virtually all alignment papers (Neufeld, 2000; Morrison, 2006).

b) Retain the relationship between the deterministic and explanatory variables in the deterministic component of the model (O’Donoghue, 2010). In achieving the external totals, the alignment process should not bias the underlying relationship between the dependent and explanatory variables.

c) Retain the shape of distributions in different subgroup and inter-relations unless there is a reason not to do so. Morrison (2006) suggests that alignment is about implementing the right number of events in the right proportions for a pool's prospective events, as opposed to simply getting the right expected numbers of events. Although alignment processes focus on the aggregated output, it should also minimise the distributions of the relative distribution within different subgroups. For instance, if the number of people in work need to be aligned, the numbers not only need to be right at the aggregate level, but also at the micro/meso level, e.g. the labour participation rate for 30 year olds should be higher than the rate for 80 year olds. This relative distribution should not be changed, at least not substantially, by the alignment method. A highly distorted alignment process would adversely affect the distributional analysis, a typical usage of microsimulation models.

d) Compute efficiently. There is no doubt that today's computing resources are much more abundant than ever before; however, when handling large datasets, e.g. a full population dataset, computational constraint is still an important issue. Some projects, e.g. LIAM2/MiDaL (Liegeois, 2010), redesigned their entire framework in order to achieve faster speeds and accommodate larger datasets.

\subsubsection{Indicators of Alignment Performance}

In order to assess the alignment algorithms with very different designs, a set of quantitative indicators that can measure the simulation properties according to the criteria discussed earlier are used. The indicators include:

- A general measure of fit: a false positive rate $\operatorname{Pr}(Y=1 \mid 0)$ and a false negative rate $\operatorname{Pr}(Y=0 \mid 1)$, which reflect how well the prediction fits the actual data in general.

- A target deviation index (TDI), which measures the difference between the external control and the simulation outcome. This indicator is directly linked to the criterion a) above. 
- A distribution deviation index (DDI), which measures the distortion of the relationship between different variables and inter-relations, as discussed in criteria b) and c) above.

- A computational efficiency measurement: the number of seconds it takes to execute one round of alignment as outlined in criterion d) above.

\subsubsection{False Positive and False Negative}

One of the most straightforward ways of evaluating the accuracy of a binary simulation model is to examine its false positive and false negative rate. Higher rates indicate poorer prediction performance while lower rates suggest better accuracies in prediction. Both values range from zero to one.

\subsubsection{Target Deviation Index (TDI)}

Assuming among $N$ observations, the ideal number of events is $T$ and the actual simulated number of events after alignment is $S$. The TDI is then defined as:

$$
T D I=\frac{T-S}{N}
$$

The TDI is a percentage number ranged 0 to 1 , and shows how the alignment replicates the external control. Higher values imply the outcome is further away from the external control. This is a straightforward indicator used to evaluate the first alignment algorithm criterion.

\subsubsection{Distribution deviation index (DDI)}

In order to evaluate the second and the third alignment algorithm criteria, it is necessary to find an indicator that can reflect how well the relationships are preserved and how different the new distribution is from the old one.

An initial method would be to compare the original coefficients with re-estimated coefficients from the aligned data. Statistically identical coefficients indicate that the relationship remains the same, at least mathematically. However, this might not be applied to alignment tests, as alignment itself by definition, distorts the original probabilities. The coefficients as a result, are bound to change even under optimal alignment, and in most cases, the "correct" aligned coefficients are not available.

A second method to compare the relationships is to see whether the distribution of key variables have changed following alignment, e.g. whether the proportion of male workers and females workers has changed substantially. A Chi-square test would be useful for this scenario, as it is frequently used to test whether the observed distribution follows the 
theoretical distribution. Assuming $S_{i}$ and $T_{i}$ represent the post-alignment frequency and the target frequency respectively, the Pearson's chi-square test can be defined as:

$$
\chi^{2}=\sum_{i=1}^{n} \frac{\left(S_{i}-T_{i}\right)^{2}}{T_{i}}
$$

Nevertheless, this test requires "no more than $20 \%$ of the expected counts to be less than 5 and all individual expected counts are 1 or greater" (Yates, Moore and McCabe, 1999). These requirements might not be always fulfilled in microsimulation depending on the scenario assumptions and the way the groups are defined. As a result, an adaptation is required in order to best measure the deviation between two distributions for the purpose of binary variables and possibly low or zero expected counts.

This chapter proposes a self-defined distribution deviation index (DDI) to evaluate the second and third criteria in choosing an alignment method. Assuming there is a data pool with $N$ observations, it can be divided into $n$ groups using variable $X$. $X$ could be any variable such as age, gender, or age gender interaction etc. In each group, $O_{i}$ represents the probability of event occurrence before alignment, and $P_{i}$ is the probability after alignment. Assuming $O_{i}$ is different from the target probability by a multiplying factor $R, O_{i} R$ would therefore represent the ideal probability after alignment. A distribution deviation index (DDI) can consequently be defined as:

$$
D D I=\sum_{i=1}^{n(X)} \frac{N_{i}}{N}\left(\left(S_{i}-O_{i} R\right)^{2}\right)
$$

This indicator describes how well the micro-simulated data retains the relationships between the dependent variable and variable $X$. It is a minimum distance estimation tailored for binary variable outcome within a simulation.

Essentially, the DDI calculates the sum of squares of differences weighted by the number of observations, measuring the differences between distributions before and after alignment in multiple dimensions, depending on the vector $X$. When $X$ is an independent variable, it measures the distortion introduced between the independent variable and the dependent by alignment. When $X$ is a dependent variable, the DDI reports the degree of nonlinearity in the probability distortion of the alignment. When $X$ is a variable outside of the equation, then the DDI assesses the level of distortion in an implicit relationship. In short, $X$ could be a vector consisting of any variable and interaction terms.

The indicator is positively correlated with the alignment deviation, it increases when the aligned distribution departs from the original and decreases when the distributions become similar. The scale of the indicator is independent to the choice of variable $X$ and the number of groups that $X$ may produce. Since $S_{i}$ and $O_{i}$ are both probabilities between 0 
and 1 , the DDI has a range of 0 to 1 . When the dataset preserves the shape of distribution perfectly, the index has a value of 0 , this increases when the difference between the two redistributions grows, reaching a maximum value of 1 .

\subsubsection{Computation efficiency}

The most intuitive indicator for the computational efficiency of an alignment algorithm is the execution time: the length of time an alignment method takes to execute one round of alignment when the input is in a randomised order. In order to have comparable inputs and outputs, all methods are required to retain the initial order of the inputs. This makes the alignment algorithm a module within the microsimulation model. However, this extra requirement penalizes the speed of the methods that require randomly shuffling, as the observations need to be re-sorted before the end of the execution.

The evaluation of the computational efficiency is performed in Stata because of its easy integration of estimation and simulation. Given that the computer speed varies greatly, the results presented in this chapter may alter dramatically when executed on a different platform although the relative ranking would be expected to remain stable in most cases.

\subsubsection{Alignment Algorithms Evaluated}

This chapter evaluates all the alignment algorithms discussed earlier, including:

- Multiplicative scaling

- Sidewalk Hybrid with Nonlinear Adjustment

- Central Limit Theorem Approach

- Sort by predicted probability (SBP)

- Sort by the difference between predicted probability and random number (SBD)

- Sort by the difference between logistic adjusted predicted probability and random number (SBDL)

When implementing the sidewalk hybrid with nonlinear adjustment, there are two important parameters required, $\eta$ and $\lambda . \eta$ is the maximum allowed difference between the actual number of events and the expected number of events before $\lambda$ is added or subtracted from the predicted probability. In this chapter, $\eta$ is set to 0.5 and $\lambda$ to 0.03 , the same values that the DYNACAN model used (Neufeld, 2000). The order of the initial input is randomly shuffled in order to get rid of undesired serial correlations. 


\subsection{Datasets and Scenarios in Alignment Algorithm Evaluation}

In order to understand the simulation properties of alignment algorithms, this chapter evaluates the performances of various methods under two settings, a "lab setting", where a synthetic dataset is used, and a "real-world setting", where the algorithms are applied to a real world dataset. The evaluation commences using synthetic datasets in a controlled setting, where alignments are used to correct some artificial "errors" in the outcome of the statistical model. Since it is possible to control the exact source of the error within a synthetic dataset, the simulation properties of different alignment algorithms and the probabilities transformation in a fully transparent setup can be analysed.

The alignment performances of different models in four different scenarios are evaluated using a synthetic dataset. Each scenario represents a potential statistical error that alignment methods try to address or which is compensated for within a microsimulation model. The quality of the alignment is measured by the TDI and the DDI, where the grouping variable $X$ is the percentile of the correct probabilities. Computation cost is measured by the number of seconds the algorithm takes to execute one run.

\subsubsection{Baseline Scenario}

Assuming there is a binary model, this can be expressed as follows:

$$
y_{i}=\operatorname{logit}^{-1}\left(\alpha+\beta x_{i}+\varepsilon\right)
$$

Where $\alpha$ and $\beta$ are the parameters in the equation, and $\varepsilon$ is an error term which follows a logistic distribution with zero mean and a variance of $\pi / \sqrt{3}$. To simplify the calculation in the evaluation, $\alpha$ is assigned 0 and $\beta, 1$, while is randomly drawn from a standard normal distribution $N(0,1)$. The number of observations in the synthetic dataset is 100,000 . Table 4.1 lists all the key statistics in the baseline scenario and Figure 4.1 illustrates the distribution of the baseline probabilities graphically.

\subsubsection{First Scenario: Sample Bias}

The first synthetic test scenario replicates a type of sample bias that commonly exists in survey datasets. In practise, the bias is often corrected by using observation weights. Unbiased estimations of behaviour equations depend on accurate weights. Nonetheless, despite all efforts, survey datasets may still suffer from various sample bias, particularly selection bias and attrition bias within panel datasets such as ECHP (Vandecasteele and Debels, 2007). Sample bias leads to a non-representative dataset, which affects the quality of the simulation output and alignment is sometimes used to compensate for the error of sample bias. 
In the evaluation, a simple sample bias was recreated. $50 \%$ of the observations with positive responses $\left(y^{*}>0\right)$ were randomly removed from the baseline dataset. This produces a non-representative sample with an equivalent size of $75 \%$ of the original. In other words, the observations with negative response $\left(y^{*} \leq 0\right)$ weigh twice as much as they should within the dataset. In addition, the error structure $\left(\varepsilon_{i}\right)$ has a different distribution when compared to the baseline scenario as a consequence of the bias introduced.

\subsubsection{Second Scenario: Biased Alpha (Intercept)}

The second synthetic scenario aims to replicate a monotonic shift of the probabilities. This is commonly used in scenario analysis where a certain ratio, e.g. unemployment rate, is required to be increased or decreased to meet the scenario assumptions.

By manipulating the intercept of the equations, it is possible to shift the probabilities across all observations. In this scenario, $\alpha$ was changed to -1 while everything else remained constant. The result is a monotonic, but non-uniform change in the probabilities. A nonuniform transformation is required to ensure that the probabilities are still bounded within the range of $[0,1]$ and Figure 4.2 displays the transformation graphically. As can be seen, the probabilities transformation curve for the second scenario stays below the 45 degree line and has a varying slope. This indicates that the transformation is monotonic but non-uniform. Contrary to the previous scenario, the error structure and the number of observations stays the same within this setup. Table 4.1 highlights the statistical differences between this scenario and the others.

\subsubsection{Third Scenario: Biased Beta}

The third synthetic test scenario introduces a biased slope $\beta$ into the equation. This represents a change in the behaviour pattern that could not be captured at the time of estimation (e.g. the evolution of fertility patterns). In this scenario, it may be assumed that the behaviour pattern shifts over time. This particular setup tests how the alignment works as a correction mechanism for behaviour pattern correction.

The simulated dataset in this scenario was generated for $\beta=0.5$, half of its value in the baseline dataset, which therefore creates a different distribution of probability. Since $x$ has a mean value of 0 , the change does not affect the total sample mean of $y$ at the aggregate level. The transformation would yield a different distribution but with an unchanged sample mean and Figure 4.1 graphically illustrates the difference in probability distribution. As can be seen, the standard deviation of probabilities in this scenario is much lower than the baseline scenario while the mean value remains the same. 
Unlike the first and second scenarios, the transformation in this scenario causes a nonmonotonic change in probabilities. Observations with low probability $(p<0.5)$ in the baseline scenario have increased their probability since their $x$ values are now negative, while the observations with high probability $(p>0.5)$ have lowered probabilities compared with the baseline scenario.

\subsubsection{Forth Scenario: Biased Intercept and Beta}

The last synthetic test scenario combines both the change in intercept and the shift in slope. The new transformed dataset has an $\alpha$ value of -1 and a $\beta$ value of 0.5 , a scenario which represents a relatively complex change. This results in a lowered aggregate mean of $y$ and a nonlinear change in the individual probabilities.

Table 4.1 Overview of the Synthetic Data Scenarios

\begin{tabular}{lccccc}
\hline \multirow{2}{*}{ Synthetic Scenario } & \multicolumn{5}{c}{ Scenario } \\
\cline { 2 - 5 } & Baseline & 1 & 2 & 3 & 4 \\
\hline Number of observations in estimation & 100,000 & 75,000 & 100,000 & 100,000 & 100,000 \\
Number of observation in simulation & 100,000 & 100,000 & 100,000 & 100,000 & 100,000 \\
Mean value of outcome variable & 0.500 & 0.330 & 0.303 & 0.500 & 0.277 \\
$\alpha$ & 0.000 & -0.695 & -1.000 & 0.000 & -1.000 \\
$\beta$ & & $(0.008)$ & & & 0.500 \\
Target Ratio for Alignment & 1.000 & 0.998 & 1.000 & 0.500 & 0.5 \\
\hline
\end{tabular}

N.B. Coefficients in the first scenario are estimated using logit model. Standard errors are given in brackets.

As an overview, Table 4.1 summarises the changes of $\alpha$ and $\beta$ in the different scenarios and compares the key statistics. As can be seen, all the scenarios have the same number of observation except the first one. The mean value of the outcome variable ranges from 0.277 to 0.5 , and the target for alignment (external value) is 0.5 across all scenarios. Figure 4.1 gives a visualisation of the probability distributions in the different scenarios and as can be seen, all the probability distributions, with the exception of baseline and the third scenario, exhibit a right skewed pattern. Figure 4.2 further compares the differences between "correct" probability and the transformed probabilities in the above scenarios.

\subsubsection{Evaluation Using a Real World Dataset}

There is no doubt that synthetic evaluation contributes to the understanding of alignment methods thanks to its complete transparency. An alignment algorithm, however, is only useful when applied to a real-world dataset. Therefore, this chapter also analyses the performance of different alignment algorithms using a real dataset. 
Figure 4.1 Overview of Probability Distribution in Different Scenarios

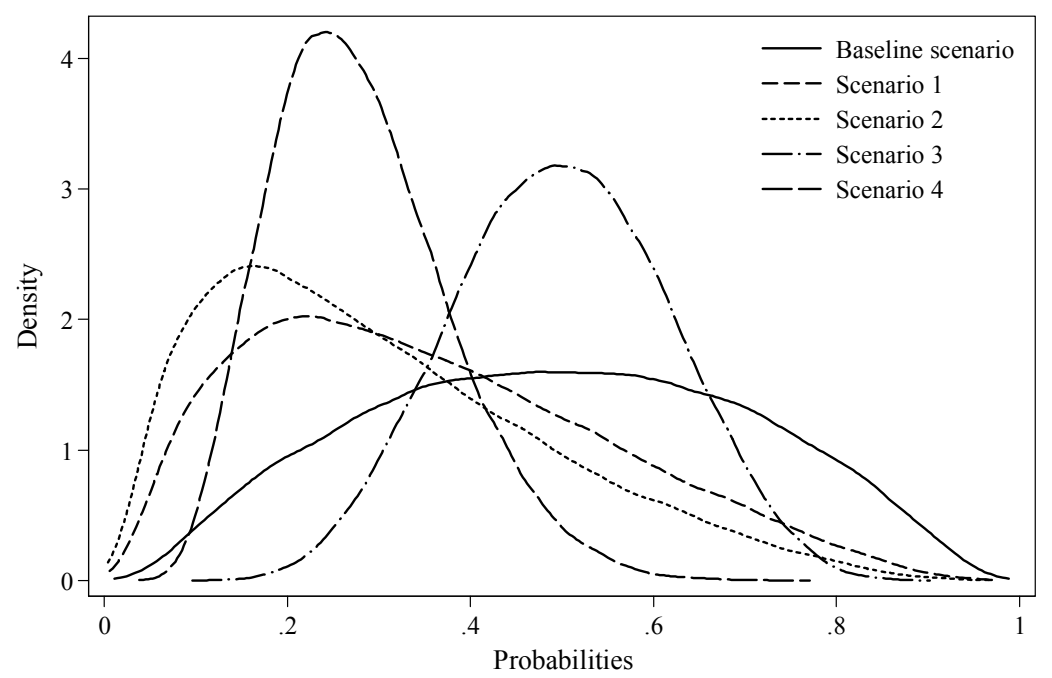

Figure 4.2 Overview of Probability Transformation in Different Scenarios

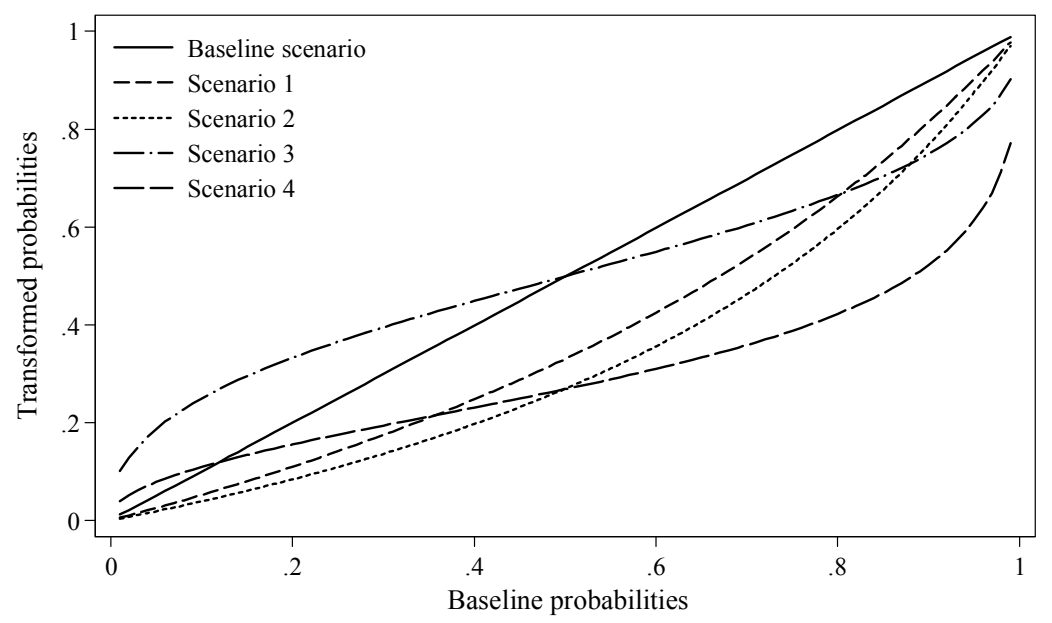

NB. Probability transformation curve records how probabilities change due to the artificial errors introduced in the scenario.

In this real-world evaluation, the 1994-2001 ECHP-LII dataset was utilised for a simple exercise of labour participation simulation. The LII survey constitutes the Irish component of the European Community Household Panel (ECHP). It is a representative household panel survey conducted on the Irish population annually for eight waves until 2001. The 
data contains information on demographic, employment, and other social economic characteristics of around 3500 households in each wave. In 2000, additional 1500 households were brought into the dataset to compensate for the attrition since 1994. The dataset has been cleaned and adjusted to ensure the consistency as described in $\mathrm{Li}$ and O’Donoghue (2010).

Labour participation simulation was selected because it is one of the popular components in dynamic microsimulation models. The simulation uses a reduced form equation for labour participation, assuming the in-work status $y_{i}^{*}$ is derived from the following specification:

$$
y_{i}^{*}=\operatorname{logit}^{-1}\left(\alpha+\beta X_{i}\right)
$$

Where $X$ is a vector that covers lagged in-work status, education, gender, age, age squared, interaction term between gender and having a new-born, interaction term between marriage and gender. In the estimation, individuals aged 15 to 69 with known previous working status were included. Table 4.2 provides some basic summary statistics of the variables included and the estimation results are reported in appendix 4.A.

Table 4.2 Overview of variables included in the in-work estimation

\begin{tabular}{|c|c|c|c|c|}
\hline \multirow[b]{2}{*}{ Variable (Mean value) } & \multicolumn{2}{|c|}{ In-work } & \multicolumn{2}{|c|}{ Out-work } \\
\hline & Mean & Standard Deviation & Mean & $\begin{array}{l}\text { Standard } \\
\text { Deviation }\end{array}$ \\
\hline Lagged in-work status & 0.86 & 0.32 & 0.14 & 0.31 \\
\hline Gender $($ female $=1)$ & 0.38 & 0.49 & 0.62 & 0.49 \\
\hline Age & 37.18 & 13.18 & 37.60 & 17.79 \\
\hline Age squared & 1555.98 & 1053.01 & 1730.53 & 1447.02 \\
\hline Having a new-born & 0.03 & 0.17 & 0.02 & 0.12 \\
\hline Marriage & 0.54 & 0.50 & 0.44 & 0.50 \\
\hline Secondary education & 0.24 & 0.43 & 0.19 & 0.39 \\
\hline University education & 0.31 & 0.46 & 0.15 & 0.35 \\
\hline Interaction term: new-born and gender & 0.01 & 0.10 & 0.01 & 0.11 \\
\hline Interaction term: marriage and gender & 0.18 & 0.39 & 0.33 & 0.47 \\
\hline Number of observations in the category & \multicolumn{2}{|r|}{31784} & \multicolumn{2}{|c|}{29448} \\
\hline Total number of observations & \multicolumn{4}{|c|}{61232} \\
\hline
\end{tabular}

In the previous published literature on microsimulation validation, Caldwell and Morrison (2000) suggest using in-sample validation, out-of-sample validation and multiple-module validation to evaluate simulation output. This chapter follows a similar approach for 
algorithm evaluation except that there is no multi-module evaluation since alignment is usually an integrated part of a more complex model.

In-sample evaluation assesses the predictive power of the model for describing the data on which it was estimated. In this scenario, how well the model replicates the labour participation rate in 1998 with a known external control (observed number of workers) was tested using different alignment methods. The year 1998 was selected because it is in the middle of the period the data covers. Equation coefficients were estimated from the whole panel with the exception of the first wave where lagged in-work status is not available. Alignment performance indicators were calculated in the same way as in the synthetic dataset evaluation.

An in-sample evaluation test is useful but is different to the real microsimulation exercise where the values are predicted from the sample. An out-of-sample evaluation attempts to measure the predictive power of the model in explaining data of a similar type which were not used in the estimation of the model (Caldwell, 1996). In this particular test, data from the years 1995-1998 was used to predict the period 1999-2001 with the known external control (the observed number of workers) and analyse the differences in alignment methods performances. The benchmark distribution for DDI is the actual observed distribution for 1999-2001.

\subsection{Evaluation Results}

This section reports the evaluation results of six different alignment algorithms and compares their performances under different scenarios through false positive/negative rates, two self-defined indices (TDI, DDI) and computational time.

\subsubsection{Evaluation Results using Synthetic Datasets}

Figure 4.3 lists four key indicators obtained from evaluations using synthetic datasets and includes:

- Target deviation index (TDI)

- False positive rate

- False negative rate

- Distribution deviation index (DDI) - the synthetic dataset based test uses the percentile of dependent variables as the grouping variable $X$. 
Table 4.3 Properties of Different Alignment Methods in Synthetic Dataset Test

\begin{tabular}{|c|c|c|c|c|}
\hline Method & $T D I$ & $\begin{array}{c}\text { False } \\
\text { Positives }\end{array}$ & $\begin{array}{c}\text { False } \\
\text { Negatives }\end{array}$ & $D D I$ \\
\hline \multicolumn{5}{|l|}{ Scenario 1: Selection Bias } \\
\hline Multiplicative scaling & $-0.43 \%$ & $19.33 \%$ & $19.76 \%$ & $0.40 \%$ \\
\hline Sidewalk hybrid with nonlinear adjustment & $0.00 \%$ & $20.63 \%$ & $20.63 \%$ & $0.03 \%$ \\
\hline Central limit theorem approach & $0.00 \%$ & $19.65 \%$ & $19.65 \%$ & $0.43 \%$ \\
\hline Sort by predicted probability (SBP) & $0.00 \%$ & $16.31 \%$ & $16.31 \%$ & $11.50 \%$ \\
\hline $\begin{array}{l}\text { Sort by the difference between predicted probability and } \\
\text { random number (SBD) }\end{array}$ & $0.00 \%$ & $21.09 \%$ & $21.09 \%$ & $0.15 \%$ \\
\hline $\begin{array}{l}\text { Sort by the difference between logistic adjusted } \\
\text { predicted probability and random number (SBDL) }\end{array}$ & $0.00 \%$ & $20.69 \%$ & $20.69 \%$ & $0.03 \%$ \\
\hline \multicolumn{5}{|l|}{ Scenario 2: Biased Alpha (Intercept) } \\
\hline Multiplicative scaling & $-1.41 \%$ & $18.74 \%$ & $20.15 \%$ & $0.61 \%$ \\
\hline Sidewalk hybrid with nonlinear adjustment & $0.00 \%$ & $20.69 \%$ & $20.69 \%$ & $0.03 \%$ \\
\hline Central limit theorem approach & $0.00 \%$ & $19.29 \%$ & $19.29 \%$ & $0.65 \%$ \\
\hline Sort by predicted probability (SBP) & $0.00 \%$ & $16.31 \%$ & $16.31 \%$ & $11.50 \%$ \\
\hline $\begin{array}{l}\text { Sort by the difference between predicted probability and } \\
\text { random number }(\mathrm{SBD})\end{array}$ & $0.00 \%$ & $21.31 \%$ & $21.31 \%$ & $0.30 \%$ \\
\hline $\begin{array}{l}\text { Sort by the difference between logistic adjusted } \\
\text { predicted probability and random number (SBDL) }\end{array}$ & $0.00 \%$ & $20.70 \%$ & $20.70 \%$ & $0.03 \%$ \\
\hline \multicolumn{5}{|l|}{ Scenario 3: Biased beta coefficients } \\
\hline Multiplicative scaling & $-0.18 \%$ & $22.58 \%$ & $22.76 \%$ & $0.90 \%$ \\
\hline Sidewalk hybrid with nonlinear adjustment & $-0.01 \%$ & $22.59 \%$ & $22.60 \%$ & $0.84 \%$ \\
\hline Central limit theorem approach & $0.00 \%$ & $22.69 \%$ & $22.69 \%$ & $0.91 \%$ \\
\hline Sort by predicted probability (SBP) & $0.00 \%$ & $16.31 \%$ & $16.31 \%$ & $11.50 \%$ \\
\hline $\begin{array}{l}\text { Sort by the difference between predicted probability and } \\
\text { random number (SBD) }\end{array}$ & $0.00 \%$ & $22.54 \%$ & $22.54 \%$ & $0.87 \%$ \\
\hline $\begin{array}{l}\text { Sort by the difference between logistic adjusted } \\
\text { predicted probability and random number (SBDL) }\end{array}$ & $0.00 \%$ & $22.56 \%$ & $22.56 \%$ & $0.88 \%$ \\
\hline \multicolumn{5}{|l|}{ Scenario 4: Biased alpha and beta (all coefficients) } \\
\hline Multiplicative scaling & $0.18 \%$ & $21.57 \%$ & $21.39 \%$ & $0.26 \%$ \\
\hline Sidewalk hybrid with nonlinear adjustment & $0.00 \%$ & $22.45 \%$ & $22.44 \%$ & $0.85 \%$ \\
\hline Central limit theorem approach & $0.00 \%$ & $21.54 \%$ & $21.54 \%$ & $0.28 \%$ \\
\hline Sort by predicted probability (SBP) & $0.00 \%$ & $16.31 \%$ & $16.31 \%$ & $11.50 \%$ \\
\hline $\begin{array}{l}\text { Sort by the difference between predicted probability and } \\
\text { random number (SBD) }\end{array}$ & $0.00 \%$ & $22.97 \%$ & $22.97 \%$ & $1.33 \%$ \\
\hline $\begin{array}{l}\text { Sort by the difference between logistic adjusted } \\
\text { predicted probability and random number (SBDL) }\end{array}$ & $0.00 \%$ & $22.67 \%$ & $22.67 \%$ & $0.92 \%$ \\
\hline
\end{tabular}




\begin{tabular}{|c|c|c|c|c|}
\hline Method & $T D I$ & $\begin{array}{c}\text { False } \\
\text { Positives }\end{array}$ & $\begin{array}{c}\text { False } \\
\text { Negatives }\end{array}$ & $D D I$ \\
\hline \multicolumn{5}{|l|}{ Average Performances } \\
\hline Multiplicative scaling & $-0.46 \%$ & $20.55 \%$ & $21.02 \%$ & $0.54 \%$ \\
\hline Sidewalk hybrid with nonlinear adjustment & $0.00 \%$ & $21.59 \%$ & $21.59 \%$ & $0.44 \%$ \\
\hline Central limit theorem approach & $0.00 \%$ & $20.79 \%$ & $20.79 \%$ & $0.57 \%$ \\
\hline Sort by predicted probability (SBP) & $0.00 \%$ & $16.31 \%$ & $16.31 \%$ & $11.50 \%$ \\
\hline $\begin{array}{l}\text { Sort by the difference between predicted probability and } \\
\text { random number }(S B D)\end{array}$ & $0.00 \%$ & $21.98 \%$ & $21.98 \%$ & $0.66 \%$ \\
\hline $\begin{array}{l}\text { Sort by the difference between logistic adjusted } \\
\text { predicted probability and random number (SBDL) }\end{array}$ & $0.00 \%$ & $21.66 \%$ & $21.66 \%$ & $0.46 \%$ \\
\hline
\end{tabular}

As can be seen in Table 4.3, all alignment methods except multiplicative scaling, in all scenarios, have less than $0.01 \%$ deviation from the target number of event occurrence, while multiplicative scaling shows a deviation of up to $1.41 \%$ from the target during the evaluation. The result is largely driven by the design of the algorithm, as multiplicative scaling cannot guarantee a perfect alignment ratio although the expected deviation is zero. Sidewalk hybrid sometimes has a slight deviation (less than $0.01 \%$ ), as the non-linear transformation may not always be perfect under existing implementations ${ }^{10}$. Central limit theorem methods have built-in counters that prevent the events from manifesting when the target is met. Sorting based algorithms only pick the exact number of observations required, which is why their TDI is always zero.

In terms of false positive and false negative rates when compared with the "correct" values, alignment method $S B P$ yields the best result, which is on average 4 to 6 percentage points lower than the other algorithms. Sidewalk Hybrid together with $S B D$ and SBDL, have the highest false positive/false negative rates on average. It seems that the false positive and false negative rates are closely related to the complexity of the algorithms. The "nonlinear transformation" in Sidewalk Hybrid and "differencing" operations in SBD and SBDL are both more complicated computationally than the other methods. This pattern is consistent across all scenarios, although absolute numbers fluctuate across the different scenarios.

\footnotetext{
${ }^{10}$ The process usually requires several iterations and it is computationally expensive (Neufeld, 2000). The test model used in this chapter stops its calibration when the iteration only improves the average probability by no more than $10^{-8}$. This increases the calculation speed but sometimes results in imperfectly aligned probabilities. Details of the calibration steps can be found in the book published by Society of Actuaries (SOA, 1998).
} 
Whilst false positive and false negative rates are a useful indicator when the correct value is known, it is a less critical indicator for simulation as microsimulation exercises tend to focus more on distributions. Therefore, the DDI is particularly important in judging how well the relative relations between variables are preserved after alignment. Appendix 4.B demonstrates the difference between actual probabilities and aligned probabilities for all the synthetic tests.

The results show that the $S B P$ method heavily distorts the original distribution of the probabilities across all the scenarios using percentile grouping. This is also reflected by the DDI, which is effectively calculating a weighted size of the gap in this case. It seems that there is no method which consistently outperforms across all the scenarios. In the first two scenarios, the sidewalk bybrid and SBDL methods give the best result; in the third scenario, where the synthetic dataset modifies the slope of $x_{i}$, all methods have similar DDI values except SBP; whilst in the last scenario, multiplicative scaling and central limit methods generally perform much better than the rest. Compared with other methods, those methods which involve "differencing" and "logistic transformation" (including sidewalk hybrid with non-linear transformation, SBD and SBDL) seem to be more sensitive to the change in the $\beta$ coefficient and their performances are much better when $\beta$ remains stable, e.g. scenarios 1 and 2 . This may be due to the nature of these algorithms, as the "differencing" and "logit transformation" operations assume monotonic changes in the probabilities.

\subsubsection{Evaluation Results using a Real-world Dataset}

The synthetic dataset based evaluation offers an overview of the performances of different algorithms under a particular source of noise, but the performance of the algorithms when applied to a real-world dataset is more interesting for empirical modellers. Table 4.4 reports all the key indicators calculated when applying alignment to a real life dataset with the example of estimating the in-work population. The DDI is calculated based on independent variables, including sex, education, marriage status with childbirth interaction, and the external variable, nationalities. It reflects an overall shift of the distribution in multi-dimensions.

Similar to the results from the synthetic dataset, multiplicative scaling is the only method with a TDI greater than $0.01 \%$ and the SBP method outperforms all other methods in terms of false positive and false negative rates by a significant margin. All other evaluated methods have similar false positive and negative rates. 
Table 4.4 Properties of Different Alignment Methods with a Real World Dataset (LII)

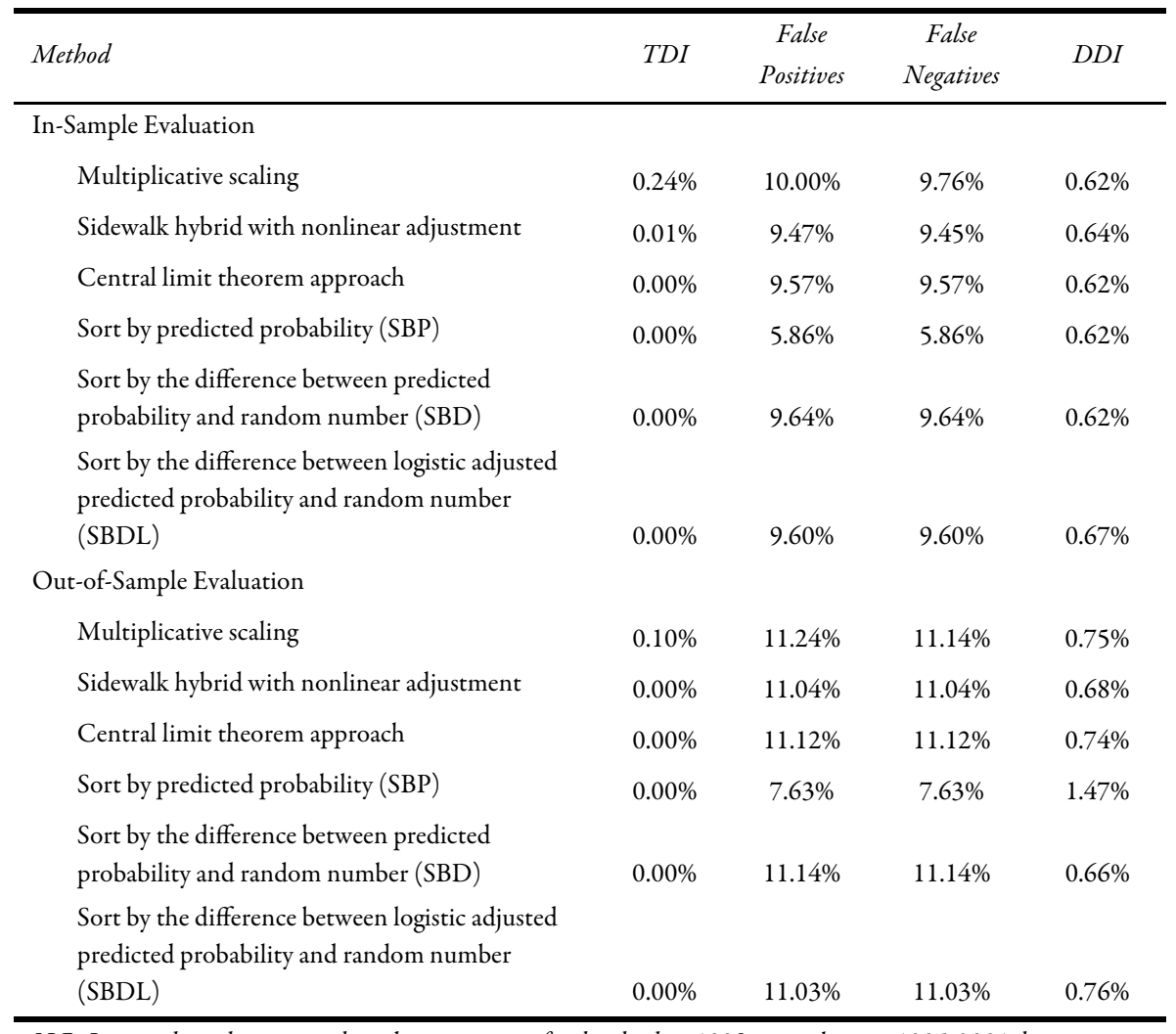

N.B. In-sample evaluation predicts the proportion of individuals in 1998 in-work using 1995-2001 data

Out-of-Sample evaluation predicts the proportion of individuals in 1999-2001 in-work using 1995-1998 data

With regard to the DDI, there is no dramatic difference between different methods in the in-sample evaluation. It can be noted that the $S B P$ method has a much more comparable DDI performance in the real life dataset than in the synthetic dataset, and in fact, SBP has one of the best results for the in-sample evaluation. In the out-of-sample exercise, $S B D$, a method with average performance for the synthetic datasets, has the lowest DDI value, while SBP has the worst result. Besides the algorithm design, the change of grouping variables also affects the observed DDI pattern in this evaluation. With the synthetic datasets, groups are divided based on the percentile value of the dependent variable, while in the real-world dataset, observations were grouped using a realistic setting via different characteristics variables, such as age, gender etc. 


\subsubsection{Computing Performance and Scalability}

Computational efficiency is another main criterion for evaluating alignment algorithms. Given the increasing availability of large-scale datasets used in microsimulation and the complexity of the models, alignment may consume considerable resources during the computation processes. Nonetheless, the study of computational efficiency is rather scarce within the field of microsimulation and there are no papers to date analysing how the number of observations affects the algorithms' performance. This section compares different alignment algorithms in terms of computation efficiency and discusses the issue of scalability of the algorithms.

Table 4.5 presents an overview of the computation time required during the synthetic scenario evaluation and real-world data evaluation. The computational premium was timed using the windows version of Stata SE with an Intel i5-520m processor. As indicated, the method that takes least computational resources is the multiplicative scaling method. This is not surprising, as multiplicative scaling involves only a single calculation for each observation. Sorting-based alignment methods seem to be in the next tier, and consume up to 5 times more resources when compared to multiplicative scaling. The variations in sorting method does not appear to change the execution time much although the last sorting variation, $S B D L$, consumes around $10 \%$ more resources than the other sorting based algorithms due to its higher computation complexity.

Table 4.5 Computational Costs of Different Alignment Methods

\begin{tabular}{|c|c|c|c|c|c|c|}
\hline \multirow[b]{2}{*}{ Method } & \multicolumn{4}{|c|}{ Synthetic Dataset Scenario } & \multicolumn{2}{|c|}{ Real-world Dataset } \\
\hline & 1 & 2 & 3 & 4 & $\begin{array}{c}\text { In- } \\
\text { Sample }\end{array}$ & $\begin{array}{l}\text { Out- } \\
\text { Sample }\end{array}$ \\
\hline Multiplicative scaling & 0.07 & 0.07 & 0.07 & 0.07 & 0.04 & 0.13 \\
\hline $\begin{array}{l}\text { Sidewalk hybrid with nonlinear } \\
\text { adjustment }\end{array}$ & 5.71 & 5.88 & 5.49 & 5.78 & 1.30 & 4.22 \\
\hline Central limit theorem approach & 3.34 & 3.40 & 3.50 & 3.55 & 0.63 & 2.12 \\
\hline Sort by predicted probability (SBP) & 0.32 & 0.33 & 0.33 & 0.35 & 0.17 & 0.58 \\
\hline $\begin{array}{l}\text { Sort by the difference between } \\
\text { predicted probability and random } \\
\text { number }(\mathrm{SBD})\end{array}$ & 0.34 & 0.34 & 0.34 & 0.34 & 0.18 & 0.61 \\
\hline $\begin{array}{l}\text { Sort by the difference between } \\
\text { logistic adjusted predicted probability } \\
\text { and random number (SBDL) }\end{array}$ & 0.36 & 0.36 & 0.36 & 0.38 & 0.18 & 0.63 \\
\hline
\end{tabular}

Sidewalk Hybrid with nonlinear transformation seems to be at the bottom of the list in terms of efficiency, as it takes approximately 80 times more CPU time than the fastest method, and 15-20 times more CPU time than the sorting based algorithms. There are 
three reasons for its relatively poor performances. Firstly, the nonlinear transformation may take many iterations and is itself computationally expensive (Neufeld, 2000). Secondly, the method itself suffers from serial correlation in the original design, as the calculation is dependent on the result of the last observation and in order to mitigate this effect, an extra randomisation via sorting is implemented, accompanied by a reverse process which restores the original order of the input at the end of the alignment. Thirdly, the Sidewalk method requires iterating through observations. Stata, which is the platform used for the evaluation, is not particular efficient at individual observation iteration compared with the batch processing for which Stata is optimised ${ }^{11}$. This is also the primary reason why the Central limit theorem approach had a relatively long run-time. From a theoretical point of view, it can be speculated that the performances of the Sidewalk method and the Central limit theorem approach could be significantly improved when implemented correctly as native code in $\mathrm{C} / \mathrm{C}++$, as compiled code does not re-interpret the syntax over the iterations. Nonetheless, the sidewalk method may still be slower than the other algorithms when nonlinear probability transformation is applied.

When increasing the number of observations, i.e. size of input, all algorithms exhibit a mostly linear growth rate of execution time in Stata (see Figure 4.3 to Figure 4.5) for a dataset of under 15 million observations, and the run-time seems to be directly proportional to its input size. All alignments are using the same input dataset, which is a randomly generated pool of uniformly distributed probabilities. The linear growth rate indicates that Stata might use a non-comparison sorting algorithm, e.g. Radix sort, in its default implementation.

As the actual implementation in different environments may vary, the results do not reflect the performance in real projects on different platforms, but do provide a reference to illustrate the potential computational cost. It is important to note that since the sorting algorithm and most calculations are encapsulated in Stata, the actual performance is the mixed result of Stata performance, algorithm design quality, and implementation quality. The actual performance may be very different in other implementation settings (e.g. $\mathrm{C} / \mathrm{C}++)$. Results are timed with the internal timer from Stata on a windows box.

\footnotetext{
${ }^{11}$ Observation iteration, a necessary step for these two algorithms, tends to be very slow in Stata because loops are reinterpreted for each iteration. Stata recommends using a compiled plug-in for the best performance for this type of scenarios (Stata, 2008). However, algorithm specific optimization using compiled code is beyond the scope of this chapter and would make the comparison difficult.
} 
Figure 4.3 Computational Time Curve of Multiplicative Scaling Alignment

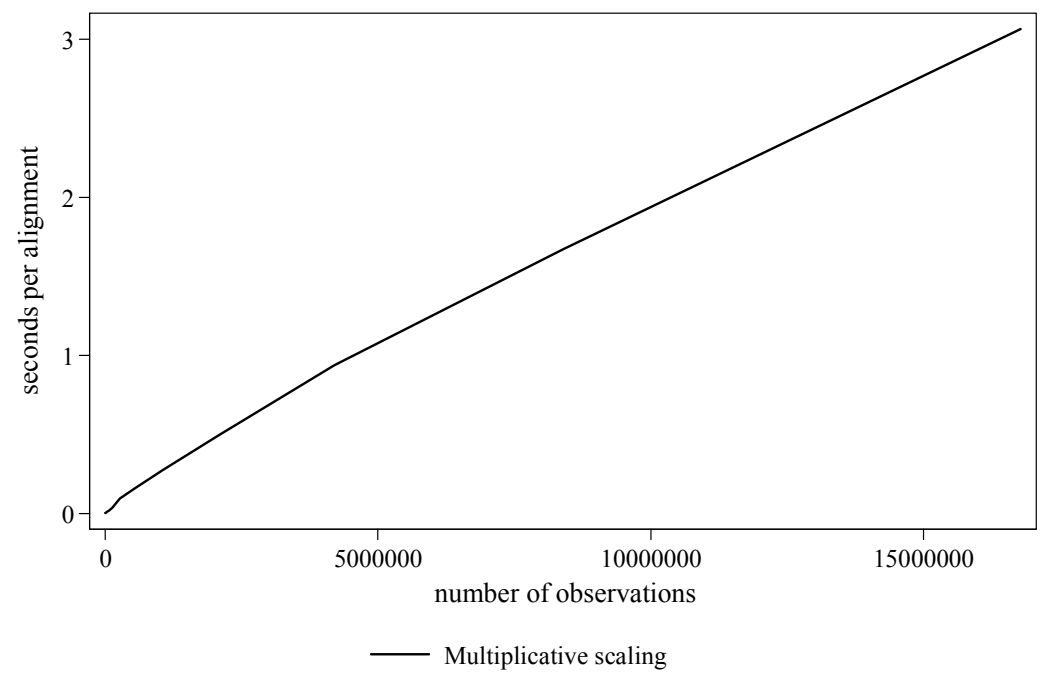

Figure 4.4 Computational Time Curve of Sidewalk and Central limit theorem approach

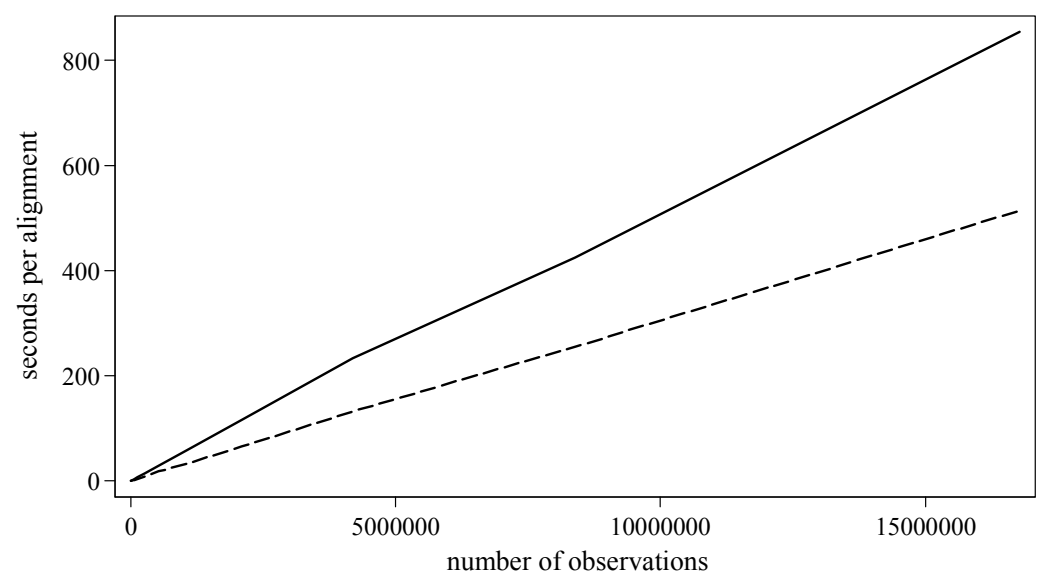

Sidewalk hybrid with non linear adjustment

- - - Central limit approach 
Figure 4.5 Computational Time Curve of Sorting Based Alignment Algorithms

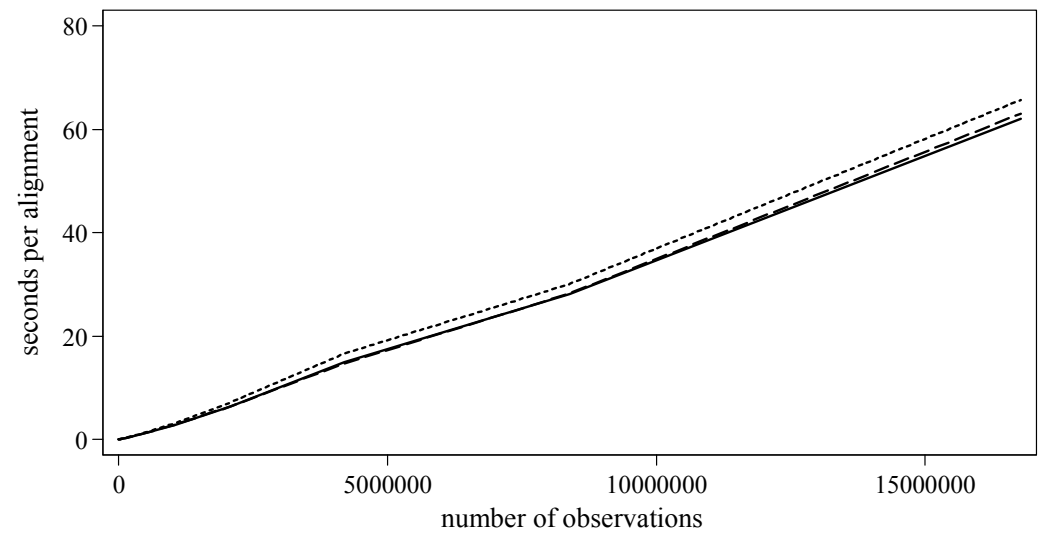

Sorting: predicted probability (SBP)
--- Sorting: difference between predicted probability and random number (SBD)
----- Sorting: difference between logistic adjusted random number and probability (SBDL)

\subsection{Conclusion}

Calibration of the results of a statistical forecasting model using an alignment algorithm has been de facto widely adopted over the past decade in the field of microsimulation despite its controversy. Microsimulation models use alignment for various purposes, e.g. historical data alignment in CORSIM, forecasting alignment in APPSIM etc. Although the alignment cannot be used as a replacement for a well-specified statistical model, it is an effective pragmatic solution in order to undertake analyses of complex phenomena such as the performance of pension systems within a highly complex context of evolving social and economic change. Many alignment methods have been proposed in the literature as the development of dynamic microsimulation progresses.

This chapter fills a gap in the literature in relation to the evaluation of different alignment algorithms. Although the previous literature, (Johnson, 2001; Morrison, 2006; O'Donoghue, 2010) has listed a limited number of criteria that a "good" alignment method should meet, and has analysed some theoretical expectations of alignment simulation properties and their performances (Morrison, 2006), there is no direct or quantitative comparison of the various methods.

In this chapter, most binary model alignment techniques, including multiplicative scaling, hybrid sidewalk method, central limit theorem approach and sorting based algorithms (including its variations) have been reviewed and evaluated. The chapter compared 
different algorithms through a set of indicators including the false positive rate, false negative rate, target deviation index (TDI), distribution deviation index (DDI), and computation time. The TDI gives a scale independent view on how well an alignment method replicates the external control, while the false positive and false negative rates give an overview on the general quality of the output following the alignment. The preservation of inter-correlations is measured by the DDI, an indicator ranging from 0 to 1 , which calculates the distance between the ideal distribution and the actual distribution after the alignment.

The evaluations reported a mixed result of alignment performances and showed that the selection of the "best" alignment method is not only concerned with the algorithm design, but also the requirements and reasoning of a particular scenario.

Overall, multiplicative scaling is the easiest to implement and the fastest to compute method for alignment, as it was able to align more than 3 million observations in less than 1 second on a laptop computer in 2010 . Nonetheless, it cannot perfectly alignments to an external control as the events are calculated purely based on the calculated probabilities. Moreover, due to the lack of restrictions in the algorithm design, the outcome produced by the multiplicative scaling method is subject to higher fluctuations than other methods.

The sidewalk hybrid with nonlinear adjustment is a very computationally expensive method due to its nonlinear adjustment and observation iterations. However, the method has an above average performance for all the scenarios tested and it exhibited a similar pattern to one of the sorting based methods, sort by the difference between logistic adjusted predicted probability and random number (SBDL). Because of the logistic transformation applied in both algorithms, both methods are good at handling the error of intercept in a logit model.

The central limit theorem approach tends to have a similar statistical pattern to the multiplicative scaling method, except that it can match the alignment target more precisely. The method exhibits an above average performance in the evaluations with a real world dataset, although it performs poorly in the first scenario using the synthetic data, where the intercept in the equation is shifted. Nonetheless, the algorithm is very slow when implemented in Stata due to the need for observation iteration.

With regard to the sorting based algorithms, the sort by probabilities (SBP) method yielded the best results in terms of false positive and false negative rates, whilst it distorted the internal distributions heavily in most cases. This is due to the nature of the algorithm which over-predicts the observations with higher probabilities and under-predicts the observations with lower probabilities. However, the method is easy to implement and does not involve random number sorting. Its simulation properties suggest that $S B P$ is a good method for imputation, but not ideal for forward or backward simulation. 
The Sort by the difference between predicted probability and random number (SBD) and the Sort by the difference between logistic adjusted predicted probability and random number $(S B D L)$ are similar in terms of computation steps, but produce very different distributions of probabilities. $S B D L$ works better with logit models, especially when the intercept is used for alignment calibration, whereas $S B D$ seems to have below average performances when looking at all indicators and scenarios.

As the results show, the selection of alignment methods is more complicated than previously thought, with each algorithm having its own advantages and disadvantages. For a microsimulation project that is speed oriented, multiplicative scaling seems to be a good choice, but the central limit theorem approach could also be considered when implemented in a compiled language, such as $\mathrm{C} / \mathrm{C}++$. In a project where speed is not a major concern, the choice might depend on the reason for the alignment. For instance, if the alignment is to be used to create a shift in intercept, $S B D L$ or sidewalk hybrid with nonlinear transformation may be the best choice. In addition, for microsimulation analysis where the focus is on distributional analysis, SBP may not be ideal because of its distortion of distributions.

Understanding the simulation properties is not an easy job as there are many implicit and explicit assumptions in every simulation project. The evaluation method used in this chapter also has its own limits. In the synthetic dataset based tests, the evaluations only covered the most common scenarios. However, the sources of errors in a real simulation are more complex than has been illustrated and the assumption regarding the distribution of independent variables, e.g. normal distribution, may not always be true. Further work is required to understand the simulation properties of different methods under different assumptions and more complicated error structures. In addition, algorithms should also be evaluated using further panel datasets with stripped-down microsimulation models in order to understand the impact of alignments in real-life projects. 


\subsection{References}

Anderson, J.M., 1990. Micro-Macro Linkages in Economic Models, in Lewis, G.H., Michel, R.C. (eds.) Microsimulation techniques for tax and transfer analysis. Washington DC: Urban Institute.

Bacon, P. B., 2009. Microsimulation, Macrosimulation : model validation, linkage and alignment, NATSEM Working paper

Baekgaard, H., 2002. Micro-macro linkage and the alignment of transition processes : some issues, techniques and examples, National Centre for Social and Economic Modelling Technical paper

Bardaji, J., B. Sédillot and E. Walraet., 2003. Un outil de prospective des retraites: le modèle de microsimulation Destinie, Économie et prévision pp. 193-214.

Caldwell S., Favreault M., Gantman A., Gokhale J., Johnson T. and Kotlikoff L.J., 1998. Social Security's Treatment of Postwar Americans, NBER Working Paper No. W6603

Caldwell S. and R. Morrison, 2000. Validation of longitudinal microsimulation models: experience with CORSIM and DYNACAN, in Mitton et al. (eds.) Microsimulation in the New Millennium, Cambridge: Cambridge University Press.

Chénard, D., 2000a. Earnings in DYNACAN: distribution alignment methodology, Paper Presented to the 6th. Nordic Workshop on Microsimulation, Copenhagen, June.

Chénard, D., 2000b. Individual alignment and group processing: an application to migration processes in DYNACAN D. in Mitton, L., Sutherland, H. and Weeks, M. Microsimulation Modelling for Policy Analysis: Challenges and Innovations. Cambridge: Cambridge University Press.

Curry, C., 1996. PENSIM: A Dynamic Simulation Model of Pensioners' Income, in Government Economic Service Working Paper No. 129, London: Analytical Services Division , Department of Social Security.

Davies, J.B., 2004. Microsimulation, CGE and Macro Modelling for Transition and Developing Economies. UNU/WIDER research paper

Duncan, A., \& Weeks, M., 1998.. Simulating transitions using discrete choice models, In Proceedings of the American Statistical Association (Vol. 106, p. 151-156)

Flood, L., Jansson, F., Pettersson, T., Sundberg, O., Westerberg, A., 2005. SESIM III-a Swedish dynamic micro simulation model. Handbook.

Flood, L., 2007. Can we Afford the Future? An evaluation of the new Swedish pension system, Modelling our future: population ageing, social security and taxation pp. 33 .

Harding, A., 2007. Challenges and Opportunities of Dynamic Microsimulation Modelling": Citeseer.

Johnson, T., 2001. Nonlinear Alignment by Sorting, CORSIM Working Paper

Kelly, S. and R. Percival, 2009. Longitudinal benchmarking and alignment of a dynamic microsimulation model, IMA Conference Paper.

Li, J., O'Donoghue, C., 2010. Simulating Histories for Dynamic Microsimulation Models, in: O’Donoghue, C. (Ed.), Life-Cycle Microsimulation Modelling: Constructing and Using Dynamic Microsimulation Models. LAP LAMBERT Academic Publishing.

Liegeois, P., 2010. MiDaL Project Meeting Minutes, MiDaL Project Paper 
Mantovani, D., F. Papadopoulos, H. Sutherland and P. Tsakloglou., 2007. Pension incomes in the European Union: policy reform strategies in comparative perspective, Micro-simulation in action: policy analysis in Europe using EUROMOD pp. 27.

Morrison, R., 2006. Make it so: Event alignment in dynamic microsimulation. DYNACAN paper.

Neufeld, C., 2000. Alignment and Variance Reduction in DYNACAN" in Anil Gupta and Vishnu Kapur (eds) Microsimulation in Government Policy and Forecasting. North-Holland.

O'Donoghue, C., 2001. Redistribution in the Irish Tax-Benefit System, PhD Thesis

O’Donoghue, C., 2010. Alignment and calibration in LIAM, LIAM working paper

O’Donoghue, C., Stephen Hynes and John Lennon, 2008. The Life-Cycle Income Analysis Model (LIAM): A Study of a Flexible Dynamic Microsimulation Modelling Computing Framework", International Journal of Microsimulation.

Scott, A., \& A., 2001. computing strategy for SAGE: 1. Model options and constraints. Technical Note 2. London, ESRC-Sage Research Group.

SOA, 1997. Chapter 5 on CORSIM, Society of Actuaries, [http://www.soa.org/files/pdf/Chapter_5.pdf] accessed June 10th 2010.

SOA, 1998. Chapter 6 on DYNACAN, Society of Actuaries, [http://www.soa.org/files/pdf/Chapter_6.pdf] accessed June 10th 2010.

Stata, 2008. Creating and using Stata plugins, [http://www.stata.com/plugins/] accessed June 10th 2010.

Vandecasteele, L., \& Debels, a., 2007. Attrition in Panel Data: The Effectiveness of Weighting. European Sociological Review, 23(1), 81-97.

Winder, N., 2000. Modelling within a thermodynamic framework: a footnote to Sanders. Cybergeo : European Journal of Geography Systèmes, Modélisation, Géostatistiques, Vol. 138, No. 05. 


\subsection{Appendices}

Appendix 4.A Estimation Results for In-work Variable in LII

\begin{tabular}{|c|c|c|}
\hline \multirow[t]{2}{*}{ Variables } & $\begin{array}{l}\text { Estimation using 1995-2001 } \\
\text { (for in-sample evaluation) }\end{array}$ & $\begin{array}{l}\text { Estimation using 1995-1998 } \\
\text { (for out-of-sample evaluation) }\end{array}$ \\
\hline & $\begin{array}{c}\text { Coefficients } \\
\text { (Standard Error) }\end{array}$ & $\begin{array}{c}\text { Coefficients } \\
\text { (Standard Error) }\end{array}$ \\
\hline Lagged inwork status & $\begin{array}{l}3.86 \\
(0.03)\end{array}$ & $\begin{array}{l}4.00 \\
(0.04)\end{array}$ \\
\hline Gender $($ female $=1)$ & $\begin{array}{l}-0.36 \\
(0.03)\end{array}$ & $\begin{array}{l}-0.46 \\
(0.04)\end{array}$ \\
\hline Age & $\begin{array}{l}0.15 \\
(0.01)\end{array}$ & $\begin{array}{l}0.19 \\
(0.01)\end{array}$ \\
\hline Age squared & $\begin{array}{l}0.002 \\
(0.00)\end{array}$ & $\begin{array}{l}0.002 \\
(0.00)\end{array}$ \\
\hline Secondary education & $\begin{array}{c}0.96 \\
(0.03)\end{array}$ & $\begin{array}{c}1.01 \\
(0.05)\end{array}$ \\
\hline University education & $\begin{array}{c}1.20 \\
(0.03)\end{array}$ & $\begin{array}{c}1.24 \\
(0.05)\end{array}$ \\
\hline $\begin{array}{l}\text { Interaction term: new-born } \\
\text { and gender }\end{array}$ & $\begin{array}{l}-0.33 \\
(0.12)\end{array}$ & $\begin{array}{l}-0.25 \\
(0.15)\end{array}$ \\
\hline $\begin{array}{l}\text { Interaction term: marriage } \\
\text { and gender }\end{array}$ & $\begin{array}{l}-0.44 \\
(0.04)\end{array}$ & $\begin{array}{l}-0.51 \\
(0.06)\end{array}$ \\
\hline Constant & $\begin{array}{l}-4.58 \\
(0.1)\end{array}$ & $\begin{array}{l}-5.26 \\
(0.14)\end{array}$ \\
\hline Number of Observations & 61232 & 36053 \\
\hline
\end{tabular}

N.B. Models were estimated using standard Logit 
Appendix 4.B Actual vs. Aligned Probabilities with Synthetic Datasets

Synthetic Dataset Scenario 1: Sample bias
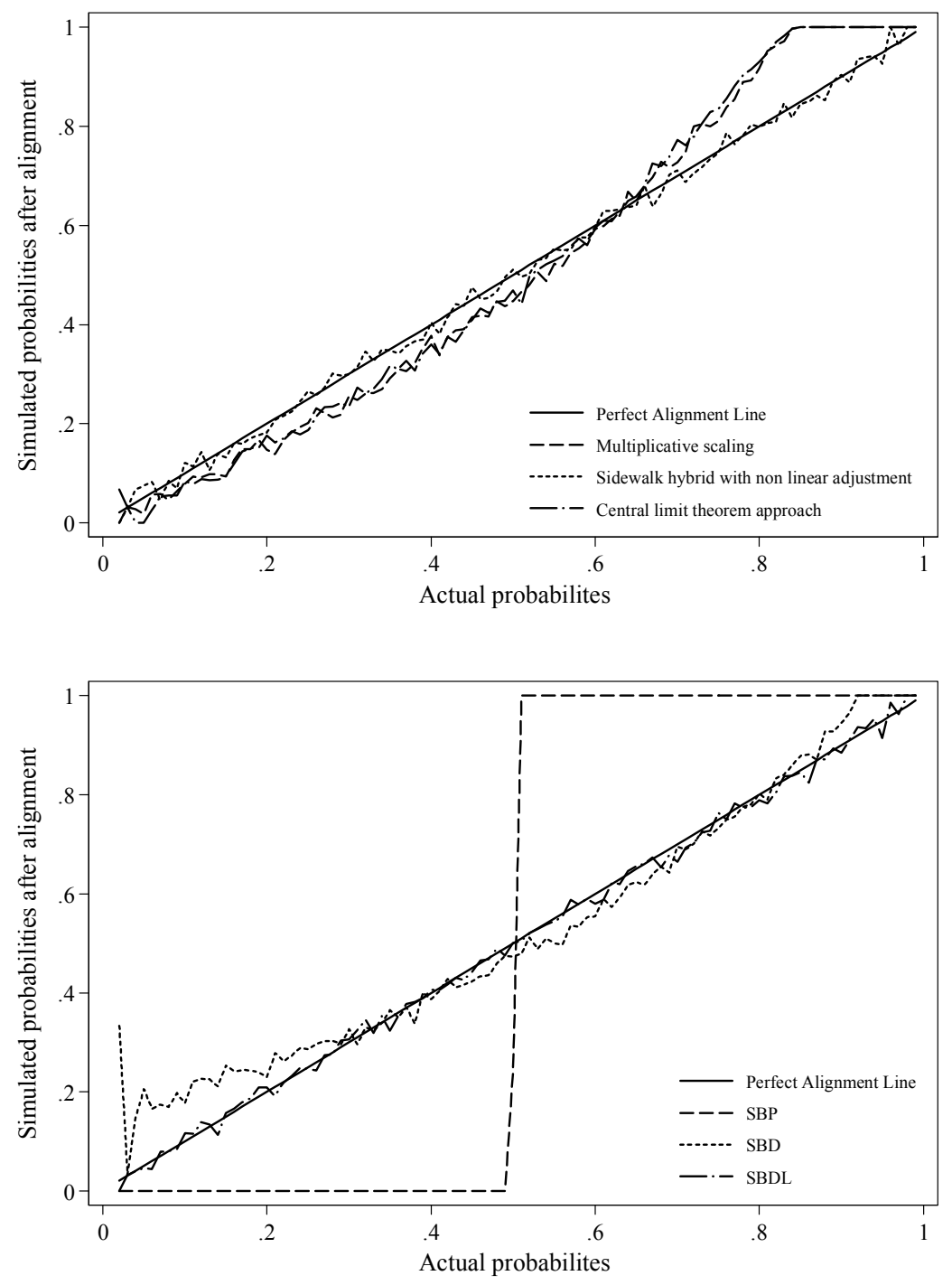
Synthetic Dataset Scenario 2: Biased Alpha (Intercept)
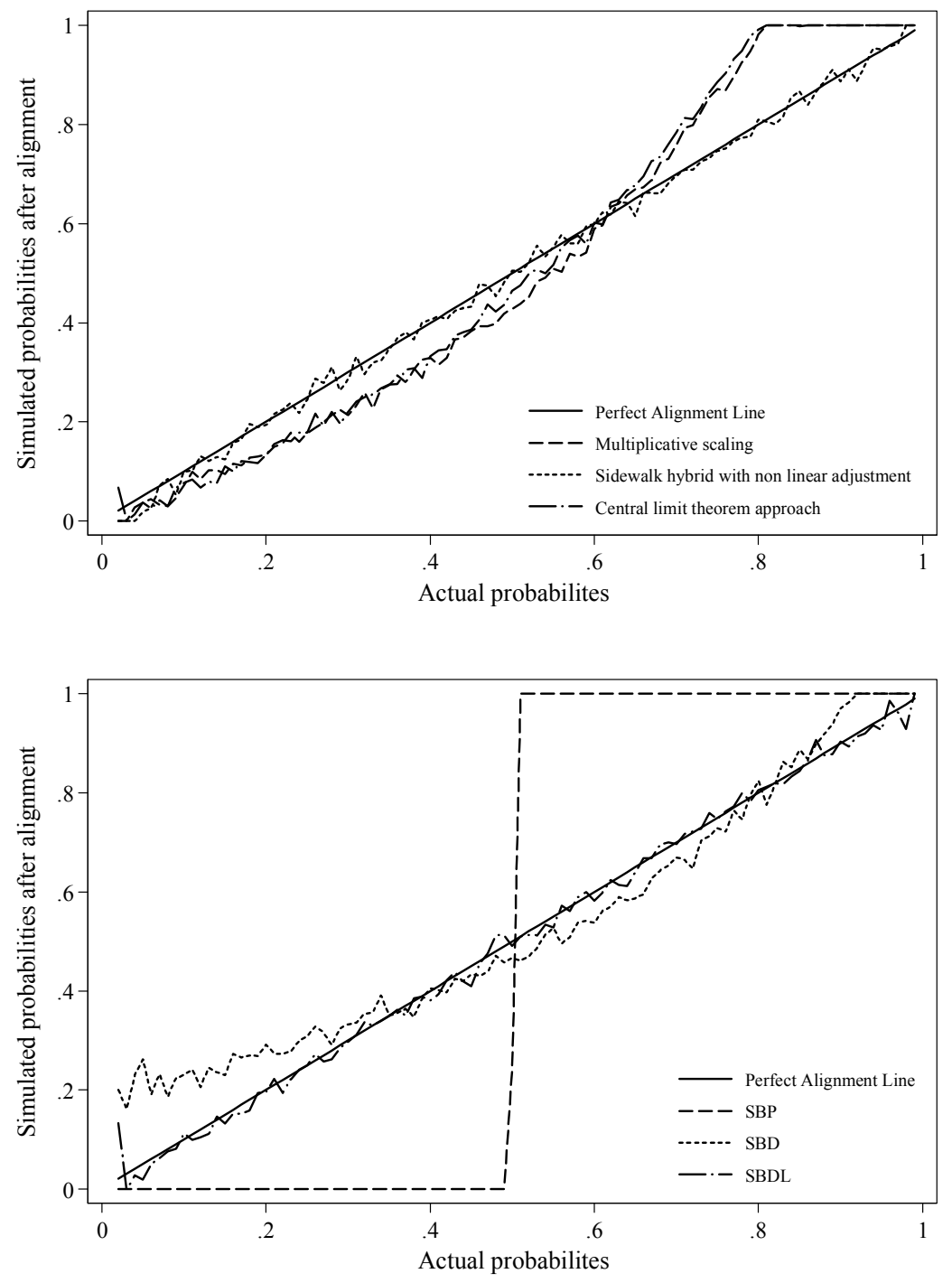
Synthetic Dataset Scenario 3: Biased Slope (Beta)
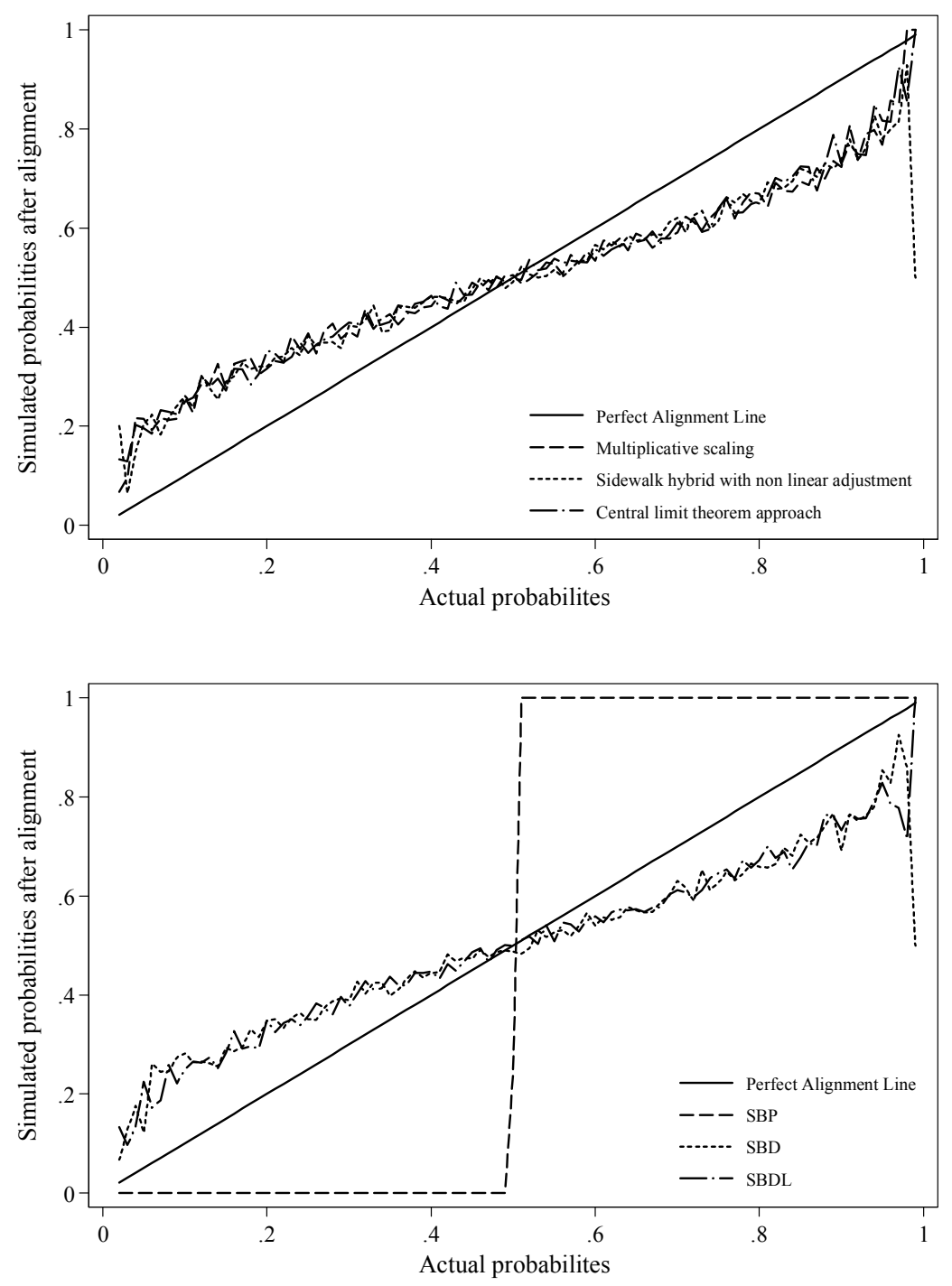
Synthetic Dataset Scenario 4: All coefficients biased
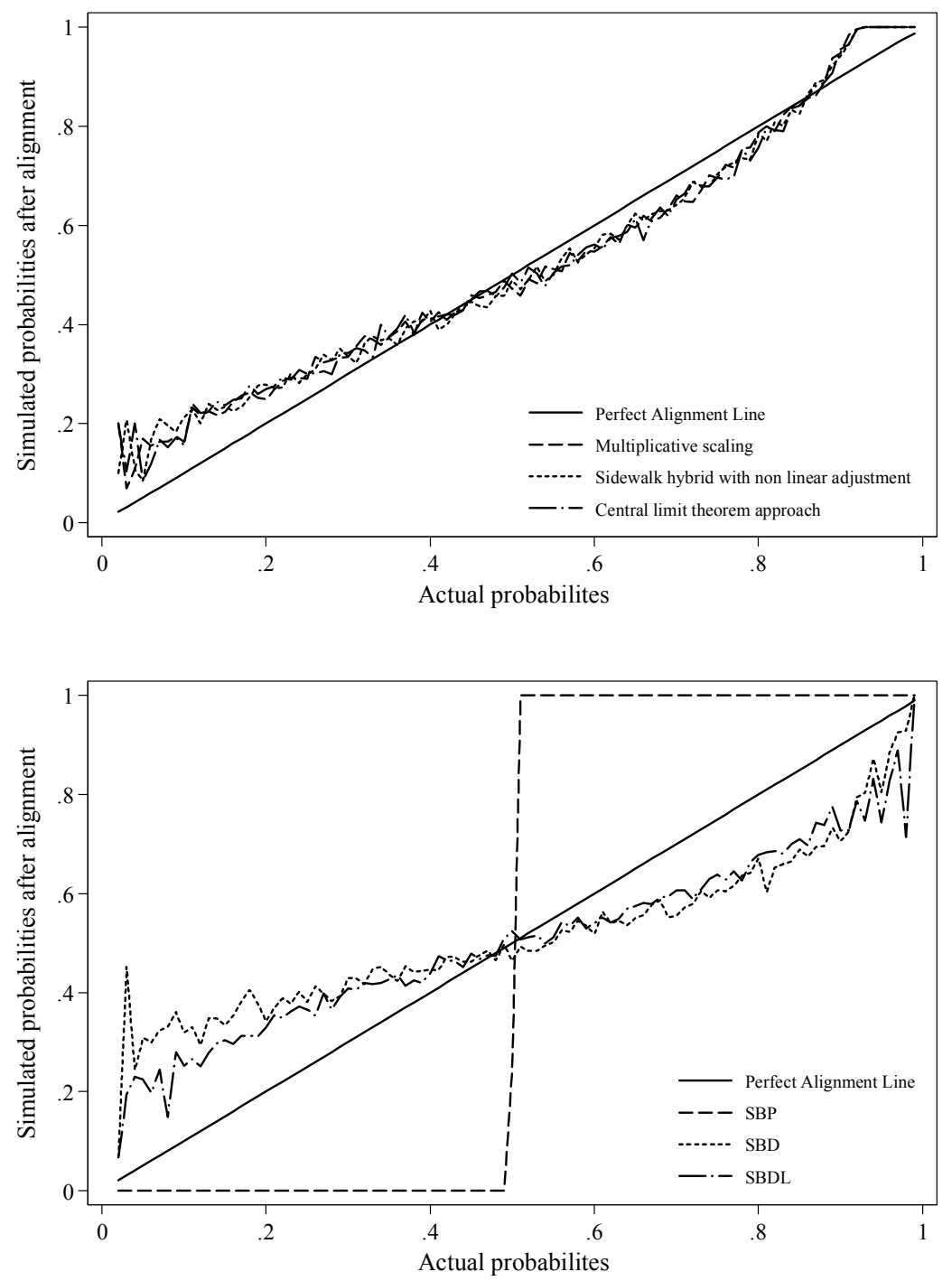

Abbreviations used in Appendix 4.B

- SBP: Sort by predicted probability

- SBD: Sort by the difference between predicted probability and random number

- SBDL: Sort by the difference between logistic adjusted predicted probability and random number 
Appendix 4.C Computation Efficiency and Scalability

\begin{tabular}{lcccc}
\hline \multicolumn{1}{c}{ Method } & \multicolumn{5}{c}{ Computation time for Nobservations (seconds) } \\
& $\begin{array}{c}N=65536 \\
\left(2^{16}\right)\end{array}$ & $\begin{array}{c}N=524288 \\
\left(2^{19}\right)\end{array}$ & $\begin{array}{c}N=4194304 \\
\left(2^{22}\right)\end{array}$ & $\begin{array}{c}\text { Average } \\
\text { Computation Time } \\
\text { for one million } \\
\text { observations }\end{array}$ \\
\hline $\begin{array}{l}\text { Multiplicative scaling } \\
\text { Sidewalk hybrid with nonlinear } \\
\text { adjustment }\end{array}$ & 0.02 & 0.15 & 1.19 & 0.28 \\
$\begin{array}{l}\text { Central limit theorem approach } \\
\begin{array}{l}\text { Sort by predicted probability } \\
\text { SBP) }\end{array}\end{array}$ & 2.03 & 29.20 & 233.83 & 55.61 \\
$\begin{array}{l}\text { Sort by the difference between } \\
\text { predicted probability and }\end{array}$ & 0.14 & 1.29 & 132.27 & 31.55 \\
random number (SBD) \\
$\begin{array}{l}\text { Sort by the difference between } \\
\text { logistic adjusted predicted } \\
\text { probability and random number } \\
\text { SBDL) }\end{array}$ & 0.13 & 1.28 & 14.94 & 3.18 \\
\hline
\end{tabular}

N.B. Results obtained using Stata 11 SE on a Windows 7 box with Intel i5-520M CPU 
Appendix 4.D Distribution Deviation in LII dataset

\begin{tabular}{cc}
\hline Year & $\begin{array}{r}\text { DDI using previous year's distribution } \\
\text { as the benchmark value }\end{array}$ \\
\hline 1995 & $0.60 \%$ \\
1996 & $0.46 \%$ \\
1997 & $0.76 \%$ \\
1998 & $0.69 \%$ \\
1999 & $0.92 \%$ \\
2000 & $1.11 \%$ \\
2001 & $0.65 \%$ \\
\hline
\end{tabular}




\title{
[5] A Continuous Labour Supply Model in Microsimulation ${ }^{12}$
}

\author{
A Life-cycle Modelling Approach with \\ Heterogeneity and Uncertainty Extension
}

${ }^{12}$ This chapter is available as: Li, J. and Sologon, D., 2011. Simulating Labour Supply: A Lifetime Modelling Approach with Heterogeneity and Uncertainty Extension, IZA Discussion Paper No. 6098 


\subsection{Introduction}

The empirical literature on labour supply has gained an increasing interest over the past decades. The continuous approach in the tradition of Burtles and Hausman (1978) has been complemented by an approach which focuses on a discrete choice specification, mainly inspired by Van Soest (1995). Most studies focus on estimating and simulating labour supply in a static context, whereas only a few focus on the dynamics of labour supply (Blundell and MaCurdy, 1999).

Some of the existing models for estimating and/or simulating labour supply in a static or dynamic setting lack the robustness of economic theory. Other models are based on specifying utility functions used to derive consistent labour supply functions, which is fundamental for projecting the labour supply behaviour. The latter models, however, suffer from two major shortcomings. First, as utility is not observed, many assumptions are assumed in order to estimate the parameters of the utility function. This becomes less robust when more items/behaviours are introduced into the utility function. Secondly, this approach does not incorporate individual heterogeneity as every agent shares the same parameters.

Some models deal with the heterogeneity problem by capturing the individual specific effects using error components models or by estimating random-coefficients models. The individual specific effect is used in the context of the fixed or random effects estimations, where the main issue concerns the choice between fixed and random effects and whether the individual specific effects can be assumed to be independent of the explanatory variables included in the model. Assuming that the individual component is correlated with the explanatory variables triggers many problems when undertaking a simulation. The estimated coefficients cannot be used to generate a conditional prediction of individual earnings without specifying the joint process determining the individual specific effects and the explanatory variables (Pudney, 1992). The impracticality of this option, together with the fact that the fixed-effect specification cannot accommodate covariates that are constant over time, constrained most studies to maintain the assumption of a zero correlation between the individual specific effects and the other covariates, a rather strong and improbable assumption. The main drawback of the error components models is that they provide less stable simulations due to the stochastic components, which affects the reproducibility of the results.

One way to incorporate the heterogeneity effects is to use random coefficient models. Provided that heterogeneity is present in the empirical models of labour supply, the application of random coefficients models is necessary to avoid biased estimates. The main drawback of these models, however, is their high computational cost. Given this limitation, existing studies suggest that if heterogeneity is non-existent or the bias is insignificant, the standard fixed coefficient models represent the optimal choice (Haan, 2004). Several 
studies estimating discrete choice labour supply models compare the fixed and random specifications and find no significant differences between the results (van Soest, 1995; Duncan and MacCrae, 1999; Haan, 2004) The estimation of continuous labour supply models using the random coefficient specification is limited.

This chapter proposes a structural inter-temporal model of labour supply, which estimates and predicts the dynamics of labour supply in a continuous setting. It aims to capture the individual heterogeneity to a larger extent than the existing labour supply models while maintaining the consistency with the lifetime economic theory. The model is estimated using both a transformed fixed effect specification that circumvents the standard problems mentioned above, and a random coefficient specification. Additionally, the model incorporates uncertainties regarding future wages to further explore the heterogeneities.

\subsection{Theoretical Background}

Most of the empirical work on labour supply is based on a static, within-period framework, where the labour supply decision rule refers to one period. Typically, the annual hours of work are regressed on the current hourly wage rate and some measure of property income. Labour supply responses are estimated using the standard labour supply models, which ignore the importance of future wages on current hours supplied. This yields a wage coefficient that confuses the labour supply response to three types of wage changes: "evolutionary wage changes" arising from movements along the lifetime wage profile, "parametric wage changes" arising from shifts in the wage profile, and those arising from changes in the profile slopes. As a result, the wage coefficients reported in many empirical studies have no economic interpretation and are not useful for policy evaluations (MaCurdy, 1980).

The elasticity derived from the static specification can be placed in an inter-temporal setting, but is economically meaningful only under the strong assumption of either complete myopia or perfectly constrained capital markets. These assumptions imply that it is impossible to transfer capital across periods. In this situation, the coefficient on wage represents the uncompensated substitution elasticity given income, equivalent to the Marshallian wage elasticity in the static model (Blundell and MaCurdy, 1998).

There are three types of substitution elasticises relevant for predicting the response of hours of work to changes in the wage rate: the inter-temporal elasticity, which determines the labour supply wage changes resulting from life-cycle wage growth and movements over a perfectly foreseen business cycle, the uncompensated elasticity, which determines the labour supply response to shifts in wage profiles whilst holding the marginal utility of wealth constant, and the compensated elasticity, which can be used to predict the differences in hours of work across consumers with different wage profiles but an identical 
lifetime utility constant. In order to estimate meaningful behavioural parameters for the inter-temporal and the uncompensated substitution effects, it is crucial to recognize that individuals make their labour supply decisions within a life-cycle framework. Moreover, formulating a model that relies on the economics of lifetime behaviour leads to a better understanding of consumer behaviour (Blundell and MaCurdy, 1998; MaCurdy, 1980).

The acknowledgement that labour supply is part of a lifetime decision process is realized by the multi-period models of labour supply. In the context of this chapter, special attention is devoted to the Frisch labour supply functions, which estimate the effect of labour supply whilst holding the marginal utility of wealth constant. These functions are useful when analysing life-cycle maximization problems. The Frisch labour supply functions represent a third type of labour supply functions together with the Marshalling and Hicksian functions.

The original interest in the life-cycle labour supply is motivated by the need to investigate the various dimensions of labour supply, such as the determinants of the shape of the lifecycle hours profile, the labour supply response to the aggregate wage, the changes and the source of the idiosyncratic year-to-year changes in labour supply. The existing literature, however, manages to shed little light on the original questions focusing mainly on one aspect of the inter-temporal hours variation - the labour supply response to the wage growth along a known life-cycle trajectory, whilst ignoring other aspects. One ignored aspect is the labour supply response to wage changes under uncertainty, meaning wage changes that determine individuals to revise their expectations of their future wages (Card, 1991). MaCurdy $(1983,1985)$ makes the most significant contribution in incorporating uncertainty.

The life-cycle framework is proposed as an explanation for all the components of the individual labour supply (Card, 1991). Lucas and Rapping (1970) consider that the lifecycle model can be used to explain the aggregate year-to-year movements in labour supply "time effects". Heckman (1974, 1975), Ghez and Becker (1975) claim that the life-cycle model is able to explain the systematic age effects in hours of work ("age effects") and the differences across people with respect to their hours of work over the life-cycle "personspecific effects”. MaCurdy (1980) and Altonji (1986) formulate life-cycle models of labour supply which explain the "person-and-year specific" changes in hours of work through changes in wages.

In the context of estimating and simulating life-cycle labour supply, the choice of the labour supply elasticity to be simulated depends on the scope of the exercise. If the interest is in comparing the impact of wage variations across consumers on labour supply, the variation in the entire wage profile must be examined. Because the variation of the wage profile affects the value of the marginal utility of wealth, Frisch elasticity cannot be used to measure the effect of this variation. The estimation of the full impact on wages requires the 
estimation of the effect of the shifts of the wage profile on the hours of work besides the estimation of the inter-temporal elasticity.

The estimation of the parametric shift requires the specification of the impact of the wage profile on the marginal utility of wealth. The estimation of the uncompensated substitution elasticity is undertaken in a limited number of studies as it relies on specifying the functional form of the "marginal-utility-of-wealth constant" parameter, proven to be difficult in practice. Some studies (MaCurdy 1980, 1985) ignore the functional form of this parameter because of its complicated functional form in initial assets, lifetime wages, the interest rate, the rate of time preference and the "taste" parameters. They assume that the approximation of its life-cycle specification is a linear function of measured characteristics, the natural log of wages at each age, initial wealth and an unobserved random variable representing unmeasured characteristics. Others derive an expression of the marginal utility of wealth by taking into account the restrictions of the optimization process (e.g. Bover, 1989).

The estimation of the full impact of wage changes, both evolutionary and parametric, are of core importance for policy evaluation. Assuming that the tax and benefit reforms represent unanticipated shifts in net real wages today and in the future, the elasticity measuring the cumulated response to evolutionary changes and parametric shifts in the life-cycle wage profile represent the most appropriate means for describing the response to these reforms (Blundell and MaCurdy, 1981).

\subsection{Aife-Cycle Model of Labour Supply}

The model in this chapter follows the theoretical specification introduced by MaCurdy (1980, 1985) and Medoff and Abraham (1981), and the unifying labour supply framework introduced by Blundell and MaCurdy (1998). The model aims to estimate the effect of evolutionary wage changes assuming no parametric shift in the wage profiles.

The labour supply responses are estimated and simulated under two scenarios: first, assuming that individuals make labour supply decisions in a world of perfect certainty, and second, assuming that individuals make decisions in a world in which they are uncertain about their future wages.

\subsubsection{A Life-Cycle Model of Labour Supply under Certainty}

Under the assumption of certainty, the effect of evolutionary wage changes on hours of work represents the conventional "marginal-utility-of-wealth constant" inter-temporal elasticity of labour supply obtained from the Frisch labour supply equations and the Euler condition. The marginal-utility-of-wealth parameter serves as a sufficient statistic that 
captures the information from the other periods needed to solve the maximization process in the current period (Blundell and MaCurdy, 1998).

The inter-temporal elasticity estimated from the Frisch specifications is relevant for predicting the individual labour supply into the future assuming a steady state, mainly due to the presence of the marginal utility of wealth, which is individualized, constant over time, and accounts for the worker's future plans (MaCurdy, 1980).

Following MaCurdy (1980, 1983), the theory underlying the model of lifetime hours of work used in this chapter represents an extension of Friedman's (1957) permanent income theory to a situation where the relative price of consumption and leisure varies over the life-cycle. The permanent income hypothesis can be extended to the lifetime labour supply to assume that individuals/households look into the future when deciding the current number of hours supplied on the labour market. This theory allows us to make the distinction between a consumer's dynamic behaviour and the factors determining the differences in hours of work between consumers. This separation leads to a manageable empirical model that accommodates the differentiation between the labour supply responses to evolutionary changes and those to parametric changes in the wage profiles.

\subsubsection{An economic model of labour supply under certainty with homogenous preferences and heterogeneous individual effects}

This section presents an economic model of life-cycle labour supply decisions assuming that a worker takes his/her decisions in an environment of perfect certainty with respect to his/her future income. The worker is assumed to choose consumption and hours of work at each age to maximize a lifetime preference function, strongly separable over time, subject to wealth constraints. The model described in this chapter is designed for single decisionmakers, but an extension to joint decision makers is straightforward.

In the application below, male's labour supply behaviour is considered as independent while women's labour supply is conditioned on other household incomes besides their own earnings. Assuming that the consumer $i$ at the age of $t$ has a utility given by the concave function $U_{t}(C(t), L(t), X(t))$, where $C(t)$ is the consumption at age $t, L(t)$ is the number of hours of leisure at age $t$ and $X(t)$ is a vector of "taste shifters" variables at age $t$, the vector $X(t)$ can include both observed and unobserved variables.

Due to the assumption of separating utility, the lifetime preference function can be formally presented as the sum of discounted future utilities at the moment $t=a$, equivalent to the beginning of the active life, where $t$ represents age and $a$ the age of entrance into the labour market: 


$$
\sum_{t=a}^{T} \frac{1}{(1+\rho)^{t}} U_{t}(C(t), L(t), X(t))
$$

The lifetime (active life) is assumed to consist of $T-a+1$ periods, where $T$ represents the age of retirement. The rate of time preference used for discounting the value of future utility is represented by $\rho$. Formally, the consumer has to choose $C(t)$ and $L(t)$ at each age to maximize their lifetime preference function (5.1) subject to a lifetime wealth constraint:

$$
A(0)+\sum_{\mathrm{t}=a}^{\mathrm{T}} R(t) H(t) W(t)=\sum_{t=a}^{T} R(t) C(t)
$$

Where $A(0)$ is the level of assets at the beginning of the active life of each consumer, $H(t)$ the number of labour market hours at age $t, W(t)$ the exogenous wage rate at age $t$, then $R(t)=1 /\left((1+r(1))^{*} \ldots{ }^{*}(1+r(t))\right)$ is the discount rate which is used to convert the real income at age $t$ into its equivalent for age $a$ and $j$ refers to the sample period. In period $j$, the consumer can borrow and lend at a rate of interest equal to $r(j)$. It is assumed that the rate of interest stays constant over time, so that the discount rate at age $R(t)=1 /(1+r(t))^{t}$.

To create the Frisch labour supply functions, it is assumed that the contemporaneous utility function for each individual at age $t$ takes the form:

$$
U_{i t}=G\left(C_{i t}, X_{i t}\right)-\Psi_{i t}\left(H_{i t}\right)^{\sigma}
$$

Where $G$ is a monotonically increasing function of $C_{i t}, \sigma$ is a time-invariant preference parameter common across consumers and $\Psi_{i t}$ is an age-specific parameter of "tastes", which depends on the consumer characteristics expected to influence his/her utility at age $t$ (age, education, number of children, etc.). The participation decision is included in the preference parameter. The analysis assumes $\Psi_{i t}$ is related to the worker's characteristics by the function $\Psi_{i t}=\exp \left\{-X_{i t} \psi^{*}-v_{i t}^{\prime}\right\}$ where $v_{i t}^{\prime}$ represents the contribution of unobserved characteristics and $\psi^{*}$ is a vector of preference parameters. Assuming an interior optimum, the implied Frisch labour supply function or marginal utility of wealth constant labour supply function is obtained from maximizing the utility in period $t$ subject to the lifetime wealth constraint. The Lagrange function then takes the form:

$$
\mathcal{L}_{i}=U_{i t}-\lambda_{i}\left(A_{i 0}+\sum_{t=0}^{T} R_{t} H_{i t} W_{i t}-\sum_{t=0}^{T} R_{t} C_{i t}\right) .
$$


The notation is simplified by considering the age of entrance into the labour market equal to zero. The first order conditions result in the Frisch or " $\lambda$ constant" consumption and labour supply functions:

$$
C_{i t}=C\left(\lambda_{i}, W_{i t}, X_{i t}\right) ; H_{i t}=H\left(\lambda_{i}, W_{i t}, X_{i t}\right)
$$

The first order condition with respect to hours of work at age $t$ implies that:

$$
\ln H_{i t}=\alpha(\ln \lambda-\ln \sigma)+\psi X_{i t}+\beta t+\alpha \ln W_{i t}+v_{i t}
$$

Where $\alpha=\frac{1}{1-\sigma} ; \psi=\alpha \psi^{*}, v_{i t}=\alpha v_{i t}^{*}$, and $\beta=\alpha(\rho-r)$. At this stage of the analysis the assumption is that $\alpha, \psi$ and $\beta$ are constant across consumers and time.

The expression (5.4) represents the Frisch or marginal utility of wealth constant labour hours of work function. Its functional form depends on the form of the utility function and on whether a corner solution is chosen for hours of work at age $t$ (Blundell and MaCurdy, 1999). If an individual chooses to participate in the labour market, then model (5.4) applies and an interior solution is assumed. If however, the decision is not to participate, the hours of work are set to zero.

The Frisch labour supply function decomposes the labour supply decision with respect to the hours of work into personal and professional characteristics ( $X_{i t}$ and age) observed at time $t$, the wage rate at time $t\left(W_{i t}\right)$ and the $\lambda$ component, which represents the sufficient statistic summarizing the relevant information for each consumer from the other periods.

The optimal value of $\lambda$ is obtained by substituting the $\lambda$ constant consumption and labour supply functions into the budget constraint given by equation (5.3). $\lambda$ is expressed as a function of initial assets, lifetime wages, interest rates, rates of time preference and tastes. In other words, $\lambda$ summarizes the lifetime information that the consumer requires when choosing his/her optimal level of current consumption and labour supply. $\lambda$ represents the correspondent statistic to the permanent income from Friedman's (1957) permanent income theory and represents a permanent component, which together with the current wage, determines the consumer's current consumption and labour supply. $\lambda$ also represents a statistic capable of characterising historic and future information for lifetime wages and assets that are relevant for the current choices of consumption and labour supply. The general conclusion is that, assuming perfect certainty, the " $\lambda$ constant" consumption and labour supply functions fully characterize a consumer's dynamic behaviour (Blundell and MaCurdy, 1998; MaCurdy, 1980, 1985). 
As shown by Blundell and MaCurdy (1999), in a world of perfect certainty, $\lambda$ can be captured as an individual specific effect, which is constant over time. For this reason, for each individual, changes in wages have no impact on $\lambda$. In conclusion, the Frisch elasticity is the correct elasticity for assessing the impact of the evolutionary changes along the lifecycle wage profile on labour supply. The main characteristics of the $\lambda$ component, the fact that it is specific to each individual, constant over time and incorporates the future plans of each worker in a simple way, allows the use of the $\lambda$ constant function (5.4) to forecast individual labour supply outside the sample period.

Given that $\lambda$ is time-invariant and unique for each worker, the intercept term from the labour supply equation (5.4) is:

$$
F_{i}=\alpha\left(\ln \lambda_{i}-\ln \sigma\right)
$$

This represents a time-invariant component, unique to each individual and can therefore be treated as a fixed effect in the estimation. The argument in favour of this choice steams from the content of the $\lambda$ component that depends on the past and future information of the variables relevant for determining the individual labour supply. Because $\lambda$ is correlated with the exogenous variables in the model, the natural conclusion is that $F_{i}$ is also correlated with the exogenous variables in the model, and therefore cannot be treated as a "random effect". The parameters in model (5.4) are estimated by fixed effects. In order to circumvent the problem induced by the fixed effects specification in a simulation context, this chapter applies a three-stage procedure to decompose the unit fixed effects.

The empirical specification of the individual effects requires a formal specification of the $\lambda$ component. The one obtained from the optimisation process is too complicated to estimate it empirically. This chapter adopts the suggestions made by MaCurdy (1981), Blundell and MaCurdy (1999). For the empirical specification, $\ln \lambda_{i}$ can be approximated by:

$$
\ln \lambda_{i}=D_{i} \varphi^{*}+\sum_{t=0}^{T_{i}} \gamma_{t}^{*} \ln W_{i t}+A_{i 0} \vartheta^{*}+a_{i}^{*}
$$

$D_{i}$ is a vector of observed time-invariant characteristics or rarely changing variables, $\varphi^{*}$, $\gamma_{t}^{*}, \vartheta^{*}$ are parameters assumed constant across consumers, and $a_{i}^{*}$ is an error term. This empirical specification imposes strong restrictions, as it is assumed that the worker knows he/she will work $T_{i}$ years, and their total lifetime income. It also incorporates the effect of interest rates and rates of time preference in the intercepts and the other parameters. Under this assumption, the time-invariant intercept of equation (5.4) can be approximated by: 
$F_{i}=\alpha\left(D_{i} \varphi^{*}+\sum_{t=0}^{T_{i}} \gamma_{t}^{*} \ln W_{i t}+A_{i 0} \vartheta^{*}+u_{i t}^{*}-\ln \sigma\right)=D_{i} \phi+\sum_{\mathrm{t}=0}^{\mathrm{T}_{\mathrm{i}}} g_{t} \ln W_{i t}+a_{i}$

$\varphi=\alpha \varphi^{*}, \gamma=\alpha \gamma_{t}^{*}, \vartheta=\alpha \vartheta^{*}$ and the intercept include the term $(-\alpha \ln \sigma)$, and $A_{i 0}$ represents the initial income, assumed to be zero for all individuals. The present value of lifetime income is constant for each individual and can be approximated by functions of all the personal and professional characteristics influencing a lifetime wage path as:

$$
\sum_{\mathrm{t}=0}^{\mathrm{T}_{\mathrm{i}}} \gamma_{\mathrm{t}} \ln W_{i t}=f\left(X_{i 1}, X_{i 2}, \ldots, X_{i T_{i}}\right)
$$

Where $X_{i k}, k=1,2 \ldots, T_{i}$ represents a vector of personal and professional career characteristics which can be expressed as functions of two components: a time invariant part $D_{1}$ and an unobserved part $D_{2}$ :

$$
\sum_{\mathrm{t}=0}^{\mathrm{T}_{\mathrm{i}}} \gamma_{\mathrm{t}} \operatorname{lnW}_{\mathrm{it}}=f\left(X_{i 1}\left(D_{i 1}+D_{i 2}\right), X_{i 2}\left(D_{i 1}+D_{i 2}\right), \ldots, X_{i T_{i}}\left(D_{i 1}+D_{i 2}\right)\right)
$$

Assuming that this is an additive function for $D_{1}$ and $D_{2}$, the present value of the lifetime wage can be approximated by:

$$
\sum_{\mathrm{t}=0}^{\mathrm{T}_{\mathrm{i}}} \gamma_{\mathrm{t}} \ln \mathrm{W}_{\mathrm{it}}=f\left(D_{i 1}\right)+f\left(D_{i 2}\right)
$$

By substituting equation (5.6) into (5.5), the individual effect can be presented as follows:

$$
F_{i}=D_{i} \varphi+f\left(D_{i 1}\right)+f\left(D_{i 2}\right)+a_{i}
$$

The time invariant characteristics $D$, can be decomposed into the observed part $D_{1}$ and the unobserved part $D_{2}$ :

$$
F_{i}=\left(D_{i 1}+D_{i 2}\right) \varphi+f\left(D_{i 1}\right)+f\left(D_{i 2}\right)+a_{i}
$$

The observed part can then be approximated by a linear form of $D_{i 1}$, whereas the unobserved part, assumed to follow a normal distribution, is incorporated in the error term as:

$$
\begin{aligned}
& F_{i}=D_{i 1} \varphi+f\left(D_{i 1}\right)+D_{i 2} \varphi+f\left(D_{i 2}\right)+a_{i} \\
& F_{i}=D_{i 1} \varphi^{*}+\mathrm{c}_{\mathrm{i}}
\end{aligned}
$$

Therefore, the individual unit effect can be approximated by a linear function of the timeinvariant characteristics plus a normally distributed error that accounts for the 
unexplained part of the individual effect. Substituting equation (5.9) into (5.4), the hours of work process can be approximated as follows:

$$
\ln H_{i t}=D_{i} \dot{\varphi}^{*}+\psi X_{i t}+\beta t+\alpha \ln W_{i t}+c_{i}+v_{i t}
$$

The simulation of labour supply based on the economic model given in (5.4) requires also a mechanism for predicting lifetime wage profiles. It is assumed that the lifetime wage profile is:

$$
\ln W_{i t}=L_{i}+\pi_{0, k} P_{i t}+\pi_{1} t+\pi_{2} t^{2}+\varepsilon_{i t}
$$

$L_{i}$ is the individual specific effect, $P_{i t}$ is a vector of personal and professional career characteristics, $\pi_{0, k}$ is a vector of coefficients which are constant across time and individuals, $k$ is the number of personal and professional career characteristics in the model and $\varepsilon_{i t}$ the error term. Experience and education are assumed to be exogenously determined.

\subsubsection{An expansion of the economic labour supply model under certainty with heterogeneous preferences}

In this section, the model is extended by allowing for increased heterogeneity amongst the individuals, who are assumed to have different preferences on their labour supply. The preference parameter $\sigma \sim N(0, \Gamma)$ is individual specific but time invariant. $\alpha_{i}, \beta_{i}$, $\alpha\left(\ln \lambda_{i}-\ln \sigma_{i}\right)$ are assumed to be individual specific and follow normal distributions across individuals. Given these assumptions, the lifetime labour supply function is:

$$
\begin{aligned}
& \ln H_{i t}=\alpha_{i}\left(\ln \lambda_{i}-\ln \sigma_{i}\right)+\psi X_{i t}+\beta_{i} t+\alpha_{i} \ln W_{i t}+v_{i t}, \\
& \ln H_{i t}=\left(\zeta_{0}+\varsigma_{0, i}\right)+\psi X_{i t}+\left(\zeta_{1}+\zeta_{1, i}\right) t+\left(\zeta_{2}+\varsigma_{2, i}\right) \ln W_{i t}+v_{i t}
\end{aligned}
$$

$\alpha\left(\ln \lambda_{i}-\ln \sigma_{i}\right)=\zeta_{0}+\varsigma_{0, i}$ is the individual effect constant over time, $\beta_{i}=\zeta_{0}+\varsigma_{1, i}$ the random coefficient of age and $\alpha_{i}=\zeta_{2}+\zeta_{2, i}$ the random coefficient of wage. $\zeta_{\text {is }}$ the mean intercept of hours of work, $\beta$ the mean slope of age, $\alpha$ the mean slope of the natural logarithm of wage and $\varsigma_{k, i}, k \in[0,2]$ the deviation of individual intercept and slopes from the mean values of $\zeta_{0}, \zeta_{1}, \zeta_{2} \cdot \psi$ is a vector of fixed coefficients, constant across individuals and time.

In addition, in order to allow for increased heterogeneity also in wage, the lifetime wage path has the following specification:

$$
\ln W_{i t}=\left(\pi_{0}+\xi_{0, i}\right)+R_{i t}\left(\pi_{1}+\xi_{1, i}\right)+\left(\pi_{2}+\xi_{2, i}\right) t+\pi_{3} P_{i t}+\pi_{4} t^{2}+\varepsilon_{i t}
$$


$R_{i t}$ and age represents the variables with random coefficients, $\pi_{0}$ represents the mean intercept of wage, $\pi_{k}, k=1,2$ is a vector of coefficients illustrating the mean slopes of $R_{i t}$ and age, and $\xi_{k, i}, k=0,1,2$ represents the deviation of the individual intercepts and slopes from the mean values of $\pi_{0}, \pi_{1}$ and $\pi_{2}$.

\subsubsection{An expansion of the economic labour supply model under uncertainty}

The above economic models of life-cycle consumption and labour supply behaviours are assumed to be certain at the time period 0 , meaning that agents have perfect information and perfect predictions in the beginning. The following model extension relaxes the assumption of certainty as individuals are assumed to act in a world of uncertainty, where they adjust their expectations every period based on current and past information. This uncertainty is accounted for in the model by including a forecasting error which incorporates the past and future differences between realized values and their expectations.

It is assumed that agents form an expectation of wage adaptively based on what has happened in the past. Due to the imperfection of forecasting, the wealth constraint needs to be updated every time period. Therefore the lifetime wealth constraint at time period $k$ in time period 0 with a value of $\mathrm{WC}_{0}(\mathrm{k})$, can be expressed as the sum between the assets in period 0 , the discounted sum of the total earnings between period 0 and period $\mathrm{k}$, and the sum of the expected total earnings, with discount factor $d(t)$ between period $k$ until retirement $(\operatorname{period} T)$ :

$$
W C_{0}(k)=A(0)+\sum_{t=0}^{k} d(t) H(t) W(t)+\sum_{t=k+1}^{T} d(t) E(W(t) H(t))
$$

Alternatively, it can be expressed as the sum between the assets in period 0 , the expected discounted total earnings over the active life formed before entering the labour market and an adjustment error. The adjustment error equals the sum between the difference between the realised earnings and their expectations made before entering the labour market over the period 0 to $k$ (part A), and the expectations adjustment of the total earnings made in the period $t+1$ to $T$ (part $\mathrm{B})$. 


$$
\begin{aligned}
W C_{0}(k) & =A(0)+\sum_{t=0}^{T} d(t)\left(E(H(t)) \mid I_{-1}\right)\left(E(W(t)) \mid I_{-1}\right) \\
& +\underbrace{\sum_{t=0}^{k}\left(d(t) H(t) W(t)-d(t)\left(E(H(t) W(t)) \mid I_{-1}\right)\right)}_{A} \\
& +\underbrace{\sum_{t=k+1}^{T}\left(d(t)\left(E(H(t) W(t)) \mid I_{k}\right)-d(t)\left(E(H(t) W(t)) \mid I_{-1}\right)\right)}_{B} \\
& =W C_{0}(0)+\mho_{k}
\end{aligned}
$$

$I_{t}$ represents all the information available to an agent at time period $\mathrm{t}$, which includes personal characteristics and labour supply activities, and $\mho_{k}$ represents the error adjustment term. This suggests that current expectations of life time wealth reflects past expectations, and an error adjustment term that could either lower or raise the total constraint. To further simplify the equation, it is assumed that the interest rate certain. Therefore, the error adjustment term $\mho$ is expressed as:

$$
\mho_{t}=f\left(v_{t}(W), v_{t}(H), v_{t}(X)\right)=f\left(v_{t-1}(W), v_{t-1}(H), v_{t}(X), W_{t}, H_{t}\left(W_{t}\right)\right)
$$

$\mathrm{v}_{\mathrm{t}}(\mathrm{W})$ is a vector of all wage information until the time period $t, \mathrm{v}_{\mathrm{t}}(\mathrm{H})$ is a vector of working hour information until time period $t$, and $\mathrm{v}_{\mathrm{t}}(\mathrm{X})$ is a vector of personal characteristics information until time period $t$. As the working hour is modelled using the wage rate and the personal characteristics, the new expectation adjusted lifetime wealth constraint can be approximated as:

$$
W C_{0}(k)=W C_{0}(0)+\boldsymbol{\mho}_{k} \approx W C_{0}(0)\left(p e^{\sum_{t=0}^{k}\left(d(t)\left(W(t)-\left(E(W(t)) \mathfrak{I}_{k-1}\right)\right)\right)+\hbar X_{i t}}\right)
$$

$p$ is an approximation parameter, $X_{i t}$ is a vector of personal characteristics which affect the form of the current expectation, and $\hbar$ is the vector of coefficients of personal characteristics. $\ln \left(W C_{0}(k)\right)-\ln \left(W C_{0}(0)\right)$ can be formulated as:

$$
\begin{aligned}
& \ln \left(W C_{0}(k)\right)-\ln \left(W C_{0}(0)\right)=\mu \AA_{k}+\hbar X_{i t} \\
& \AA_{k}=\sum_{t=0}^{k}\left(\frac{1}{\prod_{j=0}^{k}(1+r(j))}\left(W(t)-\left(E(W(t)) \mid \mathrm{I}_{k-1}\right)\right)\right)
\end{aligned}
$$

Combining the anticipated paths for wages and income with the approximated empirical Lagrange function modifies the lifetime constraint. Therefore, the $\lambda$ component takes the form: 


$$
\ln \lambda_{i t}=D_{i} \dot{\varphi}^{*}+\sum_{t=0}^{T_{i}} \gamma_{t}^{*} \ln W_{i t}+\mu \AA_{k}+\hbar X_{i t}+A_{i 0} \vartheta^{*}+a_{i}^{*}
$$

$\mu$ is an adjustment ratio, which shows the marginal change of working hours caused by the error term $\left(\frac{\partial H_{i}}{\partial A_{k}^{\circ}}\right) \cdot \hbar$ explains the role of personal characteristics in the formulation of expectation. It is not possible, however, to distinguish $\hbar$ from the personal character coefficient vector $\psi$ in equation (5.12).

\subsection{Empirical Implementation}

This section introduces the econometric and the simulation techniques for estimating and simulating lifetime labour supply, both under certainty and uncertainty. The model is structured in three parts: a selection model, a model for lifetime wage profiles and a model for lifetime labour supply profiles.

\subsubsection{Data}

This study uses the German Socio Economic Panel (GSOEP) data from 1996 to 2003 for estimation and 2004-2005 data for the simulation validation exercise. Only adults respondent who have not reached the retirement age are included in the study. Some basic employment variable information is presented in Table 5.1.

Table 5.1 Basic Descriptives of Some Employment Variables

\begin{tabular}{l|cc}
\hline Variable & Mean & Std. Dev. \\
\hline Age & 40.52 & 12.78 \\
Number of children & 0.94 & 1.00 \\
Employed in formal sector & 0.50 & 0.50 \\
Fulltime experience & 1.63 & 1.49 \\
Part-time experience & 0.24 & 0.64 \\
Unemployment period & 0.39 & 0.79 \\
Health situation & 0.08 & 0.28 \\
Hours of working & 19.78 & 20.78 \\
Education (Years) & 11.43 & 2.95 \\
\hline Total number of observations & & 11456 \\
\hline
\end{tabular}

The dependent variable is the logarithmic value of actual working hours per week. The wage rate in the estimation and the simulation is calculated using the actual working hours. "Participation" is defined as employment in the formal labour market, except for 
vocational training, zero working hours, military service and community service, which are all modelled as "non-participation" in the selection model.

\subsubsection{The Empirical Model of Lifetime Labour Supply under Certainty}

This subsection develops the econometric model for the labour supply under certainty. The empirical model follows the structure of the economic model: in the first stage it assumes a homogenous preference parameter $\sigma$, and in the second it allows for a higher degree of heterogeneity amongst individuals.

5.4.2.1 An Econometric Model of Labour Supply under Certainty with Homogenous Preferences

For estimating a lifetime labour supply which incorporates a lower degree of heterogeneity this chapter proposes a model similar to Plumper and Troeger (2007) and Hsiao (2003). The model extends the standard fixed effects specification to an estimation procedure which enables an efficient estimation of time-invariant and rarely changing variables by applying a "fixed effects vector decomposition".

The lifetime labour supply model follows the structure of the economic model in (5.4):

$$
y_{i t}=\zeta+\sum_{k=1}^{K} \vartheta_{k} X_{k i t}+\sum_{c=1}^{C} \varrho_{c} D_{c i}+u_{i}+v_{i t}
$$

$y_{i t}$ is the natural logarithm of hours worked per week, $\zeta$ is the intercept of the base unit, $X$ are the time-varying variables (the natural logarithm of wage, age, age squared, children, health dummies, household type dummies, cumulated experience until last year (full time, part-time, unemployment), other household income (for women only), sector dummies), $D$ are the time-invariant variables (education, education squared, cohort dummies), $u_{i}$ are the unobserved individual specific effects, $v_{i t}$ is an i.i.d. error term, and $J$ and $\varrho$ are parameters common to all individuals and constant over time.

The lifetime labour supply model is estimated using a three-stage procedure. To start, the model (5.19) is estimated using the standard fixed effects estimator and it is possible to extract the individual fixed effects or unit effects as:

$$
\widehat{u_{i}}=\overline{y_{i}}-\sum_{k=1}^{K} \vartheta_{k}^{F E} \bar{x}_{k i}-\overline{v_{i}}
$$

The estimated individual specific effect $\widehat{u}_{i}$ captures the unobserved individual-specific effect, the observed individual -specific effects $\mathrm{D}$, the individual means of the residuals $\overline{v_{i}}$ and the individual means of the time-varying variables. In the second step, the estimated 
individual specific effect is regressed against the observed time-invariant characteristics and the rarely changing variables to obtain the unexplained part of the individual-specific effects. The individual specific effects are decomposed as follows:

$$
\widehat{u_{i}}=\sum_{c=1}^{C} \varrho_{c} D_{c i}+h_{i}
$$

$\sum_{c=1}^{C} \varrho_{c} z_{c i}$ is the explained part. $h_{i}$ is the residual from equation (5.21) and captures the unexplained part of the individual-specific effect:

$$
h_{i}=\widehat{u_{i}}-\sum_{c=1}^{C} \rho_{c}^{O L S} D_{c i}
$$

In the third stage, the individual effect from the model (5.19) is substituted with the unexplained part of the decomposed individual fixed effect vector obtained in the previous stage, resulting in an error that is no longer correlated with the time varying covariates included in the model. Therefore, the model (5.23) can be estimated consistently by pooled OLS:

$$
y_{i t}=\zeta+\sum_{k=1}^{K} \vartheta_{k} X_{k i t}+\sum_{c=1}^{C} \varrho_{c} D_{c i}+\rho h_{i}+v_{i t}
$$

The Monte Carlo simulations conducted by Plumper and Troeger (2007) reveal the circumstances under which the FEVD is inferior to the pooled OLS, random effects (RE) and fixed effects (FE). OLS is more appropriate when there are no individual effects, RE when the individual effects are uncorrelated with the other explanatory variables, and FE when the assumptions of the RE are violated and the within-variance of the variables of interest is sufficiently large compared with the between-variance. If this condition does not occur, the vector decomposition technique has better finite sample properties in estimating models that have time-invariant or rarely changing variables correlated with individualspecific effects.

The lifetime wage process is estimated based on model (5.24) using the same procedure:

$$
w_{i t}=\pi_{0}+X_{i t}^{\prime} \pi_{1}+D_{i}^{\prime} \pi_{2}+\xi_{0, i}+\varepsilon_{i t}
$$

$w_{i t}$ is the natural logarithm of gross hourly wage is, $X_{i t}$ is a vector of time-varying variables, and $D_{i}$ a vector of time invariant characteristics. $\xi_{0, i}$ is the individual-specific effect and $\varepsilon_{i t}$ the error term. The time-varying covariates in the wage equations are age, age squared, children, health dummies, household type dummies, cumulated unemployment experience until last year, and sector dummies. The time-invariant variables are education, education squared and cohort dummies. 
When analysing the wage and the labour supply processes using panel data, the natural question that arises is whether the non-response or the missing observations are endogenously determined.

One source of sample selectivity is the unbalanced nature of the panel. If the panel attrition is endogenous to the wage and the hours processes, sample selection would be informative for wage and hours, and therefore the estimates from the wage and hours equations would be biased. The panel attrition bias is disregarded from the analysis because previous studies using the GSOEP have indicated that the sample selection bias is not significant (Galler, 1996; Rendel and Buechel, 1994).

Another sample selectivity bias comes from the fact that wages and working hours are observed only for the individuals in the labour market and selection bias is determined by the differences between workers and non-workers. If the sample under analysis is randomly selected, it is assumed that both workers and non-workers have similar observed and unobserved characteristics and the selection process does not bias the estimates obtained using the working sample. In contrast, if the decision to work is no longer random and people select themselves into the labour market based on certain characteristics, then it is reasonable to assume that workers and non-workers have different observed and unobserved characteristics. A selection bias arises when some component of the participation decision is relevant to the wage and hours processes. Disregarding these relationships, the estimates of wages and hours of work from the subsample of working individuals will be biased.

If the relationships between the participation decision and the wage and hours processes occur through the observables, the section bias can be controlled by introducing the appropriate conditioning variables in the wage and hours equations. If the relationships between the participation decision and the wage and hours processes occur through the unobservable, meaning that the unobserved characteristics affecting the participation decision are correlated with the unobservable from the wages and hours equations, simply controlling for the observables is not enough to obtain unbiased estimates. If the observables are correlated with the unobservable, in order to get unbiased estimates, the wage and hours equations should include an estimate for the unobservable (Vella, 1998).

The selection model is defined using the latent variable model:

$$
s_{i t}^{*}=X_{i t}^{\prime} \vartheta+D_{i}^{\prime} \varrho+u_{i}+v_{i t}
$$

The selection indicator $s_{i t}$ defines the observed employment status $y_{i t}$ :

$$
y_{i t}= \begin{cases}1 & \text { if } s_{i t}^{*}>0 \\ 0 & \text { if } s_{i t}^{*} \leq 0\end{cases}
$$


For fixed $u_{i}$ the probability of observing $y_{i t}=1$ is given by:

$$
P\left\{y_{i t}=1 \mid X_{i t}, D_{i}\right\}=\Phi\left(u_{i}+X_{i t}^{\prime} \vartheta+D_{i}^{\prime} \varrho\right)
$$

$\Phi($.$) is the cumulative distribution function and v_{i t}$ is assumed to be normally distributed. With i.i.d. error terms, the log likelihood function for a fixed effect probit model is given by:

$$
\begin{aligned}
\log L\left(\vartheta, \varrho, u_{1}, u_{2}, \ldots, u_{N}\right) & =\sum_{i, t} y_{i t} \log \Phi\left(u_{i}+X_{i t}^{\prime} \vartheta+D_{i}^{\prime} \varrho\right) \\
& +\sum_{i, t}\left(1-y_{i t}\right) \log \Phi\left(u_{i}+X_{i t}^{\prime} J+D_{i}^{\prime} \varrho\right)
\end{aligned}
$$

For a fixed $T$ and $N \rightarrow \infty$, the maximum likelihood is inconsistent because the number of unknown parameters grows with the number of individuals in the sample. This is the so called "incidental parameter problem" which impedes the fixed effects probit model to be estimated consistently for a fixed number of periods. To circumvent this problem and to estimate the selection model accounting for the unobserved heterogeneity, the model decomposes the unobserved effect $u_{i}$, following the approach introduced by Mundlak (1978). The assumption is that the unobserved effect can be modelled as:

$$
u_{i}=\eta+\bar{X}_{i}^{\prime} \tau+a_{i}
$$

This equation assumes that the correlation between $u_{i}$ and $x_{i t}$ acts only through the time averages of the exogenous variables, whereas $a_{i}$ represents the remaining part of the unobserved effect which is independent of the time-varying variables. Equation (5.28) can be substituted into the selection model as follows:

$$
\begin{aligned}
& y_{i t}= \begin{cases}1 & \text { if } \eta+X_{i t}^{\prime} \vartheta+Z_{i}^{\prime} \varrho+\bar{X}_{i} \tau+a_{i}+v_{i t}>0 \\
0 & \text { if } \eta+X_{i t}^{\prime} \vartheta+Z_{i}^{\prime} \varrho+\bar{X}_{i} \tau+a_{i}+v_{i t} \leq 0\end{cases} \\
& v_{i t}^{*} \mid X_{i}, Z_{i} \sim N(0,1), t=1, \ldots, T
\end{aligned}
$$

To summarize, the selection model includes time-invariant characteristics (education, education squared, cohort dummies, nationality dummies), time-varying variables (age, age squared, interaction between education and age, cumulated experience (full time, parttime, unemployment), health dummies, household type dummies, children and other household income (for women only)) and the means for the time-invariant variables (except for age).

To test for selection bias in both hours and wage equations for men and women, the study applied the approach introduced by Wooldridge (1995) for the FE specification. A 
standard probit was run for each time period based on the model (5.30). For people participating in the labour market, the inverse Mills ratios were computed and then introduced into the initial models for hours and wages. The final step involved estimating the augmented models by applying the FE specification and testing the coefficient of the inverse Mills ratios.

To correct for the sample selection in the wage and hour equation, the inverse Mills ratios for each year were included as time varying variables in the FEVD estimation of the wage and hours models.

For simulating both labour supply and wage processes, the main requirement imposed on the estimation method is to provide consistent and unbiased estimates. Allowing for unobserved heterogeneity and for a correlation between the unobserved individual effects and the other explanatory variables requires the use of FE estimation, however this estimation technique is rather useless in a simulation context. A good alternative is the FEVD technique, which circumvents the problems of a standard FE model (i.e. assumes a correlation structure between the unobserved individual effects and the other explanatory variables) by decomposing the individual effect and estimating the last stage as a pooled OLS.

\subsubsection{An Econometric Model of Labour Supply under Certainty with} Heterogeneous Preferences

For the estimation of the lifetime labour supply model which incorporates a high degree of individual heterogeneity, the study proposes a mixed fixed and random coefficient model similar to Rabe-Hesketh and Skrondal (2005). The fixed coefficients are considered constant across consumers and time, and the random coefficients are unique for each individual, but constant over time.

The assumption is that the labour supply model can be approximated by:

$$
y_{i t}=\zeta_{0}+J_{i t}^{\prime} \vartheta+\left(\varsigma_{0, i}+v_{i t}\right), i=1, \ldots, N ; t=1, \ldots, T
$$

$J_{i t}$ is a $1 \times(K+M)$ vector of explanatory variables, $\vartheta$ is the corresponding vector of coefficients, $\varsigma_{0, i}$ is the individual-specific effect, and $v_{i t}$ the error term. As the $\varsigma_{0, i}$ component induces a within-individual dependence, the composite error term $\left(\varsigma_{0, i}+v_{i t}\right)$ is correlated over time. Serially correlated errors imply then the OLS or maximum likelihood standard errors are no longer valid. This dependence can be taken into account either by using the sandwich estimator for the standard errors, which does not make any assumptions about the distribution of within-dependence of the residuals, or by modelling the dependence explicitly (Rabe-Hesketh and Skrondal, 2005). 
One way to model dependence is to decompose the error component into a time-constant or a permanent error component $\varsigma_{0, i}$, unique for each individual, and a transitory error component $v_{i t}$, which varies across individuals and time. The permanent error component represents the combined effect of the omitted time-constant covariates and of the unobserved heterogeneity. $\varsigma_{0, i}$ and $v_{i t}$ are assumed normally distributed, independent of each other. $v_{i t}$ is assumed independent across individuals and over time. Model (5.31) can be rewritten by moving $\varsigma_{0, i}$ in the intercept:

$$
y_{i t}=\left(\zeta_{0}+\varsigma_{0, i}\right)+J_{i t}^{\prime} \vartheta+v_{i t}
$$

Model (5.32) represents a random-intercept model, which is a regression model with an individual specific intercept. $\varsigma_{0, i}$ can be interpreted as a random parameter that is estimated together with the variance of the $v_{i t}$. The parameters of the random-intercept model are estimated by maximum. To conclude, the linear random-intercept model allows the overall level of hours to vary across individuals after controlling for covariates.

Additional heterogeneity is incorporated by including additional random coefficients besides the random intercept, meaning that the effects of some covariates are allowed to vary across individuals. The resulting model is a mixed fixed and random coefficient model. By introducing individual-specific slopes, the assumption of parallel individual-specific regression lines is relaxed and our model becomes:

$$
y_{i t}=\left(\zeta_{0}+\varsigma_{0, i}\right)+X_{i t}^{\prime} \psi+R_{i t}^{\prime}\left(\zeta_{k}+\varsigma_{k, i}\right)+v_{i t}, k=1,2
$$

$\zeta_{0}$ represents the mean intercept of hours of work, $\zeta_{k}, k=1,2$ the mean slopes of the covariates chosen to have random coefficients, and $\varsigma_{k, i}, k \in[0,2]$ the deviation of individual intercept and slopes from the mean values of $\zeta_{k} \cdot \psi$ is a vector of fixed coefficients, constant across individuals and time $X_{i t}^{\prime}$ represents a $1 \times \mathrm{K}$ vector of covariates with fixed coefficients, whereas $R_{i t}^{\prime}$ is a $1 \times \mathrm{M}$ vector of covariates with random coefficients.

The wage model follows a similar specification; besides the random individual-specific intercept, the model is specified with two additional random coefficients for age and education:

$$
w_{i t}=\left(\pi_{0}+\xi_{0, i}\right)+R_{i t}^{\prime}\left(\pi_{1}+\xi_{1, i}\right)+P_{i t}^{\prime} \pi_{2}+\varepsilon_{i t}
$$

$R_{i t}$ is the vector of covariates with random coefficients. $P_{i t}$ is the vector of covariates with fixed coefficients. $\pi_{0}$ is the mean intercept of wage, $\pi_{1}$ the vector of coefficients illustrating the mean slopes of the $R_{i t}$ variables and $\xi_{k, i}, k=0,1$ represents the deviation of individual intercept and slopes from the mean values of $\pi_{0}, \pi_{1}$. 
Given the high computation costs of estimating the selection model using a random coefficient specification, only fixed coefficient specification is used in the study. The inverse Mills ratios from the estimated probit regressions are included in the random coefficients wage equation of both men and women, whereas for hours, the additional term is included only for women.

\subsubsection{The Empirical Model of Lifetime Labour Supply under Uncertainty}

The extension of the empirical model of lifetime labour supply to incorporate uncertainty is straightforward. The methodology is the same as the one under certainty, except for an additional regressor that captures the forecasting error. This term is introduced to incorporate that individuals adapt their expectations regarding their future wages each period.

5.4.3.1 An Econometric Model of Labour Supply under Uncertainty with Homogenous Preferences

Under uncertainty, the labour supply model assuming homogenous preferences is expressed as:

$$
\begin{aligned}
& y_{i t}=\zeta+X_{i t}^{\prime} \vartheta+D_{i}^{\prime} \varrho+\mu \ln \mho+u_{i}+v_{i t} \\
& \ln \mho=\sum_{k=a}^{t}\left(\ln w_{i k}-\ln \widehat{w_{i t}} \widehat{p_{i k}}\right) \frac{1}{\prod_{j=a}^{t}(1+r(j))}
\end{aligned}
$$

$\ln \mho$ represents the forecasting error equal to the cumulated discounted difference between the actual wage and the expected wage multiplied by the probability of being employed, from the start of the active life (a) until the current year. The selection and the wage models are maintained as under certainty, assuming homogenous preferences.

\subsubsection{An Econometric Model of Labour Supply under Uncertainty with Heterogeneous Preferences}

Under uncertainty, the labour supply model assuming heterogeneous preferences is expressed as under certainty, with the assumption that the forecasting error in equation (5.36) has a random coefficient. This change implies that the effects of the variables vary across individuals, but the selection and wage models remain the same as under certainty. Table 5.2 summaries the differences of all model variants proposed. 
Table 5.2 An Overview of All Models Described

\begin{tabular}{|c|c|c|}
\hline Models & $\begin{array}{l}\text { Estimation Method for } \\
\text { Labour Supply }\end{array}$ & $\begin{array}{l}\text { Uncertainty in } \\
\text { Future Wages }\end{array}$ \\
\hline $\begin{array}{l}\text { Standard Random Effect (Heckman extended) } \\
\text { Model }\end{array}$ & Random Effects Model & No \\
\hline $\begin{array}{l}\text { Proposed Labour supply model with homogenous } \\
\text { preferences }\end{array}$ & FEVD & No \\
\hline $\begin{array}{l}\text { Proposed Labour supply model with heterogeneous } \\
\text { preferences }\end{array}$ & $\begin{array}{l}\text { Mixed Coefficients } \\
\text { Model }\end{array}$ & No \\
\hline $\begin{array}{l}\text { Proposed Labour supply model with homogenous } \\
\text { preferences under uncertain extension }\end{array}$ & FEVD & Yes \\
\hline $\begin{array}{l}\text { Proposed Labour supply model with heterogeneous } \\
\text { preferences under uncertain extension }\end{array}$ & $\begin{array}{l}\text { Mixed Coefficients } \\
\text { Model }\end{array}$ & Yes \\
\hline
\end{tabular}

All variables included in the estimations are the same except when the adjustment variable under uncertainty cases

\subsubsection{Simulations}

This section describes how the models developed are applied to simulate the labour supply responses for 2004 and 2005. The accuracies of the projections obtained from these models are compared with the simple extended Heckman model that is commonly used in simulating continuous labour supply. Since the GSOEP dataset is a panel, the Heckman model is extended to incorporate the unobserved heterogeneity. While the estimation of the probit model is identical with one used by the selection model, the second step of the Heckman procedure is estimated by a standard RE model.

The simulations are performed using the estimates from the empirical models presented in the previous sections. The simulation follows the basic structure of a dynamic microsimulation. To simplify the exercise, this simulation only consists of the demographic and labour market module. The demographic module updates some basic demographic variables like age over time. Besides, it also updates the variables that may interact with the demographic variables. The labour market module is the core part of the simulation, which updates employment status, wage, and the hours of work. Figure 5.1 illustrates the steps of simulation.

For the employment model (selection model), the simulation uses pooled probit as yearly probit is unfeasible in a simulation exercise. This also circumvents the problem that the inverse Mills ratios cannot be updated during simulation. The number of formally employed individuals is aligned with the real data in 2004 and 2005. The wage and the hours simulations are based on the updated personal characteristics and are the result of the selection simulation including the selection correction. The results of the wage simulation are used in the working hour simulation. 
Figure 5.1 An Overview of Simulation Steps

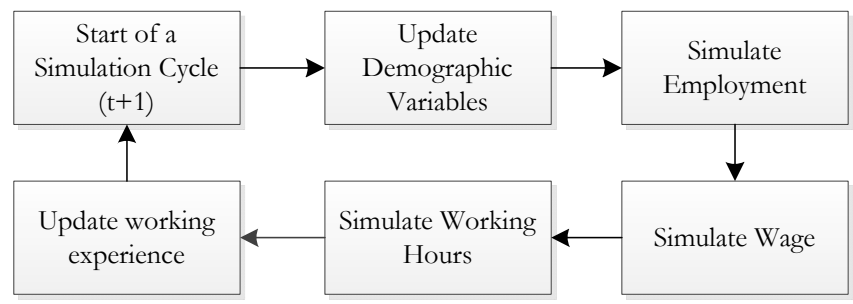

The simulation follows the sequence as follows: It starts by determining the value of demographic variables in the new time period and updates the related variables. For the personal characteristics that are not influenced by employment, the simulation uses the actual characteristics observed in 2004 and 2005. The simulation then moves on to the next step where labour market variables are simulated. It predicts the probability of employed given the employment selection model. Afterwards, wage can be predicted using previously estimated equations. With the wage and personal characteristics information, it is now possible to simulate the hours of work. In the case of models with uncertainty extension, correction terms were calculated right after the predicted wage becomes available. Lastly, the variables that reflect the labour trajectory are updated, this include working experience (full time, part-time, unemployed) etc. The projections of the models are compared with the actual observed hours of work for 2004 and 2005.

\subsection{Results}

This section presents the estimation and simulation results. All models, including wage and labour supply models are estimated separately for men and women. Simulation is conducted under a simple framework as described in earlier section.

\subsubsection{Estimation Results}

The parameter estimates for the probit models are largely skipped as the estimates are in line with previous findings and all key variables are significant. Inverse Mill's ratios were included in wage and labour supply model with the exception of male labour supply equation, where the inverse Mill's ratio is not significant using any estimation method. For the random coefficients models, a test was performed to verify whether the random intercept model is sufficient to capture the heterogeneity in the wage and hours estimation. The likelihood-ratio test suggests that the random coefficients model fits better than the simple random intercept model, both for wage and labour supply.

Table 5.3 and 5.4 show the parameter estimates for the wage equations for women and men. Both model specifications are standard. The age effect is as expected for both men and 
women in all three models: a positive impact with decreasing marginal effects, showing that hourly wage has the standard humped-shaped age pattern. When estimated using FEVD, the wage profile of women shows a stronger curvature than for men. The larger coefficients of the linear and quadratic age variables show that the growth rate of wages is higher for women at younger ages, but the growth rate reduces more rapidly at later ages than for men. After the introduction of heterogeneity, the impact of age is reduced for women, whereas for men it is increased. At younger ages, however, both men and women have a similar curvature of the wage profile. The estimated rate of return on education differs quite a lot between men and women and between the three models. The model estimated with FEVD illustrates a positive return for education for women, whereas for the other models the return appears not to be significant. For men, the returns appear to be negative in the FEVD variant model and insignificant in the other models.

Unemployment experience has a significant negative impact on wages for both men and women. The model with FEVD method illustrates the highest absolute impact, while the random coefficient model and the RE model show similar effects. In all three models, having or not having children influences wages negatively, and the impact in absolute value is higher for women than for men. The estimates of the inverse Mills ratios imply small positive correlations between the individual-specific error components of the selection model and the wage equation for men in all three models. For women, these correlations are negative in the mixed and the extended Heckman model.

To conclude, the estimation results from the wage models are in line with expectation. Among all the specifications, the FEVD estimator appeared to fit the data the best.

The estimation results for the labour supply models are extensively examined in this study. Tables 5.5 and 5.6 present the coefficients estimated. Five labour supply models for both men and women are compared in the tables: the FEVD under certainty and uncertainty, the mixed fixed and random coefficients model under certainty and uncertainty, and the extended Heckman under certainty. The estimated coefficients are in general significant and stable across models.

The estimated wage elasticity is highly significant and stable for both men and women across models. Men record on average, in absolute value, a higher elasticity than women do. The highest wage elasticity is found under certainty when estimated using FEVD. Assuming that the effect of wage varies across individuals dampens the magnitude of the effect. Assuming uncertainty, the effect increases by 2 percentage points. The Heckman model provides higher wage elasticity estimates than the random coefficient model. 


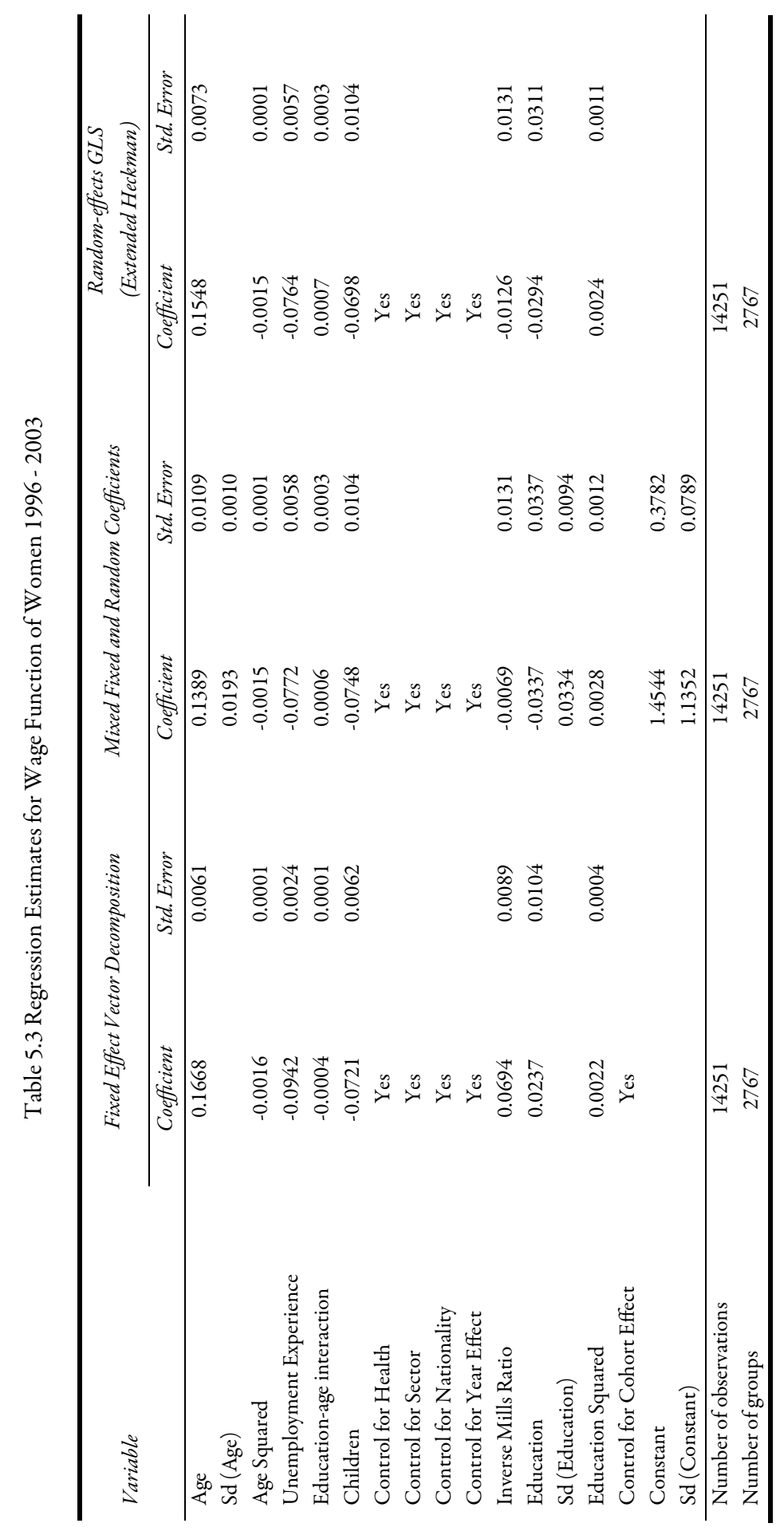




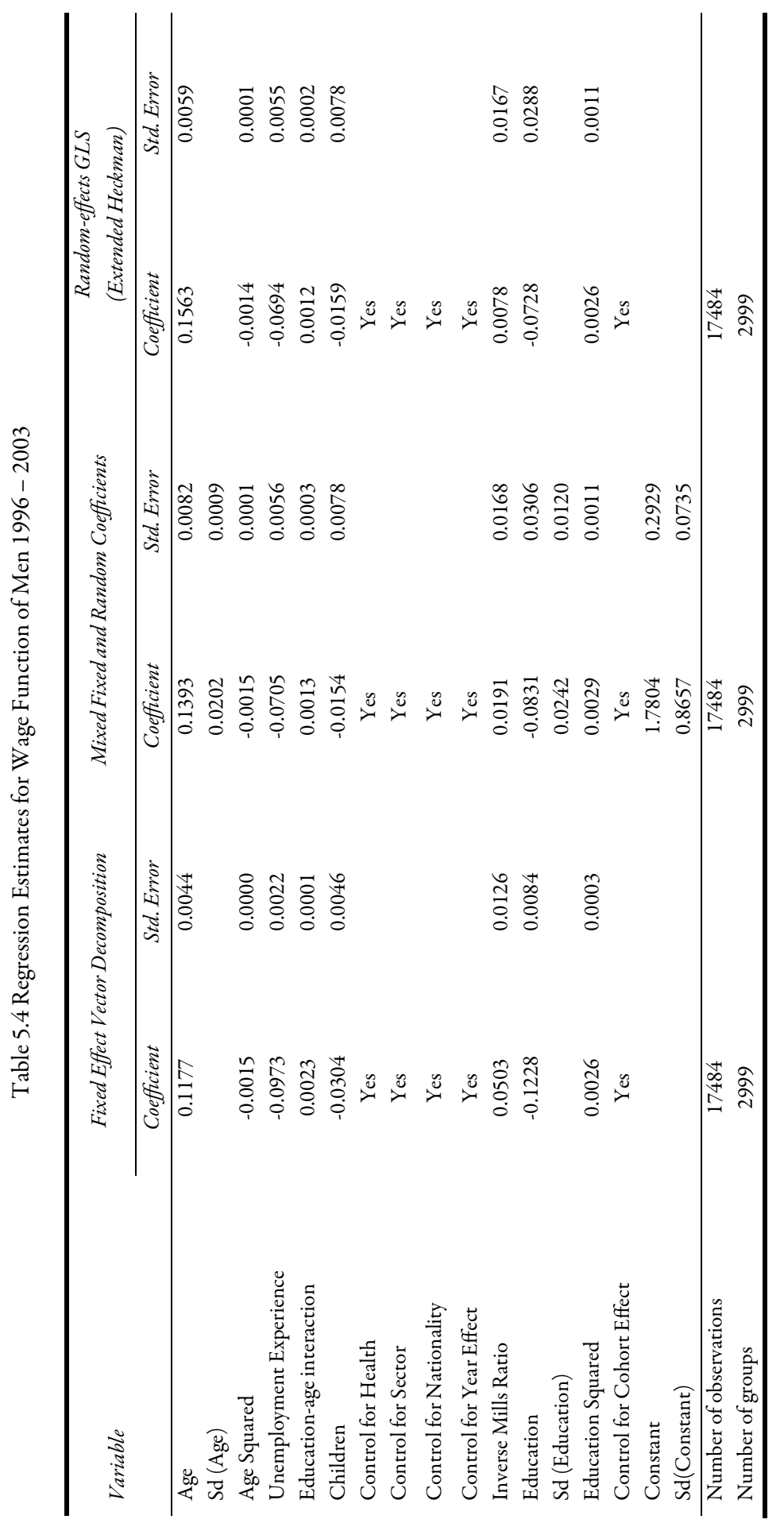




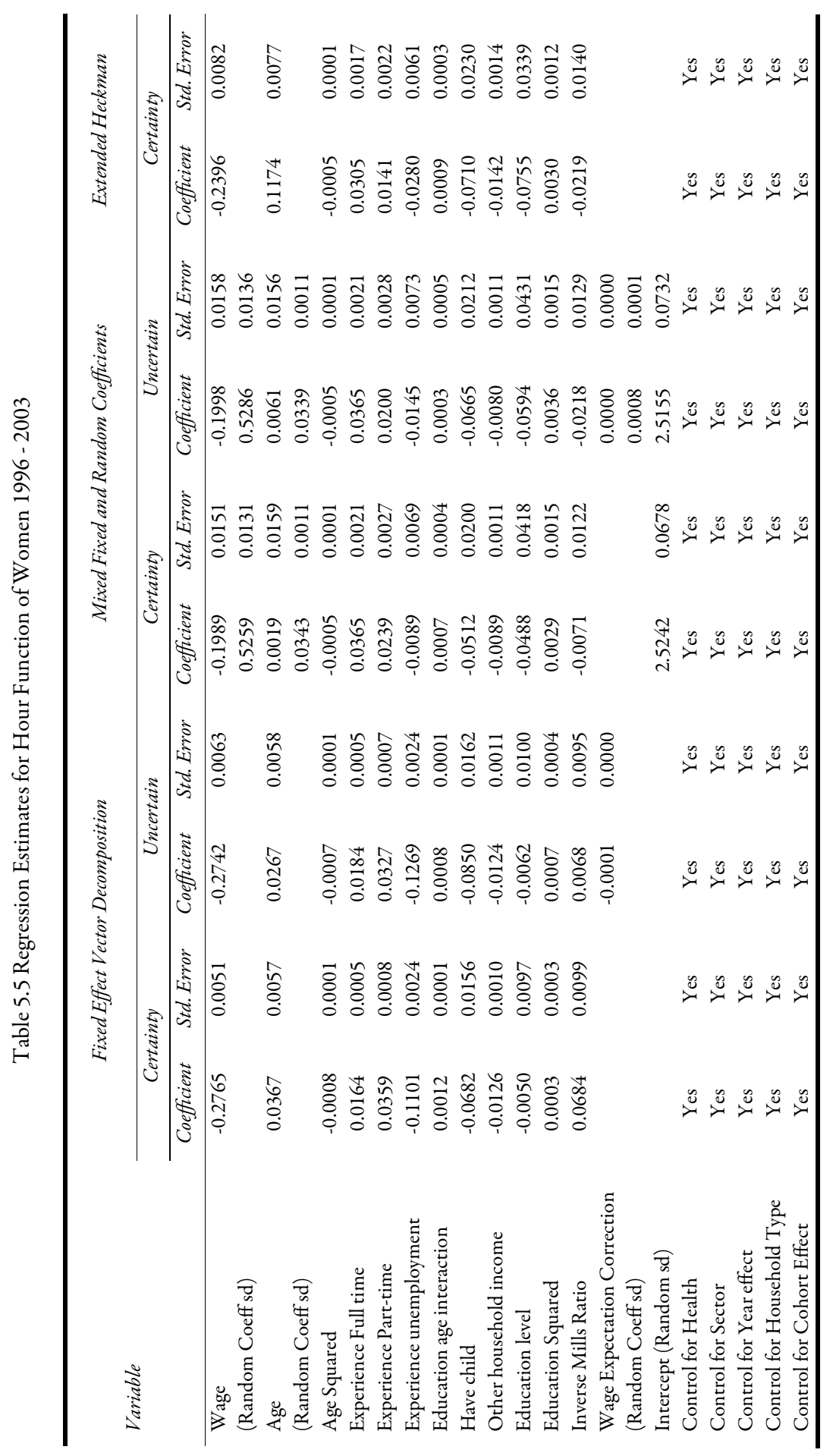




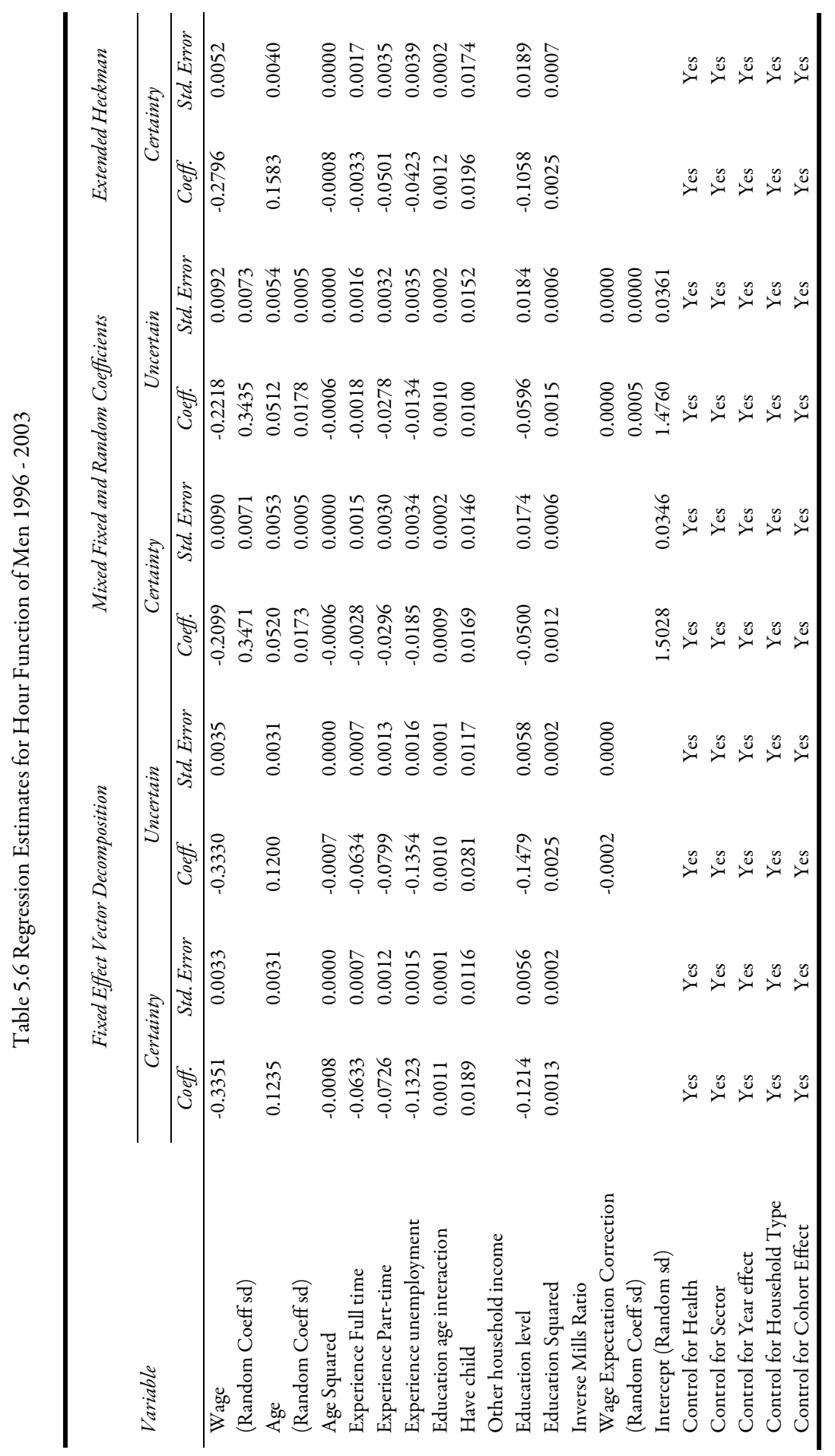


As expected, the wage expectation correction has a small but significant negative effect on labour supply in both the FEVD and the random coefficient models. Incorporating that people adapt their expectations in a heterogeneous manner dampens the average impact of the wage expectation correction.

With regard to age, the labour supply profile of men illustrates a higher growth rate of hours worked at younger ages than the profile for women. The rate of growth in hours worked, however, reduces more rapidly toward later ages for men than for women. When the age effect is allowed to vary across individuals, its effect reduces in magnitude compared to the FEVD variant. The Heckman model provides the highest estimates for the age effect.

The estimates for the return to experience (full time and part-time) are similar across models: all key variables are significant, have the same shape and similar magnitudes. For men, the cumulated work experience has a negative effect on the lifetime labour supply response, which can be explained by the age-labour supply profile. For women, the cumulated work experience has a small positive effect on the labour supply response. Unemployment experience has a negative effect for the labour supply of both men and women, and the effect is higher in absolute value for women.

The presence of children in the family has a negative effect on the labour supply of women, whereas for men the effect is not significant. The effects are stable across models. For women, the estimates of the inverse Mills ratios differ greatly across models. The estimate of the Heckman model is similar to the random coefficient model under uncertainty. To conclude, the estimates are stable across the different model specifications and show on average a high level of significance. The FEVD variant of the model fits the best.

\subsubsection{Simulation Results}

The simulation exercise evaluates the model's out-of-sample prediction performance. Each model is estimated on the same dataset and is used to predict the labour supply in year 2004 to 2005 . The simulation uses a simple dynamic microsimulation framework, where only crucial demographic variables are updated. The performance of the simulation is judged according to the distance between the actual value and the predicted value. Table 5.7 gives a general overview of each model's performance using this indicator. Both simulated and actual values are coded in logarithm scale.

The errors in the simulation come from three sources. The first source is the selection model, common to all models. The second source is the continuous labour supply models, which cover five different model setups. The last source of errors is the wage estimation, as in the models under uncertainty, the residual of the wage equation is crucial. In general, the FEVD fixed coefficients under certainty and uncertainty perform the best in terms of mean value and standard deviation of the simulated residuals. In terms of unbiasedness, the two 
FEVD estimated models and the mixed coefficients model under certainty perform better than the Heckman extension model. The mixed coefficients estimation, however, can be significantly affected by outliers and has a large standard error for the random intercepts, which may lead to errors in the simulation.

Table 5.7 Simulation Models Comparison

\begin{tabular}{lcccc}
\hline Simulation Residual (logarithm) & Mean & Std. Dev. & Min & Max \\
\hline Heckman Extension Model & -0.354 & 0.432 & -3.728 & 0.732 \\
FEVD Fix coefficient with certainty & -0.027 & 0.444 & -3.673 & 2.020 \\
FEVD Fix coefficient with uncertainty & -0.031 & 0.441 & -3.626 & 1.988 \\
Mixed coefficients with certainty & -0.039 & 0.888 & -8.364 & 8.936 \\
Mixed coefficients with uncertainty & 0.465 & 5.744 & -50.933 & 55.689 \\
\hline
\end{tabular}

Figure 5.2 sorts the observations in terms of the absolute difference between simulated and actual values. Since the wage expectation adjustment (uncertainty) term does not play a major role numerically as suggested in the estimation result, models with uncertainty correction have a very similar curve compared with the ones without, provided same estimation method is used. As a result, only 3 models are selected present in Figure 5.2. The figure shows that the models estimated with FEVD method performs the best in terms of the percentage of observations with the prediction error of less than 20 hours, while the Heckman extended model performs the worst judged by this criteria. This suggests that in a simulation study where the absolute error is a key factor, the proposed models estimated with FEVD.

Figure 5.2 Simulation Residual for all three models 2004-2005

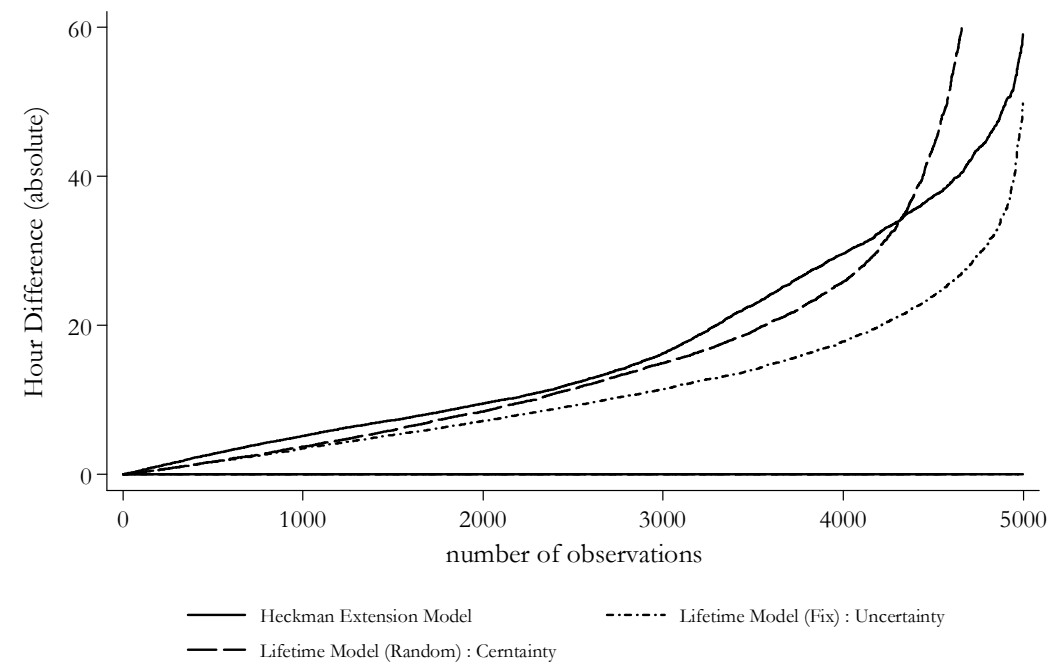


Figure 5.3 extends the previous graph by showing the results for different groups, whereas Figures 5.4 and 5.5 show the distribution of the simulation for different groups. The simulation shows that Heckman model is biased for 2004 and it continues to get worse in 2005. This bias may come from the biased estimation of time-invariant characteristics. The model estimated with mixed coefficients, although the mean predicted value is closer to the actual ones, it has a much larger standard error in the prediction. This finding is consistent with Figure 5.5, which shows that the mixed coefficients method has one of the most unbiased performances.

Figure 5.3 Simulation Residual for all three models 2004-2005

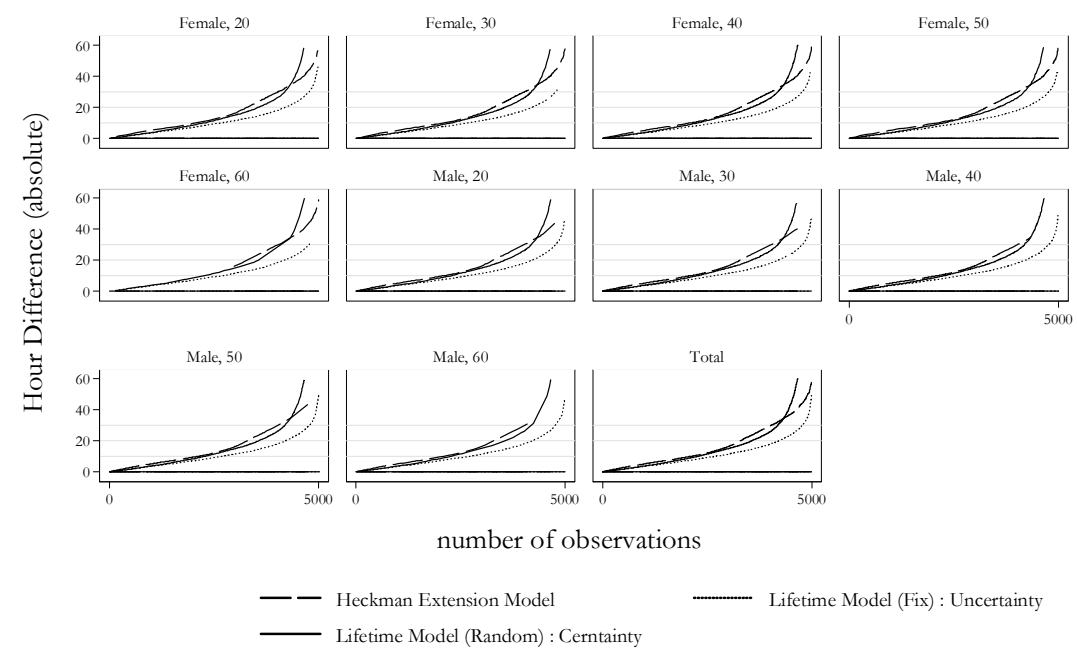

Graphs by Sex and Age Group (10 Years Interval)

Overall, the FEVD variant of the model has the best simulation result according to the validation tests. The uncertainty extension, however, does not seem to have a large impact, this may partially be due to the error from the wage estimation. The mixed coefficient estimation seems to handle the heterogeneity better than the other models, but is less than ideal for simulations. 
Figure 5.4 Simulated Value Distributions by year

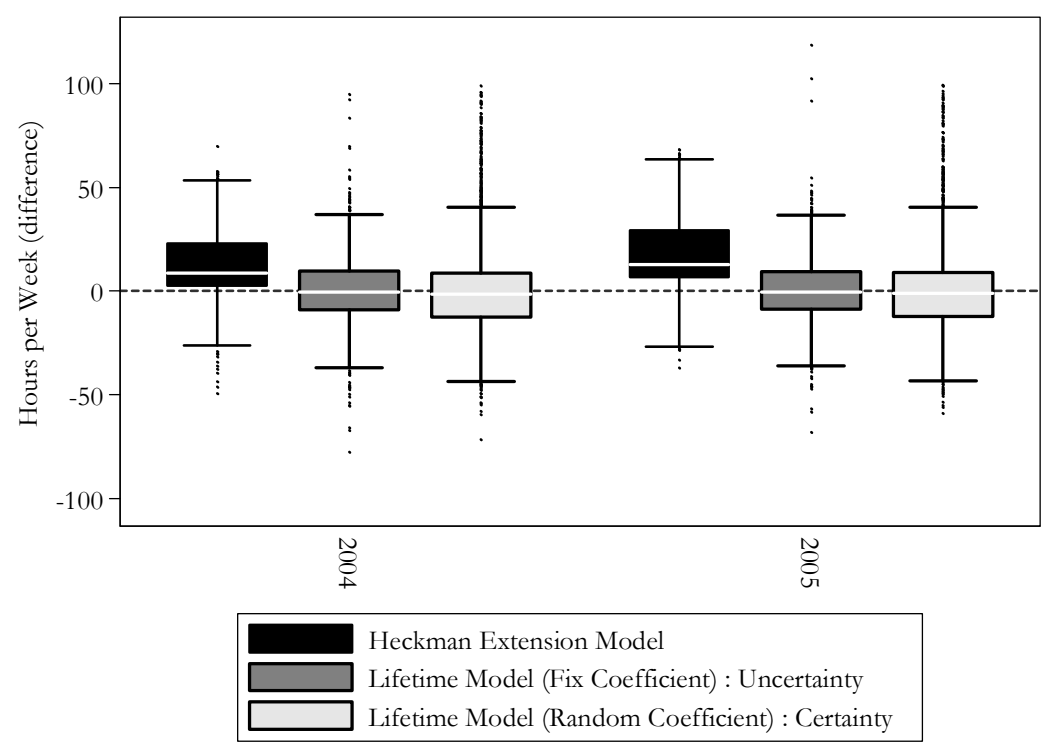

Figure 5.5 Simulated Value Distributions by real value of working hours

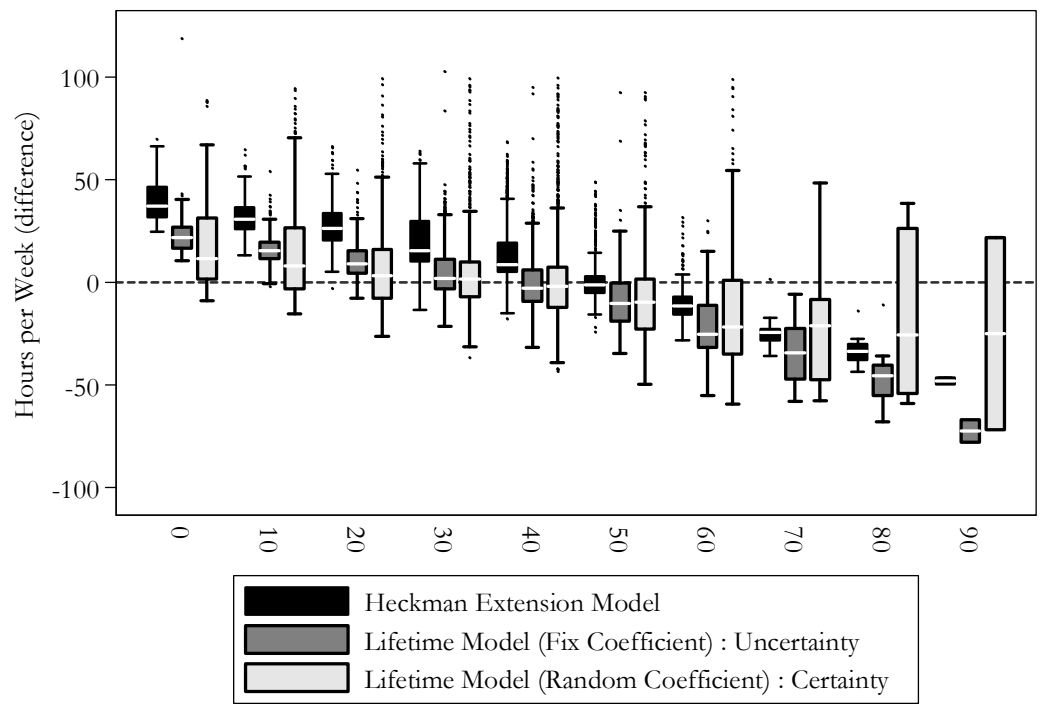

$\mathrm{X}$-axis shows the real hours of supply 


\subsection{Conclusion}

This chapter develops a structural lifetime model for estimating and simulating continuous labour supply. The model is consistent with the lifetime economic theory and is able to capture the individual heterogeneity to a larger extent than the existing labour supply models by using more refined estimation techniques, including fixed effect vector decomposition (FEVD) and the mixed coefficients estimation method. In addition, one variant of the model loosens the certainty assumption in the life cycle modelling. Instead, individuals are assumed to adjust their labour supply behaviours based on the differences between expected and actual earnings.

The chapter compares different combinations of the model specifications and estimation methods, as well as the standard random effects model (Heckman) for their simulation performances. In a simple simulation presented in this paper, models were estimated with different combinations of estimation techniques and uncertainty correction term. The results suggest that the models estimated using the FEVD method has the highest prediction accuracy judged by the mean error of simulation.

While the expectation correction introduced is also found to be significant in the estimation, it is found to be less important in the simulation exercise due to its relatively small coefficient and the potential wage estimation errors. When estimated using the FEVD method, the lifetime labour supply model developed in this study outperforms the Heckman panel extension model in the simulation by all indicators calculated. In practice, the models presented in this study could potentially benefit the microsimulation models where continuous labour supply models are used. 


\subsection{References}

Altonji, J. G., 1986. Inter-temporal Substitution in Labor Supply: Evidence from Micro Data. The Journal of Political Economy, 94(3), S176-S215.

Blundell, R., \& MaCurdy, T. E., 1998. Labor Supply: A Review of Alternative Approaches: Institute for Fiscal Studies.

Bover, O., Muellbauer, J. and Murphy, A., 1989. Housing, Wages and UK Labour Markets. Oxford Bulletin of Economics and Statistics, 51: 97-136.

Card, D., 1991. Inter-temporal labour supply: an assessment. Advances in Econometrics: Sixth World Congress.

Galler, H., 1996. Microsimulation of pension reform proposal: Modelling the earning of couples in Harding A. Microsimulation and Public Policy, New York, US: North-Holland.

Haan, P., 2004. Discrete Choice Labor Supply: Conditional Logit Vs. Random Coefficient Models: DIW.

Hsiao, 2003. Analysis of Panel Data, 2nd edition, Cambridge University Press

MaCurdy, T. E., 1980. An Empirical Model of Labor Supply in a Life Cycle Setting: NBER.

MaCurdy, T. E., 1983. A Simple Scheme for Estimating an Inter-temporal Model of Labor Supply and Consumption in the Presence of Taxes and Uncertainty. International Economic Review, 24(2), 265-289.

MaCurdy, T. E., 1985. Interpreting Empirical Models of Labor Supply in an Inter-temporal Framework with Uncertainty. Longitudinal Analysis of Labor Market Data, 111-155.

Medoff, J. L., \& Abraham, K. G., 1981. Are Those Paid More Really More Productive? The Case of Experience. The Journal of Human Resources, 16(2), 186-216.

Plumper T., Troeger V. E., 2007. Efficient estimation of time-invariant and rarely changing variables in finite sample panel analyses with unit fixed effects. Political Analysis 15, 124-139

Pudney S., 1992. "Dynamic simulation of pensioners' incomes: methodological issues and a design for a computer model for Great Britain”, Cambridge.

Rabe-Hesketh, S., \& Skrondal, A., 2005. Multilevel and Longitudinal Modelling using Stata: Stata Press.

Rendel, U., \& Buechel, F., 1994. Tests for non-ignorable panel attrition and their application on wage estima-tion from the German Socio Economic Panel. Berlin: Deutsches Insitut fuer Wirthschaftsforschung.

Van Soest, A., 1995. Structural Models of Family Labor Supply: A Discrete Choice Approach. The Journal of Human Resources, 30(1), 63-88.

Vella, F., 1998. Estimating Models with Sample Selection Bias: A Survey. The Journal of Human Resources, $33(1), 127-169$. 


\title{
[6] Incentives of Retirement Transition for Elderly Workers ${ }^{13}$
}

\author{
An Analysis of Actual and Simulated \\ Replacement Rates in Ireland
}

\footnotetext{
${ }^{13}$ An earlier version of this chapter is available as: $\mathrm{Li}$, J. and O'Donoghue, C., 2011. Incentives of Retirement Transition for Elderly Workers: An Analysis of Actual and Simulated Replacement Rates in Ireland, IZA Discussion Paper No. 5865
} 


\subsection{Introduction}

Retirement behaviours and elderly poverty issues have been the subject of much attention and discussion in recent years as most countries are facing a rapidly ageing society. Ireland enjoys a relatively young population compared with other European countries, but is also struggling with increasing fiscal pressures. Although Ireland has reformed its pension system over the past few years (Whelan, 2007), little work has been undertaken to understand what contributes to the pattern of retirement in Ireland, and what monetary incentives are introduced by the existing regulations.

There are many reasons for people to retire: retirement regulations, financial incentives, health status etc., may all contribute. From the supply side of the labour market, an individual may choose to retire if the expected post-retirement income is sufficiently high. Meanwhile, from the demand side, employers may use incentives to keep productive employees working as long as possible in order to save the total pay-out of occupational pension. While many factors are weighted when an individual makes the transition to retirement, it is impossible to analyse all the factors at once. Therefore, this chapter focuses only on the monetary incentive, which is one of the most quantifiable and used variables.

From a social policy point of view, the absolute amount of postretirement income is important since it determines the minimum living standard that a retiree is able to secure during their retirement, whilst the absolute benefit level determines the public expenditure necessary to finance the pension system. While economists may be more interested in the smoothing of marginal utility rather than the income per se, the data required for the calculations does not exist. Instead, most researchers have taken an indirect approach by comparing income before and after retirement by using the replacement rate. This is defined as the ratio of a person's consumption or income after retirement to before retirement, and has become a popular measurement for analysing post-retirement welfare.

In order to analyse the potential replacement rates for elderly workers under differing scenarios, it is necessary to build the analysis around a dataset with rich social economic variables and a tax-benefit microsimulation tool. A sub-component of the LIAM model was used to facilitate the analysis based on a long dataset derived from the LII dataset. The framework built around this dataset allows the labour market trajectory of each potential retiree to be investigated. Previous literature on the effect of the Irish state pension regulations on retirement behaviour is relatively rare. Some studies have looked at the work incentives in the Irish labour market through replacement rates (Callan et al., 2006; Immervoll and O'Donoghue, 2003a), while others have attempted to estimate the implicit tax rate for elderly workers (Blöndal and Scarpetta, 1997), and more recent studies (e.g. Hughes and Watson, 2005) have examined how the income of pensioners in 2000 has varied across social groups based on reported retirements. However, little attention has been paid to the individual's choice of actual retirement in Ireland. Existing research on 
retirement typically uses the reported retirement status, which suggests that almost everyone retires within one year of becoming eligible for the state pension (Raab and Gannon, 2009). By including working individuals, bias may be introduced with regard to the real incentives behind retirement behaviour, meaning that the potential behaviour change resulting from regulation change cannot be inferred.

Ireland, in some aspects of its retirement regulations, is different from many other countries. The state pension is not linked to employment status, which means an individual can claim his/her pension whilst still working full time. This type of regulation effectively creates two retirement time points: classified as retired and receiving state pension, and actually exiting the labour market. While the first time point of retirement is mostly the result of an individual's age and job sector, the second time point is more interesting from the policy point of view as it is an active individual choice instead of a passive transition. One of the primary concerns of the pension policy is that retirees should have an income sufficient to secure a reasonable standard of living. Analysing the retirement income based solely on the official status may introduce a bias towards the living standard of the retirees as this is a mixed group containing also individuals employed in full time jobs.

This chapter examines the monetary incentives behind the tax benefit system for elderly workers in Ireland using an estimated replacement rate and compares the monetary incentives with the pattern of retirement. A combined method of synthetic household simulation and empirical estimations from the panel dataset LII is used. By performing simulations with the synthetic household data, the existing incentives embedded in the state pension regulation can be understood, and by relating the replacement rate information to an empirical micro dataset, it is possible to analyse the factors behind different observed replacement rate levels and retirement ages (e.g. benefit levels, household composition etc.). With this combined approach, it is possible to analyse the monetary driving forces behind retirement and to investigate how it compares with the retirement patterns observed in Ireland.

The institutional features of the state pension system in Ireland are outlined briefly in section 6.2 and the methodology and measurements of the replacement rates are discussed in section 6.3. Section 6.4 describes some of the details of the simulation model used in the tax-benefit calculation and is followed by a description of the data in section 6.5. The results of the analysis are presented in sections 6.6, 6.7 and 6.8. Section 6.6 reports the result of the replacement rate analysis via a set of synthetic households and section 6.7 takes a closer look at the distribution of replacement rates estimated from the panel dataset from different aspects. Finally, section 6.8 compares the distribution of retirement with replacement rates. 


\subsection{Description of the Irish Tax-Benefit Systems for Elderly}

The Irish tax-benefit system is in many respects similar to the Anglo welfare state, with relatively insignificant social insurance systems in place. In this type of system, means testing and progressive income taxes are more important than in equivalent continental social security systems (Esping-Andersen, 1996). Many welfare benefits in Ireland are flat rate based and are not earnings related (Evans et al., 2000; Callan, 1997). Ireland has a set of categorical instruments, covering contingencies such as unemployment, old age disability, lone parenthood etc., with different means tests and eligibility conditions, but similar levels of benefit (O’Donoghue, 2001).

The Irish pension system is frequently presented as a multi-pillar system with a relatively small mandatory first pillar consisting of a flat (i.e. no earnings related) social insurance system, and means-tested social assistance. The occupational and private pension systems (the second and third pillars) play a major role in the replacement of earnings. Public pensions are in general pay as you go (PAYG), with the private sector providing funded occupational or private pensions to about half of the workers in 2005. Table 6.1 provides an overview of the components of the relevant welfare benefits for the elderly in Ireland ${ }^{14}$.

Table 6.1 Irish Pension System

\begin{tabular}{l|l}
\hline $1^{\text {st }}$ Pillar & $\begin{array}{l}\text { Old Age Non-Contributory Pension } \\
\text { Old Age Contributory Pension } \\
\text { Invalidity Pension } \\
\text { Widow, Widower, Orphan and other Pensions Benefits }\end{array}$ \\
\hline $2^{\text {nd }}$ Pillar & $\begin{array}{l}\text { Public service pay-as-you-go schemes } \\
\text { Funded occupational pension schemes set up by employers }\end{array}$ \\
\hline $3^{\text {rd }}$ Pillar & Supplementary private pensions arranged by individuals \\
\hline
\end{tabular}

\subsubsection{First Pillar: State Pension System}

The state pension applies automatically to everyone who lives and works in Ireland and consists of several different provisions which together constitute the social welfare pension. It includes the basic old age non-contributory pension, an old age contributory pension, and smaller pension items such as invalidity, widow's pension etc. The non-contributory pension is independent of employment trajectory and covers residents aged over 66 with

\footnotetext{
${ }^{14}$ This section aims to give a brief description of the current Irish pension system. For a more detailed description of the tax benefit system in Ireland and its pension system, please refer to O'Donoghue (2001; 2003) and Baroni \& O’Donoghue (2009).
} 
an income below the threshold level set via a means-test. Only those people whose income satisfies the test are entitled to the full means-tested benefit. If an individual's income is above certain income threshold then the benefit is withdrawn completely. The amount of pension received by an individual is determined by age and household composition, e.g. whether the individual is living alone etc.

The old age contributory pension, as suggested by its name, requires an established contribution record from an individual before it can be drawn. The amount of contribution that a worker pays depends on the earnings and the type of work. In Ireland, contributions are referred to as PRSI (Pay Related Social Insurance). The nature and the wage of the job determine the type of class and rate of contribution paid by an employee. According to the Irish regulations, the recipient of a contributory pension must have paid or credited at least 260 social insurance full-rate contributions during their working years (counted from either 1953 or the date when they started insurable employment, to when they reach the age of 56). This qualifies an individual to be eligible for a flat rate nonearnings related weekly benefit once they retire from the labour market at the age of 65 or when they reach 66, regardless of their current employment status. The PRSI contribution conditions may be based on either of the spouses' records but cannot be combined.

\subsubsection{Second Pillar: Occupational and Private Pension Membership}

Ireland places an important emphasis on supplementary funded occupational and private pensions (second and third pillars) as do other countries with multi-pillar systems. The system is however still relatively immature since it only covers around half of the working population and elder workers are likely to be excluded due to the inexistence of private pension plans during their early ages.

Depending on the nature of their job, type of employment etc., individuals may be eligible for additional pension plans. This may include an occupational pension or a private pension. Table 6.2 gives an overview of the occupational and private pension coverage in Ireland in 2001. Occupational pensions in Ireland are usually organized by employers and the plans can be divided between those guaranteed by the state, covering all public sector employees, and those provided by firms. The latter category is much newer and has a relatively lower coverage. Since 2003 , employers who do not offer an occupational plan are now obliged to provide access to a private retirement saving account. According to the pension question survey in the QNHS Q1-2002, conducted by Ireland's Central Statistics Office (CSO), nearly $20 \%$ of the working population contributed to a private pension fund and around $40 \%$ of workers had occupational pension coverage. Approximately $47 \%$ of all workers do not have additional pension rights besides the state coverage. Appendix 6.A provides a more detailed overview of pension coverage by gender. 
Table 6.2 Occupational and private pension coverage among Irish workers

\begin{tabular}{l|cc}
\hline Overall pension status for workers & Freq. & Percentage \\
\hline Self-employed with a private pension & 1,967 & 8.3 \\
Employee with an occupational pension only & 8,645 & 36.3 \\
Employee with a private pension only & 1,083 & 4.6 \\
Employees with both occupational and private & 709 & 3.0 \\
pension & & \\
Employees with no pension & 8,823 & 37.0 \\
Self-employed with no pension & 2,574 & 10.8 \\
\hline
\end{tabular}

(Source: QNHS Q1-2002, and author's calculation)

\subsubsection{Retirement Age}

The working population in Ireland, as in most other parts of the world, does not have a single fixed retirement age. The earliest retirement age with full rights varies according to occupation and job sector.

As stated earlier, the state old age pension is either means tested or contribution based. There is no penalty for retirees who retire early, although they cannot claim the benefit until aged 65/66. For occupational pensions, the retirement age is usually set out in the contract of employment. Some contracts of employment have a mandatory retirement age and also contain provisions for earlier retirement, generally and/or on the grounds of ill health. Public sector workers who started working before 1 April 2004 have to retire at age 65 , with the exception of a limited number of occupations, e.g. the defence forces, who have provisions for earlier retirement. For people who joined the public sector after 1 April 2004, the earliest retirement age is 65 except a few occupations such as police and fire fighters.

Since receiving certain old age benefits (e.g., old age contributory pension) does not necessarily mean that an individual is out of the labour market, a more strict definition of retirement was used in this study. Here, it is defined as an individual who has stopped working or receiving unemployment benefit after the age of 55 and who does not re-enter the labour market.

\subsection{Methodology I: Replacement Rate Measures}

\subsubsection{Replacement Rate}

Replacement rates are often used to assess how well elderly people can maintain their preretirement level of consumption once they stop working (Munnell and Soto, 2005). The idea behind the replacement rate concept is that a person's welfare being or living standard 
in retirement can be measured as a proportion of their living standard during their working life. It is usually defined as the ratio of a person's consumption or income after retirement compared to before retirement.

There are a number of different approaches when conducting replacement rate analyses. Some research (e.g. Central Planning Bureau, 1995) uses one or a few artificially created synthetic households to illustrate the effect of the tax benefit system on the replacement rate, while other studies (e.g. Engen et al., 1999; Scholz et al., 2004; Immervoll and O'Donoghue, 2003b) have used simulation techniques to calculate the counterfactual income to estimate the replacement rate. Depending on what type of data is used, the methods can be grouped into three categories: synthetic analysis, empirical data based analysis, and simulated data based analysis. A discussion of the usage of each method can be found in Immervoll and O'Donoghue (2002).

Synthetic or stylised household analysis is widely used within the tax-benefit literature. This uses one or a set of "average households" to estimate the benefit level. The most common type of calculations assume a set of average characteristics (e.g., in-work income of an average production worker) which is considered appropriate for the household type under consideration, and apply the relevant tax and benefit rules to find out its replacement rate levels. Research investigating effective tax rates e.g. OECD (1994, 1998, 1999), use this method to evaluate the replacement rates. This type of analysis allows the part of the tax-benefit rules under investigation to be isolated, and offers straightforward and easy to interpret results. There are however, a number of problems with this approach as it attempts to reduce complex tax-benefit systems to a single (or few) point estimates (Immervoll and O'Donoghue, 2002). Therefore, this analysis is likely to miss many of the important features of the tax-benefit system, which although not applicable to the average household, may affect a large part of the population.

Another approach taken to study replacement rates is to use a representative household panel. This method typically looks at time-series information for individuals and records the changes. In this way, the problems of assumed homogeneity within stylised households can be avoided. One common criticism of this method is its potential selection bias, as it only looks at people whose status changes during the year and excludes those for whom it does not. For example, if the low replacement rate after retirement makes it less likely for someone currently employed to retire, then only measuring for people who decide to retire will result in higher replacement rate estimates than if all people currently working were taken into account. One possible solution is to also compute replacement rates for people whose status does not change by simulating the income they would receive in an alternative labour market situation (Immervoll and O’Donoghue, 2003b). 
An alternative way to study the replacement rate is to use a simulated dataset. Essentially, this would need to simulate all the possible statuses within the labour market (working, unemployed, retired etc.) in the panel dataset, and would use the simulated replacement rates for the analysis. Due to the complexity of the possible retirement choices and modelling, there have only been a few papers published where this method has been used in retirement studies, although the method has been well used in tax rate analyses in Europe (e.g. Immervoll and O'Donoghue, 2003b; Berger et al., 2003). This method overcomes some of the shortcomings of synthetic analysis by taking the actual population structure into account. However, as a natural consequence of simulation, the accuracy of the results is highly dependent on the quality of the model and the dataset.

This chapter uses a combined analysis from both the synthetic household and panel data approaches and there are a number of reasons for this choice. First, individuals are very different, and a benchmark is needed; second, the interest here is in the replacement rates in the real world; and third, a simulation approach would potentially offer more information on why people are retiring. However, this type of analysis is restricted to only those individuals whose history can be reconstructed. Although a historical dataset is available for LII (Li \& O’Donoghue, 2010), it only contains the individuals presented in the first wave, as certain variables were only collected in this segment. Therefore, there is a trade-off between more detailed simulated information and fewer actual observations, and less detailed simulated information and an increased number of actual observations. Since the value from actual transitions has a higher accuracy than the simulated one, the decision was made to use as many actual values as possible within this chapter in order to reflect the actual replacement rate distribution of retirees in Ireland.

\subsubsection{Constructing Replacement Rates}

There are a number of approaches for estimating the replacement rate of the elderly, Immervoll and O'Donoghue (2003b) presented some of the analytical choices faced in calculating replacement rates (see also Atkinson and Micklewright, 1991). The two basic dimensions that are relevant in this context are: (a) which income components to include in the numerator and the denominator of the replacement rate and for whom; and (b) which direction of labour market transition to compute the replacement rate for.

There are different measures in the existing literature which may lead to confusion and different estimations regarding the replacement rates (e.g. Steuerle, Spiro, and Carasso, 2000). In order to be consistent with the original intentions of this study, the total net disposable income prior to retirement was selected as the dominator. This is because it is available for many datasets and is commonly used, thereby allowing the results of this study to be compared to others. Also, some pensions, especially occupational pensions, are largely correlated to an individual's income immediately prior to retirement. This makes the 
replacement rate useful for predicting retirement behaviours and analysis of the incentives for individuals to retire. Therefore, the replacement rate in this chapter is defined as the net disposable income following retirement divided by the net income immediately prior to retirement, as suggested in equation (6.1).

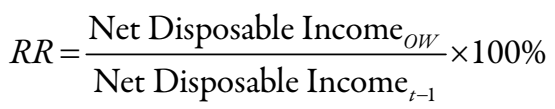

Therefore, the household replacement rate can be defined as:

$$
R R_{b}=\frac{\text { Net Household Income }_{O W}}{\text { Net Household Income }_{t-1}} \times 100 \%
$$

In general, the higher the replacement rate, the more protected an individual is from the impact of losing their work income. High replacement rates however, may reduce individuals' effort to stay within employment and provide incentives to retire early. The labour market opportunities that are faced by unemployed may be such that accepting the jobs offered to them would result in no or little financial gain. This may be particularly true for low-skilled individuals. Similarly, those currently employed on a low income may not lose much by entering unemployment or retirement.

The replacement rate offers a direct way of analysing monetary incentives and income smoothing. However, it is also worth noting that the change of welfare being can only be indirectly inferred from the replacement rate. Due to the different consumption patterns, a replacement rate lower than $100 \%$ of pre-retirement income may still be sufficient to maintain a living standard as the cost of living can decline in the transition from work to retirement. For instance, a retiree will have less work-related expenses such as clothing and transportation, but may have an increased health-related expenditure.

\subsubsection{Income Decomposition}

In order to analyse what drives the replacement rate, the sources of income before and after retirement also need to be studied. In most countries, an individual has the option to have more than one source of income over lifetime; however, the fluctuation of these income sources may depend on the status of retirement. For instance, if after becoming fully retired, there is a sharp decline of labour income, whilst at the same time, the dividend from a fund that was previously accumulated may start to be received together with money from private and public pensions. Therefore, the driving force of replacement rate cannot be fully understood unless all the possible income sources are explored. In this chapter, the income sources are grouped into five categories: labour and capital income, state pension, occupational and private pension, social benefit, and tax (negative income). 
While the transition from one labour market state to another is a process at the individual level, the subsequent change in income potentially affects the well-being of other household members. Concurrently, the incomes of others within the household will influence the welfare measure of the individual or may even be sufficiently strong to change an individual's behaviour. In addition, the employment status and incomes of individual household members can have important consequences for the amounts of taxes paid or benefits received by other household members (e.g. due to a joint income tax system or the assessment of total household income for computing means tested benefits). As a result, replacement rates at both the individual and household level are computed in this chapter.

\subsection{Methodology II: The Use of Tax-Benefit Microsimulation Model}

The chapter uses a sub-component of the LIAM model to facilitate the calculation of tax benefits for synthetic individual cases. The tax benefit model is derived from LIAM, a dynamic microsimulation model designed to evaluate potential reforms of the Irish pensions system and other policies in terms of changes to life-cycle incomes, with a particular focus on old age income replacement rates, poverty and inequality measures (O’Donoghue et al., 2009).

Simulations are run on the LII and synthetic dataset based on the systems of tax and benefit rules for the corresponding year. The synthetic based simulation uses the year 2000 data for the baseline analysis and the variables simulated and relevant for this exercise are income taxes, various family benefits (e.g. child benefit, lone parent benefit), pensions (e.g. state contributory pension, state non-contributory pension, survivors' pension etc.), and other benefits (e.g. unemployment benefits, disability benefit etc.). In simulating postretirement income and computing the relevant replacement rates, a number of noteworthy assumptions are made:

- Any provisions made for special retirement compensation in collective agreements are disregarded

- Partial retirement is disregarded and individuals are treated as part-time workers

- In the case of transitions from work to retirement, it is assumed that the individuals are no longer employed or claiming pension at the start of the current tax year

- In computing incomes, in-kind benefits such as the provision of social/subsidised housing or child-care are not included. Also not taken into account are work-related expenses (union fees, costs of commuting to work, costs of providing care for dependants during working hours, etc.), any discounts or rebates that may be available to benefit recipients (e.g. for utilities and phone bills, public transport, medical expenses, or school-related expenses such as books or uniforms). 


\subsection{Data and Sample Selection}

This chapter uses the 1994-2001 Living in Ireland Survey (ECHP-LII) dataset for a simple exercise of labour participation simulation. The LII survey constitutes the Irish component of the European Community Household Panel (ECHP). It is a representative household panel survey conducted on the Irish population annually for eight waves until 2001. The data contains information on demographic, employment, and other social economic characteristics of around 3500 households in each wave. Since the pension eligibilities and entitlements are often linked with career trajectories which are not readily available in the LII dataset, a back-simulation module was developed in order to recreate the working histories by exploitation of the existing variables. This module extracts the retrospective information from the LII dataset and applies a dynamic microsimulation in a reversed direction to simulate population histories. With some calibrations and alignments at both the cross-sectional and longitudinal levels, a simulated historical dataset that matched over 95\% of the individual pension entitlements was recreated together with a labour market history that matched the macro statistics to a fairly high degree (Li and O'Donoghue, 2010). During this exercise, a partial working history was used to recalculate the pension eligibility for the simulation of early retirement.

\subsubsection{Overview of Retirements in LII}

This chapter looks at retirement from the perspective of individual choices. Retirement is defined in this chapter as exiting the labour market after the age of 55. This definition is different from the official retirement status, but it is more closely linked to an individual's engagement in the labour market. Individuals between 55 and 75 years old who made the transition to retirement during the 8 waves of the panel were selected for the analysis. Since being a pensioner does not automatically mean quitting the Irish labour market, the reported retirement status cannot be used directly. In practice the following groups were included: individuals who had stopped working and were claiming pensions, individuals who had stopped working and who had not returned to the labour market for at least 3 of the waves (thus excluding temporary unreported unemployment), and individuals who had stopped claiming unemployment benefits without returning to work. Figure 6.1 compares the difference between reported retirement and observed retirement. As seen, the observed retirement results in a more flattened curve than the reported retirement due to the inclusion of unreported early retirement. The observed retirement pattern has a lower density around the age of $65 / 66$, while the general trend looks similar to the pattern observed for reported retirement. 
Among nearly 24,000 individuals included in the LII dataset, there were around 4000 individuals in the age group 55-75, and in total, 257 transitions to retirement were observed. Table 6.3 describes the details of the observation filtering in this analysis.

Table 6.3 Observation Filtering in LII

\begin{tabular}{l|c}
\hline Condition & Cases \\
\hline Total Number of Observations & 100,639 \\
Total Number of Individuals & 23,955 \\
Exclude Observations with Zero Weight & 22,286 \\
Age 55-75 in the dataset & 3970 \\
Number of Retirement Observed within the Panel & 257 \\
Transition from work & 218 \\
Transition from unemployment & 39 \\
\hline
\end{tabular}

Figure 6.1 Comparison of reported retirement and observed retirement

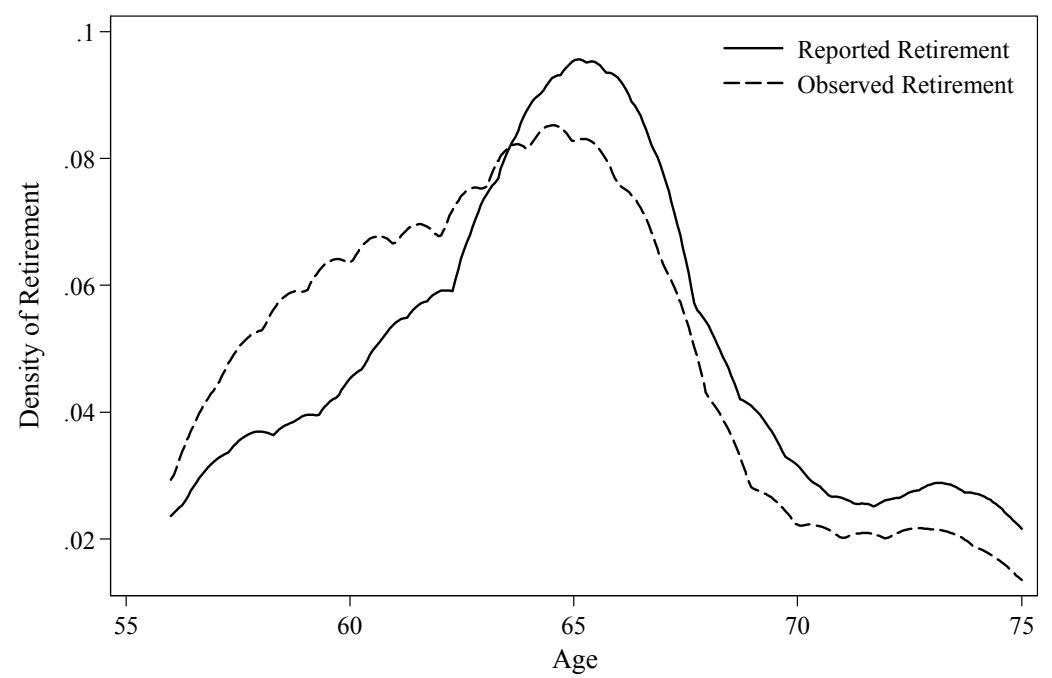

N.B. The observed retirement is calculated using the definition defined above, while reported retirement uses the variable from the original dataset

Figure 6.2 gives an intuitive presentation of how the observed retirements are distributed within the LII dataset. Since this is a panel dataset with attritions over time, a gradual drop of the qualifying individuals over waves was expected. In addition, those reporting retirements in the first wave were excluded as the transition for these individuals could not 
be observed. In general, what was observed was as expected except for the last two waves and the particular pattern observed is due to two reasons. First, in order to distinguish unreported unemployment from retirement, an individual was required to remain outside of the labour market for at least three waves and not returning to work. Since the panel ends in 2001, it is impossible to test unemployment in 2000 and 2001 using the same method and therefore results in a reduction of observed retirement. Second, to account for the data attrition, the LII dataset introduces some new individuals in wave of year 2000. The additional individuals enlarge the base of our analysis and increases the number of retirement transitions observed in 2001.

\subsubsection{Income Level of Elderly Workers in Ireland}

Among those aged 55 to 75 , the median income level of the elderly working population was $€ 9272$ in 1994 and $€ 12680$ in 2001 . The average income of the elderly followed a similar pattern over this period except for a small dip in 1996. On average, public sector workers received an annual income of around $€ 30656$, while private sector workers earned on average $€ 10200$. Those classed as self-employed on average had an annual labour income of $€ 28429$ per year.

Figure 6.2 Retirement Transitions Reported in the LII Survey

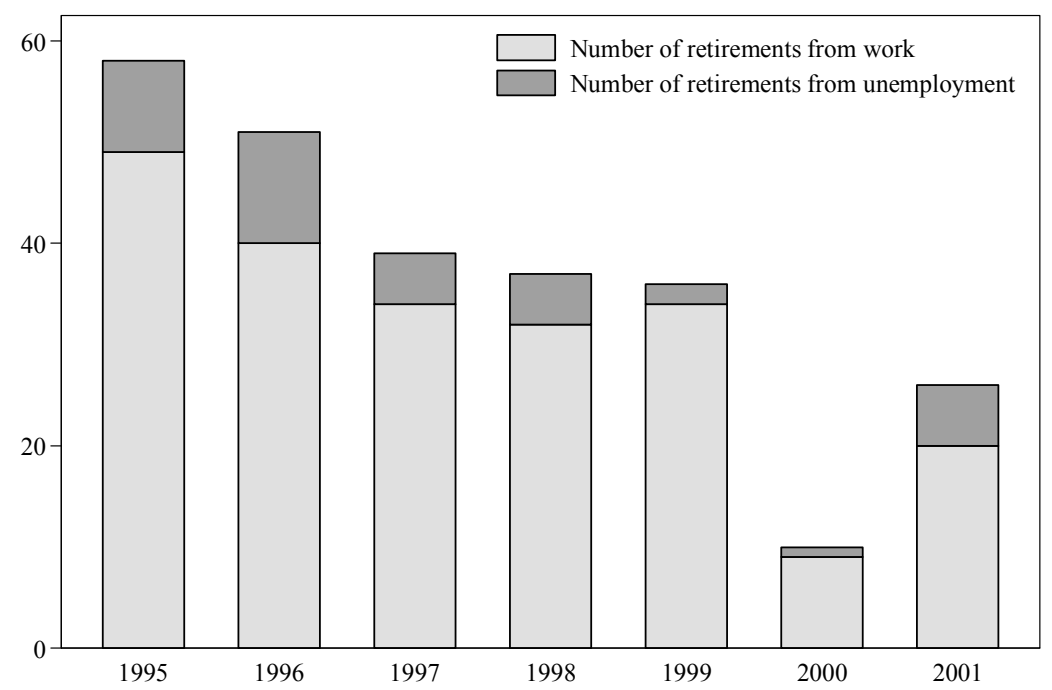


Table 6.4 Average Earnings between the ages of 55 and 75 in Ireland for 1994-2001

\begin{tabular}{lcc}
\hline Group & Earnings & Usual hours of work \\
\hline Public sector employee & 19617.0 & 35.3 \\
Private Sector employee & 14101.2 & 45.4 \\
Self-employed & 15780.7 & 40.0 \\
Average & 15187.3 & 42.1 \\
\hline
\end{tabular}

Figure 6.3 illustrates the age-earning patterns of elderly workers in Ireland. As a general trend, the average income declines gradually as age increases. This result is typically what is found when ignoring cohort effects in estimating age-earnings profiles (Thornton, 1997; Polachek and Sidbert, 1993). However, since the older people in the dataset represent a different cohort to the younger people, a large amount of the wage differences can be explained by the cohorts' effect and their gap in education.

Figure 6.3 Age-Earning Profile for Elderly workers in Ireland
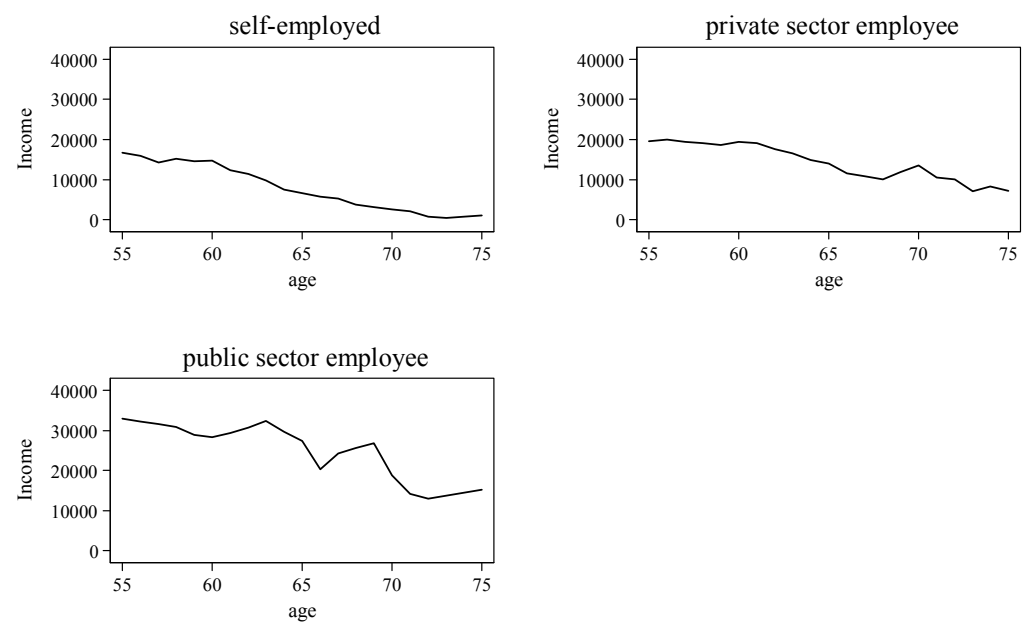

Income is smoothed using three years average

Figure 6.4 illustrates the composition of the individual income for working and retired individuals in the age group 55-75. As can be seen, the labour and capital income dramatically declines after retirement, while the size of pension income increases correspondingly. Welfare benefits, including child benefit and various other benefits, play a larger role after retirement, although the absolute size of the benefits received alters little on average. 


\subsection{Results I - Synthetic Replacement Rate of Irish Tax-Benefit System}

Tax benefit systems are typically complex and highly dependent on the household composition and employment histories. Consequently, the incentive structure of the retirement income support system might not be precisely measured due to the complex interactions of various social policies. Therefore, in order to better understand the Irish system, the analysis was commenced using a set of simple synthetic households with relatively simple employment trajectories. Through a synthetic simulation, it is possible to isolate the complex interactions of employment history, family composition, dynamics of earnings etc., and therefore observe the "pure" effect of the tax benefit system. The synthetic household starts with the following simple household structure:

- The household consists of only a single male member who has an average income level for the 55-75 age band

- The synthetic individual is assumed to have worked in the same sector and contributed to the occupational pension for 10 years

- The worker has worked long enough and meets the eligibility criteria to receive the state contributory old age pension after the age of 66 .

Figure 6.4 Income Decomposition of Working and Retired Individuals in Reported in the LII Survey

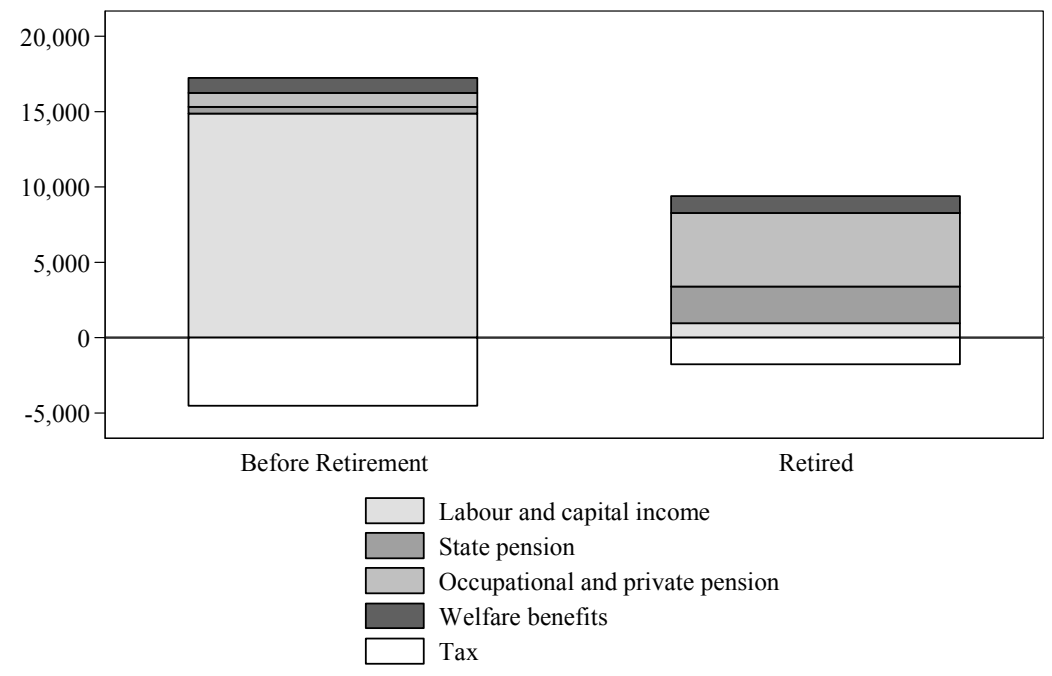

In the analysis, 20 possible ages (56-75) for exiting the labour market were simulated, combined with four possible retirement paths; namely exiting from the public sector, private sector, self-employment or unemployment. For this synthetic calculation, only the 
individual replacement rate was calculated, as the inclusion of extra household members may eradicate the pattern due to the assumptions of employment trajectories of other members which would increase the complexity of the interpretations.

For the calculation of the replacement rate with synthetic individuals, this chapter uses the last year's disposable income, instead of the simulated counterfactual one as the denominator. There are for two reasons for this:

First, one of the main goals of replacement rate analysis is to evaluate how well the welfare standard is maintained after retirement. By using the counterfactual income as the denominator, the rate may underestimate the potential earning changes in the last year as only limited variables can be incorporated in a wage model. This may not be a major issue for synthetic analysis if a constant income stream is assumed but the earning level in real life may not be stable as a model implies. As a result, the replacement rate based on the counterfactual income under-represents the change of earnings, and consequently the consumption level and welfare being also.

Second, in order to compare the replacement rate between a synthetic and a real life dataset, it is important to have a consistent definition of the replacement rate. Since counterfactual earnings do not exist within the real dataset, a variable which can be derived from both the synthetic and real-life datasets needs to be identified. The variable earning prior to retirement serves this purpose well, since it is available in both datasets and also correlates to the counterfactual earnings.

Figure 6.5 illustrates the distribution of the replacement rate if an individual qualifies for the old age contributory pension. Although the actual contribution periods needed to qualify for the contributory state pension may vary depending on an individual's occupation (PRSI classification) and the year of retirement, it was assumed that this synthetic individual has contributed to the system for at least 10 years before the age of 65 and therefore is eligible for the contributory pension under existing Irish regulations.

The graph reveals the replacement rate if individuals decide to retire at a given age. An obvious surge of replacement rate is observed for all scenarios at age 65/66, the official retirement age for receiving the state pension. This pattern is also reflected in the income decomposition graphs presented in Appendix 6.B. Since the pension entitlement is independent of the working status after the age of 66, earnings in all scenarios are increased, despite retirement from the labour market. The higher level of income prior to retirement increases the size of the denominator in the replacement rate calculation and as a result, the replacement rate starts to fall after age 66 .

For the self-employed, the replacement rate dramatically increases at age 65 for retirees and reaches around $100 \%$ when assuming that an individual had a previous income of $€ 7795$. For private sector workers, the replacement rate is lower due to the higher average income 
level. An average single private sector retiree may have the highest replacement rate (53\%) at age 66 if no additional occupational pension is received. Public sector workers have a similar pattern although the replacement rate is lowered to $33 \%$ due to their high income level. For the unemployed, the spike is most obvious as the contributory old age pension is much higher than the unemployment benefit and can increase to $640 \%$ of the unemployment benefit level. Since an individual cannot claim transitory pension if unemployed, the spike of replacement rate starts at age 66 instead of 65 .

Figure 6.5 Synthetic Replacement Rate with stable income and old age contributory pension
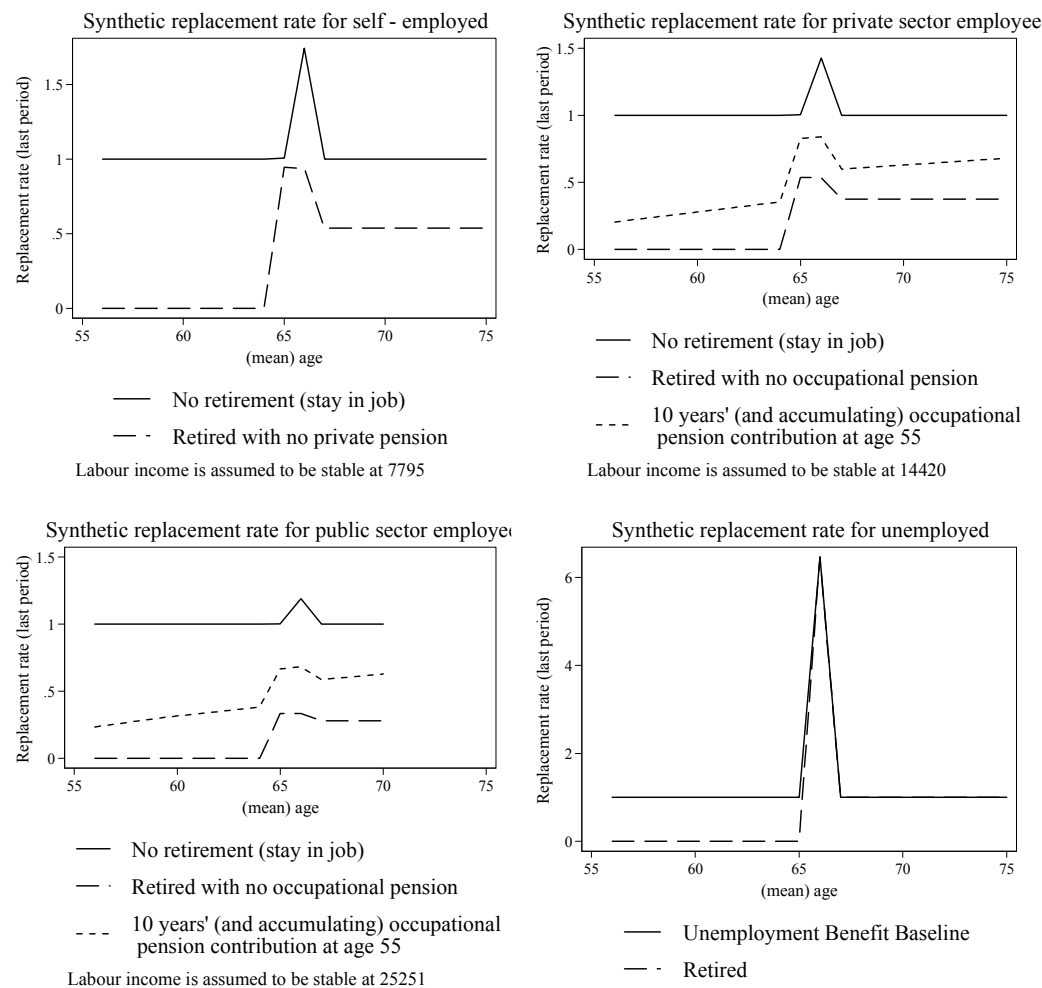

Assuming the individual is eligible for the state old age contributory pension. All reported rates are net replacement rates.

In the above analysis, it was assumed that income is stable between the ages of 55 and 75 , and although this might be the case for some employees, it is not necessarily true for all. By combining the average wage level in the age group into the replacement rate analysis, a more realistic distribution of replacement rate can be obtained. Figure 6.6 illustrates how this earning profile affects the synthetic replacement rate. As shown, although some extra volatility has been introduced into the replacement rate, the general trend remains the 
same. The replacement rate for public sector workers after age 70 is not reported as they are required to retire at age 65 except a limited number of exceptions.

Figure 6.6 Synthetic Replacement Rate with Changing Income and Old Age Contributory Pension
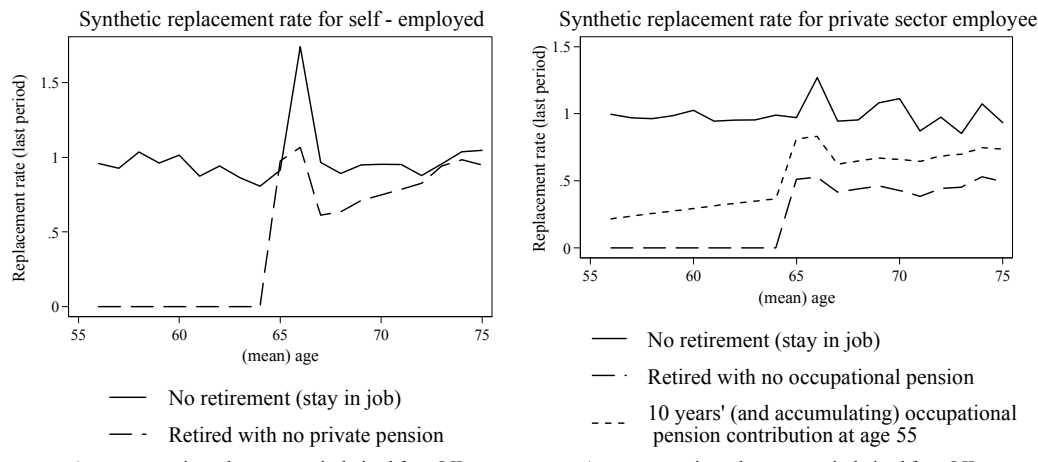

Average wage in each age group is derived from LII

Average wage in each age group is derived from LII
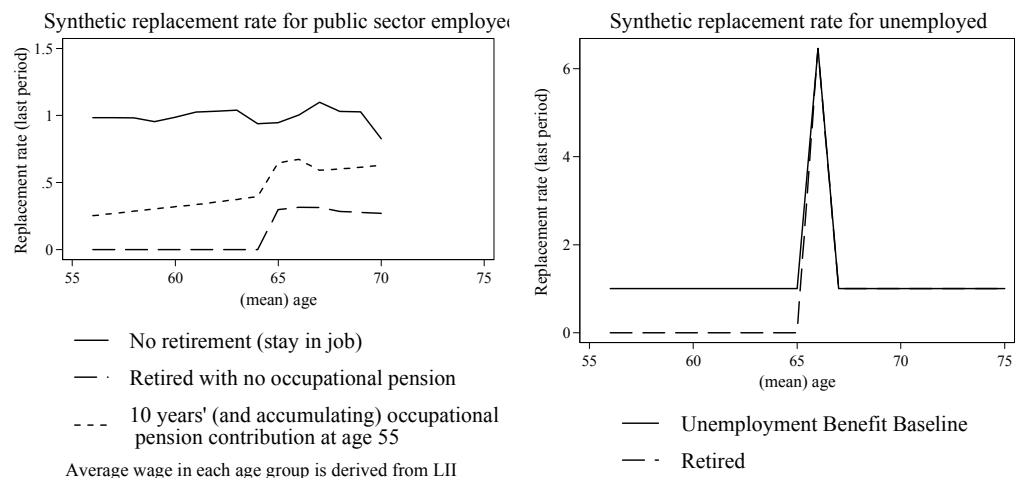

Assuming the individual is eligible for the state old age contributory pension. All reported rates are net replacement rates.

Despite the change in income level, the surge of replacement rate at age 65/66 can be easily spotted, which indicates that the pension entitlement can potentially provide a strong incentive for retiring at at this age ${ }^{15}$. However, for private and public sector employees, there is an earnings rebound immediately after retirement age 65/66. It is likely that these retirement decisions could be endogenous, which means that people with a lower income

${ }^{15}$ The effective retirement age in Ireland has been declining since the 1970s. However, mostly thanks to a rise in older female employment participation rates in the late 1980s, as well as a high level of self-employment, retirement ages among the elderly are still high by EU standards: in 2000 it was 63.4 for males and 60.1 for females, compared to the EU effective average retirement age of 58 . 
retire as soon as the legal retirement age is reached, while higher income earners postpone their retirement, thus increasing the average wage for the post-retirement age.

The synthetic analysis provides valuable information regarding the existing financial patterns in the tax-benefit system and illustrates the impacts when retiring at different ages. Since retirement income is often highly correlated to the previous employment trajectory, which varies greatly across the population, the synthetic analysis is likely to miss many of the important features of the tax-benefit system, which although not applicable to the synthetic household, may affect a large part of the population.

In the synthetic analysis, a single household individual was used in order to prevent the influence of the choices of other household members. However, over $90 \%$ of people aged over 55 live in a household with at least two members. Although extra individuals can be included within the synthetic household, it would remain a "non-typical" or "nonrepresentative" household, no matter what assumptions used. The additional household member may have a very different employment trajectory or benefit entitlement which could dramatically change the replacement rate. In order to mitigate this problem, Immervoll et al. (2000) computed a wide range of stylised households with different income levels to investigate the dynamics of tax-benefit systems. However, in the case of replacement rates, it is not only the design of the tax-benefit system per se that is of interest but also how it applies to existing populations. As a result, further analysis was conducted using a representative household survey dataset (LII).

\subsection{Results II - The Distribution of Replacement Rates}

\subsubsection{Distribution of Net Replacement Rates for Retired}

While the synthetic replacement rate provides in-depth analysis on the potential replacement rate for one particular scenario, notably a single person with an average income, this pattern may look very different if all the possible scenarios are pooled together from a real life dataset. Figure 6.7 presents the average net replacement rate for each of the four types of transition while an overview of the replacement rate by age and sector is reported in Appendix 6.C and 6.D. It seems that the actual replacement rate, to some extent, resembles part of the replacement rate pattern for an individual with 10 years of occupational pension with the exception of retiring from unemployment. 
Figure 6.7 Average Individual Replacement Rate (net) by Working Sector

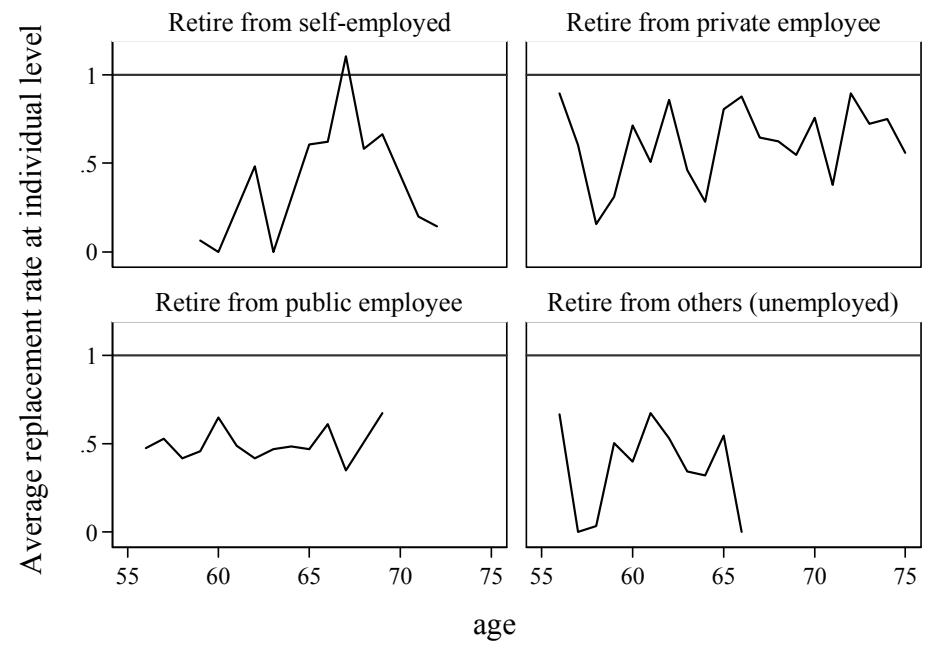

Average replacement rate at individual level

\subsubsection{Distributions of Simulated Replacement Rate}

By only looking at people whose status changes during the year and excluding those for whom it does not, a potential sample selection problem arises. If replacement rates have an influence on people's behaviour and people whose status remains unchanged face different replacement rates than those who experience transitions into or out of employment, then excluding one of these groups will result in a systematic bias. In order to determine whether replacement rates have an impact on retirement decisions it is necessary to measure them for both groups. Figure 6.8 reports the potential replacement rates for all individuals who are not retired. An obvious peak of replacement is observed in all four retirement paths around the age of 65/66, corresponding to the popular choice for retirement in Ireland. 
Figure 6.8 Average individual replacement rate (net) by working sector (Simulated)

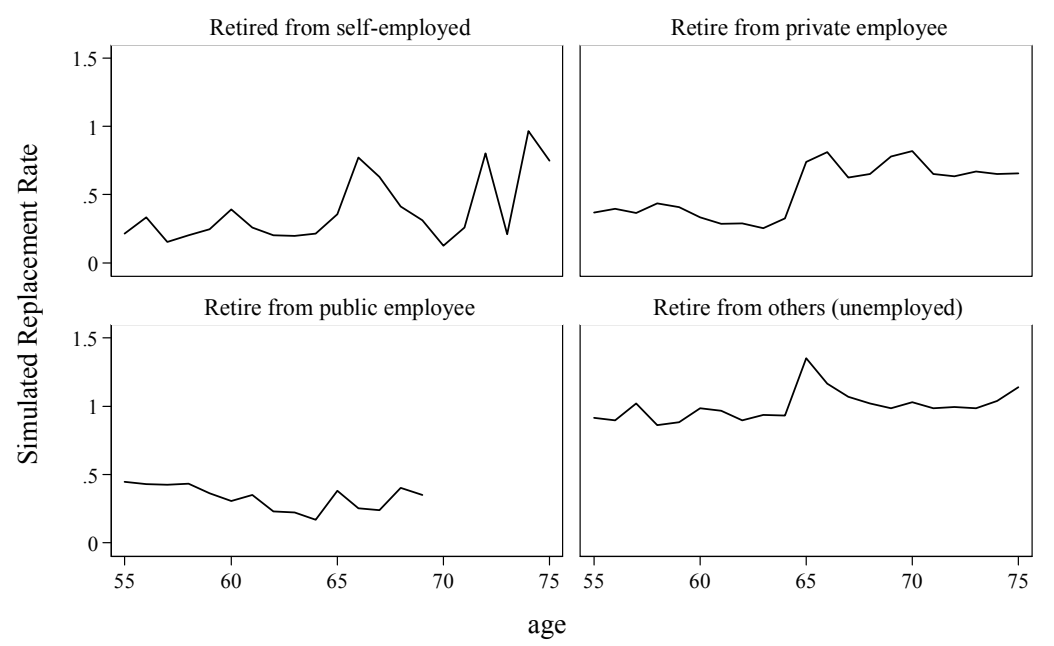

\subsubsection{The Socio-Economic Characteristics of Retirees with Different Replacement Rates}

As the data suggests, individual and household replacement rates have a very wide range in Ireland. This implied that they might also have very different career trajectories and patterns in social economic behaviours. A wide variety of summary statistics were used to determine how socio-economic characteristics are related to the replacement rate level. Table 6.5 briefly describes the 15 measures which were found to be relevant in describing the socio-economic characteristics of individuals with different replacement rates.

When looking at three groups of individuals with differing replacement rates (lower than $40 \%$, $40-80 \%$, and more than $80 \%$ ), these groups exhibited very different patterns in behaviour. When comparing the low net replacement rate group with the other groups, then this group, on average, had an individual replacement rate of merely $11.1 \%$. However, the household replacement rate was dramatically higher for this group and amounted to 91.1\%. In addition, this group has the youngest retirement age amongst the three groups, which may indicate that this particular group retires early due to the stable income stream of other household members. This also explains why individuals with zero replacement rates still retire before being able to claim the state old age pension.

The mid net replacement rate group seemed to be dominated by people retiring from work. Over $94 \%$ of these people were either employees or self-employed before they started to claim their pension. In addition, this group has the highest education attainment amongst the three groups. 
Table 6.5 Socio-Economic Characteristics of High/Mid/Low replacement rate group

\begin{tabular}{|c|c|c|c|c|}
\hline Group & $\begin{array}{c}\text { Low } \\
\text { Replacement } \\
\text { Rate } \\
(0-0.4)\end{array}$ & $\begin{array}{c}\text { Mid } \\
\text { Replacement } \\
\text { Rate } \\
(0.4-0.8)\end{array}$ & $\begin{array}{c}\text { High } \\
\text { Replacement } \\
\text { Rate } \\
(0.8+)\end{array}$ & Total \\
\hline Percentage with higher education & $14.89 \%$ & $25.71 \%$ & $8.62 \%$ & $17.90 \%$ \\
\hline Individual net replacement rate & $11.10 \%$ & $55.90 \%$ & $123.20 \%$ & $54.70 \%$ \\
\hline Household net replacement rate & $91.10 \%$ & $75.80 \%$ & $108.20 \%$ & $88.70 \%$ \\
\hline Male & $54.26 \%$ & $74.29 \%$ & $89.66 \%$ & $70.43 \%$ \\
\hline Have a spouse & $79.79 \%$ & $87.62 \%$ & $79.31 \%$ & $82.88 \%$ \\
\hline Chronic Illness & $2.13 \%$ & $3.81 \%$ & $17.24 \%$ & $6.23 \%$ \\
\hline Still have a mortgage to pay & $14.63 \%$ & $14.56 \%$ & $11.11 \%$ & $13.81 \%$ \\
\hline Household size & 3.1 & 3.0 & 3.1 & 3.1 \\
\hline Retire from work (\%) & $77.66 \%$ & $94.29 \%$ & $79.31 \%$ & $84.82 \%$ \\
\hline $\begin{array}{l}\text { Usual working hours per week before } \\
\text { retirement (if working) }\end{array}$ & 34.21 & 35.26 & 30.20 & 33.84 \\
\hline Was in public sector (if working) & $20.55 \%$ & $37.37 \%$ & $8.70 \%$ & $25.69 \%$ \\
\hline Average retirement age & 62.8 & 64.1 & 64.8 & 63.8 \\
\hline $\begin{array}{l}\text { Individual Disposable Income after } \\
\text { retirement }\end{array}$ & 2501 & 9310.2 & 9054.4 & 6761.9 \\
\hline $\begin{array}{l}\text { Household Disposable Income after } \\
\text { retirement }\end{array}$ & 19788.8 & 20494.0 & 19396.7 & 19988.4 \\
\hline $\begin{array}{l}\text { Individual disposable income before } \\
\text { retirement }\end{array}$ & 14410.9 & 17062.9 & 8191.6 & 14090.8 \\
\hline Proportion of people in this group & $36.58 \%$ & $40.86 \%$ & $22.57 \%$ & $100.00 \%$ \\
\hline
\end{tabular}

The high net replacement rate group on average has a replacement rate of over $123 \%$, which suggests that their post-retirement earnings are higher than their pre-retirement income. This group exhibited some distinct patterns, it had the lowest educational attainment compared with the other groups and also much lower pre-retirement earnings compared with any other group. These two observations tally, as workers with a lower education attainment tend to have lower wages, which decreases the size of denominator. Additionally $20 \%$ of the individuals in this group retired from unemployment compared with less than $6 \%$ in the mid replacement rate group. Finally, welfare benefits played a larger role percentage wise in the post-retirement income of this group compared with other groups.

Figure 6.9 further analyses the income decompositions amongst high and low replacement rate groups. By comparison, the high replacement rate group derived a larger share of their post retirement income from state pension and other welfare benefits, than the other two 
groups. Occupational and private pensions were the main source of income for the group with the mid replacement rate, which for the years 1994-2001, accounted for $79.0 \%$ of their post retirement income, compared with $42.9 \%$ for the high replacement rate group and $54 \%$ for the low replacement rate group.

Figure 6.9 Income Decomposition by Replacement Rate Group

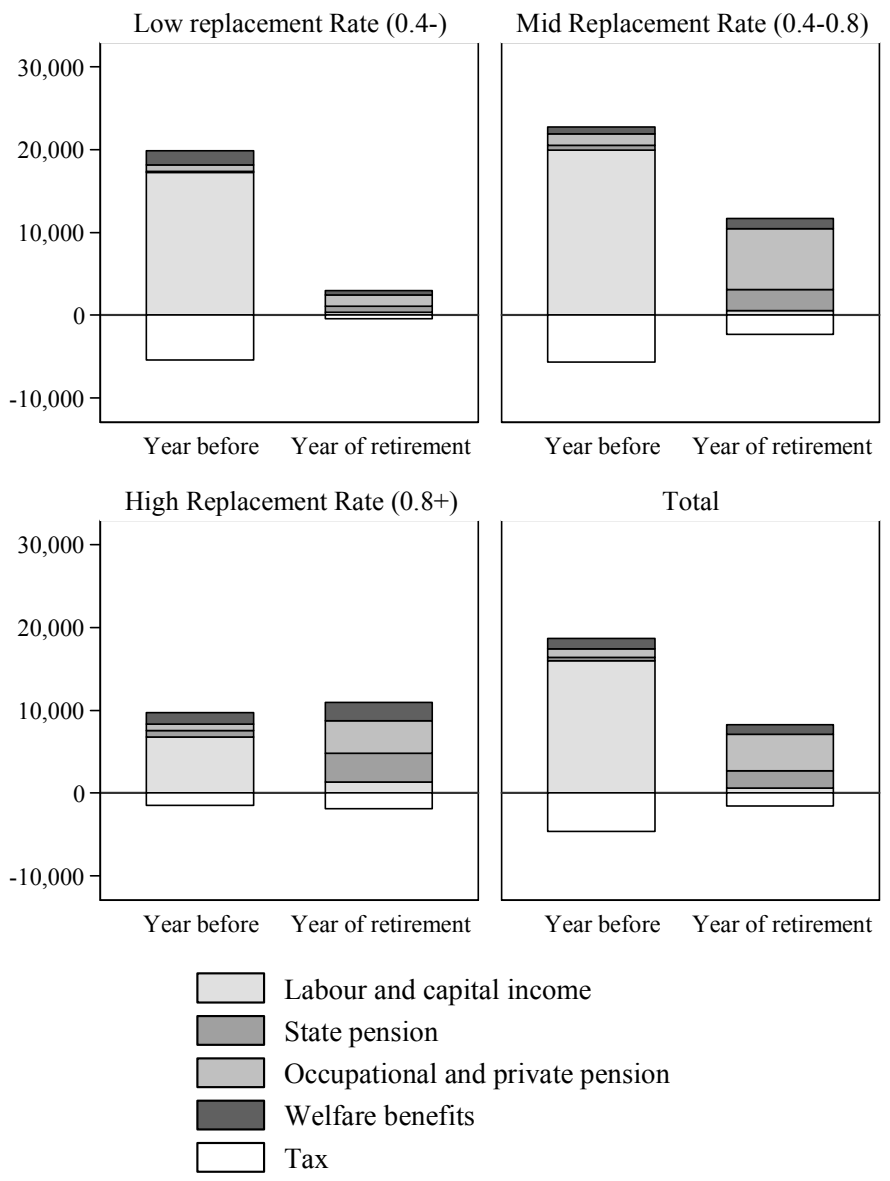

\subsubsection{Time dependency of the replacement rate and earning decomposition}

In addition to the level of replacement rate measured immediately after retirement, it is also interesting to look at how the level of income and replacement rate fluctuates following a few years of retirement. If the net disposable income prior retirement is kept as the common denominator for replacements rate in all years, then the replacement rate 
changes over time. The addition of a time dimension would therefore allow both the short and long term monetary incentives of retirement to be understood.

Figure 6.10 Income after Retirement Over Time (By Retirement Age)
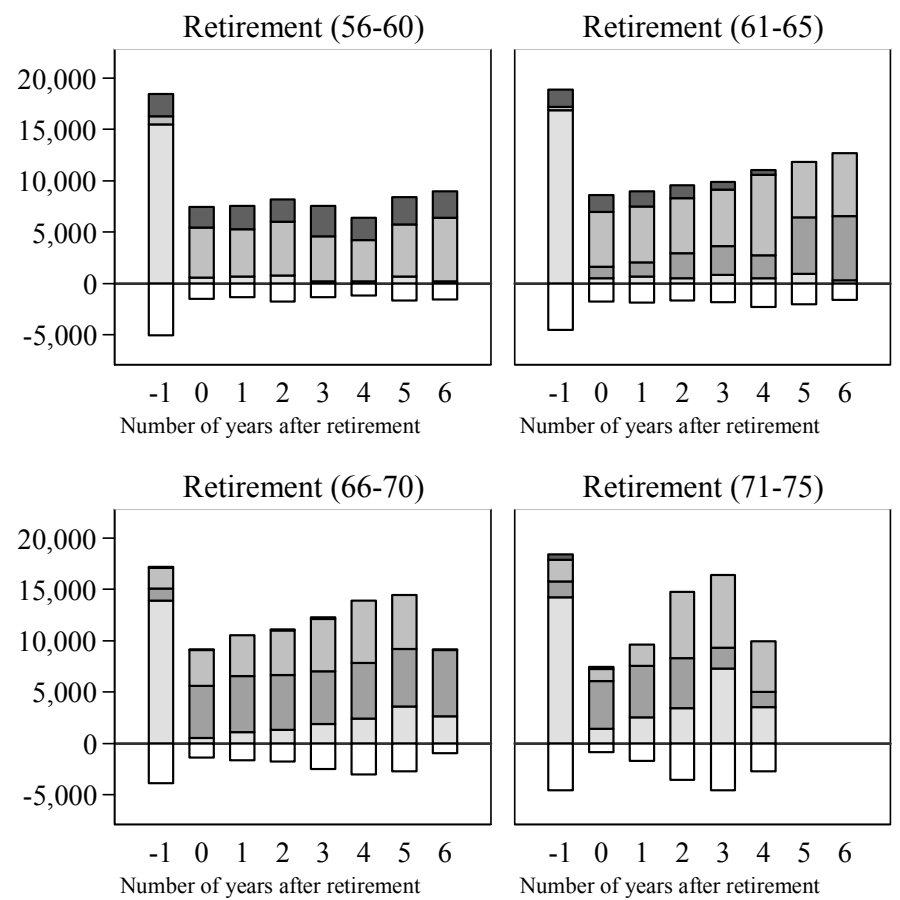

Retirement (71-75)
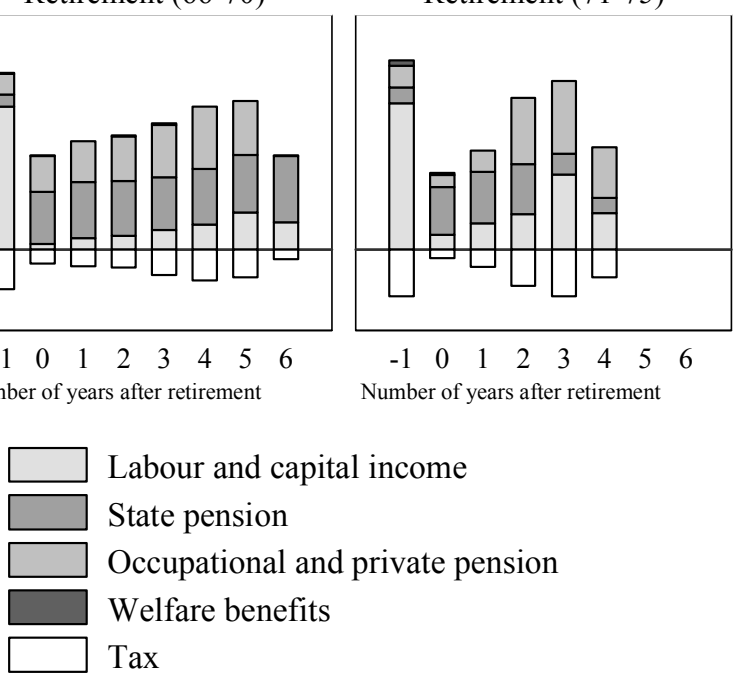

Figure 6.10 presents a graph which adds the time dimension into the replacement rate analysis. The figure shows that for people retiring before the age of 60 , the replacement rate remained relatively stable for the 6 years after retirement. This suggests that there is not much change in the total income level as all the rates were calculated using earnings before retirement as the common denominator. For the population who retired after the age of 60 , the replacement rate exhibited a slow upwards trend. This increase is mostly driven by the state pension for people who retire before the age of 65 , as they have had to wait for a few years before they can claim this pension. In addition, the indexation of the pension payout may also play a role in driving up the retired income in absolute term over time. Public pensions are slightly adjusted every year while the private pensions may subject to 
their own rules of indexations. Among the population who retired later, capital income accounts for most of the increase observed. The increase in capital income might come from the maturation of previous investments and certain private pension arrangements.

Figure 6.11 Income after Retirement Over time (By Replacement Rate)

Low replacement Rate (0.4-) Mid Replacement Rate (0.4-0.8)
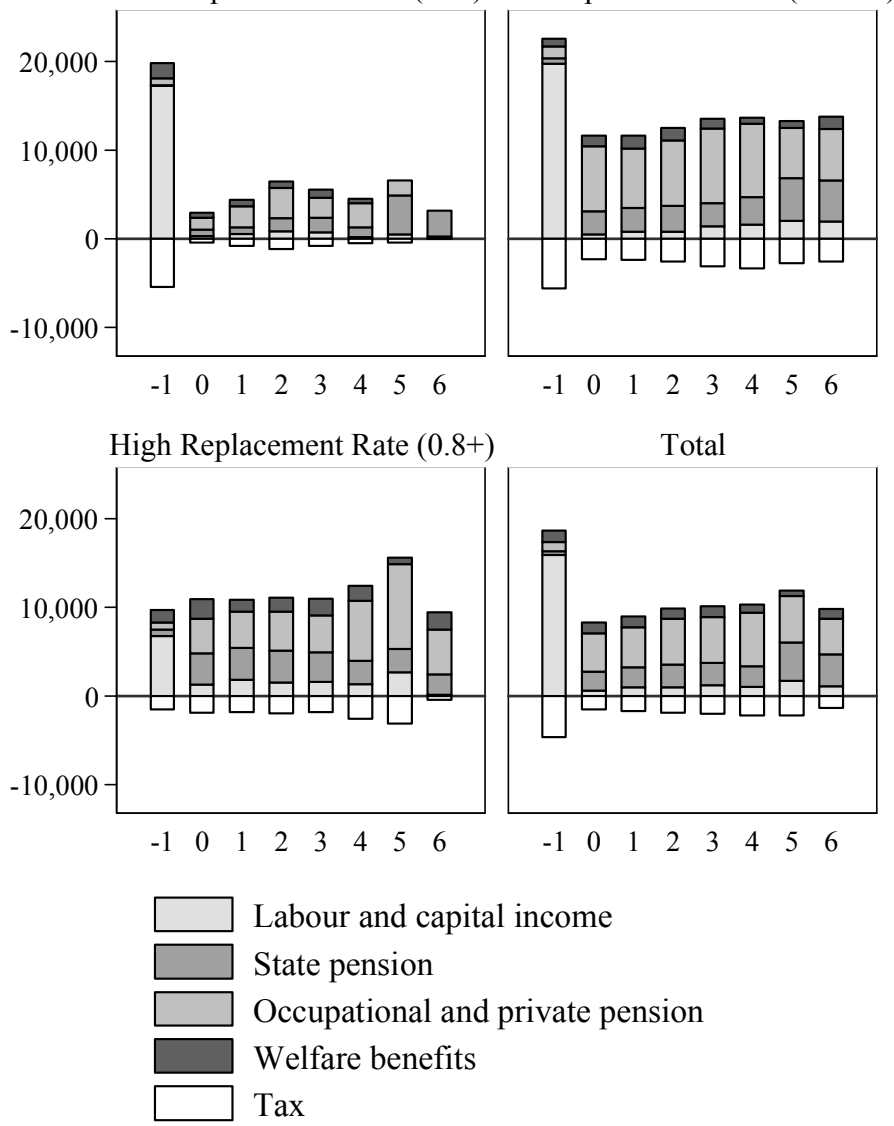

If the observations are grouped by their level of replacement rate instead of retirement age, as in Figure 6.11, then it seems that the total income level, as well as the replacement rates, is more or less stable except for the low replacement rate group, who appears to have more fluctuated income due to their lower income level, and the later years of the high replacement rate group (see also Appendix 6.E). This indicates that retirees in the low replacement rate group typically do not have as stable an income source as the retirees in the other groups. This pattern may also explain why these people belong to the low replacement rate group to start with. Among the mid and high replacement rate groups, 
capital income, on average slowly increased after retirement, a finding which is consistent with the results from the previous analysis.

\subsection{The Retirement Pattern and Replacement Rates}

\subsubsection{Observed Retirement Pattern and the Observed Replacement Rates}

This section compares the replacement rate patterns and the retirement patterns, to examine whether monetary incentives play a role in the retirement decision. The Irish regulations, as reviewed earlier, suggest that the system provides a strong incentive to retire at age 65/66. At the same time, the estimations from the synthetic and LII datasets confirm the rise of replacement rate at around age 65 and 66, two crucial ages in the Irish tax system in terms of pension eligibility. It would therefore be interesting to investigate whether the retirement pattern matches the replacement rate pattern.

Previous figures suggest that the relationship between the net replacement rates and retirement crudely correspond in terms of the peak period at the age of 65/66. However, the benefits and entitlements of the Irish tax benefit system are usually highly related to the job sector and previous contributions. As a result, the retirement and replacement rate patterns were investigated further by grouping individuals according to their employment status prior to retirement, as shown in Figure 6.14 and Figure 6.15.

Figure 6.12 overlaps the age-retirement pattern with the individual replacement rate profile. The age-replacement rate curve measures the fluctuations of earnings level as well as the monetary incentive of retirement introduced by the social welfare system. As can be seen, although the two patterns do not resemble each other completely and the scales are different, nevertheless the retirement pattern does respond to change in the replacement rates.

Figure 6.13 uses the household based replacement rates instead of the individual replacement rates. Since a household usually consists of several people who may not all retire at the same time, this replacement rate is less volatile when compared with the individual based replacement rate. Because the curve is smoother, the matching is less obvious graphically, although the replacement rates still correspond to the change in the number of retirees.

Previous figures suggest that the relationship between the net replacement rates and retirement crudely correspond in terms of the peak period at the age of $65 / 66$. However, the benefits and entitlements of the Irish tax benefit system are usually highly related to the job sector and previous contributions. As a result, the retirement and replacement rate patterns were investigated further by grouping individuals according to their employment status prior to retirement, as shown in Figure 6.14 and Figure 6.15. 
Figure 6.12 Observed Retirement and Individual Replacement Rate

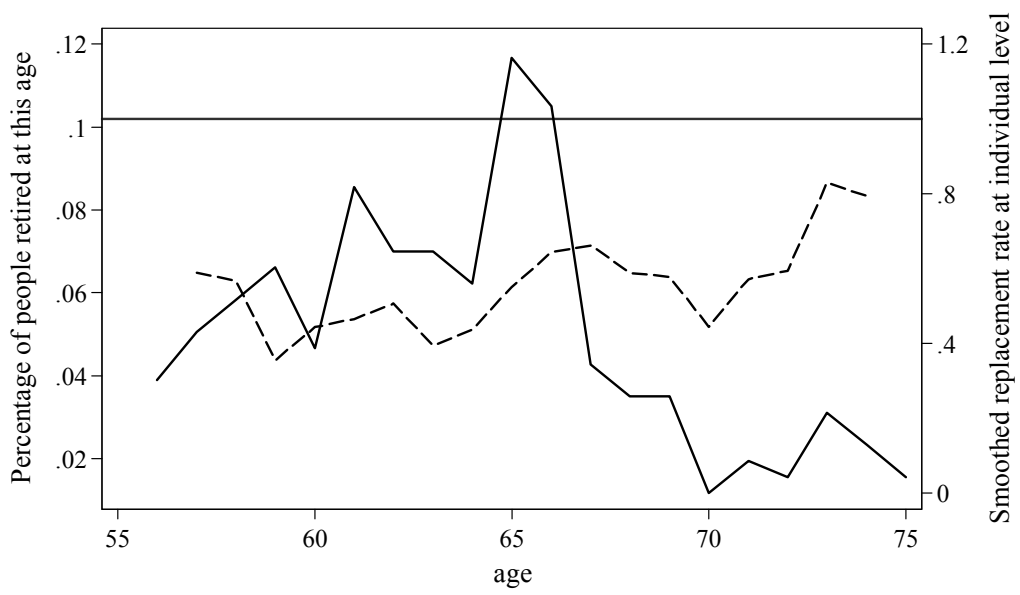

Percentage of people retired at this age

Smoothed replacement rate at individual level

Figure 6.13 Observed Retirement and Household Replacement Rate

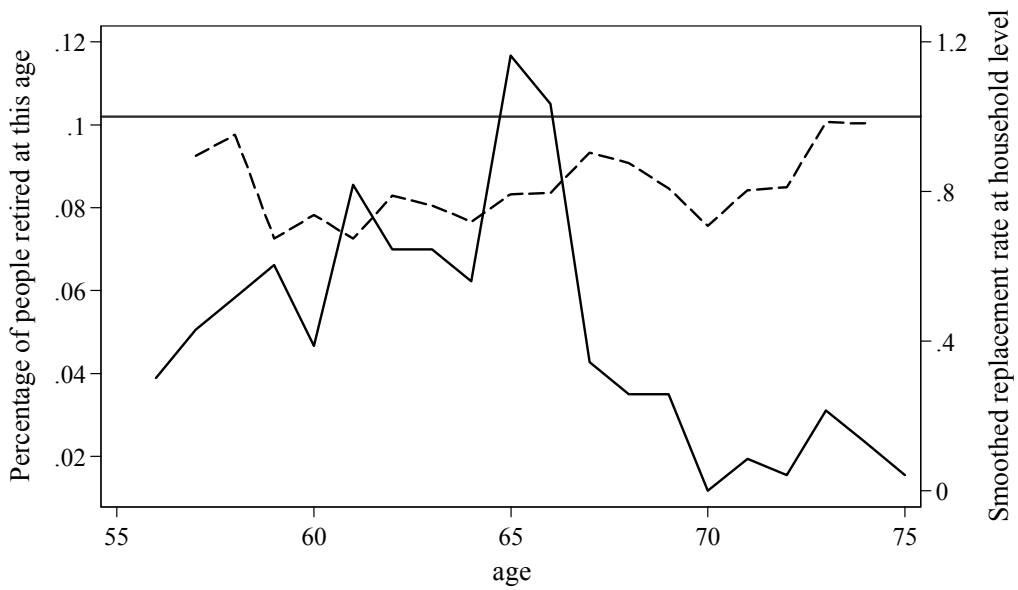

Percentage of people retired at this age

- - - Smoothed replacement rate at household level 
Figure 6.14 Retirement and Individual Replacement Rate by Retirement Path 1

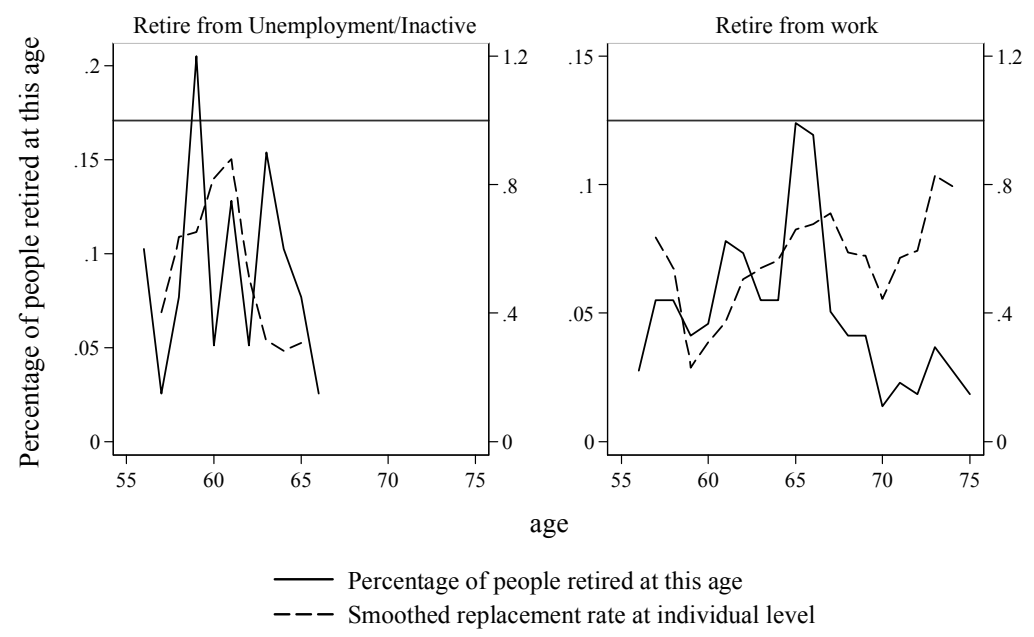

Figure 6.15 Retirement and Individual Replacement Rate by Retirement Path 2

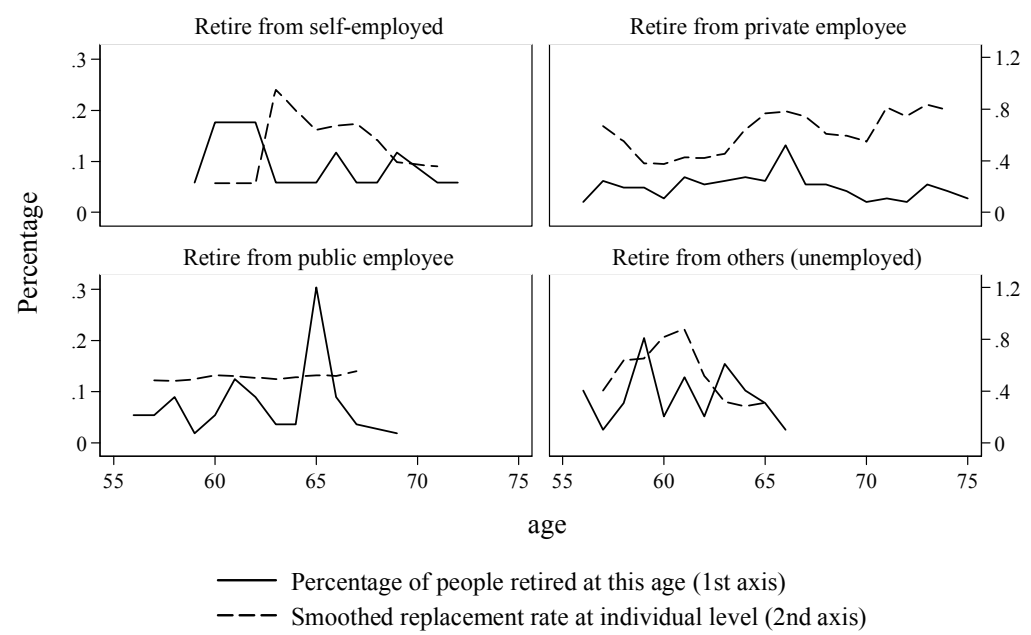

It seems that the replacement rate matches well with the retirement pattern for people who retired from work as indicated in Figure 6.14. Figure 6.15 looks at the nature of the retiree's last job, shows that the correlation between replacement rate and the number of retired seems to be strongest for those who retire from the private sector. The vast majority of public sector workers retire at age 65 despite a relatively flat replacement rate curve, although this is mainly due to the mandatory retirement age present in the public sector. 


\subsubsection{Social-Economic Characteristics of the Early and Late Retirement Groups}

As presented in the previous tables and graphs, the age of 65/66 is the most popular choice for retirement in Ireland. Nonetheless, there are still many individuals who retire much earlier or later than at the average age. Table 6.6 highlights some of the main social economic characteristics found for the four different retirement age groups.

Table 6.6 Socio-Economic Characteristics of the early and late retirement group

\begin{tabular}{|c|c|c|c|c|c|}
\hline Group & $\begin{array}{l}\text { Retirement } \\
(56-60)\end{array}$ & $\begin{array}{l}\text { Retirement } \\
(61-65)\end{array}$ & $\begin{array}{c}\text { Retirement } \\
(66-70)\end{array}$ & $\begin{array}{l}\text { Retirement } \\
(71+)\end{array}$ & Total \\
\hline $\begin{array}{l}\text { Percentage with higher } \\
\text { education }\end{array}$ & $16.42 \%$ & $18.27 \%$ & $22.03 \%$ & $11.11 \%$ & $17.90 \%$ \\
\hline Individual net replacement rate & $43.84 \%$ & $50.95 \%$ & $69.60 \%$ & $63.26 \%$ & $54.67 \%$ \\
\hline Household net replacement rate & $105.11 \%$ & $79.66 \%$ & $84.15 \%$ & $92.49 \%$ & $88.67 \%$ \\
\hline Male & $58.21 \%$ & $75.00 \%$ & $69.49 \%$ & $85.19 \%$ & $70.43 \%$ \\
\hline Have a spouse & $80.60 \%$ & $84.62 \%$ & $79.66 \%$ & $88.89 \%$ & $82.88 \%$ \\
\hline Chronic Illness & $5.97 \%$ & $6.73 \%$ & $5.08 \%$ & $7.41 \%$ & $6.23 \%$ \\
\hline Still have a mortgage to pay & $22.81 \%$ & $17.35 \%$ & $5.17 \%$ & $0.00 \%$ & $13.81 \%$ \\
\hline Household size & 3.42 & 3.06 & 2.88 & 2.52 & 3.05 \\
\hline Retirement from work (\%) & $73.13 \%$ & $80.77 \%$ & $98.31 \%$ & $100.00 \%$ & $84.82 \%$ \\
\hline $\begin{array}{l}\text { Usual working hours per week } \\
\text { before retirement (if working) }\end{array}$ & 31.18 & 36.98 & 33.25 & 30.15 & 33.84 \\
\hline Was in public sector (if working) & $30.61 \%$ & $39.29 \%$ & $13.79 \%$ & $0.00 \%$ & $25.69 \%$ \\
\hline $\begin{array}{l}\text { Average retirement age } \\
\text { Individual Disposable }\end{array}$ & 58.12 & 63.13 & 67.15 & 73.00 & 63.79 \\
\hline Income after retirement & 5902.98 & 6807.06 & 7624.12 & 6835.57 & 6761.93 \\
\hline $\begin{array}{l}\text { Household Disposable Income } \\
\text { after retirement }\end{array}$ & 24342.53 & 19291.70 & 17333.24 & 17669.57 & 19988.43 \\
\hline $\begin{array}{l}\text { Individual disposable income } \\
\text { before retirement }\end{array}$ & 13376.59 & 14507.87 & 13666.70 & 15183.44 & 14090.81 \\
\hline $\begin{array}{l}\text { Proportion of people in this } \\
\text { group }\end{array}$ & $26.07 \%$ & $40.47 \%$ & $22.96 \%$ & $10.51 \%$ & $100.00 \%$ \\
\hline
\end{tabular}

There are several noteworthy trends from Table 6.6. First, it seems that the individual replacement rates are higher in the late retirement groups than the ones in the early retirement groups. The household replacement rates, however, do not follow the same trend. In fact, the group that retires earliest also has the highest household replacement rate, indicating that some early retirements may be induced by the monetary incentives provided by other household members. In addition, a higher replacement rate also implies a relatively lower cost of retirement. 
Second, the average household size is declining as retirement age increases, for which there may be two reasons. The higher mortality rate at the later age may result in a smaller household size or, alternatively, a smaller household might be the reason behind later retirement as there are less people to pool resources.

Third, people who retired before the age of 65 were found to have a higher chronic illness rate when compared to the group who retired at age 66-70. This might indicate that the chronic illness may drive people to retire earlier; however, the chronic illness rate is highest for people who retire after the age of 71 . This pattern may suggest that the incentive structure in the current legislation may push more physically healthy people out of the labour market at age 66-70 than for the other age brackets.

Fourth, retiring from unemployment tends to occur at an earlier stage. As shown in Table 6.6, the percentage of people who retired from work increased steadily as the retirement age rose. In the LII dataset, more than $98 \%$ of people who retired after the age of 66 made the transition from work, compared with only $73 \%$ if they retired before the age of 60 . This suggests that the early retirees might have had to retire early because they could not find another job. It is also worth noting that the percentage of elderly retiring from unemployment might be under-reported for late retirees. Since the unemployment benefit is same as the state pension benefits, there is no additional benefit by applying for unemployment benefit for elderly people if they are eligible for both benefits. This might lead to some underreporting of the retirement transition from unemployment.

To further analyse the differences between early and late retirees, the income sources in the year prior to retirement and in the year of retirement were decomposed (Figure 6.16). This showed that early retirees relied much more heavily on welfare benefits compared to those retired later.

Figure 6.16 shows that not only does the level of income differ between early and late retirees as illustrated in Table 6.6, but that their income sources are also largely different. Between 1994 and 2001 when the LII survey was conducted, occupational and private pensions were the largest source of income for those retired at age 55 or earlier. This accounted for 82.4 per cent of their disposable income on average, compared with 17.6 per cent for retirees who retired after age 70 . In addition, it seems that early retirees rely more heavily on welfare benefits (33.9\%), which is much higher than the late retirees (2.9\%). In general, early retirees rely mostly on welfare benefits and occupational pension, while later retirees have more diverse income sources. 
Figure 6.16 Income Decomposition for Early and Late Retirees (Percentage)

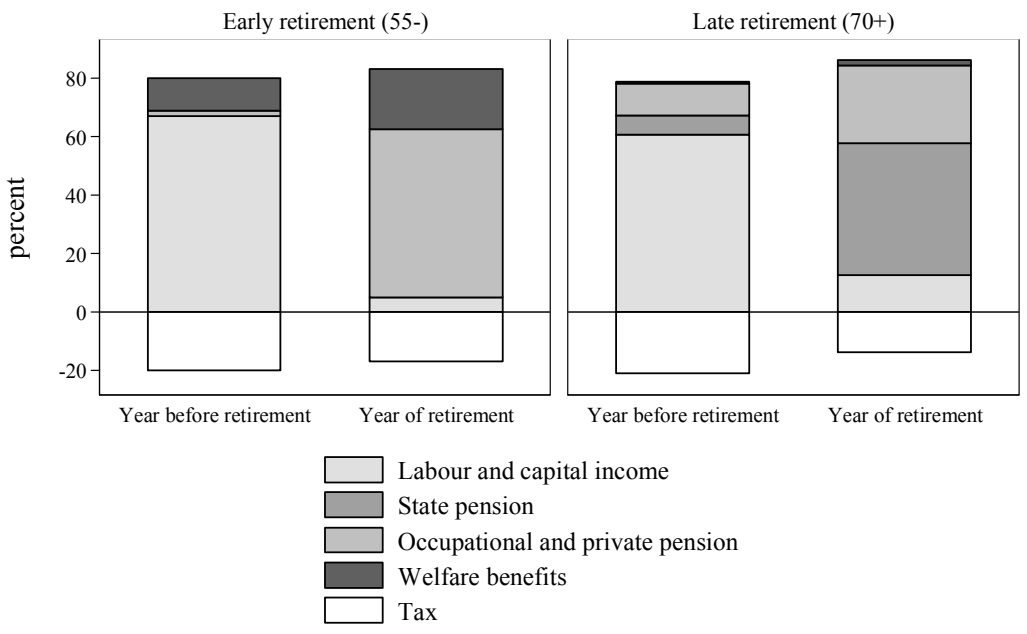

\subsection{Conclusion}

This chapter analyses the retirement pattern and the replacement rate observed in Ireland using the LII panel dataset. Due to the fact that the Irish regulations allow working while receiving the state pension, this chapter used the observed retirement instead of the reported retirement status to address the potential differences between pension eligibility and retiring from the labour market.

The chapter found that the average replacement rate for newly retired workers using the LII dataset was approximately $54.7 \%$ but this figure has a high standard deviation value and this suggests that there is a large inequality of replacement rates among retirees. Workers from different sectors had very different earning profiles and replacement rates according to the synthetic calculation performed. A typical self-employed worker would be able to maintain an income that is more than $50 \%$ of his/her pre-retirement earnings, while workers from other sectors had a dramatically lower replacement rate, mostly due to their higher pre-retirement earnings.

The observed replacement rates and earning profiles present in the dataset had a high degree of fluctuation due to the complexities in the household structure and employment trajectories. In addition, the relatively low number of observations resulted in graphs less smooth than expected. Individuals with high and low replacement rates were found to have very different social economic characteristics. The high replacement rate group tended to be less educated, had a lower income and a higher dependency on social benefits. 
Individuals in the low replacement rate group, however, had a high household replacement rate of $91 \%$ on average. The state pension was a major source of income for all categories except for those retiring earlier than 65 , who relied heavily on occupational and private pensions.

In addition, the chapter found that the number of people going through retirement roughly corresponded to the individual worker replacement rate, especially for those who retired from the private sector or who were self-employed. The replacement rate is not stable as people remain retired for longer and, on average, there was a slight increase due to welfare benefits and capital income. It seems that the growth rate of the replacement rate is positively correlated to the age of retirement.

Although replacement rate is one of the most intuitive measurements that can be obtained from the dataset, it is still simplistic and potentially inaccurate for measuring welfare being as it does not account for employment status related expenditures and savings, e.g. transportation costs, medical costs. However, it does give an overview of the general trend and an analysis of the incentive structure among retirees in Ireland. This chapter could potentially benefit from further research using a larger dataset where greater heterogeneities can be further explored. 


\subsection{References}

Atkinson, A., Micklewright, J., 1991. Unemployment compensation and labor market transitions: a critical review. Journal of economic literature 29, 1679-1727.

Baroni, E., O'Donoghue, C., 2009. Research Working Paper 2009/09: Poverty Impact of State Pension Reform on the Elderly: an analysis of reform proposals in the 2007 Irish Green Paper. Combat Poverty Agency.

Berger, F., Borsenberger, M., Immervoll, H., Lumen, J., Scholtus, B., De Vos, K., 2003. The impact of tax-benefit systems on low income households in the Benelux countries. A simulation approach using synthetic datasets. Microeconomics.

Blöndal, S., Scarpetta, S., 1997. Early retirement in OECD countries: the role of social security systems. OECD Economic studies, 7-54.

Bureau, C.P., 1995. Replacement rates - A transatlantic view, CPB Working Paper, No. 80.

Callan, T., Coleman, K., Walsh, J., 2006. Assessing the Impact of Tax/Transfer Policy Changes on Poverty: Methodological Issues and Some European Evidence. Micro-Simulation in Action (Research in Labor Economics, Volume 25), Emerald Group Publishing Limited 25, 125-139.

Callan, T., Van Soest, A., 1996. Family labour supply and taxes in Ireland. Papers.

Engen, E., Gale, W., Uccello, C., 1999. The adequacy of household saving.

Esping-Andersen, G., 1990. The three worlds of welfare capitalism. Polity Pr.

Evans M., O.D., C. and Vizard, P., 2000. Means Testing and Poverty in 5 European Countries, in: V., A. (Ed.), Le Politiche Sociali in Italia ed in Europa Coerenza e Convergenza nelle Azioni 1997-1999, Bologna: il Mulino.

Hughes, G., Watson, D., 2005. Pensioners' Incomes and Replacement Rates in 2000. Economic and Social Research Institute (ESRI).

Immervoll, H., Economics, U.o.C.D.o.A., 2000. Fiscal drag-an automatic stabiliser? University of Cambridge, Dept. of Applied Economics.

Immervoll, H., O’Donoghue, C., 2003a. Welfare benefits and work incentives: an analysis of the distribution of net replacement rates in Europe using EUROMOD, a multi-country microsimulation model. Labor and Demography. Economics Working Paper Archive EconWPA.

Immervoll, H., O’Donoghue, C., 2003b. Employment transitions in 13 European countries. Levels, distributions and determining Factors of net replacement rates.

Li, J., O’Donoghue, C. 2010. Simulating Histories for Dynamic Microsimulation Models in: O’Donoghue, C. (Ed.), Life-Cycle Microsimulation Modelling: Constructing and Using Dynamic Microsimulation Models. LAP LAMBERT Academic Publishing.

Munnell, A., Soto, M., 2005. How Do Pensions Affect Replacement Rates? Issues in Brief.

OECD, 1994, The OECD Jobs Study.Paris.

OECD, 1998, Benefit systems and work incentives,Paris.

OECD, 1999, Benefit systems and work incentives,Paris.

O'Donoghue, C., 2001. Redistribution over the lifetime in the Irish tax-benefit system: an application of a prototype dynamic microsimulation model for Ireland. Economic and Social Review 32, 191-216. 
O’Donoghue, C., 2003. Redistributive forces of the Irish tax-benefit system.

O’Donoghue, C., Lennon, J., Hynes, S., 2009. The Life-cycle Income Analysis Model (LIAM): a study of a flexible dynamic microsimulation modelling computing framework. International Journal of Microsimulation 2, 16-31.

Polachek, S., Siebert, W., 1993. The economics of earnings. Cambridge Univ Pr.

Raab, R., Gannon, B., 2009. Public Pensions and Retirement in Ireland, Irish Social Sciences Platform Conference, p. 225.

Scholz, J., Seshadri, A., Khitatrakun, S., 2004. Are Americans saving 'optimally' for retirement? NBER working paper.

Steuerle, C., 1999. Does Social Security Treat Spouses Fairly?

Thornton, R., Rodgers, J., Brookshire, M., 1997. On the interpretation of age-earnings profiles. Journal of Labor Research 18, 351-365.

Whelan, S., 2007. Valuing Ireland's Pension System. Quarterly Economic Commentary: Special Articles 2007, 55-80. 


\subsection{Appendices}

Appendix 6.A Private and Occupational Pension Coverage (Percentage) in 2002

\begin{tabular}{|c|c|c|c|c|c|c|c|}
\hline Age Group & 20 & 25 & 35 & 45 & 55 & $65+$ & Total 20-65 \\
\hline \multicolumn{8}{|l|}{ Males } \\
\hline Self-Employed with Employment Pension & 0.6 & 6.9 & 15.2 & 18.9 & 19.8 & 19.7 & 12.3 \\
\hline $\begin{array}{l}\text { Employees with an Employer's Pension } \\
\text { Only }\end{array}$ & 21.7 & 36.2 & 40.2 & 38.6 & 29.7 & 7.4 & 35.1 \\
\hline Employees with a Personal Pension Only & 1.3 & 5.5 & 6.6 & 4.8 & 5.0 & 2.2 & 5.0 \\
\hline $\begin{array}{l}\text { Employees with both Employer's and } \\
\text { Personal Pension }\end{array}$ & 0.7 & 2.8 & 4.3 & 5.1 & 3.2 & 1.1 & 3.4 \\
\hline Employees with no Pension & 71.7 & 37.9 & 19.6 & 16.5 & 18.6 & 16.8 & 30.8 \\
\hline Self-Employed with no Pension & 3.8 & 10.7 & 14.0 & 16.0 & 23.7 & 52.8 & 13.3 \\
\hline \multicolumn{8}{|l|}{ Females } \\
\hline Self-Employed with Employment Pension & 0.0 & 1.5 & 3.3 & 4.3 & 4.3 & 6.3 & 2.4 \\
\hline $\begin{array}{l}\text { Employees with an Employer's Pension } \\
\text { Only }\end{array}$ & 22.5 & 40.1 & 42.8 & 35.6 & 27.4 & 11.5 & 36.2 \\
\hline Employees with a Personal Pension Only & 0.8 & 3.6 & 3.9 & 4.9 & 4.9 & 6.0 & 3.6 \\
\hline $\begin{array}{l}\text { Employees with both Employer's and } \\
\text { Personal Pension }\end{array}$ & 1.0 & 2.3 & 2.4 & 2.8 & 1.9 & 0.0 & 2.2 \\
\hline Employees with no Pension & 74.7 & 48.2 & 41.7 & 45.0 & 48.2 & 50.8 & 50.2 \\
\hline Self-Employed with no Pension & 1.0 & 4.3 & 5.9 & 7.4 & 13.3 & 25.3 & 5.4 \\
\hline
\end{tabular}

(Source: QNHS 2002-Q1) 


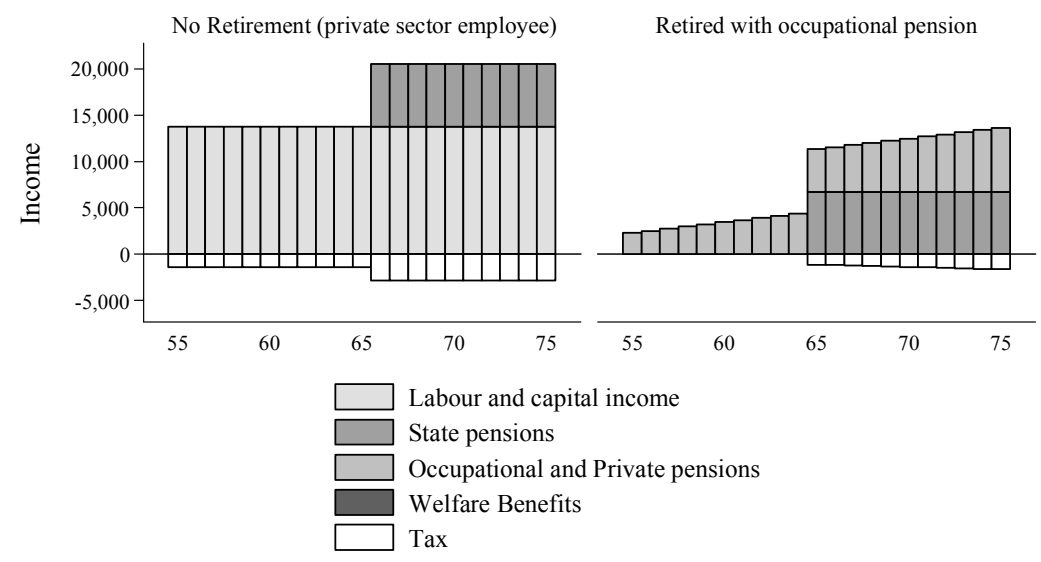

Graphs by scene

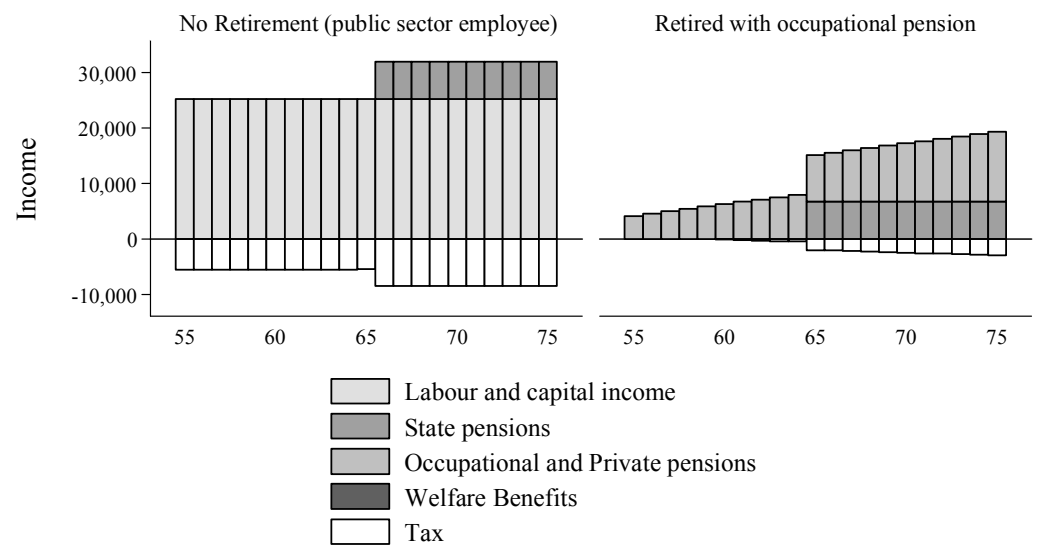

Graphs by scene 


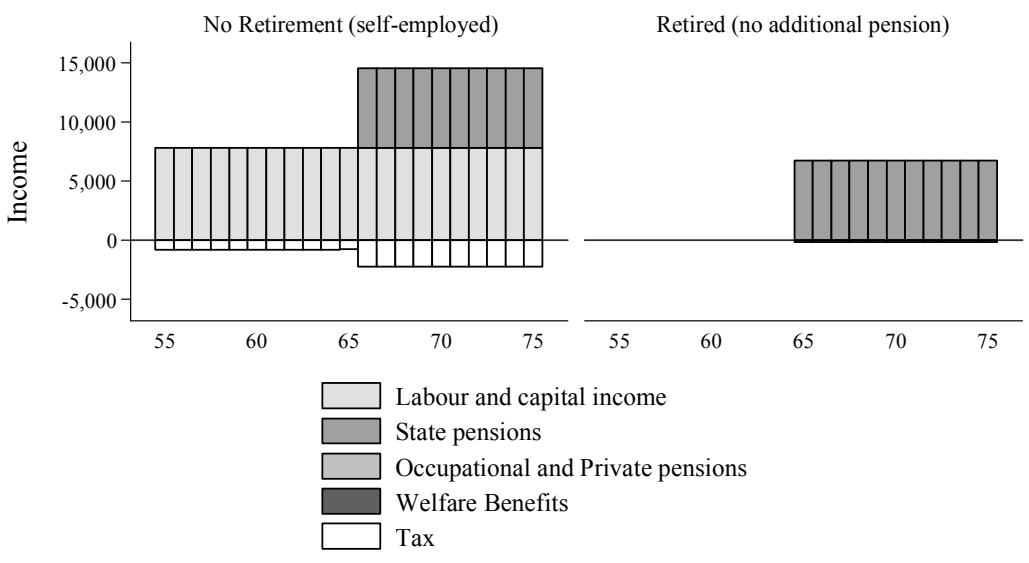

Graphs by scene

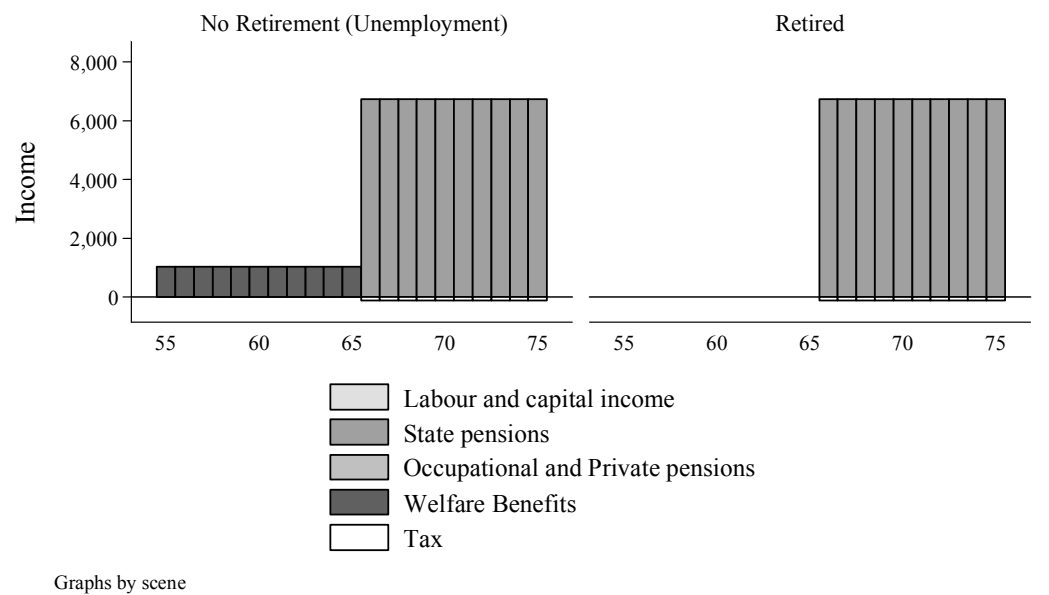


Appendix 6.C Replacement Rate by Age

\begin{tabular}{c|cc}
\hline Age & Individual Replacement Rate & Household Replacement Rate \\
\hline 56 & $67.8 \%$ & $100.5 \%$ \\
57 & $54.0 \%$ & $90.3 \%$ \\
58 & $21.8 \%$ & $122.2 \%$ \\
59 & $39.4 \%$ & $120.3 \%$ \\
60 & $46.6 \%$ & $82.1 \%$ \\
61 & $53.9 \%$ & $80.8 \%$ \\
62 & $63.6 \%$ & $76.7 \%$ \\
63 & $39.7 \%$ & $86.3 \%$ \\
64 & $31.7 \%$ & $99.4 \%$ \\
65 & $58.3 \%$ & $66.0 \%$ \\
66 & $77.6 \%$ & $88.1 \%$ \\
67 & $63.3 \%$ & $73.1 \%$ \\
68 & $62.0 \%$ & $83.5 \%$ \\
69 & $58.8 \%$ & $72.9 \%$ \\
70 & $75.6 \%$ & $125.2 \%$ \\
71 & $34.2 \%$ & $81.2 \%$ \\
72 & $70.9 \%$ & $102.4 \%$ \\
73 & $72.4 \%$ & $83.5 \%$ \\
74 & $75.1 \%$ & $92.3 \%$ \\
75 & $55.9 \%$ & $114.9 \%$ \\
\hline
\end{tabular}

Appendix 6.D Individual and Household Replacement Rate by Sector and Age Group

\begin{tabular}{ccccc}
\hline \multirow{2}{*}{ Age Group } & \multicolumn{3}{c}{ Retirement Path } \\
\cline { 2 - 5 } & Self-employed & Employee (Private) & Public & Unemployment \\
\hline Individual Replacement Rate & & & \\
Retirement Age group (56-60) & $1.59 \%$ & $47.53 \%$ & $49.84 \%$ & $42.06 \%$ \\
Retirement Age group (61-65) & $41.06 \%$ & $56.86 \%$ & $46.63 \%$ & $46.97 \%$ \\
Retirement Age group (66-70) & $71.01 \%$ & $73.61 \%$ & $55.21 \%$ & $0.00 \%$ \\
Retirement Age group (71-75) & $17.20 \%$ & $66.95 \%$ & & \\
Household Replacement Rate & & & & \\
Retirement Age group (56-60) & $53.61 \%$ & $111.30 \%$ & $66.80 \%$ & $138.17 \%$ \\
Retirement Age group (61-65) & $87.16 \%$ & $90.27 \%$ & $58.46 \%$ & $88.33 \%$ \\
Retirement Age group (66-70) & $67.84 \%$ & $91.70 \%$ & $59.52 \%$ & $46.48 \%$ \\
Retirement Age group (71-75) & $74.55 \%$ & $93.93 \%$ & & \\
\hline
\end{tabular}


Appendix 6.E Replacement Rate by Years of Retirement

\begin{tabular}{c|cc}
\hline Years in Retirement & Individual Replacement Rate & Household Replacement Rate \\
\hline -1 (Year before Retirement) & $100.0 \%$ & $100.0 \%$ \\
0 (Retirement Year) & $57.9 \%$ & $89.1 \%$ \\
1 & $72.3 \%$ & $98.7 \%$ \\
2 & $92.1 \%$ & $109.1 \%$ \\
3 & $92.2 \%$ & $104.3 \%$ \\
4 & $87.3 \%$ & $125.6 \%$ \\
5 & $105.8 \%$ & $130.8 \%$ \\
6 & $60.8 \%$ & $157.7 \%$ \\
\hline
\end{tabular}





\section{[7] Household Retirement Choice Simulation with Heterogeneous Pension Plans ${ }^{16}$}

\footnotetext{
${ }^{16}$ Acknowledgement: The authors are grateful for the helpful discussions with Michele Belloni on the development of retirement choice models.

An earlier version of this chapter is available as: Li, J. and O’Donoghue, C., 2011. Household Retirement Choice Simulation with Heterogeneous Pension Plans, IZA Discussion Paper No. 5866
} 
With many countries around the world facing rapidly ageing demographics, great attention has been paid to the economics of retirement. Population ageing in most developed countries is expected to produce significant public expenditure problems as the cost of public transfers such as pensions, health care and long-term care increases. It is important to understand, not only the immediate effect of retirement policy reforms in terms of fiscal sustainability, but more importantly, the change of retirement behaviour induced by the reforms needs to be understood.

Retirement behaviour modelling is one of the fields that have been continuously developed over the past two decades and various methods have been employed to model the labour supply behaviour of elderly workers. One of the oldest methods is the reduced form model, where social and economic variables of individuals are used to estimate their time of retirement. This model, although convenient for estimating, cannot be used in policy simulation since no aspects of a policy are incorporated into the model, i.e. it assumes a policy to remains stable. In addition, reduced form models are not very successful in explaining the spikes observed in the retirement age distribution. Another popular model, the option value model which was originally suggested by Stock and Wise (1988, 1990), utilises a structural retirement decision model that is characterised by employing utility functions to optimize the retirement decision over the lifetime of a worker (MacDonald, 2006). Previous literature suggests that this model performs well in predicting the behaviour of individuals as it incorporates financial incentives. Although the model is straightforward, the empirical estimation may sometimes be difficult and only a few authors have succeeded in estimating a fully-fledged option value model (Euwals, 2006). Models such as dynamic programming models (e.g. Burkhauser et al., 2004), further incorporate the dynamics of choices over time. However, these models tend to need highly complex computation without offering a better predictive power when compared with the option value approach (Lumsdaine et al., 1992; Burkhauser et al., 2004).

Option value models are typically individual based, which means that the heterogeneity of the household types could be ignored. This may lead to issues with regard to individuals who do not live in a single person household. In addition, many countries including Ireland, evaluate tax and welfare benefits based on the total income of the household rather than individual income. Furthermore, a few studies have suggested that there is a correlation between spouses' retirement timing (e.g. Maestas, 2001; Gustman, 2000), as a large proportion of spouses are found to retire within a few years of each other. This was observed in the LII dataset, where more than $60 \%$ of the married couples retired within 5 years of each other. The existing reduced form analyses of couples' retirement suggest that this is partly due to complementarities in spouses' tastes for leisure activities, which are present when one or both partners enjoy retirement (Coile, 2000; Banks et al., 2007). 
Joint retirement choices models first appeared in 1990 when Hurd (1990) reviewed the joint retirement decision of husbands and wives and later efforts have improved the modelling (Casanova, 2009). More recent versions of the model have incorporated family factors and have been proven to be useful for dual career households (Gustman, 2000). Different theoretical models have been developed for household based modelling and the oldest approach is the unitary model developed by Mincer (1963) and used by Becker (1965) and others. The unitary model treats a household as a single individual and assumes that the Slutsky matrix must be symmetrical. This assumption implies that the marginal compensated wage changes of the two partners must have the same effect on each other's labour supply (van Klaveren et al., 2008). However, this approach is often criticized in the literature, due to the strict assumptions imposed, and many papers have refuted this assumption when using empirical data (Thomas, 1990; Browning et al., 1994; Blundell et al., 2007).

Another method used to model household behaviour is called the collective approach. This was initially introduced by Chiappori $(1988,1992,1997)$ and later used by Apps and Rees (1988, 1997). The collective modelling approach assumes that the household decision processes should result in a Pareto-efficient intra-household allocation. Compared with the unitary approach, the assumption in the collective modelling approach seems to be more difficult to reject when tested on an empirical dataset (Cherchye et al., 2009, 2011). To date, there have only been a few papers published on the collective retirement choice model (Michaud and Vermeulen, 2010); however, due to dataset limitations and the limitations of the model, few have considered the comprehensive welfare benefits and DC pensions to which individuals may be entitled to. Other papers have used non-cooperative (strategic) models to analyse household behaviours (Jia, 2003; Chiappori and Donni, 2006). This type of model typically assumes that the outcome of household bargaining results in a Nash or Stackelberg equilibrium. However, this model is less popular due to its complexity and the difficulties in identification.

There are a number of limitations to the existing implementations of household based retirement choice models for policy analysis. Due to the restriction on the model specification calculation and numeric calculation, many models are estimated via approximations, and certain numeric calculations are not feasible for future simulations. Additionally, the construction of social security wealth are typically approximated by a time-series function and combined with some synthetic old age benefits calculations. The heterogeneity of households and the receipt of other social benefits are largely ignored in almost all studies due to dataset limitations and calculation complexity. Finally, with more countries having engaged in pension reform over the recent decades and the gradual move towards DC pension plans, models need to be refined to adopt mixed pension plans within the same dataset. 
This chapter uses a lifetime discrete choice framework that is in line with the random utility approach. It adopts the collective modelling approach with a household extension to provide increased pension information and estimates a structured model using a unique historical dataset back simulated from the LII survey (Li and O'Donoghue, 2010). The model takes advantages of the dataset and models the retirement decision in terms of the monetary and leisure incentives, which in turn reflects the complicated Irish welfare system. The household extension version of the model adapts the collective modelling approach allowing intra-household bargaining to be considered. This methodology allows the capture of the dynamics of pension and tax-benefit policies, and can be used to simulate the effect of policy reform on household retirement behaviours.

Section 7.2 covers the background of the Irish pension system and theoretical models are described in section 7.3. Empirical specifications are presented in section 7.4, section 7.5 describes the dataset and section 7.6 reports the estimation results. Section 7.7 applies the model to the analysis of a synthetic pension reform of raising the minimum state pension entitlement age.

\subsection{The Background of Irish Pension System}

As discussed in detail in the previous chapter the Irish tax-benefit system is in many respects similar to the UK welfare state. Many welfare benefits in Ireland are flat rate based, and not earnings related (Evans et al., 2000; Callan, 1997) and Ireland uses a set of means tests and eligibility conditions to cover contingencies such as unemployment, old age disability, lone parenthood etc. (O’Donoghue, 2003). The Irish pension system is frequently presented as a multi-pillar system and Table 7.1 provides an overview of the components of the relevant welfare benefits provided for the elderly in Ireland ${ }^{17}$.

Ireland has no single fixed retirement age and this varies depending on occupation and job sector. However, the system provides an incentive for all to retire at age 65/66 regardless of which individuals are employed in. This age has been confirmed by the synthetic analysis undertaken by Li and O'Donoghue (2011) where it has been shown that the replacement rate for all workers jumps when they become entitled to receive the public state pension.

Since receiving certain old age benefits (e.g., old age contributory pension) in Ireland does not necessarily mean that an individual is out of the labour market, a more strict definition of retirement has been used in this study. Here, it is defined as an individual who has

${ }^{17}$ For a detailed description of the tax benefit system in Ireland and its pension system, please refer to O’Donoghue (2003) and Baroni \& O’Donoghue (2009). 
stopped working or receiving unemployment benefit after the age of 55 and who does not then re-enter the labour market.

Table 7.1 Irish Pension System

\begin{tabular}{l|l}
\hline 1st Pillar & $\begin{array}{l}\text { Old Age Non-Contributory Pension; } \\
\text { Old Age Contributory Pension; } \\
\text { Invalidity Pension; } \\
\text { Widow, Widower, Orphan and other Pensions Benefits }\end{array}$ \\
\hline $2^{\text {nd }}$ Pillar & $\begin{array}{l}\text { Public service pay-as-you-go schemes; } \\
\text { Funded occupational pension schemes set up by employers }\end{array}$ \\
\hline $3^{\text {rd }}$ Pillar & Supplementary private pensions arranged by individuals \\
\hline
\end{tabular}

\subsection{Theoretical Model}

Although many pension policy analysis models use a reduced form model, this cannot be used for policy simulation for obvious reasons. First, this model assumes everything to be stable and second, a model is needed that can replicate real life scenarios, which means including all public pensions and private pensions, regardless of whether they are in the form of defined benefit (DB) or DC. Reduced form analysis tends to struggle to explain spikes observed in the retirement age distribution, and can only explain the age- 65 spike with limited success. This section presents a fully structured model for analysing the retirement choices within a household.

\subsubsection{The Incentive of Retirement}

In order to model the retirement decisions within a household, the retirement incentives must be first understood. Economically speaking, one of the largest incentives of retirement comes from the financial perspective. Pension income is an important source of retirement for most of the elderly population. In Ireland, 59.5\% of individuals receive a public or private pension after retirement, and pensions account for $71.6 \%$ of the total pretax income among those aged 65 or above. Li and O'Donoghue (2011) found that there is a link between the replacement rate and the retirement hazard rate when using the LII dataset.

Besides the strong financial incentives for retirement, leisure is also a critical component in an individual's retirement choice. As would be assumed, leisure contributes positively to an individual's utility function, just the same as monetary incentives. In a household setting, the utility of leisure is more complex as it might also be dependent on the spouse's status, as a couple may prefer to spend time together. Casanova (2009) reported a correlation of the timings of couples' retirements and suggested that this is due to the complementarity of 
spouses' tastes for leisure, which are present when one or both partners enjoy retiring together.

\subsubsection{Base Model}

In this chapter, a structured life-cycle retirement choice model is described. The model utilises a discrete choice framework (as in Van Soest, 1995; Flood et al., 2004; Michaud and Vermeulen, 2010), which allows the incorporation of a complex non-linear tax benefit system. When determining whether to retire at a particular age $\tau$, the worker seeks to maximise his/her utility among all possible retirement ages. Initially the model is individually based and it is assumed that an individual's lifetime utility is constructed of two additive components, the utility from lifetime consumption $(\Sigma C)$ and the utility from lifetime leisure $(\Sigma L)$, as described in equation (7.1).

$$
U^{\tau}=v\left(\sum_{s=1}^{T} \delta^{s} C_{s}^{\tau}\right)+u\left(\sum_{s=1}^{T} L_{s}^{\tau}\right)
$$

Where $v(\cdot)$ denotes the utility from consumption and $u(\cdot)$ is the utility from leisure. $\delta^{s}$ is the discount factor which is equal to $\left(\frac{1}{1+\gamma}\right)^{s}$, where $\gamma$ is the interest rate.

In this model it is assumed that either retirement or labour market activity can occur at a particular point but not at the same time. Lifetime consumption is assumed to the same as lifetime earnings, while lifetime leisure is captured by the number of years that are free of labour market activities. For each time period there may be multiple income sources, including wages, non-labour income, benefit from the state if eligible and tax deducted accordingly. Forced retirement is not considered within this model, as retirement is being viewed from the supply side only. Since the labour earnings, pensions and benefits would change with retirement time $R$, the total expected income at time $t$ can be presented as:

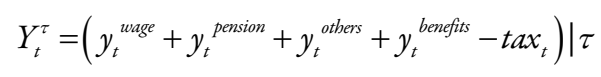

The pension component of earnings is constituted of three sub-components; public pension, occupational pension, and private pension. From a life-cycle perspective, the total budget constraint for an individual can be expressed as:

$$
\sum_{i=1}^{t-1}\left(C_{t}^{\tau}\right) \delta^{t}=\sum_{i=1}^{t-1}\left(Y_{t}^{\tau}\right) \delta^{t}
$$

The model assumes perfect capital markets (see Gustafsson, 2001; Apps and Rees 2010) where the budget constraint balances over the lifetime and resources can be saved or borrowed from the future. 


\subsection{3}

As discussed earlier, the individual based model is unable to accurately model the monetary incentives for married couples due to the nature of tax benefit systems. In addition, all household interactions are also ignored. In order to address these two shortcomings, the model was extended to a household setting, which allows spouses to influence each other's decision.

Similar to the individual based model, it was assumed that an individual is rational and chooses to retire at a point which maximizes his/her lifetime utility. The observed pattern of retirements in a household is the result of two maximized utilities. To model this, the collective approach was used due to the simplicity of the modelling whilst also taking into account household bargaining. The model describes a household $i$ 's behaviour as an outcome of maximizing a household's utility function:

$$
U_{i}^{\tau_{m}, \tau_{f}}=\pi_{i} U_{i, m}^{\tau_{m}}+\left(1-\pi_{i}\right) U_{i, f}^{\tau_{f}}
$$

The individual preferences are represented by $U_{i, m}^{\tau_{m}}$ for male and $U_{i, f}^{\tau_{f}}$ for female and the utility weight is presented by a Pareto parameter $\pi_{i}$ which is between 0 and 1 . Browning et al. (2006) argued that the model is equivalent to the standard unitary model unless the Pareto parameter is dependent on prices. Following the weight modelling approaches used by van Klaveren (2008) and Michaud and Vermeulen (2010) etc., it was assumed that $\pi_{i}$ varies across households as a function of potential wages. Empirically, the logarithm of the ratio of the male earnings and the female earnings was used as the key variable to model the Pareto weights. Personal characteristics (e.g. education) are assumed to be fully reflected in the potential earning profile. As the parameter always needs to fall between zero and one, the weight model was specified as follows:

$$
\pi_{i}=N\left(\mu \ln \left(\frac{y_{i}^{m}}{y_{i}^{f}}\right)\right)
$$

Where $N(\cdot)$ stands for the standard normal distribution function. As a result, $\pi_{i}$ is always bounded within 0 and 1. $y_{i}$ is the potential earning of a household member if he/she works full time for one year in the labour market. An increase in $\pi_{i}$ implies that the male's utility is weighted more heavily than the female's within that household. The bargaining power is assumed to be even when the potential wage rate is same $\left(y_{i}^{m}=y_{i}^{f}\right)$. By design the weight is symmetrical.

Since only the public consumption information is available for the LII dataset, the weights used in the dataset could not be identified directly, as discussed by Chiappori and Ekeland 
(2009). Over recent years, there have been several approaches developed for this estimation, including using leisure as exclusive goods (Van Klaveren et al., 2008) or assuming that widows have the same preference as individuals within the household setting (Michaud and Vermeulen, 2009). However, neither method is appropriate in this particular study because here it is the complementary leisure effect that is being specifically modelled, which makes leisure a public goods by design. Additionally, there are only a very limited number of widows entering retirement in the LII dataset and their identification would therefore be difficult or unreliable. As a result, the $\mu$ parameter was fixed according to the values obtained in the previous literature (Browning, 2006; Michaud and Vermeulen, 2009). Given the wide range of $\mu$ estimates found, 5 scenarios were considered in order to cover a large range of potential values, and $\mu$ was set at $0.1,0.2,0.3,0.4$ and $0.5^{18}$.

In order to adapt the utility function to a household setting and incorporate some interactions within a household, the base individual utility function (7.1) was extended. In the household model, it was assumed that all consumptions within the household were public and the preferences of each member allowed for the externalities of the spouse's utility. In addition, following the findings of the literature (Coile, 2000) on the correlation of retirement timing between spouses, a complementary utility of leisure was allowed if the spouse was also retired. Therefore, the leisure function for male household member becomes:

$$
U_{i}^{\tau}=v\left(\sum_{s=1}^{T} \delta^{s} C_{s}^{\tau}\right)+u\left(\sum_{s=1}^{T} L_{s}^{\tau}\right)+p\left(\sum_{s=1}^{T} L_{s}^{\tau}\right) \mid t_{i}^{\tau}<t_{\text {spouse }}^{\tau}
$$

Where $t_{i}^{\tau}$ represents the timing of individual $i$ 's retirement. $p(\cdot)$ is the complimentary utility which is only present when the spouse retires at the same time. Individuals without spouses, naturally have a zero complimentary utility, as presented in the individual based model. Accordingly, the budget constraint of the model is also extended to include the sum of two individuals' income and benefits that the household is eligible for.

\subsection{Empirical Specification}

In order to estimate the models above, it is necessary to transform them into models that can be estimated numerically, and a logarithmic function was used to specify the

\footnotetext{
${ }^{18}$ Although these five alternatives may seem to be very different Pareto weight parameters, they are found to have no significant impact on the final estimation results.
} 
consumption function $v(\cdot)$ and also the leisure functions $u(\cdot), p(\cdot)$. Given the complexity of modelling leisure, an age-leisure interaction was added to capture the shift in leisure taste over time. Additionally, health status $(H)$ was also incorporated to refine the estimation of leisure. The health variable is defined as the number of expected years that an individual may stay healthy without suffering a major chronic illness from the age of 55 onwards. Complementary leisure is reflected via a dummy variable $d_{i, s}$, which is equal to zero if the spouse is not retired or the individual does not have a spouse. As a result, the statistical form for an individual utility function can be presented as:

$$
\begin{aligned}
U_{i}^{\tau}= & \alpha_{0}+\alpha_{1} \ln \left(\sum_{s=1}^{T} \delta^{s} C_{s}^{\tau}\right)+\alpha_{2} \ln \left(\sum_{s=1}^{T} L_{s}^{\tau}\right) \\
& +\alpha_{3} \cdot \operatorname{age} \ln \left(\sum_{s=1}^{T} L_{s}^{\tau}\right)+\alpha_{4} \ln \left(\sum_{s=1}^{T} L_{s}^{\tau}\right) \cdot d_{i, s}+\alpha_{5} H_{i}
\end{aligned}
$$

Consequently, the collective household utility function becomes:

$$
\begin{aligned}
U_{b}^{\tau_{m}, \tau_{f}}= & \pi_{b}\left(U_{m}^{\tau}\right)+\left(1-\pi_{b}\right)\left(U_{f}^{\tau}\right) \\
= & \beta_{0}+\beta_{1} \ln \left(\sum_{s=1}^{T} \delta^{s} C_{s}^{\tau}\right)+\beta_{2} \cdot \pi_{b} \ln \left(\sum_{s=1}^{T} L_{s}^{\tau_{m}}\right)+\beta_{3} \cdot\left(1-\pi_{b}\right) \ln \left(\sum_{s=1}^{T} L_{s}^{\tau_{f}}\right) \\
& +\beta_{4} \cdot \pi_{b} \ln \left(\sum_{s=1}^{T} L_{s}^{\tau_{m}}\right) \cdot a g e_{m}+\beta_{5} \cdot\left(1-\pi_{b}\right) \ln \left(\sum_{s=1}^{T} L_{s}^{\tau_{f}}\right) \cdot \operatorname{age}_{f} \\
& +\beta_{6} \cdot \pi_{b} \ln \left(\sum_{s=1}^{T} L_{s}^{\tau}\right) \cdot d_{m, s}+\beta_{7} \cdot\left(1-\pi_{b}\right) \ln \left(\sum_{s=1}^{T} L_{s}^{\tau}\right) \cdot d_{f, s} \\
& +\beta_{8} \cdot \pi_{b} H_{m}+\beta_{9} \cdot\left(1-\pi_{b}\right) H_{f}
\end{aligned}
$$

Given the discrete choice setting, there are 21 possible choices of retirement, i.e. between the ages of 55 to 75 , for the individual based model and $441\left(21^{2}\right)$ possible choices of retirement for a married couple. Pareto parameters were estimated independently using the assumptions listed earlier.

As mentioned earlier, accumulated earnings were used as a proxy for lifetime consumption. Since the pre-55 earnings do not vary across different choices, only the sum of expected earnings from age 55 onwards were used as the consumption variable in practice. The wage of the individual positively depends upon the human capital accumulation from their job experience $(b)$, school $(s)$ and market rental rate of human capital $\omega$ at time $t$. As the rate of return to experience falls with experience, the square of experiences was incorporated with a negative coefficient to produce a typical age-earning profile. The model incorporates the assumption that human capital depreciates during periods out of the labour force. Therefore: 


$$
\begin{aligned}
y_{t}^{\text {wage }}= & \omega_{t} k_{t} \\
= & \omega_{t} \exp \left(\phi_{o}+\phi \sum_{i=1}^{t-1} s_{i}+\phi_{2} \sum_{i=1}^{t-1} h_{i}+\phi_{3}\left(\sum_{i=1}^{t-1} h_{i}\right)^{2}+\phi_{4} X_{t}\right) \\
& \mu_{1}, \mu_{2}>0
\end{aligned}
$$

As there is no partial retirement scheme in Ireland, it was assumed that the fluctuations in terms of working hours were minimal for elderly workers and thus the labour supply effects could be ignored. The differences for working hours per individual can be captured by the individual persistent component of the salary. In addition, economic instability was incorporated into the model through the inclusion of the expected unemployment rate at each time $t$. Hence, the expected wage earnings were $y^{\text {wage }}\left(1-u_{t}\right)$. Therefore, the household budget constraint can be expressed as:

$$
\left.\sum_{i=1}^{t-1}\left(C_{t}^{\tau_{m, f}}\right) \delta^{t}=\sum_{i=1}^{t-1}\left(\left(\begin{array}{l}
y_{m, t}^{\text {wage }}\left(1-u_{m, t}\right)+y_{f, t}^{\text {wage }}\left(1-u_{f, t}\right) \\
+y_{m, f}^{\text {pension }}+y_{m, f}^{\text {other }}+y_{t}^{\text {benefits }}-\text { tax }_{t}
\end{array}\right)\right) \tau_{m, f}\right) \delta^{t}
$$

Assuming vector $\tau_{i, j}$ represents the choice set that a male retires at time $i$, and a female retires at time $j$, the revealed preference $\tau_{i^{*}, j^{*}}^{*}$ achieves the highest level of utility for both household members, when the household utility reaches its peak. Assuming the disturbances are i.i.d. with the Gumbell (type 1 extreme value) distribution, the model could be estimated using a discrete choice framework with a conditional logit as expressed in equation (7.11).

$$
\operatorname{Prob}\left(\text { choice }=\tau_{i j}\right)=\frac{\exp \left(U\left(\tau_{i, j}\right)\right)}{\sum_{i=55}^{75} \sum_{j=55}^{75} \exp \left(U\left(\tau_{i, j}\right)\right)}
$$

Based on the model presented, the key determinants of retirement postponement and the basic assumptions underpinning the motivations influencing an individual's retirement decision can be listed. If $\Delta Y^{\tau(i+1, j)}$ is used to denote the difference in total income due to the shift of retirement timing from $i$ to $i+1$, and $d_{i}$ the working status of an individual at time $i$, if there is no change in the spouse's retirement timing, then the cost of retirement at time $i$ as opposed to one year later for a male can be expressed as: 


$$
\begin{aligned}
& U^{\tau_{i+1, j}}-U^{\tau_{i, j}}=\underbrace{\beta_{1} \cdot \pi_{b} \ln \left(\frac{\sum Y^{\tau_{i, j}}+\Delta Y^{\tau_{i+1, j}}}{\sum Y^{\tau_{i, j}}}\right)}_{A} \\
& +\underbrace{\pi_{b}\left(\beta_{2} \ln \left(\frac{\Sigma L^{\tau_{i, j}}+1}{\Sigma L^{\tau_{i, j}}}\right)+\beta_{4} \ln \left(\frac{\Sigma L^{\tau_{i, j}}+1}{\Sigma L^{\tau_{i, j}}}\right) \operatorname{age}(i)\right)}_{B} \\
& +\underbrace{\beta_{6} \cdot \pi_{b}\left(\ln \left(\sum_{s=1}^{T} L_{s}^{\tau}\right) \cdot d_{m, s} \mid j=i+1\right)}_{\mathrm{C}}+\underbrace{\beta_{8} \cdot \pi_{b}\left(\Delta H_{m}^{i+1}\right)}_{D}
\end{aligned}
$$

Where

A. The utility cost from household earnings changes. This includes the change of labour income, pension entitlement, and household benefits

B. The utility cost from leisure due to the change in leisure stream and age

C. The potential change in complimentary leisure due to the change of retirement age

D. Change in the health variable, depending on the health situation of the individual at time $i$

In addition, the cost of retirement includes the change in human capital, which is modelled through wage equations. Since re-entering the labour market around the moment of retirement in not considered in this model, the change in human capital is only reflected in the gradual increase of earnings if an individual remains in work.

As seen from the decomposition, there are several factors affecting the retirement decision. The greater the cost of retirement in the future, the earlier retirement would occur. Pension plan changes and labour earnings changes affect an individual's retirement decision through item $\mathrm{A}$, while the leisure term $\mathrm{B}$ is mostly unaffected except by life expectancy. Individuals with lower earnings tend to have lower costs through A; however, the cost may increase faster than average due to the incremental growth of the limited human capital. As a result, this group may tend to retire earlier, which is consistent with the empirical findings presented by Li and O'Donoghue (2011).

The age-gap present in a household also influences the household's retirement decision through item $\mathrm{C}$, as spouses may retire earlier or later. In the case where a spouse retires early than $i$, then there is no loss in the complimentary utility. However, this will affect the cost of retirement if two spouses' choose to retire close together, as observed in real life. The retirement decision could also be affected by a change of health (item D). This suggests that those who are affected most by health are those with deteriorating health rather than those with persistent lifetime illnesses as it is only the change that matters. When using the 
dataset from LII, no consistent pattern for health could be determined across groups with different retirement ages ( $\mathrm{Li}$ and O'Donoghue, 2011). Last but not the least, the Pareto weight $\pi_{b}$ decides the intra-household allocation of consumption, which also affects an individual's retirement decision. While equation (7.12) only presents the cost of retirement for males, the cost for females follows the same structure since the model is symmetrical. For a single person household (individual model), item $\mathrm{C}$ is always equals to zero, while $\pi_{b}$ remains constant.

From the decomposition of retirement cost, the signs of the coefficients can in theory be predicted. It would normally be expected that utility from consumption is positive, together with the utility from leisure. In addition, since leisure would normally increase in value when getting older, a positive coefficient for the age-leisure interaction would also be expected.

\section{$7.5 \quad$ Dataset}

To estimate the model described above, it is necessary to use a dataset which records the social economic variables, earnings and pension profile between age 55-75. This type of dataset, however, is not readily available in Ireland as the comprehensive household survey datasets only covers a limited number of waves. Therefore, this chapter uses a simulated long panel dataset derived from the LII longitudinal survey was used. The data covers a wide range of aspects regarding the life of an individual, but does not cover the complete career trajectory needed for pension and retirement modelling. In order to meet the requirements of the model, the historical labour market profile for individuals in the LII dataset were back simulated via a dynamic microsimulation in a reversed direction ( $\mathrm{Li}$ and O'Donoghue, 2010). The simulated dataset matches the reported pension eligibilities, including state pension, occupational pension and private pension, with higher than $95 \%$ accuracy as presented in Table 7.2.

Table 7.2 Percentage of Correctly Simulated Eligibility

\begin{tabular}{lcc}
\hline Pension Type & Correctly Simulated & Number of Observations* \\
\hline Contributory State Pension & $96.08 \%$ & 9343 \\
Occupational Pension & $98.25 \%$ & 10030 \\
Private Pension & $97.36 \%$ & 1706 (Year 2000 onwards) \\
\hline${ }^{*}$ Only age 66+ are included for state pension and 65+ for occupational and private pension
\end{tabular}

With the extensive historical information and consistent benefit eligibilities, the monetary earnings of different retirement choices could be extracted and recreated. Retirement in this chapter is defined as exiting the labour market after the age of 55. The retired 
population has two subsets, those who are officially "retired" and remain active, and those who become permanently inactive in the labour market after a certain age. An individual is considered to be "inactive" if

- They are aged 55 or above and state "not working" as their main economic activity that year

- Does not receive unemployment benefit, since this indicates that the individual is still actively seeking employment

- Their labour income, which could come from the transition period, is less than $50 \%$ of their life average earning level

Table 7.3 gives an overview of the demographic profile of the selected LII subset. The sample focuses on the individuals who retire between the age 55 and 75 as this is the main group of retirees present in Ireland. Individuals who retired outside of this range were excluded. In order to ensure the quality of the simulated labour market profile, only individuals who worked at least 3 years in the 10 year period prior to retirement were included in the estimations.

Table 7.3 Summary of Variables on Estimated Sample

\begin{tabular}{lc}
\hline Variables & Cases \\
\hline Total Number of Individuals & 390 \\
Male & 298 \\
Female & 92 \\
Percentage with at least some college education & $16.1 \%$ \\
Chronic Illness at the time of retirement & $10.3 \%$ \\
Married & $79.2 \%$ \\
Was in public sector (if working) & $17.5 \%$ \\
Average retirement age & 63.65 \\
\hline Number of Observations & 8190 \\
\hline
\end{tabular}

Since each individual is exposed to 21 choices (from age 55 to age 75 ), the total number of choices ${ }^{19}$ a household can make is $441\left(21^{2}\right)$. A dynamic microsimulation model was used to assist in the calculation of incomes for different retirement scenarios. This calculation retained the household structure of the simulated household, i.e., everyone in the household was simulated throughout the entire time period unless death occurred. The dynamic microsimulation model includes a pool of equations which were estimated for the

\footnotetext{
${ }^{19}$ Not all choices may be present due to life expectancy restrictions.
} 
LII dataset. These cover the labour supply module, earning module, state pension entitlement module, occupational pension module and private pension module ( $\mathrm{Li}$ and O'Donoghue, 2010). With a rich pool of data simulated from the model, income, leisure, and social economics characteristics could be calculated for all the scenarios.

\subsection{Estimation Results}

\subsubsection{Individual Model}

Estimations were made for both the individual and household based models. While the individual based model was estimated for all retirees, the household based model was only applicable for a dual career household exhibiting a stable marriage. Males and females were estimated separately as they may be subject to very different employment histories and preferences. In addition, the potential differences in preferences between married and single retirees were also considered.

Table 7.4 presents the estimation results from the individual based models. As would be expected, the lifetime income term is always positive and significant. Leisure is generally highly significant across the models when age-leisure interaction terms are considered at the same time. This positive interaction suggests that individuals value leisure more as they age. However, the coefficients are not the same across all models and differences are found between males and females, and married and single retirees, in terms of income and leisure coefficients.

Table 7.4 Estimation Results from Individual Models

\begin{tabular}{lcccccccc}
\hline Variables & \multicolumn{3}{c}{ Male } & & \multicolumn{3}{c}{ Female } \\
\cline { 2 - 3 } & no & with & pooled & & no & with & pooled \\
& spouse & spouse & result & & spouse & spouse & result \\
\hline Lifetime Income & 28.36 & 25.33 & 25.64 & & 94.41 & 39.99 & 44.94 \\
& $(5.10)$ & $(2.02)$ & $(1.84)$ & & $(23.52)$ & $(6.87)$ & $(6.23)$ \\
Leisure & 6.86 & 7.21 & 6.66 & & 17.31 & 27.22 & 20.04 \\
& $(2.32)$ & $(1.12)$ & $(0.96)$ & & $(9.62)$ & $(6.21)$ & $(4.45)$ \\
Leisure Age Interaction & 0.04 & 0.16 & 0.12 & & 0.68 & 0.74 & 0.65 \\
& $(0.06)$ & $(0.03)$ & $(0.03)$ & & $(0.29)$ & 0.17 & $(0.13)$ \\
Health & -0.84 & -0.45 & -0.43 & & 5.06 & 1.20 & 3.45 \\
& $(0.87)$ & $(0.49)$ & $(0.43)$ & & $(5.16)$ & $(2.47)$ & $(2.13)$ \\
\hline Number of Observations & 1155 & 5103 & 6258 & & 567 & 1365 & 1932 \\
\hline (standard errors in parentheses) & & & & & &
\end{tabular}

In general, females are more sensitive to both monetary income and leisure change. The leisure term coefficients for the female models are on a few occasions, higher than the male 
models. This may indicate that a female's retirement decision is more influenced by leisure than a male's retirement decision. It can also be seen that married retirees in general, are less sensitive to income and more sensitive to leisure than single retirees, a pattern that is repeated for both males and females.

Within these estimations, health is not found to be significant, for which there may be several reasons. Firstly, the wage model utilised here is health dependent, which means that the lifetime income is already endogenous with the health variable. Secondly, the health variable, as introduced in the data section, is defined as the number of healthy years following retirement, a variable which as a result, is correlated with leisure, therefore, making the effect of the health variable less obvious. Thirdly, as discussed earlier in the theoretical section, only those individuals with worsening health situations are most likely to be affected and this may also affect the efficiencies of the estimations.

\subsubsection{Household Model}

Before the estimation of collective models, the sharing rule must first be specified and in this study the Pareto weight was used. Figure 7.1 illustrates the impact of different sharing parameters on bargaining power. As indicated, males on average have higher bargaining powers due to their higher earning capacities. If the husband's potential earning capacity is three times higher than his wife's, the Pareto weight ranges from 0.54 when $\mu$ is 0.1 , or 0.71 when $\mu$ is 0.5 . This weighting is symmetrical between husband and wife.

Figure 7.1 Distribution of Sharing Parameters with Different $\mu$ Values

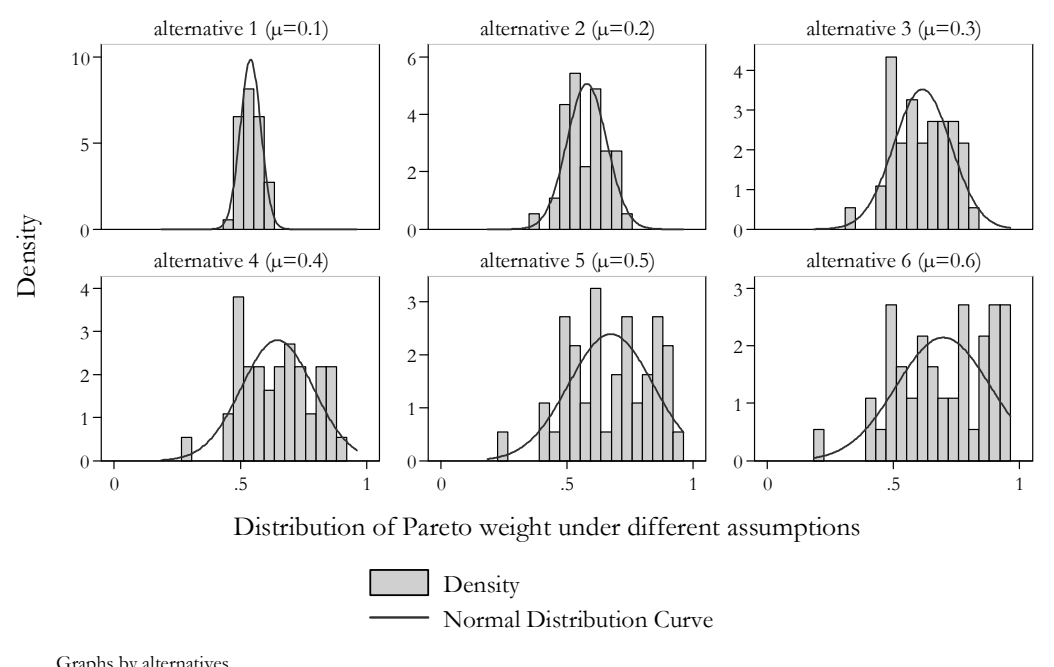


As can be seen, the higher the $\mu$ value, the higher the standard deviation found in the distribution of the Pareto weight $\pi$. When $\mu$ is very small, e.g. $<0.1$, the model is close to a unitary model. Due to the data limitations as discussed earlier, the $\mu$ parameter has been fixed in these estimations. However, the structure of the main model estimation is unaffected, as the Pareto weight is seen as an independent variable within the model. In the estimations, five scenarios are considered where $\mu$ ranges from 0.1 to 0.5 .

Table 7.5 reports the results of the estimations from the collective model. As can be seen, the coefficients are very similar across all scenarios. The standard error of the estimation is much bigger than the differences between scenarios for all coefficients. Similarly to the individual models, income is found to be highly significant, although the numeric value of the coefficients falls considerably. The intercept terms of leisure are not significant except for females. Nonetheless, a highly significant age-leisure interaction across all scenarios was demonstrated for both husbands and wives, which translates to a significant positive leisure effect overall as expected.

Table 7.5 Estimation Results from Collective Model

\begin{tabular}{lccccc}
\hline Variables & $\begin{array}{c}\text { Scenario 1 } \\
(\mu=0.1)\end{array}$ & $\begin{array}{c}\text { Scenario 2 } \\
(\mu=0.2)\end{array}$ & $\begin{array}{c}\text { Scenario 3 } \\
(\mu=0.3)\end{array}$ & $\begin{array}{c}\text { Scenario 4 } \\
(\mu=0.4)\end{array}$ & $\begin{array}{c}\text { Scenario 5 } \\
(\mu=0.5)\end{array}$ \\
\hline Shared Variable & & & & & \\
$\quad$ Household Lifetime & 14.38 & 14.13 & 13.88 & 13.65 & 13.44 \\
$\quad$ Income & $(3.59)$ & $(3.61)$ & $(3.63)$ & $(3.65)$ & $(3.68)$ \\
Husband & & & & & \\
Leisure & 5.40 & 5.54 & 5.67 & 5.77 & 5.80 \\
& $(4.82)$ & $(4.55)$ & $(4.30)$ & $(4.08)$ & $(3.90)$ \\
Leisure Age Interaction & 0.51 & 0.48 & 0.45 & 0.42 & 0.40 \\
& $(0.18)$ & $(0.17)$ & $(0.16)$ & $(0.16)$ & $(0.15)$ \\
Complementary & 0.70 & 0.74 & 0.76 & 0.76 & 0.77 \\
Leisure if spouse retired & $(0.29)$ & $(0.27)$ & $(0.25)$ & $(0.24)$ & $(0.23)$ \\
Health & 0.77 & 0.68 & 0.62 & 0.59 & 0.58 \\
& $(2.08)$ & $(1.95)$ & $(1.83)$ & $(1.73)$ & $(1.65)$ \\
Wife & & & & & \\
Leisure & 18.89 & 18.67 & 18.40 & 18.12 & 17.82 \\
& $(8.51)$ & $(9.01)$ & $(9.55)$ & $(10.11)$ & $(10.67)$ \\
Leisure Age Interaction & 0.93 & 1.04 & 1.17 & 1.31 & 1.46 \\
& $(0.29)$ & $(0.32)$ & $(0.35)$ & $(0.38)$ & $(0.41)$ \\
Complementary & 0.71 & 0.77 & 0.81 & 0.82 & 0.82 \\
Leisure if spouse retired & $(0.32)$ & $(0.34)$ & $(0.36)$ & $(0.38)$ & $(0.39)$ \\
Health & 6.89 & 7.57 & 8.32 & 9.11 & 9.87 \\
& $(3.85)$ & $(4.13)$ & $(4.45)$ & $(4.78)$ & $(5.11)$ \\
\hline Number of Observations & 19509 & 19509 & 19509 & 19509 & 19509 \\
\hline
\end{tabular}


In the collective model, complimentary leisure was incorporated as a key variable to interact between males and females utility. The result shows that the effect of a partner's retirement status is highly significant for both males and females, a finding which is consistent with earlier literature reporting that spouses tend to retire very shortly after each other (Gustman and Stienmeir, 2000; Michaud, 2005). Health was shown to be significant at the $10 \%$ level for females but insignificant for males. For both the individual model and collective model, females exhibited a higher preference towards leisure compared with males.

Compared with individual models, collective model estimates seem to generally have lower coefficients for income and higher coefficients for leisure. This difference in coefficients may reveal differences in the preferences between different social groups. The individual models included all observations, while the household models only used dual career spouses. The difference in coefficients implies a heterogeneity of preferences among the population, and seem to suggest that people with families, especially working spouses, value leisure more than the single population. To eliminate the difference caused by the sampling procedure, the individual models were re-estimated using the same dataset as the collective model. As reported in Table 7.6, the differences found in the coefficients seemed now to be reduced, thus confirming the speculation that coefficients are heavily influenced by the sample; although the re-estimated coefficients for leisure are generally smaller than the equivalent terms in the collective model.

Table 7.6 Estimation Results from Individual models using same dataset as collective model

\begin{tabular}{|c|c|c|c|c|}
\hline \multirow[b]{2}{*}{ Variables } & \multicolumn{2}{|c|}{ Individual Model } & \multicolumn{2}{|c|}{ Collective Model $(\mu=0.3)$} \\
\hline & Male & Female & Male & Female \\
\hline \multirow[t]{2}{*}{ Lifetime Income } & 8.54 & 14.95 & \multicolumn{2}{|c|}{13.88} \\
\hline & $(2.73)$ & $(3.89)$ & \multicolumn{2}{|c|}{$(3.63)$} \\
\hline \multirow[t]{2}{*}{ Leisure } & 3.28 & 13.58 & 5.67 & 18.40 \\
\hline & $(2.46)$ & $(4.57)$ & $(4.30)$ & $(9.55)$ \\
\hline \multirow[t]{2}{*}{ Leisure Age Interaction } & 0.30 & 0.45 & 0.45 & 1.17 \\
\hline & $(0.10)$ & $(0.15)$ & $(0.16)$ & $(0.35)$ \\
\hline \multirow[t]{2}{*}{ Health } & 0.32 & 3.43 & 0.62 & 8.32 \\
\hline & $(1.07)$ & $(2.05)$ & $(1.83)$ & $(4.45)$ \\
\hline Number of Observations & 942 & 932 & 19509 & 19509 \\
\hline
\end{tabular}

\subsubsection{Predictive Power of the Models}

As one of the main applications of the structured retirement choice model is to evaluate potential reforms, it is important to assess the fitness of the model. Figure 7.2 plots the 
difference between predicted retirement age and the actual retirement age. As can be seen, in the individual based model, $76.7 \%$ of the observations have an error of less than 2 years and $94.6 \%$ of the observations fall within an error of 5 years.

Figure 7.2 Difference Between Predicted and Observed Retirement Age Using the Individual Model
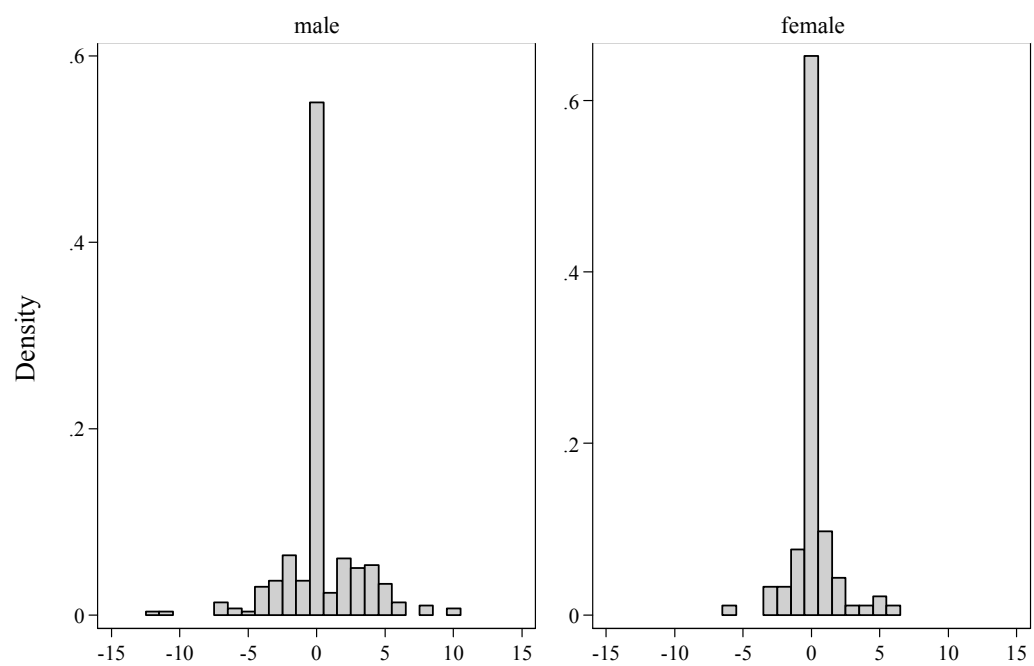

In the collective model, the retirement choice is a vector of two retirement decisions. Consequently in Figure 7.4, the graph was plotted in a two-dimensional manner, with the $\mathrm{x}$-axis illustrating the error of prediction of the husband's retirement choice, and the $y$-axis the error of the wife's retirement choice prediction. Since one error pattern may appear several times, the circles were weighted using the frequency of the error patterns. The larger the circle, the greater the number of households that fall into this pattern. Sharing rules did not seem to have any major impact on the predictive power. Figure 7.4 plots the retirement age distribution under the five scenarios with different $\mu$ values. The resulting curves look very alike and the difference in terms of predicted retirement ages are on average, less than one year. Given that there is no statistical difference between coefficients with different $\mu$ parameters, the median value, $\mu=0.3$, was chosen to validate the predictive power of the model. As shown, for $88.9 \%$ of the households the household choice was predicted with neither member of the household displaying an error larger than 5 years. The model is able to predict the retirement choice for both a husband and wife with an average error of less than 2 years for $51.1 \%$ of the observations. 
Figure 7.3 Difference Between Predicted and Observed Retirement Choices Using the Household Model

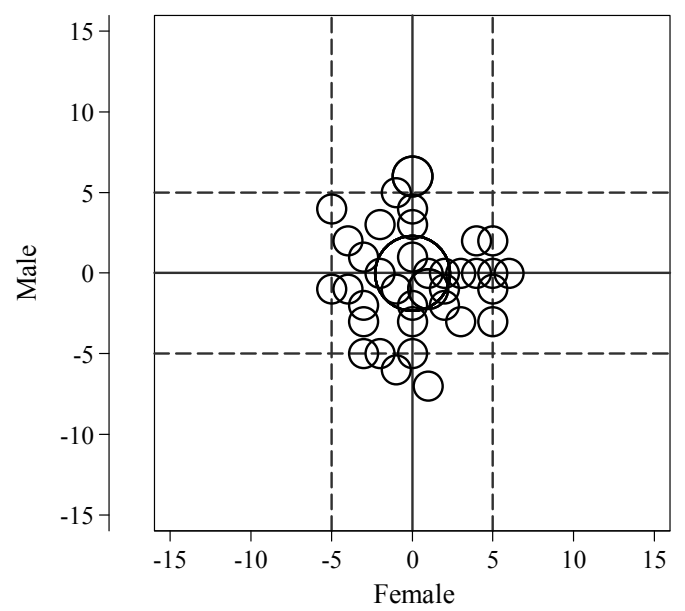

- Difference (bigger circle indicates higher frequency)

Figure 7.4 The Impact of the $\mu$ Parameter on Collective Model Performance

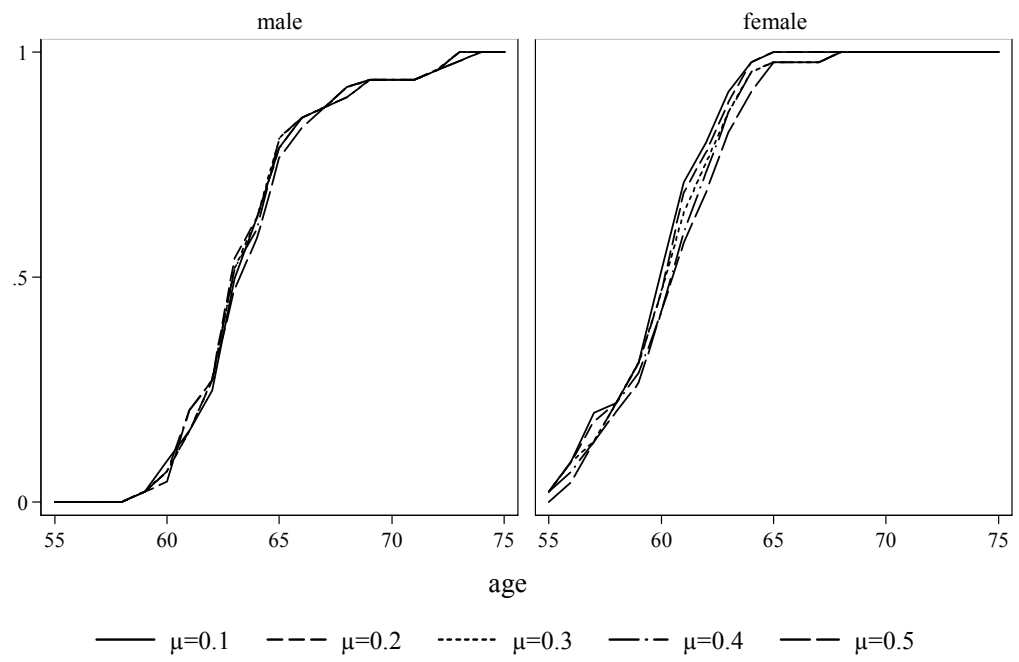




\subsection{Simulation of a Reform Scenario}

One of the main advantages of a structured retirement model is that it can be used for policy simulation. As European countries are actively seeking to postpone the minimum full retirement age, the model presented in this chapter offers opportunities for exploring the potential effect of raising the minimum retirement age. The reform scenario tested here, assumes a postponement of all state pension pay-outs until age 70 , instead of the current age of 65/66 for both contributory and non-contributory pensions. All other rules of the tax benefit system remain the same and occupation and private pension pay-outs are not affected by the change. This would result in a decreased income level between the ages of 65 and 70 due to the missing state pension. However, depending on the income level the effect might be different due to the progressive nature of the tax system.

The simulation therefore recalculates the potential lifetime earnings and changes in welfare benefit entitlements, but does not change life expectancy, leisure, preferences or any other non-monetary variables. One potential problem of the scenario is the change of the unemployment rate. With the possibility of working until a later age, the employment rate of an elderly worker would increase as more people would have the opportunity of working if they so wished, e.g. public sector workers. As a result, using the existing unemployment rate may underestimate an individual's expected income after the reform. Therefore, in order to control the potential change of the labour market structure, the risk of unemployment within the 5 years after the original individual retirement age is assumed to be the same as the risk immediately before retirement. The bargaining power within a household is assumed not to have been affected by the new pension rule and there are no changes in terms of eligibility. The reform is implemented as if all households in the dataset are subject to the new regulation at the time of retirement and the reform is simulated using both individual and household based models.

\subsubsection{Change in the Budget Constraint}

The direct consequence of the reform is a change in lifetime income, which is the result of several sources. First, abandoning the state pension between the ages of 65 to 70 decreases the earnings for those who retire before the age of 66. Second, the change of the unemployment rate increases the income level if individuals choose to continue working after their original retirement age. The reform makes later retirement more attractive as it increases the cost of retiring at the same age. In addition to the direct changes stated above, there is a third source of change. In the case of a household which has more than one family member, the change in the total income would affect the tax-benefit eligibility as well. As a result, there may be an extra household based benefit or heavier tax cost, depending on the household's circumstances. 
Table 7.7 reports the change of the budget constraints in logarithmic term for the datasets. For the dataset that covers both singles and couples, the net change of the reform is negative if retirement occurs at an early age, although this turns positive when retiring at a later age. This is expected as the early retirees have lost their state pension before the age of 70 , while late retirees are benefiting from the lower unemployment rate, which translates into a higher expected income. The trend is similar between mean and median values, although the effect is greater if presented through the mean because of the bias towards high income earners. The change in the budget constraint implies that there is a monetary incentive to retire later, although the effect might be limited given certain income brackets are more likely to be affected than the others.

Table 7.7 Change of the Budget Constraint for the Simulated Reform

\begin{tabular}{|c|c|c|c|c|c|c|c|c|}
\hline \multirow[b]{3}{*}{ Age } & \multicolumn{4}{|c|}{ Individual Models (All observations) } & \multicolumn{4}{|c|}{ Collective Models (only couples) } \\
\hline & \multicolumn{2}{|c|}{$\begin{array}{c}\text { Mean value of } \\
\text { change }\end{array}$} & \multicolumn{2}{|c|}{$\begin{array}{c}\text { Median value of } \\
\text { change }\end{array}$} & \multicolumn{2}{|c|}{$\begin{array}{c}\text { Mean value of } \\
\text { change }\end{array}$} & \multicolumn{2}{|c|}{$\begin{array}{c}\text { Median value of } \\
\text { change }\end{array}$} \\
\hline & Male & Female & Male & Female & Male & Female & Male & Female \\
\hline 55 & -0.053 & -0.034 & -0.014 & -0.005 & -0.045 & 0.014 & -0.012 & -0.004 \\
\hline 56 & -0.050 & -0.031 & -0.013 & -0.005 & -0.044 & 0.014 & -0.012 & -0.002 \\
\hline 57 & -0.047 & -0.024 & -0.011 & -0.004 & -0.044 & 0.015 & -0.012 & -0.001 \\
\hline 58 & -0.042 & -0.016 & -0.009 & -0.003 & -0.043 & 0.016 & -0.013 & 0.000 \\
\hline 59 & -0.036 & -0.007 & -0.004 & -0.002 & -0.042 & 0.018 & -0.012 & 0.000 \\
\hline 60 & -0.023 & 0.003 & -0.002 & -0.002 & -0.040 & 0.020 & -0.011 & 0.000 \\
\hline 61 & -0.009 & 0.008 & 0.000 & -0.002 & -0.033 & 0.020 & -0.011 & 0.000 \\
\hline 62 & 0.006 & 0.016 & 0.000 & -0.001 & -0.026 & 0.019 & -0.009 & 0.000 \\
\hline 63 & 0.025 & 0.027 & 0.000 & 0.000 & -0.015 & 0.020 & -0.004 & 0.000 \\
\hline 64 & 0.046 & 0.044 & 0.000 & 0.000 & -0.009 & 0.021 & -0.002 & 0.000 \\
\hline 65 & 0.070 & 0.061 & 0.013 & 0.004 & 0.003 & 0.021 & 0.000 & 0.001 \\
\hline 66 & 0.093 & 0.084 & 0.022 & 0.008 & 0.018 & 0.020 & -0.003 & -0.007 \\
\hline 67 & 0.104 & 0.085 & 0.019 & 0.001 & 0.033 & 0.013 & -0.007 & -0.018 \\
\hline 68 & 0.111 & 0.081 & 0.017 & -0.009 & 0.042 & 0.002 & -0.007 & -0.028 \\
\hline 69 & 0.114 & 0.084 & 0.008 & -0.013 & 0.050 & -0.010 & -0.004 & -0.039 \\
\hline 70 & 0.108 & 0.090 & -0.003 & -0.022 & 0.050 & -0.017 & -0.014 & -0.043 \\
\hline 71 & 0.117 & 0.109 & 0.007 & -0.010 & 0.054 & -0.012 & -0.015 & -0.043 \\
\hline 72 & 0.124 & 0.113 & 0.011 & -0.010 & 0.056 & -0.013 & -0.013 & -0.047 \\
\hline 73 & 0.133 & 0.117 & 0.016 & -0.010 & 0.062 & -0.011 & -0.012 & -0.048 \\
\hline 74 & 0.141 & 0.121 & 0.024 & 0.002 & 0.065 & -0.009 & -0.010 & -0.046 \\
\hline 75 & 0.150 & 0.124 & 0.041 & 0.003 & 0.071 & -0.008 & -0.005 & -0.044 \\
\hline
\end{tabular}

$N . B$. change is defined as $\ln \left(y^{*} / y\right)$, collective model reports the budget change at household level 
For the collective model, the pattern is more complicated due to the consideration of both dimensions, i.e. husband and wife. As a result, Table 7.7 only reflects the average changes in the household budget due to the reform. The budget change at the different retirement age for males follows a similar pattern as in the individual models, but for females, the reform causes a declining budget constraint at a later age rather than increasing trend. This is due to the fact that within the dataset, very few females retire later and in addition, female earnings have a lower impact on average on the household budget. It is possible that under certain circumstances, the loss of the state pension outweighs the potential gains of postponing retirement. To further illustrate the complex interaction of incomes, tax benefits and retirement ages, a heat map was plotted for the dataset containing couples. As can be seen in Figure 7.5, the general pattern shows that a household can benefit from the reform if both the husband and wife retire later. When combining the results from Table 7.7 and Figure 7.5, it would be expected that the reform on average, would affect males more than females due to a higher change in the budget constraint. Comparing the individual models and the household models, it would be expected that couples would be less affected by the reform due to the smoothing effect of multiple income sources, a prediction which is reflected by the smaller changes observed.

Figure 7.5 Change of the Budget Constraint for the Simulated Reform (Household)

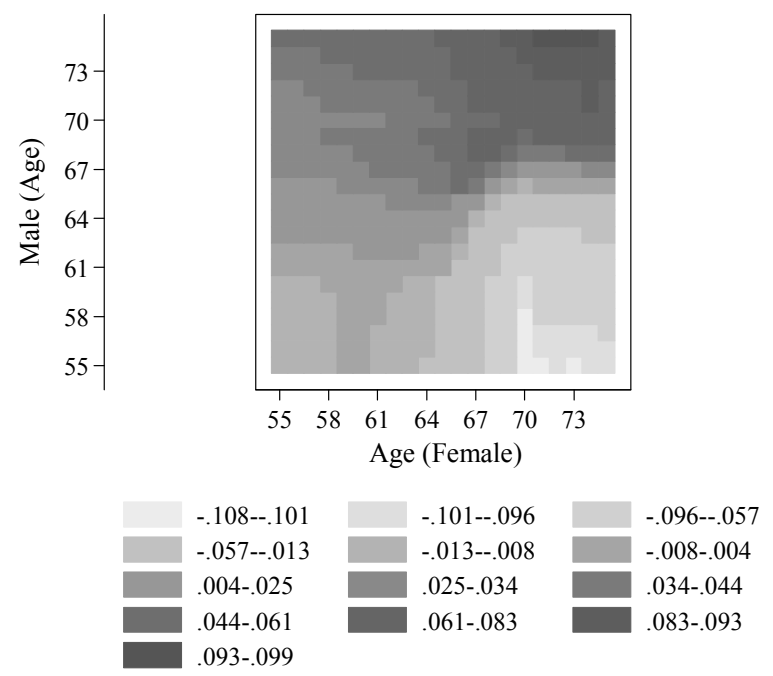

\subsubsection{Result from the Individual Based Model}

Simulating pension reform using individual based models requires some extra assumptions. As the original model is estimated on the condition that the spouse retirement timing is fixed, this implies that all choices are independent within the simulation, no matter how a 
household is structured. To illustrate the effect of the reform, a hazard graph of retirement for males and females was plotted separately (Figure 7.7). The solid line represents the percentage of people who retired at a certain age, while the dashed line shows the equivalent percentage following a rise in the minimum retirement age. As can be seen, the increase of the minimum state pension entitlement age would change the retirement pattern for both males and females and on average, the retirement age is postponed by 1.91 years for males and 1.80 years for females.

Figure 7.6 The effect of retirement reform (individual based model)

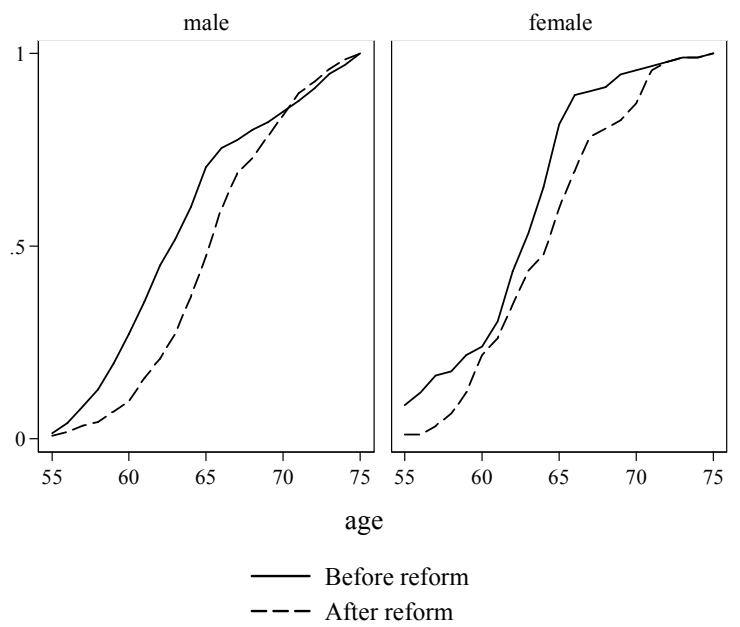

\subsubsection{Result from the Collective Model}

Since the sharing rules do not affect the predictive power of the model significantly, the median value of 0.3 was continued to be used as the sharing rule parameter. In the household setting, where consumption is public and complimentary leisure is dependent on the retirement status of the spouse, the simulation result differs from that exhibited in the individual model. Compared with the simulation results from the pure individual models estimated earlier, the household model based simulation suggests that on average, males and females postpone their retirement by $0.5 \sim 0.6$ years. As can be seen in Figure 7.7, the density of retirement for males around 65 is now reduced. However, the hazard rate of retirement does not alter significantly before the age of 60 or after the age of 70. As far as females are concerned, the number of individuals who retire at a very early age, i.e. around 55 , has declined, but the hazard rate after the age of 60 does not change significantly. 
Compared with the simulation results from the earlier individual models, the effect of reform seems to be smaller and this is consistent with what the budget constraint indicates. The change to the household budget constraint is smaller than the change to the individual budget constraint, as presented in Table 7.7. In addition, individual models and collective models are estimated on two different samples which have very different preferences for money and leisure. In order to isolate the effect of the model differences, the individual based simulation model was also run in order to compare the results. The result from the individual based models using the household model dataset is represented by the long dashed line in Figure 7.7. This new simulation suggests that the result from the individual model is very close to the result from the collective model, although it seems to have a slightly larger effect, 0.1 0.2 years extra. The differences between the models are mainly due to the calculation of tax-benefits and the interactions within a household. Complimentary leisure could potentially reduce the effectiveness of the reform as delaying retirement may reduce the total welfare of the household, depending on the time of the spouse's retirement.

Figure 7.7 The Effect of Retirement Reform (collective model)

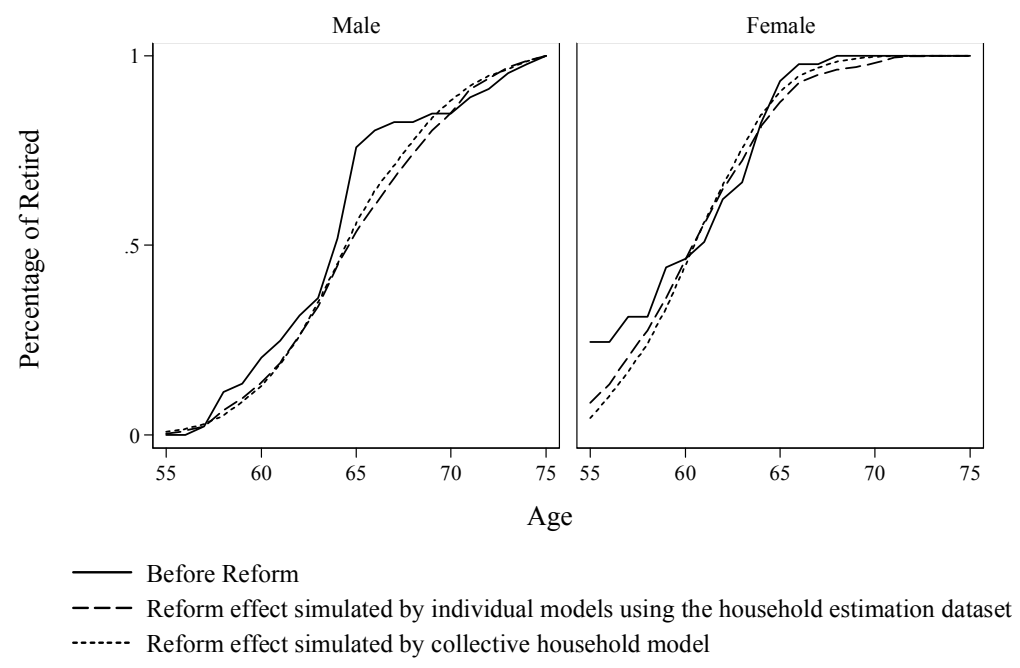

\subsection{Conclusion}

This chapter presented a structural retirement choice model to analyse the labour supply behaviour of elderly workers which is line with the random utility approach used by Van Soest (1995). The model explicitly incorporated the personal labour trajectory, DB/DC pension entitlements, detailed retirement regulations and the tax benefit system. Two 
variations of the model were presented, one which is individual based and another which is a collective household model, in which different preferences and bargaining are explicitly allowed in order to reach the observed household allocations. The intra-household allocations were assumed to be Pareto efficient as in the typical collective models suggested by Chiappori (1988, 1992). Complimentary leisure was incorporated into the model, thereby allowing further analysis of the interactions of spouses' retirement timing as previously found in the literature (Maestas, 2001; Gustman, 2000).

This chapter used a unique historical dataset that has been extensively enriched based on an eight-wave Irish survey dataset using the method described by Li and O'Donoghue (2010). Most parameters from the models were found to be significant and matched our initial expectations. It was found that individuals positively valued leisure and income as expected, and a gradual increase in leisure preference was observed for all individual ages. In the collective household model, complimentary leisure was found to be highly significant, suggesting that the retirement decision is dependent on a spouse's choices. No significant effect of health was found. The health variable was defined as the number of healthy labour free years, which by the definition used in this study is correlated with earnings and leisure. Both individual and collective models were tested to validate their predictive power. The results suggest that the models are able to replicate most retirement choices with an error of less than 2 years.

Additionally, this chapter also simulated a potential state pension reform. A scenario was envisaged whereby the minimum age for claiming the Irish state pension was raised from 65 to 70 . This reform, the simulation suggested, delays the average retirement age. However, the collective model result differed from the individual model result. The simulation based on the individual model suggested that elderly workers would postpone their retirement by about $1.8 \sim 1.9$ years on average, while the collective model suggested that the effect was only around $0.5 \sim 0.6$ years.

The differences between the models were largely due to differences in monetary structure and leisure preferences between dual career household members and the general population. Additionally, the pension reform had a smaller impact on the household budget of dual-career households than for single career households. When using the same dataset, most differences in terms of retirement age distribution were dramatically reduced. Furthermore, the calculation of welfare benefits and family interactions also contributed to the differences observed. The tax-benefit system in Ireland is household-based, and the individual-based model did not take into account the effect of regulation change on other household members. Additionally, the existence of the complimentary leisure term in the collective model also acted as a barrier if an individual decided to postpone retirement beyond the year of their spouse's retirement. This finding suggests that dual-career households have very different leisure preferences compared with single retirees. As a 
result, a simulation exercise based purely on the individual model may distort the reform effect for dual career households. Combining all of the results presented, a tentative conclusion can be reached that by raising only the minimum retirement age for state pension without changing any other regulations does delay retirement but the effect is probably smaller than may have been expected.

It should also be noted that the models presented in this chapter also have their drawbacks. First, the model is estimated based on an expanded household survey dataset which does not contains as many observations as would be present in a national administrative dataset. However, the household survey dataset does provide some important accurate information that an administrative dataset may not provide e.g. information on education. Second, the model assumes that individuals are rational but does not allow changes in family formation. These assumptions may not hold in real life where the dynamics of the life expectancy, income, and family formation are typically much more complex. Future research could incorporate more uncertainties and dynamics into the model to account for these limitations. Third, the model does not explicitly consider inheritance and savings before age 55 by assuming the lifetime wealth can be approximated by post 55 earnings. This assumption can be refined if more detailed earnings and savings data becomes available. Alternatively, one may partially address this issue through a random coefficient model, where the consumption preference parameter is assumed heterogeneous across the population. However, this approach may dramatically increase the computation time. Finally, since the bargaining parameters cannot be fully identified using the available dataset, the model was estimated using a wide range of potential parameters and median values for the simulation exercise. The results show that the model estimates are robust across all scenarios but could be further improved by access to the related variables. 


\subsection{References}

Apps, P., Rees, R., 2010. Family labor supply, taxation and saving in an imperfect capital market. Review of Economics of the Household, 1-27.

Apps, P.F., Rees, R., 1988. Taxation and the Household. Journal of Public Economics 35, 355-369.

Apps, P.F., Rees, R., 1997. Collective labor supply and household production. The Journal of Political Economy 105, 178-190.

Banks, J., Blundell, R., Casanova, M., 2007. The dynamics of retirement behavior in couples: Evidence from the UK and the US. Department of Economics, UCLA, mimeo.

Baroni, E., O'Donoghue, C., 2009. Research Working Paper 2009/09: Poverty Impact of State Pension Reform on the Elderly: an analysis of reform proposals in the 2007 Irish Green Paper. Combat Poverty Agency.

Becker, G.S., 1965. A Theory of the Allocation of Time. The economic journal 75, 493-517.

Belloni, M., Alessie, R., 2010. Retirement choices in Italy: what an option value model tells us. Tinbergen Institute Discussion Papers.

Blundell, R., CHIAPPORI, P.A., Magnac, T., Meghir, C., 2007. Collective Labour Supply: Heterogeneity and Non Participation. Review of Economic Studies 74, 417-445.

Browning, M., Bourguignon, F., Chiappori, P.A., Lechene, V., 1994. Income and outcomes: A structural model of intrahousehold allocation. The Journal of Political Economy 102, 1067-1096.

Browning, M., Chiappori, P.A., Lechene, V., 2006. Collective and unitary models: A clarification. Review of Economics of the Household 4, 5-14.

Browning, M., Chiappori, P.A., Lewbel, A., 2006. Estimating consumption economies of scale, adult equivalence scales, and household bargaining power. University of Oxford Discussion Paper.

Burkhauser, R.V., Butler, J.S., Gumus, G., 2004. Dynamic programming model estimates of Social Security Disability Insurance application timing. Journal of Applied Econometrics 19, 671-685.

Callan, T., 1997. Income Support and Work incentives: Ireland and the UK. Economic and Social Research Institute (ESRI).

Casanova, M., 2009. Happy together: A structural model of couples' joint retirement choices. Mimeo, UCLA.

Cherchye, L., De Rock, B., Vermeulen, F., 2009. Opening the black box of intra-household decision-making: theory and non-parametric empirical tests of general collective consumption models. Journal of Political Economy 117, 1074-1104.

Cherchye, L., De Rock, B., Vermeulen, F., 2011. The Revealed Preference Approach to Collective Consumption Behaviour: Testing and Sharing Rule Recovery. The Review of Economic Studies 78, 176.

Chiappori, P.A., 1988. Rational household labor supply. Econometrica: Journal of the Econometric Society, 6390.

Chiappori, P.A., 1991. Nash-bargained household decisions: a rejoinder. International Economic Review 32, 761 762.

Chiappori, P.A., 1992. Collective labor supply and welfare. The Journal of Political Economy 100, 437-467. 
Chiappori, P.A., 1997. Introducing household production in collective models of labor supply. The Journal of Political Economy 105, 191-209.

Chiappori, P.A., Ekeland, I., 2009. The Microeconomics of Efficient Group Behavior: Identification1. Econometrica 77, 763-799.

Coile, C., Gruber, J., 2000. Social security and retirement. National Bureau of Economic Research Cambridge, Mass., USA.

Esping-Andersen, G., 1990. The three worlds of welfare capitalism.

Euwals, R., Van Vuuren, D., Wolthoff, R., 2006. Early retirement behaviour in the Netherlands: Evidence from a policy reform. IZA.

Evans M., O.D., C. and Vizard, P., 2000. Means Testing and Poverty in 5 European Countries, in: V., A. (Ed.), Le Politiche Sociali in Italia ed in Europa Coerenza e Convergenza nelle Azioni 1997-1999, Bologna: il Mulino.

Flood, L., Hansen, J., Wahlberg, R., 2004. "Household Labor Supply and Welfare Participation in Sweden," Journal of Human Resources, University of Wisconsin Press, vol. 39(4).

Gustafsson, S., 2001. Optimal age at motherhood. Theoretical and empirical considerations on postponement of maternity in Europe. Journal of Population Economics 14, 225-247.

Gustman, A.L., Steinmeier, T.L., 2000. Retirement in dual-career families: a structural model. Journal of Labor Economics, 503-545.

Hurd, M.D., 1990. The joint retirement decision of husbands and wives. University of Chicago Press, 1990.

Jia, Z., 2003. A mixture model of household retirement choice. University of Oslo.

Li, J., O'Donoghue, C., 2010. Simulating Histories for Dynamic Microsimulation Models, in: O’Donoghue, C. (Ed.), Life-Cycle Microsimulation Modelling: Constructing and Using Dynamic Microsimulation Models. LAP LAMBERT Academic Publishing.

Li, J., O’Donoghue, C., 2011. Incentives of Retirement Transition for Elderly Workers: An Analysis of Actual and Simulated Replacement Rates in Ireland, IZA Discussion Paper No. 5865

Lumsdaine, R.L., Stock, J.H., Wise, D.A., 1992. Three models of retirement: Computational complexity versus predictive validity. University of Chicago Press.

MacDonald, B.J., Cairns, A.J.G., 2006. Three Retirement Models for Defined Contribution Pension Plan Members: A Simulation Study. Citeseer.

Maestas, N., 2001. Labor, love and leisure: complementarity and the timing of retirement by working couples. Berkeley: Xerox.

Michaud, P.C., Vermeulen, F., 2010. A collective labor supply model with complementarities in leisure: Identification and estimation by means of panel data. Labour Economics.

Mincer, J., 1963. Market prices, opportunity costs, and income effects. Measurement in economics, 67-82.

O’Donoghue, C., 2003. Redistributive forces of the Irish tax-benefit system.

Stock, J.H., Wise, D.A., 1988. Pensions, the option value of work, and retirement. National Bureau of Economic Research Cambridge, Mass., USA.

Stock, J.H., Wise, D.A., 1990. The pension inducement to retire: An option value analysis. University of Chicago Press, 1990. 
Thomas, D., 1990. Intra-household resource allocation: An inferential approach. The Journal of Human Resources 25, 635-664.

Van Soest, A., 1995. Structural Models of Family Labor Supply: A Discrete Choice Approach. The Journal of Human Resources, 30(1), 63-88.

Van Klaveren, C., Van Praag, B., Maassen Van Den Brink, H., 2008. A public good version of the collective household model: an empirical approach with an application to British household data. Review of Economics of the Household 6, 169-191.

Vermeulen, F., 2006. A collective model for female labour supply with non-participation and taxation. Journal of Population Economics 19, 99-118. 

[8] Conclusions 


\subsection{Main Contributions}

As stated in the first chapter, current dynamic microsimulation models have three main methodological challenges in their implementation, namely base dataset selection, the alignment process and behaviour response modelling. This thesis contributes to all of these three issues. The thesis first develops a synthetic historical data recreation method using a short panel dataset (Chapter 3), which is achieved by extrapolating retrospective variables concerning past employment status and monetary earnings. The model is able to create a 60 year panel with individual labour profiles that are consistent with observed pension entitlements. The second main contribution of this thesis is its analysis of the simulation properties of binary alignment processes, a widely adopted yet understudied simulation technique in microsimulation (Chapter 4). The third contribution is with regard to behaviour response modelling. The thesis develops a continuous labour supply model which advances existing models by allowing a higher degree of heterogeneity (Chapter 5), and a collective household retirement model which captures the monetary and leisure incentives in great details under a complex policy setup combined with mixed DB/DC pension plans (Chapters 6 - 7). All the models developed in this thesis could be used to improve the current projection techniques in microsimulation models and the accuracy of ex-ante policy evaluations.

\subsection{Summary of Findings}

\subsubsection{Part I: Data Issues and Alignment Techniques in Microsimulation}

The thesis starts with an extensive review of the practices and technical choices made by various dynamic microsimulation models (Chapter 2). It concludes that while the development of microsimulation has progressed significantly over past decades, some methodological practices are not ideal for pension policy analysis and thus require further improvement.

Chapter 3 targets at the base dataset issues as discussed in Chapters 1 and 2. It proposes a back simulation method to generate past labour market trajectories synthetically from a standard survey dataset. The method extracts the retrospective information from a household survey and applies a dynamic microsimulation technique in a reverse direction to simulate population histories. The simulated values follow the observed trend quite closely and are able to pick up the dynamics of different types of pension eligibility across time and cohorts. Consequently, the method achieves a high level of historical consistency by introducing extra calibrations and double alignment techniques.

Expanding the longitudinal information, while maintaining the consistencies of a panel dataset with limited waves, offers a viable alternative to the dilemma of base dataset choice 
as described by Cassells et al. (2006), Zaidi and Scott (2001), etc. The generated historical panel could consequently enhance the accuracy and stability of forward dynamic simulation by feeding in information on career trajectories. Given the extensive retrospective information modelled, the back simulated panel is of a much higher quality than a simple synthetic panel. Since only standardized survey questions and macro statistics are used in the simulation, this proposed back simulation method could potentially be replicable in other settings, and also be applied to many datasets that include retrospective questions, e.g. ECHP, BHPS, GSOEP, FFS. The method could potentially open the possibilities of life-cycle based simulation without the use of a scarce long panel. In addition, the historical panel provides many important insights, e.g. the dynamics of career trajectories, which would otherwise be easily overlooked in the original dataset.

Another issue raised in Chapters 1 and 2 is the alignment process in microsimulation. Chapter 4 looks into the simulation properties of all existing binary alignment techniques. Although previous literature (Johnson, 2001; Morrison, 2006; O’Donoghue, 2010) has listed the criteria that a "good" alignment method should meet and analysed some theoretical expectations of the alignment simulation properties and their performances (Morrison, 2006), there is no direct or quantitative comparison of the various methods. Hence, this chapter fills a gap in the literature in relation to the evaluation of different alignment algorithms.

Overall, multiplicative scaling is the method easiest to implement, and fastest to compute for alignment. Nevertheless, it does not result in a perfect alignment to external controls as the events are calculated based purely on calculated probabilities. Moreover, due to the lack of restrictions in the algorithm design, the outcome produced by the multiplicative scaling method is subject to higher fluctuations than other methods. The sidewalk bybrid with nonlinear adjustment method is a computationally very expensive method due to its nonlinear adjustment but exhibits a similar pattern to one sorting based method; sort by the difference between logistic adjusted predicted probability and random number (SBDL). Because of the logistic transformation applied in both algorithms, both methods are good at handling the error of intercept in the logit model. The central limit theorem approach tends to have similar statistical patterns to the multiplicative scaling method, except that it can match the alignment target more precisely. This method exhibits an above average performance in the evaluations with the real world dataset, although it performs poorly in the scenario where the intercept in the equation is shifted. However, the algorithm is very slow when implemented in Stata due to the need for observation iteration.

With regard to the sorting based algorithms, the sort by probabilities (SBP) method yields the best results in terms of false positives and false negatives whilst in most cases heavily distorting the internal distributions. However, the method is easy to implement and does 
not involve random number sorting. Its simulation properties suggest that SBP is a good method in imputation, but not ideal for forward or backward simulation. Sort by the difference between predicted probability and random number (SBD) and Sort by the difference between logistic adjusted predicted probability and random number (SBDL) are similar in terms of computation steps, but produce very different distributions of probability. SBDL works better with the logit model, especially when the intercept is used for alignment calibration. In contrast, SBD seems to have a below average performance when looking at all indicators and scenarios.

The results suggest that the selection of an alignment method is more complicated than previously thought, with each algorithm possessing its own advantages and disadvantages. For a microsimulation project that is speed-oriented, multiplicative scaling seems to be a good choice. The central limit theorem approach could also be considered when implemented in a compiled language, such as $\mathrm{C} / \mathrm{C}++$. In a project where speed is not the major concern, then the choice might depend on the reason for the alignment. For instance, if the alignment is used to create a shift in the intercept, then SBDL or sidewalk hybrid with nonlinear transformation may be the best choice. In addition, for microsimulation analysis with a focus on distributional analysis, SBP may not be ideal because of its distortion of distributions.

\subsubsection{Part II: Behaviour Modelling in Microsimulation}

The second half of the thesis continues the research into the methodological issues of microsimulation, with a focus on behaviour response modelling. In order to evaluate pension reform proposals that are designed to cause behavioural changes, dynamic microsimulation requires behaviour models that can explicitly incorporate the changes in policies. Chapters 5 to 7 are dedicated to this issue and present a labour supply model and a collective retirement choice model for use in dynamic microsimulation.

Chapter 5 develops a structural lifetime economic model for estimating and simulating labour supply. The model is consistent with lifetime economic theory and is able to capture the individual heterogeneity to a larger extent when compared to existing labour supply models. The chapter also describes four variants of the model and applies them to a short term dynamic microsimulation test. The outcome suggests that the lifetime models estimated using fixed effect vector decomposition yield the best results. The expectation correction is significant in estimation, but less important in the simulation exercise due to its relatively small coefficient and wage estimation errors. Overall, the lifetime labour supply model developed in this chapter offers a better simulation performance than the traditional Heckman panel extension model.

Chapters 6 and 7 focus on the retirement choices of elderly workers. Chapter 6 analyses the retirement pattern and the replacement rate observed in Ireland using the Living in 
Ireland (LII) panel dataset. The chapter finds that the average replacement rate for newly retired workers from LII is approximately $54.7 \%$ but with a high degree of standard deviation, therefore suggesting that there is a large inequality of replacement rates among retirees. Workers from different sectors have very different earnings profiles and replacement rates according to the synthetic calculation. A typical self-employed worker would be able to maintain an income that is more than $50 \%$ of their pre-retirement earnings, while workers from other sectors demonstrate a dramatically lower replacement rate which is mostly due to higher pre-retirement earnings.

In addition, individuals with high and low replacement rates exhibit very different social economic characteristics. The high replacement rate group tends to be less educated, with lower incomes and a higher dependency on social benefits. However, individuals in the low replacement rate group have a household replacement rate as high as $91 \%$ on average. The state pension is a major source of income for any category except for those individuals retiring earlier than 65 , who rely heavily on occupational and private pensions. The chapter also finds that the number of people going through retirement roughly corresponds to the individual worker replacement rates, especially for those who retire from the private sector or who were self-employed. This suggests the importance of monetary incentives in retirement behaviours.

Chapter 7 continues the research initiated in Chapter 6 by proposing a structural retirement choice model to analyse the labour supply behaviour of elderly workers, which is in line with the random utility approach used by Van Soest (1995). The model explicitly incorporates personal labour trajectories, DB/DC pension entitlements, detailed retirement regulations and the tax benefit system. Two variations of the model are presented, with one being individual based and the other a collective household model, in which different preferences and the bargaining to reach the observed household allocations are explicitly modelled. The models are further extended to incorporate complimentary leisure, which allows an analysis of the interactions of spouses' retirement timing as reported in the literature (Maestas, 2001; Gustman, 2000). The estimations of the model suggest that individuals positively value their leisure and income as expected, and display a gradual increase in leisure preference as individuals age. In the collective household model, it was found that complimentary leisure is highly significant, suggesting that the retirement decision is dependent on the spouse's choices. Both individual and collective models were tested to validate their predictive power and the results suggest that the models are able to replicate most retirement choices with an error of less than 2 years.

Finally, a potential state pension reform is simulated using the models developed within Chapter 7 . The chapter uses a synthetic scenario whereby the minimum age in Ireland for claiming state pension is raised from 65 to 70 . This reform results in a delay in the retirement behaviour according to both models. However, the collective model results 
differ from the individual model results. The simulation based on the individual model suggests that elderly workers would postpone their retirement by about $1.8 \sim 1.9$ years on average, whilst the collective model suggests the effect is only around $0.5 \sim 0.6$ years. This finding suggests that dual career households have very different leisure preferences compared with single career households. A simulation based purely on the individual model may exaggerate the reform effect for this social group, which is a high percentage of potential pensioners. Combining all the results presented, the tentative conclusion can be reached that by raising just the minimum retirement age for state pension without any other changes to the regulations does delay retirement, but that the effect is probably smaller than expected for such a policy reform scenario.

\subsection{Drawbacks and Future Research Directions}

While this thesis contributes several models to the methodological development of dynamic microsimulation with regard to the dataset issue, alignment, and behaviour response modelling, these new models could be further improved for a more realistic simulation.

The back simulation model presented in Chapter 3 could be further refined if the model was adjusted to incorporate the deceased proportion of the population and were to use a more refined cross-sectional and longitudinal alignment process. While the current model provides a reasonable simulated history, certain family formations and dissolutions (including death) are ignored, which could lead to a potential bias in the trajectory simulation. The dataset as it is can be used for pension related analysis but may have difficulties in understanding certain household behaviours such as fertility patterns. Future work would benefit from a more realistic demographic model.

In terms of the microsimulation techniques discussed, alignment is one of the most used but yet least studied processes. While Chapter 4 reviewed all the binary alignment techniques published to date, there are still many questions regarding this technique. For instance, there is very limited documentation on the alignment process in multi-nominal or conditional logit models. With the development of discrete choice models for dynamic microsimulation, future research could also look into alignments for more complex models.

Over the past decade, behaviour modelling has gained importance within microsimulation as more analyses require behaviour responses as a result of varying policies to be modelled. While this thesis focuses on one labour supply model and one retirement choice model, there are many other areas that require detailed behaviour responses. Certain life event related behaviours, such as fertility decisions and education choices, can all be applied to a similar life-cycle modelling framework as presented in Chapter 7. From the policy 
perspective, it is necessary for dynamic microsimulation to incorporate more intertemporal models in order to analyse many behaviour-changing reforms. In addition, future research should also address technical problems such as life-cycle alignment, which are the result of the implementation of inter-temporal models.

It should be noted that the models presented in this thesis (as in Chapters 5 and 7), also have their drawbacks. One major missing link is the interaction with the macro environment, one of the challenges listed by Harding (2007a). Besides alignment, dynamic microsimulation should also incorporate a macro model to reflect changes in the macro environment. Dynamic CGE-microsimulation models are widely discussed but rarely implemented. Although this is a challenging task (Ahmed and O'Donoghue, 2007), its full implementation would bring significant improvements to the current simulation techniques.

\subsection{Concluding Remarks}

Microsimulation models can add great value to public policy analysis because of their high potential for flexible, fine-grained analysis of proposed policy changes (Citro and Hanushek, 1991). This thesis presents a set of methodological papers on microsimulation techniques and models with the intention of advancing dynamic microsimulation development. This research illustrates the potential of dynamic microsimulation models via a pension reform evaluation using a life-cycle based decision simulation, as well as the technical complexity in constructing a reliable dynamic model for use in public policy analysis. Although many issues in microsimulation are covered within this thesis, they represent only some of the overall development challenges. Future work, such as the adaptation of various structural models, the linking of macro and micro models etc., is needed to further improve the credibility and usefulness of microsimulation models in public policy analyses. 


\subsection{References}

Ahmed, V. and O' Donoghue, C., 2007. CGE-Microsimulation Modelling: A Survey. MPRA Paper

Cassells, R., et al., 2006. Problems and Prospects for Dynamic Microsimulation: A Review and lessons for APPSIM. NATSEM Discussion Papers no. 63.

Citro, C.F., Hanushek, E.A., 1991. Improving information for social policy decisions: the uses of microsimulation modeling. Natl Academy Pr.

Gustman, A.L., Steinmeier, T.L., 2000. Retirement in dual-career families: a structural model. Journal of Labor Economics, 503-545.

Harding, A., 2007. Challenges and Opportunities of Dynamic Microsimulation Modelling

Johnson, T., 2001. Nonlinear Alignment by Sorting, CORSIM Working Paper

Maestas, N., 2001. Labor, love and leisure: complementarity and the timing of retirement by working couples. Berkeley: Xerox.

Morrison, R., 2006. Make it so: Event alignment in dynamic microsimulation. DYNACAN paper.

O’Donoghue, C., 2010. Alignment and calibration in LIAM, LIAM working paper

van Soest A., 1995. Structural models of family labor supply: a discrete choice approach, Journal of Human Resources, 30(1), 63-88.

Zaidi, A. and A. Scott, 2001, Base dataset for the SAGE model, (Sage Technical Note). 


\section{Summary}

As many countries today face the prospect of rapid demographic change in the decades ahead, numerous research papers (e.g. Börsch-Supan, 2006; Masson, 1990; Harding et al., 2009; Klevmarken and Lindgren, 2008) have been devoted to the analysis of the implications of an ageing population. However, analysis of certain aspects of the pension system, e.g. sustainability or the redistributive impact over life course may require a dataset that does not currently exist, either because the analysis relates to future events, as in the case of pension forecasts, or because the collected datasets do not cover sufficiently long time periods. Consequently, researchers use microsimulation models to assist with this type of analysis, a concept that was initially suggested by Orcutt (1957).

The thesis reviews the methodological challenges of developing a dynamic microsimulation model and surveys current practices worldwide, covering a wide range of methodological issues (Chapter 2). These include general model development aspects such as base dataset selection, cohort or population-based model structure, the programming environment, and model validation, as well as some technical choices in model implementations such as open or closed models, behaviour responses implementation, alignment usage, etc. It provides an overview of the methodological choices made in more than 50 known dynamic microsimulation models and discusses the advantages and disadvantages of different practices.

This thesis aims to advance the development of microsimulation by focusing on three main methodological issues as stated by Harding (2007), namely base dataset selection, the alignment process and behaviour response modelling. First, the thesis develops a synthetic historical data recreation method using a short panel dataset (Chapter 3) by extrapolating retrospective variables concerning past employment status and monetary earnings. The model is used to create a panel spanning 60 years and provides individual labour profiles that are consistent with observed pension entitlements. This method opens the possibility for further investigation into several fields of application such as life-cycle income analysis and pension reform evaluation, which typically require historical profiles of individuals. 
The second methodological contribution that this thesis makes is its analysis of the simulation properties of binary alignment processes, a widely adopted yet understudied simulation technique in microsimulation (Chapter 4). This chapter details and compares alignment processes, probability transformations, and the statistical properties of alignment outputs in transparent and controlled setups with both a synthetic and a real life dataset (Living in Ireland, LII).

The final methodological contribution focuses on behaviour response modelling. The thesis develops a continuous labour supply model, which advances existing models by allowing for a higher degree of heterogeneity (Chapter 5). The model addresses the two main drawbacks of most of the existing models, namely the limitation in incorporating individual heterogeneity and the perfect certainty assumption. The thesis also develops a collective household retirement model, which is able to captures monetary and leisure incentives in great details under complex policy setup combined with mixed defined benefit (DB) and defined contribution (DC) pension plans (Chapter 6-7). The model is applied to study to the effect of postponing legal retirement age on actual retirement choices in Ireland. 


\section{Samenvatting}

Aangezien veel landen momenteel worden geconfronteerd met het vooruitzicht van sterke demografische veranderingen in de komende decennia, zijn veel onderzoeken (bijv. BörschSupan, 2006; Masson, 1990; Harding et al., 2009; Klevmarken en Lindgren, 2008) gewijd aan het analyseren van de implicaties van een vergrijzende bevolking. Een analyse van bepaalde aspecten van het pensioensysteem, bijv. bestendigheid of de invloed van herverdelingsmaatregelen gedurende een mensenleven, kan echter een dataset vereisen die op dit moment nog niet bestaat, hetzij omdat de analyse betrekking heeft op gebeurtenissen in de toekomst, zoals bij pensioenvoorspellingen, hetzij omdat de verzamelde datasets niet voldoende toepasbaar zijn op langere periodes. Onderzoekers gebruiken daarom microsimulatiemodellen als ondersteuning bij dit soort analyses, een concept dat voor het eerst werd voorgesteld door Orcutt (1957).

Het proefschrift beoordeelt de methodologische uitdagingen bij het ontwikkelen van een dynamisch microsimulatiemodel en onderzoekt actuele toepassingen wereldwijd, waarbij aandacht wordt besteed aan een grote verscheidenheid aan methodologische kwesties (hoofdstuk 2). Deze omvatten algemene modelontwikkelingsaspecten zoals de selectie van een basisdataset, een cohort- of populatiegebaseerde modelstructuur, de programmeeromgeving en modelvalidatie alsook enkele technische keuzes in modelimplementaties zoals open of gesloten modellen, implementatie van gedragsreacties, gebruik van alignering etc. Het proefschrift biedt een overzicht van de methodologische keuzes die in meer dan 50 bekende dynamische microsimulatiemodellen zijn gemaakt en bespreekt de voor- en nadelen van de verschillende toepassingen.

Dit proefschrift beoogt de ontwikkeling van microsimulatie te bevorderen door zich te richten op drie centrale methodologische kwesties zoals genoemd door Harding (2007), te weten de selectie van een basisdataset, het aligneringsproces en het modelleren van gedragsreacties. Het proefschrift ontwikkelt eerst een synthetische methode om historische gegevens te reproduceren met een korte paneldataset (hoofdstuk 3) door retrospectieve variabelen met betrekking tot werkstatus en geldelijke inkomsten uit het verleden te extrapoleren. Het model wordt gebruikt om een panel te creëren dat 60 jaar bestrijkt en individuele arbeidsprofielen biedt die consistent zijn met de geobserveerde 
pensioenrechten. Deze methode biedt de mogelijkheid om verder onderzoek te doen naar verschillende toepassingsgebieden die historische profielen van individuele personen vereisen, zoals de inkomstenanalyse van een levensloop en de evaluatie van pensioenhervormingen.

De tweede methodologische bijdrage van dit proefschrift is de analyse van de simulatieeigenschappen van binaire aligneringsprocessen, een simulatietechniek bij microsimulatie die wijdverbreid is maar waar nog weinig onderzoek naar is verricht (hoofdstuk 4). Dit hoofdstuk beschrijft en vergelijkt aligneringsprocessen, waarschijnlijkheidstransformaties en de statistische eigenschappen van aligneringsresultaten in transparante en gecontroleerde situaties met zowel een synthetische als een werkelijke dataset (Living in Ireland, LII).

De laatste methodologische bijdrage richt zich op het modelleren van gedragsreacties. Het proefschrift werkt een doorlopend werkgelegenheidsmodel uit, dat verder gaat dan bestaande modellen door een hogere mate van heterogeniteit toe te staan (hoofdstuk 5). Het model besteedt aandacht aan de twee centrale nadelen van de meeste bestaande modellen, namelijk de beperking bij het opnemen van individuele heterogeniteit en de perfecte veronderstelde zekerheid. Het proefschrift werkt ook een collectief pensioensmodel uit, dat financiële motieven en vrijetijdsimpulsen tot in detail omvat onder een complexe beleidssituatie, gecombineerd met gemengde pensioenplannen op basis van het beschikbare uitkeringssysteem ( $\mathrm{DB}=$ defined benefit) en het beschikbare premiesysteem ( $\mathrm{DC}=$ defined contribution). Het model wordt toegepast om het effect te onderzoeken van het uitstellen van de wettelijke pensioenleeftijd op basis van concrete pensioenskeuzes in Ierland. 


\section{Biography}

Jinjing Li was born in 1985 in Gansu, China. He studied International Economics at Beijing Normal University and graduated in 2003 with a bachelor's degree. He continued his studies at University of Leicester, UK and later at Maastricht University, the Netherlands. In 2006, he defended his Master thesis in Maastricht on pension system analysis in China.

Jinjing started his $\mathrm{PhD}$ research at Maastricht Graduate School of Governance, Maastricht University in 2006. During his study, he has been a visiting researcher at the Kennedy School of Government, Harvard University in the U.S. and the Rural Economy Research Centre (RERC), Teagasc in Ireland. Parallel to his research, he also acted as lecturer and tutor for various courses and training programmes at Maastricht University. In addition, Jinjing has worked on a number of national and international research projects with L'Inspection Générale de la Sécurité Sociale (IGSS) in Luxembourg, Federal Planning Bureau (FPB) in Belgium, International Labor Organization (ILO) etc. Part of his research has been published or integrated in these projects while the other parts are currently under review for publications in academic journals.

After his graduation, Jinjing now works at the National Economics and Modelling Centre (NATSEM), University of Canberra, Australia with a primary focus on dynamic microsimulation modelling. 



\title{
MGSoG Dissertation Series
}

\author{
Aziz Atamanov \\ Rural Nonfarm Employment and International Migration as Alternatives to Agricultural \\ Employment: The Case of Kyrgyzstan \\ MGSoG Dissertation Series, nr 23 (2011) \\ Frieda Vandeninden \\ Poverty Alleviation: Aid and Social Pensions \\ MGSoG Dissertation Series, nr 22 (2011) \\ Juliana Nyasha Tirivayi \\ The Welfare Effects of Integrating AIDS Treatment with Food Transfers: \\ Evidence from Zambia \\ MGSoG Dissertation Series, nr 21 (2011) \\ Agnieska Ewa Sowa \\ Who's Left Behind? Social Dimensions of Health Transition and Utilization of Medical Care in \\ Poland
}

MGSoG Dissertation Series, nr 20 (2011)

Emmanaouil Sfakianakis

The Role of Private Actors in the Provision of Public Goods with Applications to Infrastructure and Financial Stability

MGSoG Dissertation Series, nr 19 (2011)

Siu Hing Lo

White Collars Green Sleeves: An Interorganizational Comparison of Determinants of EnergieRelated Behaviors among Office Workers

MGSoG Dissertation Series, nr 18 (2011) 
Treena Wu

Constraints to Human Capital Investment in Developing Countries:

Using the Asian Financial Crisis in Indonesia as a Natural Experiment

MGSoG Dissertation Series, nr 17 (2011)

Henry Espinoza Peña

Impact Evaluation of a Job-Training Programme for Disadvantaged Youths:

The Case of Projoven

MGSoG Dissertation Series, nr 16 (2011)

Florian Tomini

Between Family and Friends

Understanding the Interdependency of Private Transfers

MGSoG Dissertation Series, nr 15 (2010)

Michał Polalowski

The Institutional Transformation of Social Policy in East Central Europe:

Poland and Hungary in comparative and historical perspective

MGSoG Dissertation Series, nr 14 (2010)

Maha Ahmed

Defining, Measuring and Addressing Vulnerability:

The Case of Post Conflict Environments

MGSoG Dissertation Series, nr 13 (2010)

Pascal Beckers

Local Space and Economic Success

The role of spatial segregation of migrants in the Netherlands

MGSoG Dissertation Series, nr 12 (2011)

Victor Cebotari

Conflicting Demands in Ethnically Diverse Societies

Ethnopolitical Contention and Identity Values in Europe

MGSoG Dissertation Series, nr 11 (2010)

Dennis Gyllensporre

Competing and Complementary Perspectives on the EU as a Crisis Management Actor:

An Examination of the Common Security and Defence Policy through the Lenses of Idealism and Realism

MGSoG Dissertation Series, nr 10 (2010) 
Judit Vall Castello

Business Cycle and Policy Effects on Labour Market Transitions of Older and Disabled Workers in Spain

MGSoG Dissertation Series, nr. 9 (2010)

Keetie Roelen

False Positives or Hidden Dimensions: the definition and measurement of child poverty

MGSoG Dissertation Series, nr. 8 (2010)

Denisa Maria Sologon

Earning Dynamics in Europe

MGSoG Dissertation Series, nr. 7 (2010)

Melissa Siegel

Money and Mobility: Migration and Remittances

MGSoG Dissertation Series, nr. 6 (2010)

Jessica S. Hagen-Zanker

Modest Expectations: Causes and effects of migration on migrant households in source countries

MGSoG Dissertation Series, nr. 5 (2010)

Mirtha R. Muniz Castillo

Human Development and Autonomy in Project Aid: Experiences from four

bilateral projects in Nicaragua and El Salvador

MGSoG Dissertation Series, nr. 4 (2009)

Christiane Arndt

Governance Indicators

MGSoG Dissertation Series, nr. 3 (2009)

Britta Augsburg

Microfinance - Greater Good or Lesser Evil?

MGSoG Dissertation Series, nr. 2 (2009)

Geranda Notten

Measuring and Managing Poverty Risks

MGSoG Dissertation Series, nr. 1 (2008) 